\title{
New Tyramine and Aporphine-type Alkamides with NO Release Inhibitory Activities from Piper puberulum
}

Yuan-kun Zheng,, Bao-jun Su, " Ya-qi Wang, Heng-shan Wang, Hai-bing Liao, ${ }^{*}$ Dong Liang*

State Key Laboratory for Chemistry and Molecular Engineering of Medicinal Resources, Collaborative Innovation Center for Guangxi Ethnic Medicine, School of Chemistry and Pharmaceutical Sciences, Guangxi Normal University, Guilin 541004, People's Republic of China E-mail addresses: liangdonggxnu@163.com (D. Liang), lhbing188@163.com (H.-B. Liao). 
Contents of Supporting Information

\begin{tabular}{|c|c|c|}
\hline NO & Content & Page \\
\hline Figure S1 & Chemical structures of compounds 12-31 & 6 \\
\hline Table S1 & X-ray Crystallographic Data for Compound 7 & 7 \\
\hline Table S2 & X-ray Crystallographic Data for Compound 8 & 8 \\
\hline Table S3 & X-ray Crystallographic Data for Compound 10 & 9 \\
\hline Figure S2 & ${ }^{1} \mathrm{H}$ NMR Spectrum of Compound 1 in DMSO- $d_{6}$ & 10 \\
\hline Figure S3 & ${ }^{13} \mathrm{C}$ NMR Spectrum of Compound 1 in DMSO- $d_{6}$ & 11 \\
\hline Figure S4 & ${ }^{1} \mathrm{H}-{ }^{1} \mathrm{H}$ COSY Spectrum of Compound 1 in DMSO- $d_{6}$ & 12 \\
\hline Figure S5 & HSQC Spectrum of Compound 1 in DMSO- $d_{6}$ & 13 \\
\hline Figure S6 & HMBC Spectrum of Compound 1 in DMSO- $d_{6}$ & 14 \\
\hline Figure S7 & (+) HRESIMS Spectrum of Compound 1 & 15 \\
\hline Figure S8 & UV Spectrum of Compound 1 & 16 \\
\hline Figure S9 & IR (KBr disc) Spectrum of Compound 1 & 17 \\
\hline Figure S10 & ${ }^{1} \mathrm{H}$ NMR Spectrum of Compound 2 in $\mathrm{MeOH}-d_{4}$ & 18 \\
\hline Figure S11 & ${ }^{13} \mathrm{C}$ NMR Spectrum of Compound 2 in $\mathrm{MeOH}-d_{4}$ & 19 \\
\hline Figure S12 & ${ }^{1} \mathrm{H}-{ }^{1} \mathrm{H}$ COSY Spectrum of Compound 2 in $\mathrm{MeOH}-d_{4}$ & 20 \\
\hline Figure S13 & HSQC Spectrum of Compound 2 in $\mathrm{MeOH}-d_{4}$ & 21 \\
\hline Figure S14 & HMBC Spectrum of Compound 2 in $\mathrm{MeOH}-d_{4}$ & 22 \\
\hline Figure S15 & (+) HRESIMS Spectrum of Compound 2 & 23 \\
\hline Figure S16 & UV Spectrum of Compound $\mathbf{2}$ & 24 \\
\hline Figure S17 & IR (KBr disc) Spectrum of Compound 2 & 25 \\
\hline Figure S18 & ${ }^{1} \mathrm{H}$ NMR Spectrum of Compound $\mathbf{3}$ in $\mathrm{CDCl}_{3}$ & 26 \\
\hline Figure S19 & ${ }^{13} \mathrm{C}$ NMR Spectrum of Compound 3 in $\mathrm{CDCl}_{3}$ & 27 \\
\hline Figure S20 & ${ }^{1} \mathrm{H}-{ }^{1} \mathrm{H}$ COSY Spectrum of Compound 3 in $\mathrm{CDCl}_{3}$ & 28 \\
\hline Figure S21 & HSQC Spectrum of Compound $\mathbf{3}$ in $\mathrm{CDCl}_{3}$ & 29 \\
\hline Figure S22 & HMBC Spectrum of Compound 3 in $\mathrm{CDCl}_{3}$ & 30 \\
\hline Figure S23 & (+) HRESIMS Spectrum of Compound $\mathbf{3}$ & 31 \\
\hline Figure S24 & UV Spectrum of Compound $\mathbf{3}$ & 32 \\
\hline Figure S25 & IR (KBr disc) Spectrum of Compound $\mathbf{3}$ & 33 \\
\hline Figure S26 & ${ }^{1} \mathrm{H}$ NMR Spectrum of Compound 4 in $\mathrm{MeOH}-d_{4}$ & 34 \\
\hline Figure S27 & ${ }^{13} \mathrm{C}$ NMR Spectrum of Compound 4 in $\mathrm{MeOH}-d_{4}$ & 35 \\
\hline Figure S28 & ${ }^{1} \mathrm{H}-{ }^{1} \mathrm{H}$ COSY Spectrum of Compound 4 in $\mathrm{MeOH}-d_{4}$ & 36 \\
\hline Figure S29 & HSQC Spectrum of Compound 4 in $\mathrm{MeOH}-d_{4}$ & 37 \\
\hline Figure S30 & HMBC Spectrum of Compound 4 in $\mathrm{MeOH}-d_{4}$ & 38 \\
\hline Figure S31 & (+) HRESIMS Spectrum of Compound 4 & 39 \\
\hline Figure S32 & UV Spectrum of Compound 4 & 40 \\
\hline Figure S33 & IR (KBr disc) Spectrum of Compound 4 & 41 \\
\hline Figure S34 & ${ }^{1} \mathrm{H}$ NMR Spectrum of Compound 5 in $\mathrm{CDCl}_{3}$ & 42 \\
\hline Figure S35 & ${ }^{13} \mathrm{C}$ NMR Spectrum of Compound 5 in $\mathrm{CDCl}_{3}$ & 43 \\
\hline Figure S36 & ${ }^{1} \mathrm{H}-{ }^{1} \mathrm{H}$ COSY Spectrum of Compound 5 in $\mathrm{CDCl}_{3}$ & 44 \\
\hline Figure S37 & HSQC Spectrum of Compound $\mathbf{5}$ in $\mathrm{CDCl}_{3}$ & 45 \\
\hline
\end{tabular}




\begin{tabular}{|c|c|c|}
\hline Figure S38 & HMBC Spectrum of Compound 5 in $\mathrm{CDCl}_{3}$ & 46 \\
\hline Figure S39 & (+) HRESIMS Spectrum of Compound $\mathbf{5}$ & 47 \\
\hline Figure S40 & UV Spectrum of Compound $\mathbf{5}$ & 48 \\
\hline Figure S41 & IR (KBr disc) Spectrum of Compound 5 & 49 \\
\hline Figure S42 & ${ }^{1} \mathrm{H}$ NMR Spectrum of Compound 6 in $\mathrm{CDCl}_{3}$ & 50 \\
\hline Figure S43 & ${ }^{13} \mathrm{C}$ NMR Spectrum of Compound 6 in $\mathrm{CDCl}_{3}$ & 51 \\
\hline Figure S44 & ${ }^{1} \mathrm{H}-{ }^{1} \mathrm{H}$ COSY Spectrum of Compound 6 in $\mathrm{CDCl}_{3}$ & 52 \\
\hline Figure S45 & HSQC Spectrum of Compound 6 in $\mathrm{CDCl}_{3}$ & 53 \\
\hline Figure S46 & HMBC Spectrum of Compound 6 in $\mathrm{CDCl}_{3}$ & 54 \\
\hline Figure S47 & (+) HRESIMS Spectrum of Compound 6 & 55 \\
\hline Figure S48 & UV Spectrum of Compound 6 & 56 \\
\hline Figure S49 & IR ( $\mathrm{KBr}$ disc) Spectrum of Compound 6 & 57 \\
\hline Figure S50 & ${ }^{1} \mathrm{H}$ NMR Spectrum of Compound 7 in $\mathrm{CDCl}_{3}$ & 58 \\
\hline Figure S51 & ${ }^{13} \mathrm{C}$ NMR Spectrum of Compound 7 in $\mathrm{CDCl}_{3}$ & 59 \\
\hline Figure S52 & DEPT135 Spectrum of Compound 7 in $\mathrm{CDCl}_{3}$ & 60 \\
\hline Figure S53 & ${ }^{1} \mathrm{H}-{ }^{1} \mathrm{H}$ COSY Spectrum of Compound 7 in $\mathrm{CDCl}_{3}$ & 61 \\
\hline Figure S54 & HSQC Spectrum of Compound 7 in $\mathrm{CDCl}_{3}$ & 62 \\
\hline Figure S55 & HMBC Spectrum of Compound 7 in $\mathrm{CDCl}_{3}$ & 63 \\
\hline Figure S56 & NOESY Spectrum of Compound 7 in $\mathrm{CDCl}_{3}$ & 64 \\
\hline Figure S57 & (+) HRESIMS Spectrum of Compound 7 & 65 \\
\hline Figure S58 & UV Spectrum of Compound 7 & 66 \\
\hline Figure S59 & IR (KBr disc) Spectrum of Compound 7 & 67 \\
\hline Figure S60 & ECD Spectrum of 7 & 68 \\
\hline Figure S61 & ${ }^{1} \mathrm{H}$ NMR Spectrum of Compound 8 in $\mathrm{CDCl}_{3}$ & 69 \\
\hline Figure S62 & ${ }^{13} \mathrm{C}$ NMR Spectrum of Compound 8 in $\mathrm{CDCl}_{3}$ & 70 \\
\hline Figure S63 & ${ }^{1} \mathrm{H}-{ }^{1} \mathrm{H}$ COSY Spectrum of Compound 8 in $\mathrm{CDCl}_{3}$ & 71 \\
\hline Figure S64 & HSQC Spectrum of Compound $\mathbf{8}$ in $\mathrm{CDCl}_{3}$ & 72 \\
\hline Figure S65 & HMBC Spectrum of Compound 8 in $\mathrm{CDCl}_{3}$ & 73 \\
\hline Figure S66 & NOESY Spectrum of Compound $\mathbf{8}$ in $\mathrm{CDCl}_{3}$ & 74 \\
\hline Figure S67 & (+) HRESIMS Spectrum of Compound $\mathbf{8}$ & 75 \\
\hline Figure S68 & UV Spectrum of Compound $\mathbf{8}$ & 76 \\
\hline Figure S69 & IR ( $\mathrm{KBr}$ disc) Spectrum of Compound $\mathbf{8}$ & 77 \\
\hline Figure S70 & ECD Spectrum of $\mathbf{8}$ & 78 \\
\hline Figure S71 & ${ }^{1} \mathrm{H}$ NMR Spectrum of Compound 9 in $\mathrm{MeOH}-d_{4}$ & 79 \\
\hline Figure S72 & ${ }^{13} \mathrm{C}$ NMR Spectrum of Compound 9 in $\mathrm{MeOH}-d_{4}$ & 80 \\
\hline Figure S73 & ${ }^{1} \mathrm{H}-{ }^{1} \mathrm{H}$ COSY Spectrum of Compound 9 in $\mathrm{MeOH}-d_{4}$ & 81 \\
\hline Figure S74 & HSQC Spectrum of Compound 9 in $\mathrm{MeOH}-d_{4}$ & 82 \\
\hline Figure S75 & HMBC Spectrum of Compound 9 in $\mathrm{MeOH}-d_{4}$ & 83 \\
\hline Figure S76 & NOESY Spectrum of Compound 9 in $\mathrm{MeOH}-d_{4}$ & 84 \\
\hline Figure S77 & (+) HRESIMS Spectrum of Compound 9 & 85 \\
\hline Figure S78 & UV Spectrum of Compound 9 & 86 \\
\hline Figure S79 & IR (KBr disc) Spectrum of Compound 9 & 87 \\
\hline Figure S80 & ECD Spectrum of 9 & 88 \\
\hline Figure S81 & ${ }^{1} \mathrm{H}$ NMR Spectrum of Compound $\mathbf{1 0}$ in $\mathrm{MeOH}-d_{4}$ & 89 \\
\hline
\end{tabular}




\begin{tabular}{|c|c|c|}
\hline Figure S82 & ${ }^{13} \mathrm{C}$ NMR Spectrum of Compound 10 in $\mathrm{MeOH}-d_{4}$ & 90 \\
\hline Figure S83 & ${ }^{1} \mathrm{H}-{ }^{1} \mathrm{H}$ COSY Spectrum of Compound $\mathbf{1 0}$ in $\mathrm{MeOH}-d_{4}$ & 91 \\
\hline Figure S84 & HSQC Spectrum of Compound $\mathbf{1 0}$ in $\mathrm{MeOH}-d_{4}$ & 92 \\
\hline Figure S85 & HMBC Spectrum of Compound $\mathbf{1 0}$ in $\mathrm{MeOH}-d_{4}$ & 93 \\
\hline Figure S86 & NOESY Spectrum of Compound 10 in $\mathrm{MeOH}-d_{4}$ & 94 \\
\hline Figure S87 & (+) HRESIMS Spectrum of Compound $\mathbf{1 0}$ & 95 \\
\hline Figure S88 & UV Spectrum of Compound $\mathbf{1 0}$ & 96 \\
\hline Figure S89 & IR (KBr disc) Spectrum of Compound $\mathbf{1 0}$ & 97 \\
\hline Figure S90 & ECD Spectrum of $\mathbf{1 0}$ & 98 \\
\hline Figure S91 & ${ }^{1} \mathrm{H}$ NMR Spectrum of Compound 11 in $\mathrm{CDCl}_{3}$ & 99 \\
\hline Figure S92 & ${ }^{13} \mathrm{C}$ NMR Spectrum of Compound $\mathbf{1 1}$ in $\mathrm{CDCl}_{3}$ & 100 \\
\hline Figure S93 & DEPT135 Spectrum of Compound 11 in $\mathrm{CDCl}_{3}$ & 101 \\
\hline Figure S94 & ${ }^{1} \mathrm{H}-{ }^{1} \mathrm{H}$ COSY Spectrum of Compound 11 in $\mathrm{CDCl}_{3}$ & 102 \\
\hline Figure S95 & HSQC Spectrum of Compound 11 in $\mathrm{CDCl}_{3}$ & 103 \\
\hline Figure S96 & $\mathrm{HMBC}$ Spectrum of Compound 11 in $\mathrm{CDCl}_{3}$ & 104 \\
\hline Figure S97 & NOESY Spectrum of Compound 11 in $\mathrm{CDCl}_{3}$ & 105 \\
\hline Figure S98 & (+) HRESIMS Spectrum of Compound $\mathbf{1 1}$ & 106 \\
\hline Figure S99 & UV Spectrum of Compound 11 & 107 \\
\hline Figure S100 & IR (KBr disc) Spectrum of Compound 11 & 108 \\
\hline Figure S101 & ECD Spectrum of $\mathbf{1 1}$ & 109 \\
\hline Figure S102 & ${ }^{1} \mathrm{H}$ NMR Spectrum of Compound 12 in $\mathrm{CDCl}_{3}$ & 110 \\
\hline Figure S103 & ${ }^{13} \mathrm{C}$ NMR Spectrum of Compound 12 in $\mathrm{CDCl}_{3}$ & 111 \\
\hline Figure S104 & (+) HRESIMS Spectrum of Compound 12 & 112 \\
\hline Figure S105 & ${ }^{1} \mathrm{H}$ NMR Spectrum of Compound 13 in $\mathrm{CDCl}_{3}$ & 113 \\
\hline Figure S106 & ${ }^{13} \mathrm{C}$ NMR Spectrum of Compound 13 in $\mathrm{CDCl}_{3}$ & 114 \\
\hline Figure S107 & (+) HRESIMS Spectrum of Compound $\mathbf{1 3}$ & 115 \\
\hline Figure S108 & ${ }^{1} \mathrm{H}$ NMR Spectrum of Compound 14 in $\mathrm{CDCl}_{3}$ & 116 \\
\hline Figure S109 & ${ }^{13} \mathrm{C}$ NMR Spectrum of Compound 14 in $\mathrm{CDCl}_{3}$ & 117 \\
\hline Figure S110 & (+) HRESIMS Spectrum of Compound 14 & 118 \\
\hline Figure S111 & ${ }^{1} \mathrm{H}$ NMR Spectrum of Compound 15 in DMSO- $d_{6}$ & 119 \\
\hline Figure S112 & ${ }^{13} \mathrm{C}$ NMR Spectrum of Compound 15 in DMSO- $d_{6}$ & 120 \\
\hline Figure S113 & (+) HRESIMS Spectrum of Compound 15 & 121 \\
\hline Figure S114 & ${ }^{1} \mathrm{H}$ NMR Spectrum of Compound 16 in $\mathrm{MeOH}-d_{4}$ & 122 \\
\hline Figure S115 & ${ }^{13} \mathrm{C}$ NMR Spectrum of Compound 16 in $\mathrm{MeOH}-d_{4}$ & 123 \\
\hline Figure S116 & (+) HRESIMS Spectrum of Compound 16 & 124 \\
\hline Figure S117 & ${ }^{1} \mathrm{H}$ NMR Spectrum of Compound 17 in DMSO- $d_{6}$ & 125 \\
\hline Figure S118 & ${ }^{13} \mathrm{C}$ NMR Spectrum of Compound 17 in DMSO- $d_{6}$ & 126 \\
\hline Figure S119 & (+) HRESIMS Spectrum of Compound 17 & 127 \\
\hline Figure S120 & ${ }^{1} \mathrm{H}$ NMR Spectrum of Compound 18 in DMSO- $d_{6}$ & 128 \\
\hline Figure S121 & ${ }^{13} \mathrm{C}$ NMR Spectrum of Compound 18 in DMSO- $d_{6}$ & 129 \\
\hline Figure S122 & (+) HRESIMS Spectrum of Compound $\mathbf{1 8}$ & 130 \\
\hline Figure S123 & ${ }^{1} \mathrm{H}$ NMR Spectrum of Compound 19 in DMSO- $d_{6}$ & 131 \\
\hline Figure S124 & ${ }^{13} \mathrm{C}$ NMR Spectrum of Compound 19 in DMSO- $d_{6}$ & 132 \\
\hline Figure S125 & (+) HRESIMS Spectrum of Compound $\mathbf{1 9}$ & 133 \\
\hline
\end{tabular}




\begin{tabular}{|c|c|c|}
\hline Figure S126 & ${ }^{1} \mathrm{H}$ NMR Spectrum of Compound 20 in DMSO- $d_{6}$ & 134 \\
\hline Figure S127 & ${ }^{13} \mathrm{C}$ NMR Spectrum of Compound 20 in DMSO- $d_{6}$ & 135 \\
\hline Figure S128 & (+) HRESIMS Spectrum of Compound $\mathbf{2 0}$ & 136 \\
\hline Figure S129 & ${ }^{1} \mathrm{H}$ NMR Spectrum of Compound 21 in $\mathrm{CDCl}_{3}$ & 137 \\
\hline Figure S130 & ${ }^{13} \mathrm{C}$ NMR Spectrum of Compound 21 in $\mathrm{CDCl}_{3}$ & 138 \\
\hline Figure S131 & (+) HRESIMS Spectrum of Compound 21 & 139 \\
\hline Figure S132 & ${ }^{1} \mathrm{H}$ NMR Spectrum of Compound 22 in $\mathrm{MeOH}-d_{4}$ & 140 \\
\hline Figure S133 & ${ }^{13} \mathrm{C}$ NMR Spectrum of Compound 22 in $\mathrm{MeOH}-d_{4}$ & 141 \\
\hline Figure S134 & (+) HRESIMS Spectrum of Compound 22 & 142 \\
\hline Figure S135 & ${ }^{1} \mathrm{H}$ NMR Spectrum of Compound 23 in $\mathrm{MeOH}-d_{4}$ & 143 \\
\hline Figure S136 & ${ }^{13} \mathrm{C}$ NMR Spectrum of Compound 23 in $\mathrm{MeOH}-d_{4}$ & 144 \\
\hline Figure S137 & (+) HRESIMS Spectrum of Compound $\mathbf{2 3}$ & 145 \\
\hline Figure S138 & ${ }^{1} \mathrm{H}$ NMR Spectrum of Compound 24 in $\mathrm{MeOH}-d_{4}$ & 146 \\
\hline Figure S139 & ${ }^{13} \mathrm{C}$ NMR Spectrum of Compound 24 in $\mathrm{MeOH}-d_{4}$ & 147 \\
\hline Figure S140 & (+) HRESIMS Spectrum of Compound $\mathbf{2 4}$ & 148 \\
\hline Figure S141 & ${ }^{1} \mathrm{H}$ NMR Spectrum of Compound 25 in $\mathrm{MeOH}-d_{4}$ & 149 \\
\hline Figure S142 & ${ }^{13} \mathrm{C}$ NMR Spectrum of Compound 25 in $\mathrm{MeOH}-d_{4}$ & 150 \\
\hline Figure S143 & (+) HRESIMS Spectrum of Compound 25 & 151 \\
\hline Figure S144 & ${ }^{1} \mathrm{H}$ NMR Spectrum of Compound 26 in $\mathrm{MeOH}-d_{4}$ & 152 \\
\hline Figure S145 & ${ }^{13} \mathrm{C}$ NMR Spectrum of Compound 26 in $\mathrm{MeOH}-d_{4}$ & 153 \\
\hline Figure S146 & (+) HRESIMS Spectrum of Compound $\mathbf{2 6}$ & 154 \\
\hline Figure S147 & ${ }^{1} \mathrm{H}$ NMR Spectrum of Compound 27 in $\mathrm{MeOH}-d_{4}$ & 155 \\
\hline Figure S148 & ${ }^{13} \mathrm{C}$ NMR Spectrum of Compound 27 in $\mathrm{MeOH}-d_{4}$ & 156 \\
\hline Figure S149 & (+) HRESIMS Spectrum of Compound 27 & 157 \\
\hline Figure S150 & ${ }^{1} \mathrm{H}$ NMR Spectrum of Compound 28 in $\mathrm{MeOH}-d_{4}$ & 158 \\
\hline Figure S151 & ${ }^{13} \mathrm{C}$ NMR Spectrum of Compound 28 in $\mathrm{MeOH}-d_{4}$ & 159 \\
\hline Figure S152 & (+) HRESIMS Spectrum of Compound $\mathbf{2 8}$ & 160 \\
\hline Figure S153 & ${ }^{1} \mathrm{H}$ NMR Spectrum of Compound 29 in $\mathrm{MeOH}-d_{4}$ & 161 \\
\hline Figure S154 & ${ }^{13} \mathrm{C}$ NMR Spectrum of Compound 29 in $\mathrm{MeOH}-d_{4}$ & 162 \\
\hline Figure S155 & (+) HRESIMS Spectrum of Compound 29 & 163 \\
\hline Figure S156 & ${ }^{1} \mathrm{H}$ NMR Spectrum of Compound 30 in $\mathrm{CDCl}_{3}$ & 164 \\
\hline Figure S157 & ${ }^{13} \mathrm{C}$ NMR Spectrum of Compound 30 in $\mathrm{CDCl}_{3}$ & 165 \\
\hline Figure S158 & (+) HRESIMS Spectrum of Compound $\mathbf{3 0}$ & 166 \\
\hline Figure S159 & ${ }^{1} \mathrm{H}$ NMR Spectrum of Compound 31 in $\mathrm{MeOH}-d_{4}$ & 167 \\
\hline Figure S160 & ${ }^{13} \mathrm{C}$ NMR Spectrum of Compound $\mathbf{3 1}$ in $\mathrm{MeOH}-d_{4}$ & 168 \\
\hline Figure S161 & (+) HRESIMS Spectrum of Compound $\mathbf{3 1}$ & 169 \\
\hline Figure S162 & NOESY correlation of Compound $\mathbf{8 a}$ & 170 \\
\hline Figure S163 & NOESY correlation of Compound $9 \mathbf{a}$ and $\mathbf{9 b}$ & 171 \\
\hline Figure S164 & NOESY correlation of Compound $\mathbf{1 0 a}$ and $\mathbf{1 0 b}$ & 172 \\
\hline Figure S165 & NOESY correlation of Compound 11a & 173 \\
\hline Figure S166 & Chiral-phase HPLC Spectrum of Compound 8 & 174 \\
\hline
\end{tabular}


Figure S1. Chemical structures of compounds 12-31 isolated from $P$. puberulum.<smiles>[R]c1c([R])c2c3c(c1[R])-c1ccccc1[C@@H](O)C3N(C(C)=O)CC2</smiles>

$12 \mathrm{R}_{1}=\mathrm{H} \mathrm{R}_{2}+\mathrm{R}_{3}=\mathrm{OCH}_{2} \mathrm{O}$ $24 \mathrm{R}_{1}=\mathrm{R}_{2}=\mathrm{R}_{3}=\mathrm{OCH}_{3}$<smiles>O=C1c2ccccc2-c2c3c(cc4ccnc1c24)OCO3</smiles>

13<smiles>COc1cc2c3c(cc4ccccc4c3c1OC)NC(=O)C2=O</smiles>

14<smiles>[R]c1c([R])c2c(=O)[nH]c3cc4ccccc4c([R])c1c32</smiles>

$15 \mathrm{R}_{1}=\mathrm{H} \mathrm{R}_{2}=\mathrm{OCH}_{3} \mathrm{R}_{3}=\mathrm{OH}$ $16 \mathrm{R}_{1}=\mathrm{R}_{2}=\mathrm{R}_{3}=\mathrm{OCH}_{3}$ $17 \mathrm{R}_{1}=\mathrm{H} \mathrm{R}_{2}+\mathrm{R}_{3}=\mathrm{OCH}_{2} \mathrm{O}$ $25 \mathrm{R}_{1}=\mathrm{R}_{2}=\mathrm{OCH}_{3} \quad \mathrm{R}_{3}=\mathrm{OH}$ $26 \mathrm{R}_{1}=\mathrm{H} \mathrm{R}_{2}=\mathrm{R}_{3}=\mathrm{OCH}_{3}$<smiles>COc1ccc(O)c(C(=O)NCCc2ccc(O)c(OC)c2)c1</smiles><smiles>O=C(NCCc1ccc(O)cc1)c1ccc(O)c(O)c1</smiles><smiles>COc1cc(/C=C\C(=O)NCCc2ccc(O)cc2)ccc1O</smiles>

20<smiles>CCCCC/C=C/C=C/C(=O)NCC(C)C</smiles><smiles>CCCCC(=O)NCCc1ccc(O)cc1</smiles><smiles>COc1cc(CCNC(=O)/C=C/c2ccc(O)c(C)c2)ccc1O</smiles><smiles>COc1cc([C@@H]2c3c(cc(OC)c(O)c3O)C=C(C(=O)NCCc3ccc(O)cc3)[C@H]2C(=O)NCCc2ccc(O)cc2)cc(OC)c1O</smiles> 
Table S1. X-ray Crystallographic Data for Compound 7

\begin{tabular}{|c|c|}
\hline Empirical formula & $\mathrm{C}_{20} \mathrm{H}_{22} \mathrm{NO}_{5.5}$ \\
\hline Formula weight & 364.38 \\
\hline Temperature/K & $150.00(10)$ \\
\hline Crystal system & orthorhombic \\
\hline Space group & $\mathrm{P} 2{ }_{1} 22_{1}$ \\
\hline $\mathrm{a} / \AA$ & $10.05299(12)$ \\
\hline $\mathrm{b} / \AA$ & $10.98593(14)$ \\
\hline $\mathrm{c} / \AA$ & $31.7721(4)$ \\
\hline$\alpha /^{\circ}$ & 90 \\
\hline$\beta /{ }^{\circ}$ & 90 \\
\hline$\gamma /{ }^{\circ}$ & 90 \\
\hline Volume $/ \AA^{3}$ & $3508.95(8)$ \\
\hline $\mathrm{Z}$ & 8 \\
\hline$\rho_{\text {calc }} \mathrm{g} / \mathrm{cm}^{3}$ & 1.380 \\
\hline$\mu / \mathrm{mm}^{-1}$ & 0.834 \\
\hline $\mathrm{F}(000)$ & 1544.0 \\
\hline Crystal size $/ \mathrm{mm}^{3}$ & $0.13 \times 0.12 \times 0.11$ \\
\hline Radiation & $\mathrm{Cu} \mathrm{K} \alpha(\lambda=1.54184)$ \\
\hline $2 \Theta$ range for data collection ${ }^{\circ}$ & 5.564 to 147.814 \\
\hline Index ranges & $-12 \leq \mathrm{h} \leq 7,-13 \leq \mathrm{k} \leq 13,-37 \leq 1 \leq 39$ \\
\hline Reflections collected & 16305 \\
\hline Independent reflections & $6821\left[\mathrm{R}_{\text {int }}=0.0385, \mathrm{R}_{\text {sigma }}=0.0438\right]$ \\
\hline Data/restraints/parameters & $6821 / 0 / 491$ \\
\hline Goodness-of-fit on $\mathrm{F}^{2}$ & 1.035 \\
\hline Final $R$ indexes $[\mathrm{I}>=2 \sigma(\mathrm{I})]$ & $\mathrm{R}_{1}=0.0425, \mathrm{wR}_{2}=0.1108$ \\
\hline Final R indexes [all data] & $\mathrm{R}_{1}=0.0449, \mathrm{wR}_{2}=0.1135$ \\
\hline Largest diff. peak/hole / e $\AA^{-3}$ & $0.23 /-0.24$ \\
\hline Flack/Hooft parameter & $0.05(10) / 0.07(9)$ \\
\hline
\end{tabular}


Table S2. X-ray Crystallographic Data for Compound 8

\begin{tabular}{|c|c|}
\hline Empirical formula & $\mathrm{C}_{19} \mathrm{H}_{19} \mathrm{NO}_{4}$ \\
\hline Formula weight & 325.35 \\
\hline Temperature/K & $100.01(11)$ \\
\hline Crystal system & triclinic \\
\hline Space group & $\mathrm{P} 1$ \\
\hline $\mathrm{a} / \AA$ & $6.2855(2)$ \\
\hline $\mathrm{b} / \AA \AA$ & $7.5767(3)$ \\
\hline $\mathrm{c} / \AA \AA$ & $8.7197(3)$ \\
\hline$\alpha /{ }^{\circ}$ & $88.555(3)$ \\
\hline$\beta /{ }^{\circ}$ & $74.561(3)$ \\
\hline$\gamma /{ }^{\circ}$ & $73.387(3)$ \\
\hline Volume $/ \AA^{3}$ & $382.99(3)$ \\
\hline $\mathrm{Z}$ & 1 \\
\hline$\rho_{\text {calc }} \mathrm{g} / \mathrm{cm}^{3}$ & 1.411 \\
\hline$\mu / \mathrm{mm}^{-1}$ & 0.812 \\
\hline $\mathrm{F}(000)$ & 172.0 \\
\hline Crystal size $/ \mathrm{mm}^{3}$ & $0.14 \times 0.13 \times 0.12$ \\
\hline Radiation & $\mathrm{Cu} \mathrm{K} \alpha(\lambda=1.54184)$ \\
\hline $2 \Theta$ range for data collection ${ }^{\circ}$ & 10.542 to 146.896 \\
\hline Index ranges & $-7 \leq \mathrm{h} \leq 6,-8 \leq \mathrm{k} \leq 9,-10 \leq 1 \leq 10$ \\
\hline Reflections collected & 3874 \\
\hline Independent reflections & $2342\left[\mathrm{R}_{\text {int }}=0.0117, \mathrm{R}_{\text {sigma }}=0.0143\right]$ \\
\hline Data/restraints/parameters & $2342 / 3 / 221$ \\
\hline Goodness-of-fit on $\mathrm{F}^{2}$ & 1.080 \\
\hline Final $R$ indexes $[\mathrm{I}>=2 \sigma(\mathrm{I})]$ & $\mathrm{R}_{1}=0.0271, \mathrm{wR}_{2}=0.0741$ \\
\hline Final R indexes [all data] & $\mathrm{R}_{1}=0.0272, \mathrm{wR}_{2}=0.0741$ \\
\hline Largest diff. peak/hole / e $\AA^{-3}$ & $0.17 /-0.20$ \\
\hline Flack/Hooft parameter & $0.11(7) / 0.14(5)$ \\
\hline
\end{tabular}


Table S3. X-ray Crystallographic Data for Compound $\mathbf{1 0}$

\begin{tabular}{|c|c|}
\hline Empirical formula & $\mathrm{C}_{18} \mathrm{H}_{15} \mathrm{NO}_{4}$ \\
\hline Formula weight & 309.31 \\
\hline Temperature/K & $100.01(10)$ \\
\hline Crystal system & orthorhombic \\
\hline Space group & $\mathrm{P} 2{ }_{1} 2_{1} 2_{1}$ \\
\hline $\mathrm{a} / \AA \AA$ & $6.87976(12)$ \\
\hline $\mathrm{b} / \AA$ & $11.6221(2)$ \\
\hline $\mathrm{c} / \AA$ & $17.8667(3)$ \\
\hline$\alpha /{ }^{\circ}$ & 90 \\
\hline$\beta /{ }^{\circ}$ & 90 \\
\hline$\gamma /{ }^{\circ}$ & 90 \\
\hline Volume $/ \AA^{3}$ & $1428.58(4)$ \\
\hline $\mathrm{Z}$ & 4 \\
\hline$\rho_{\text {calc }} \mathrm{g} / \mathrm{cm}^{3}$ & 1.438 \\
\hline$\mu / \mathrm{mm}^{-1}$ & 0.845 \\
\hline $\mathrm{F}(000)$ & 648.0 \\
\hline Crystal size $/ \mathrm{mm}^{3}$ & $0.14 \times 0.12 \times 0.11$ \\
\hline Radiation & $\mathrm{Cu} \mathrm{K} \alpha(\lambda=1.54184)$ \\
\hline $2 \Theta$ range for data collection ${ }^{\circ}$ & 9.078 to 147.03 \\
\hline Index ranges & $-6 \leq \mathrm{h} \leq 8,-14 \leq \mathrm{k} \leq 13,-19 \leq 1 \leq 21$ \\
\hline Reflections collected & 7031 \\
\hline Independent reflections & $2820\left[\mathrm{R}_{\mathrm{int}}=0.0233, \mathrm{R}_{\mathrm{sigma}}=0.0213\right]$ \\
\hline Data/restraints/parameters & $2820 / 0 / 209$ \\
\hline Goodness-of-fit on $\mathrm{F}^{2}$ & 1.119 \\
\hline Final $\mathrm{R}$ indexes $[\mathrm{I}>=2 \sigma(\mathrm{I})]$ & $\mathrm{R}_{1}=0.0339, \mathrm{wR}_{2}=0.0871$ \\
\hline Final $\mathrm{R}$ indexes [all data] & $\mathrm{R}_{1}=0.0342, \mathrm{wR}_{2}=0.0873$ \\
\hline Largest diff. peak/hole / e $\AA^{-3}$ & $0.20 /-0.27$ \\
\hline Flack/Hooft parameter & $-0.02(11) / 0.04(6)$ \\
\hline
\end{tabular}


Figure S2. ${ }^{1} \mathrm{H}$ NMR Spectrum of Compound 1 in DMSO- $d_{6}$ ZTK-Pb-52. 1. fid
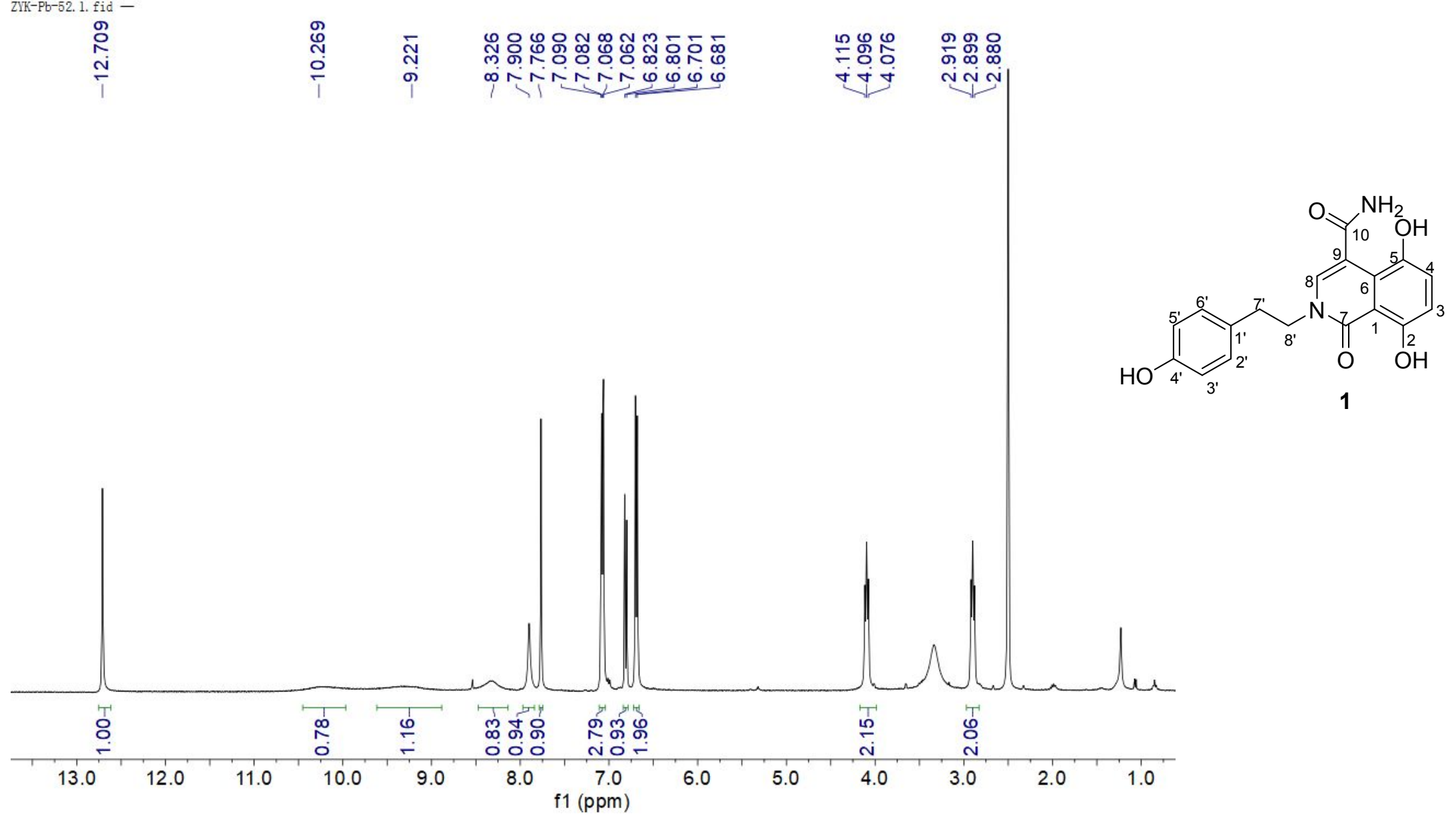
Figure S3. ${ }^{13} \mathrm{C}$ NMR Spectrum of Compound 1 in DMSO- $d_{6}$ ZJK-Pb-52. 2. fid -

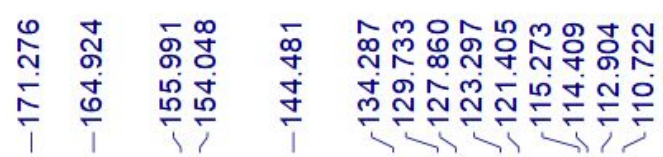
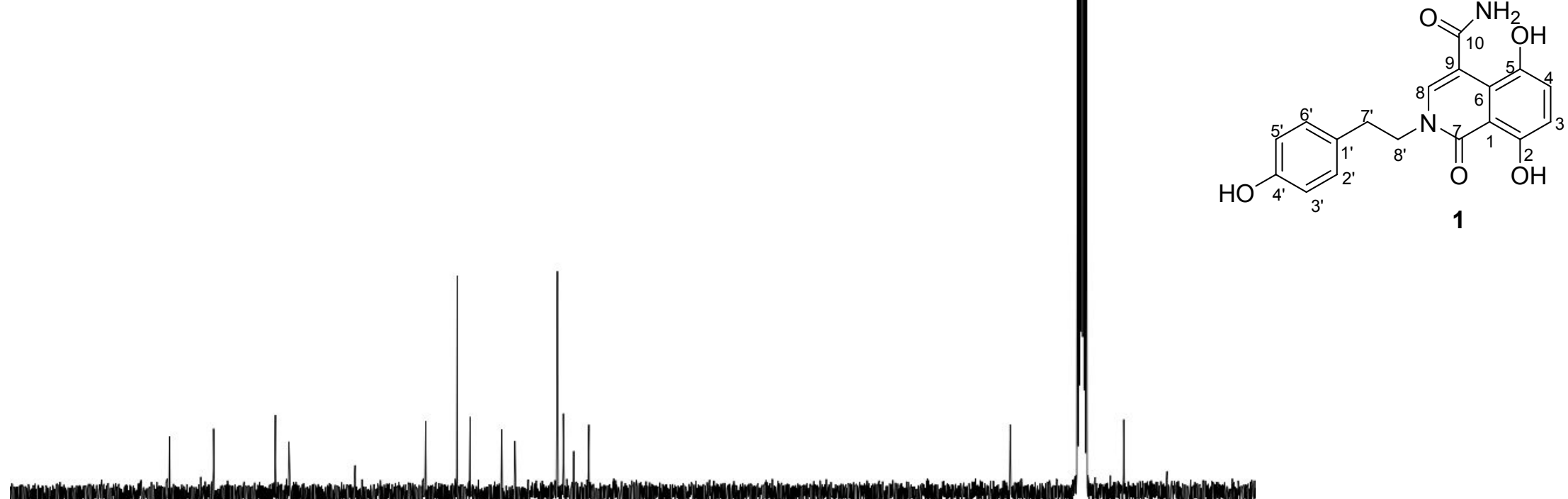

$\begin{array}{llllllllll}190 & 180 & 170 & 160 & 150 & 140 & 130 & 120 & \begin{array}{l}110 \\ \mathrm{f} 1(\mathrm{ppm})\end{array}\end{array}$ 
Figure S4. ${ }^{1} \mathrm{H}-{ }^{1} \mathrm{H}$ COSY Spectrum of Compound 1 in DMSO- $d_{6}$ ZTK-Fb-52. 4. ser -

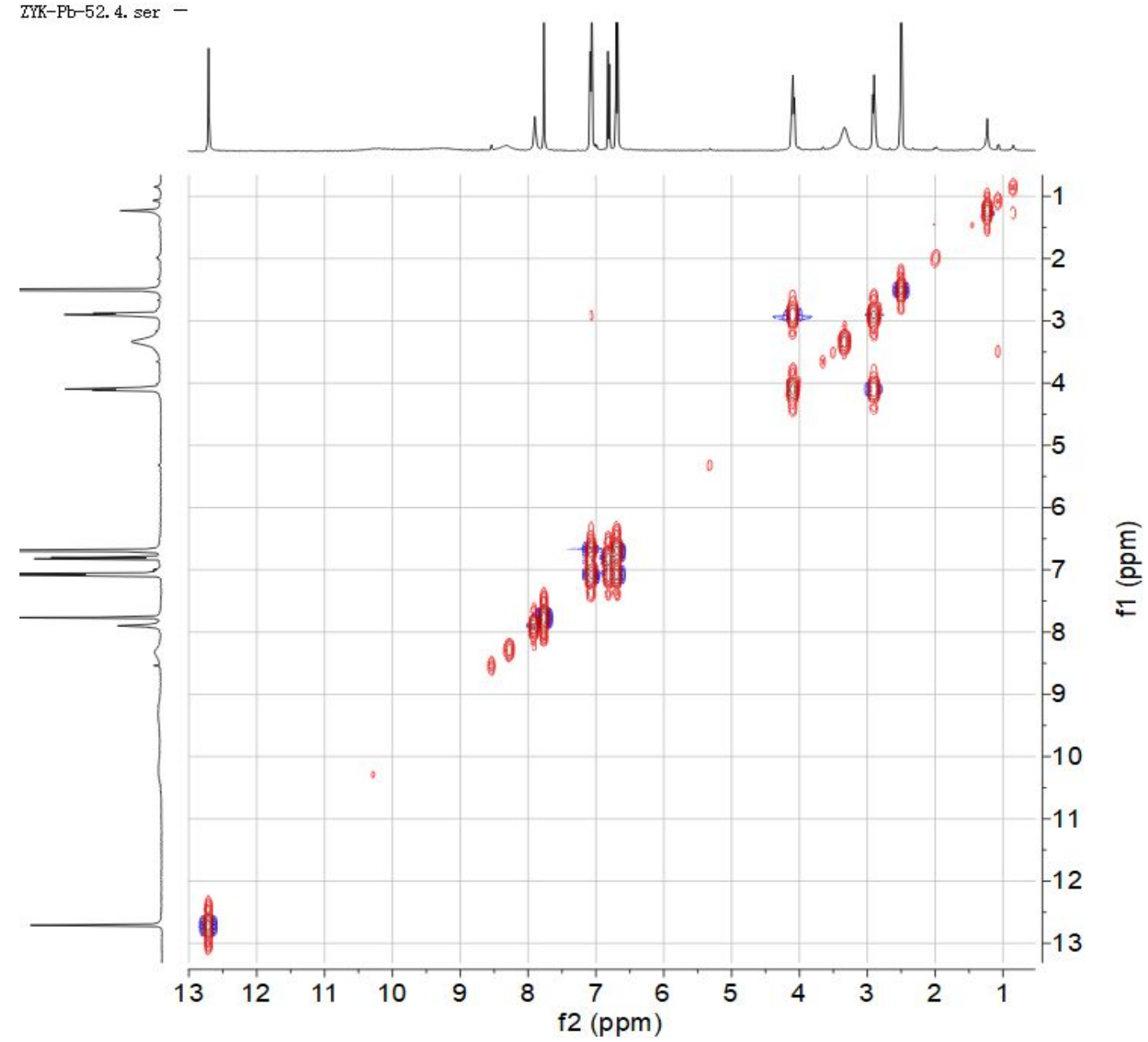

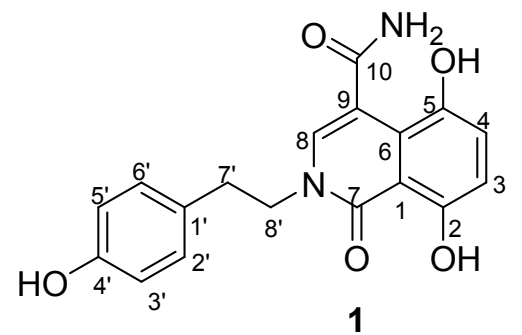


Figure S5. HSQC Spectrum of Compound 1 in DMSO- $d_{6}$

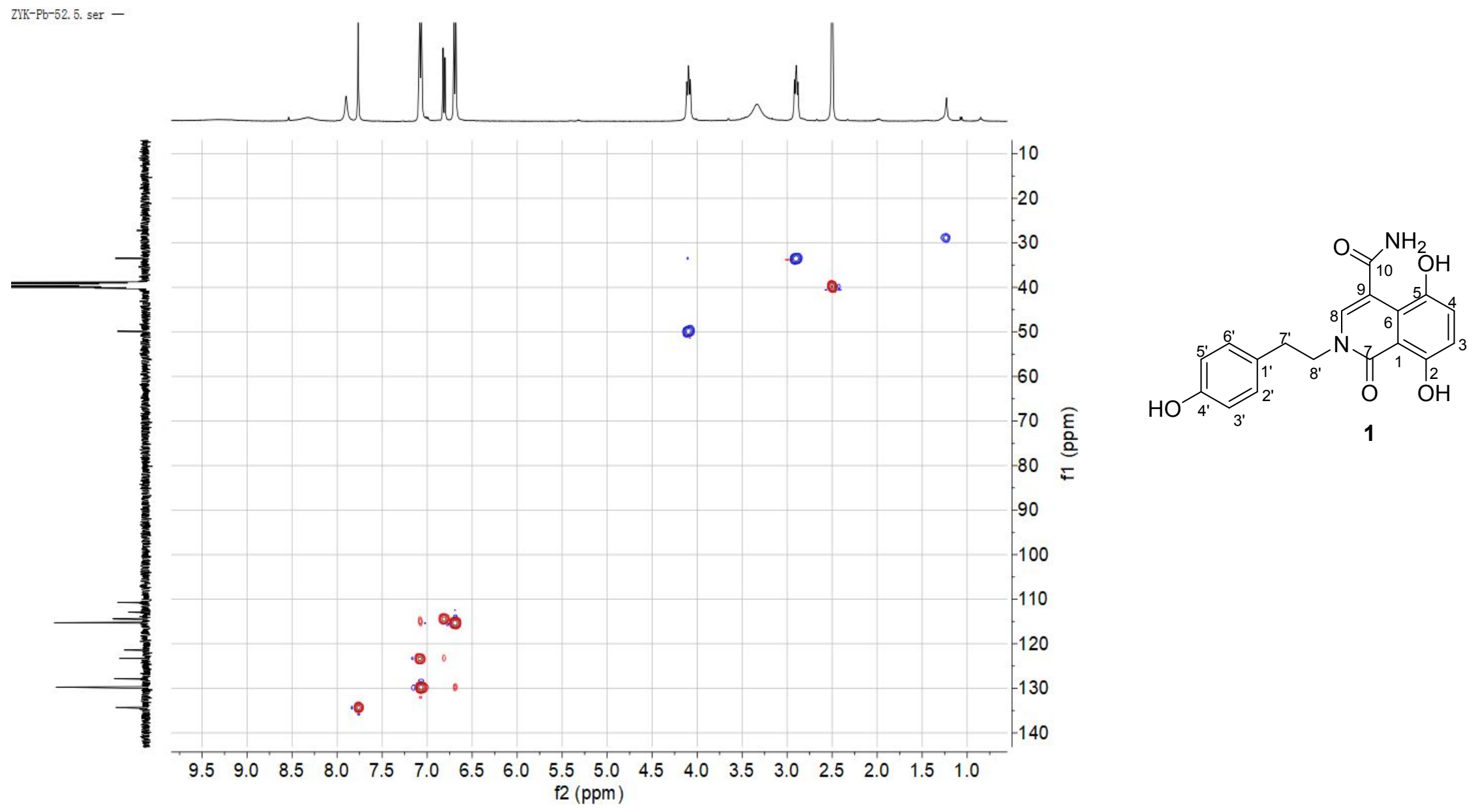


Figure S6. HMBC Spectrum of Compound $\mathbf{1}$ in DMSO- $d_{6}$ zIK-Pb-52.6. ser -
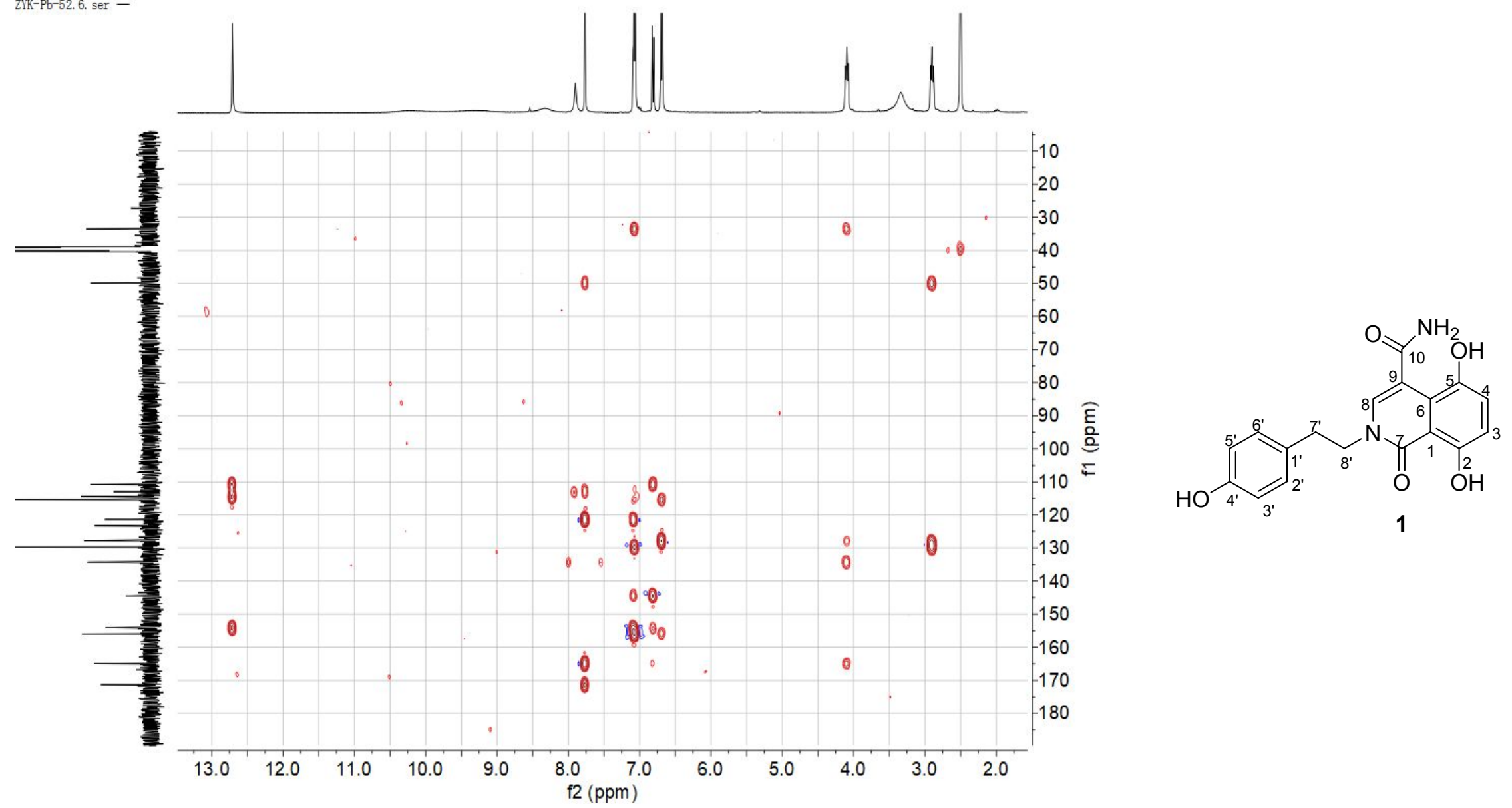
Figure S7. (+) HRESIMS Spectrum of Compound 1

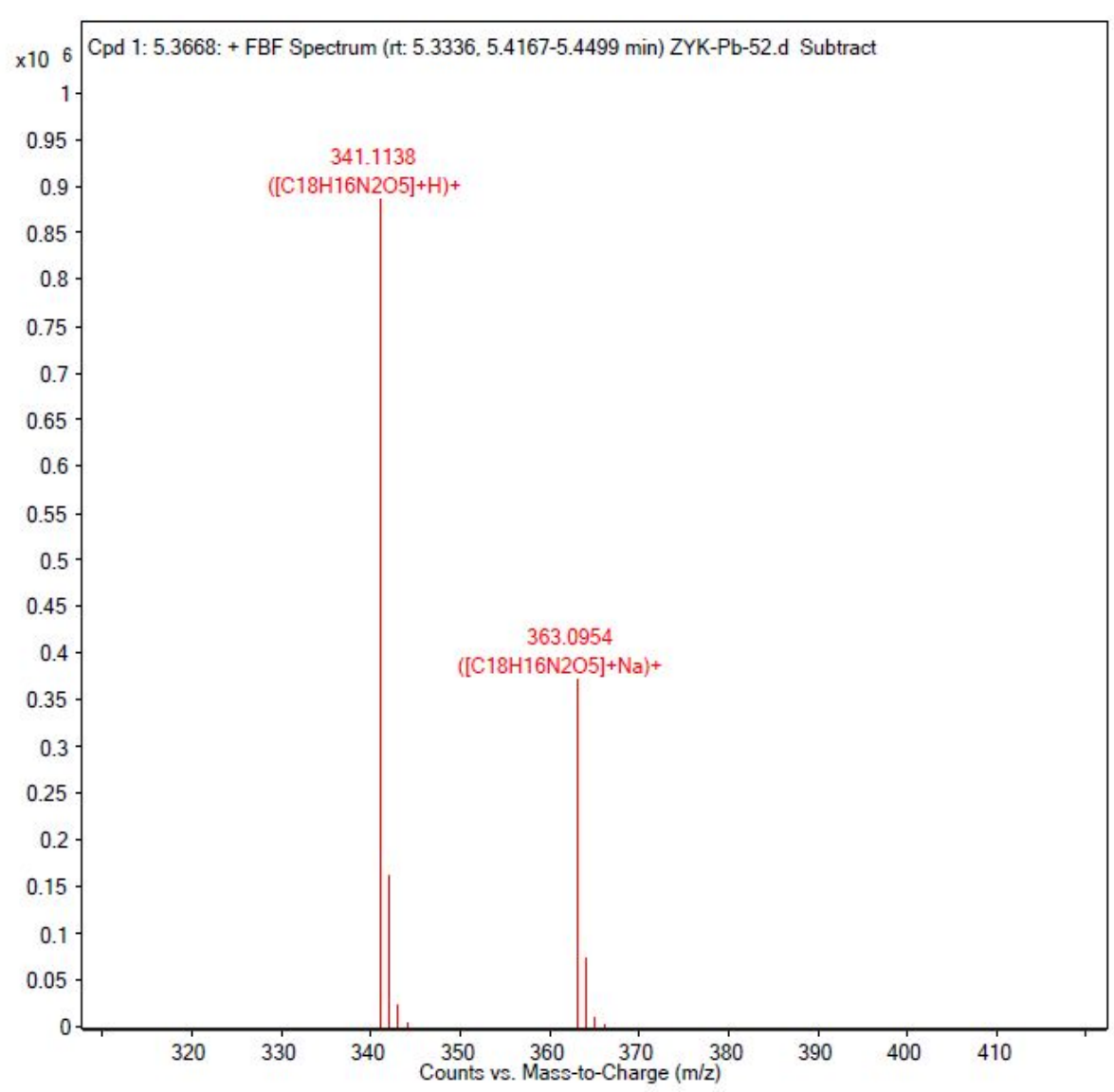

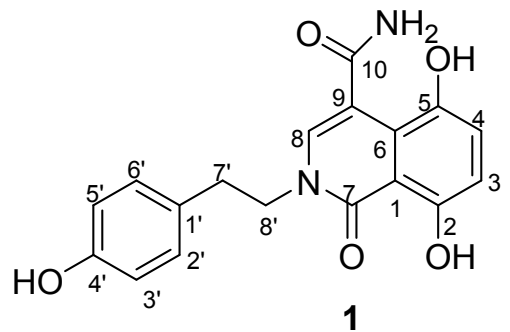


Figure S8. UV Spectrum of Compound 1

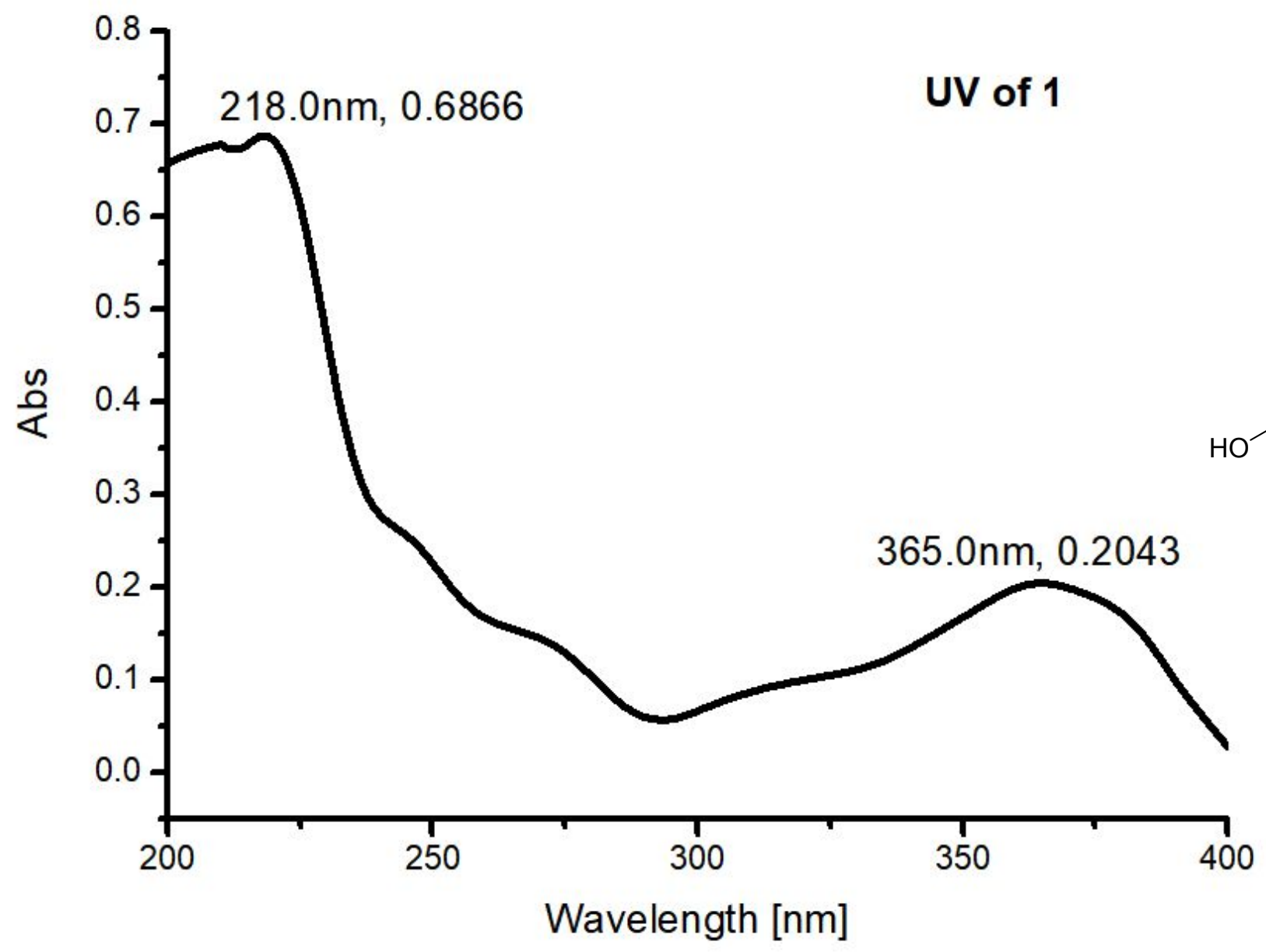


Figure S9. IR ( $\mathrm{KBr}$ disc) Spectrum of Compound 1

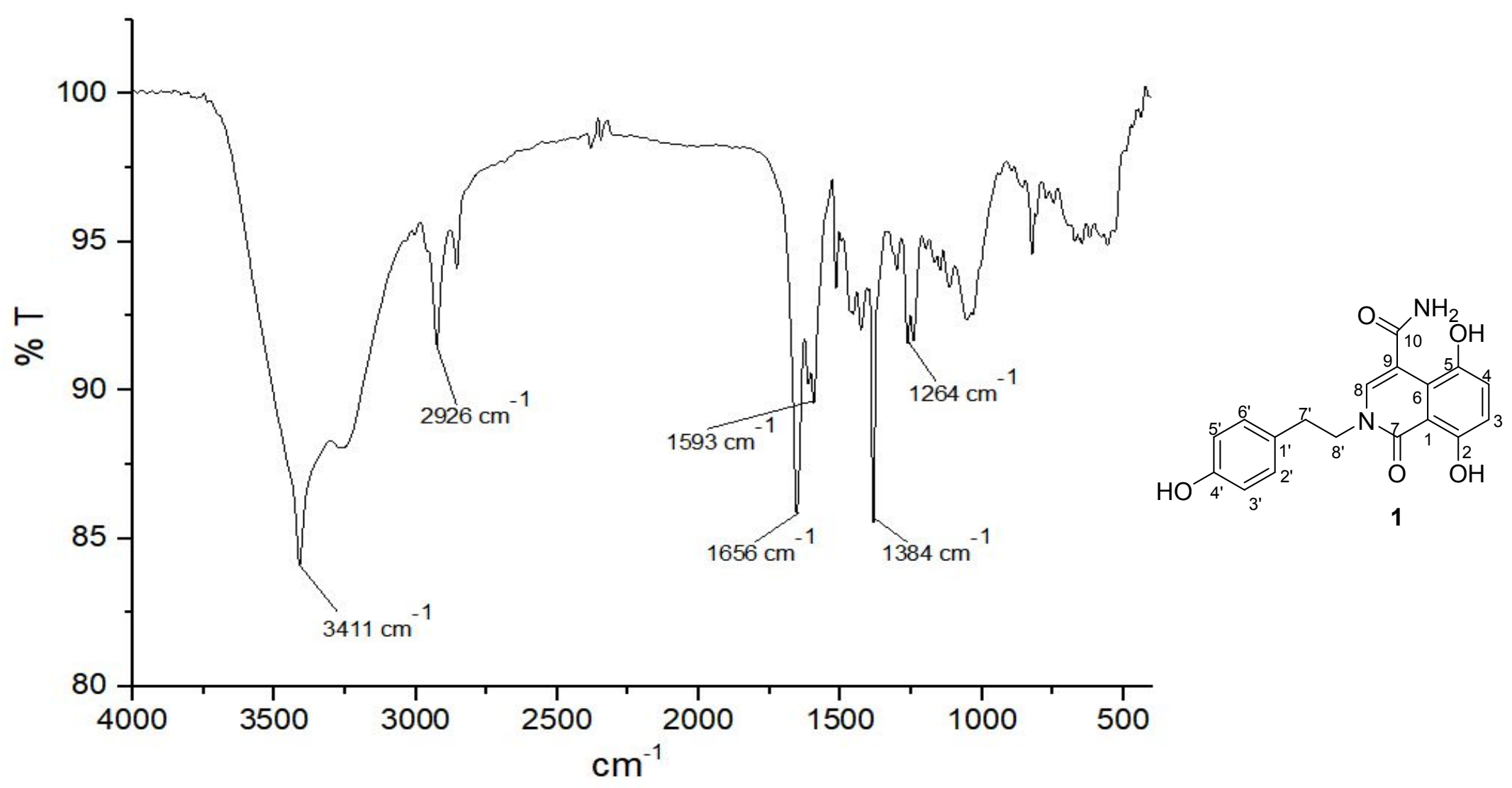


Figure S10. ${ }^{1} \mathrm{H}$ NMR Spectrum of Compound 2 in $\mathrm{MeOH}-d_{4}$ ZZK-Pb-X.1.fid -

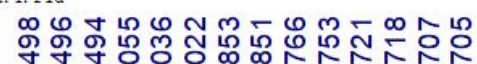

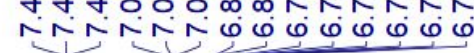

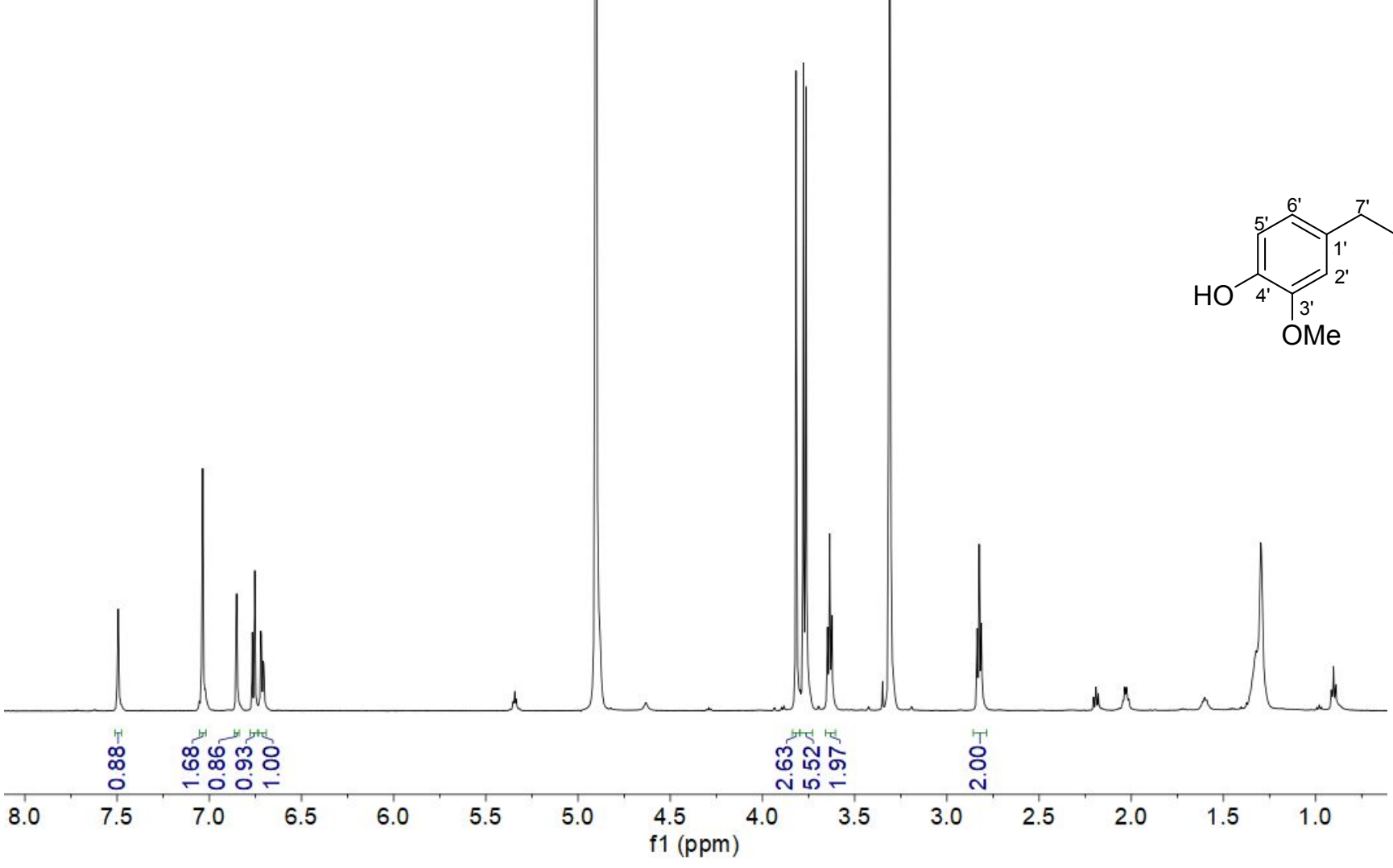


Figure S11. ${ }^{13} \mathrm{C}$ NMR Spectrum of Compound 2 in $\mathrm{MeOH}-d_{4}$

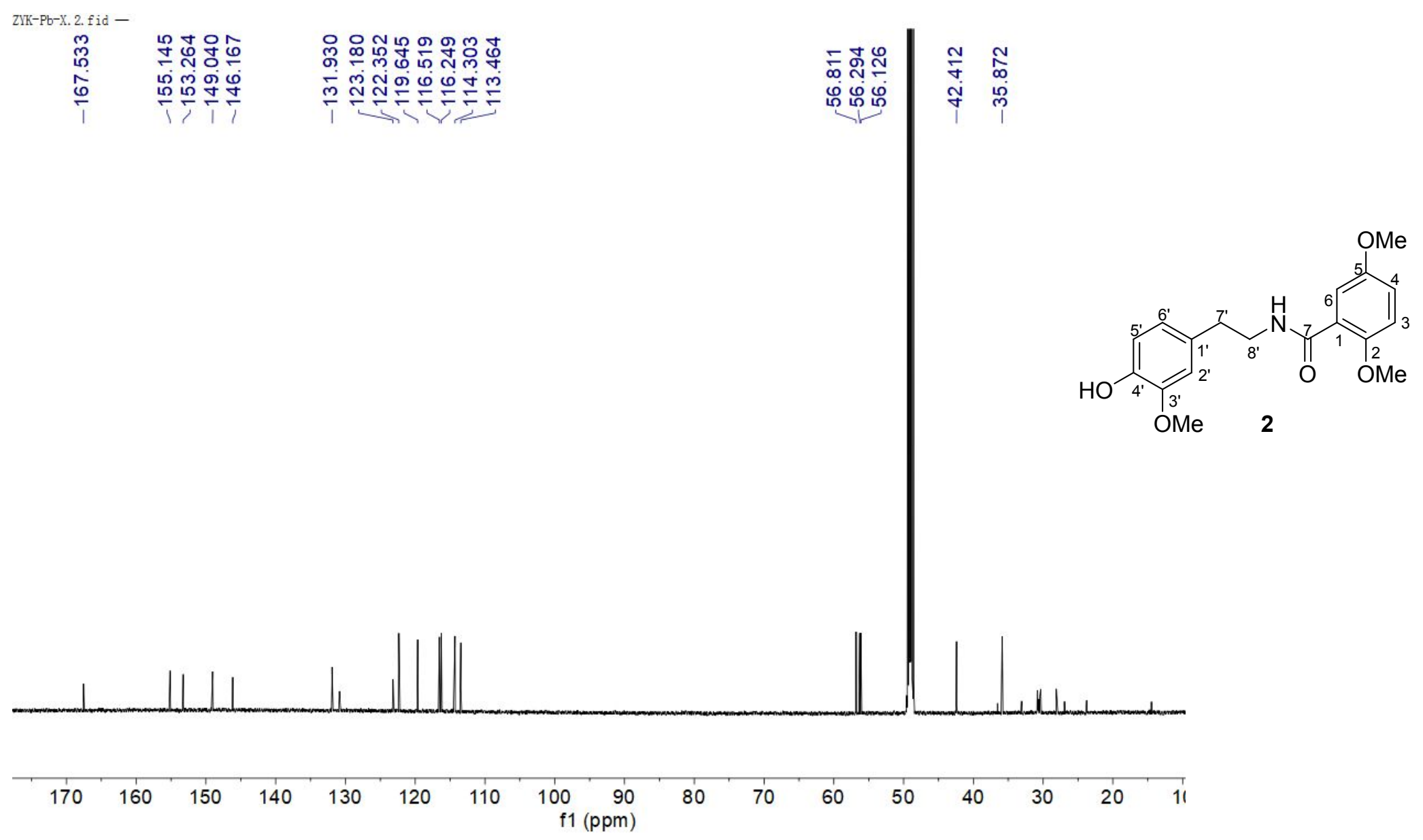


Figure S12. ${ }^{1} \mathrm{H}-{ }^{1} \mathrm{H}$ COSY Spectrum of Compound 2 in $\mathrm{MeOH}-d_{4}$ ZTK-Pb-X. 4. ser -

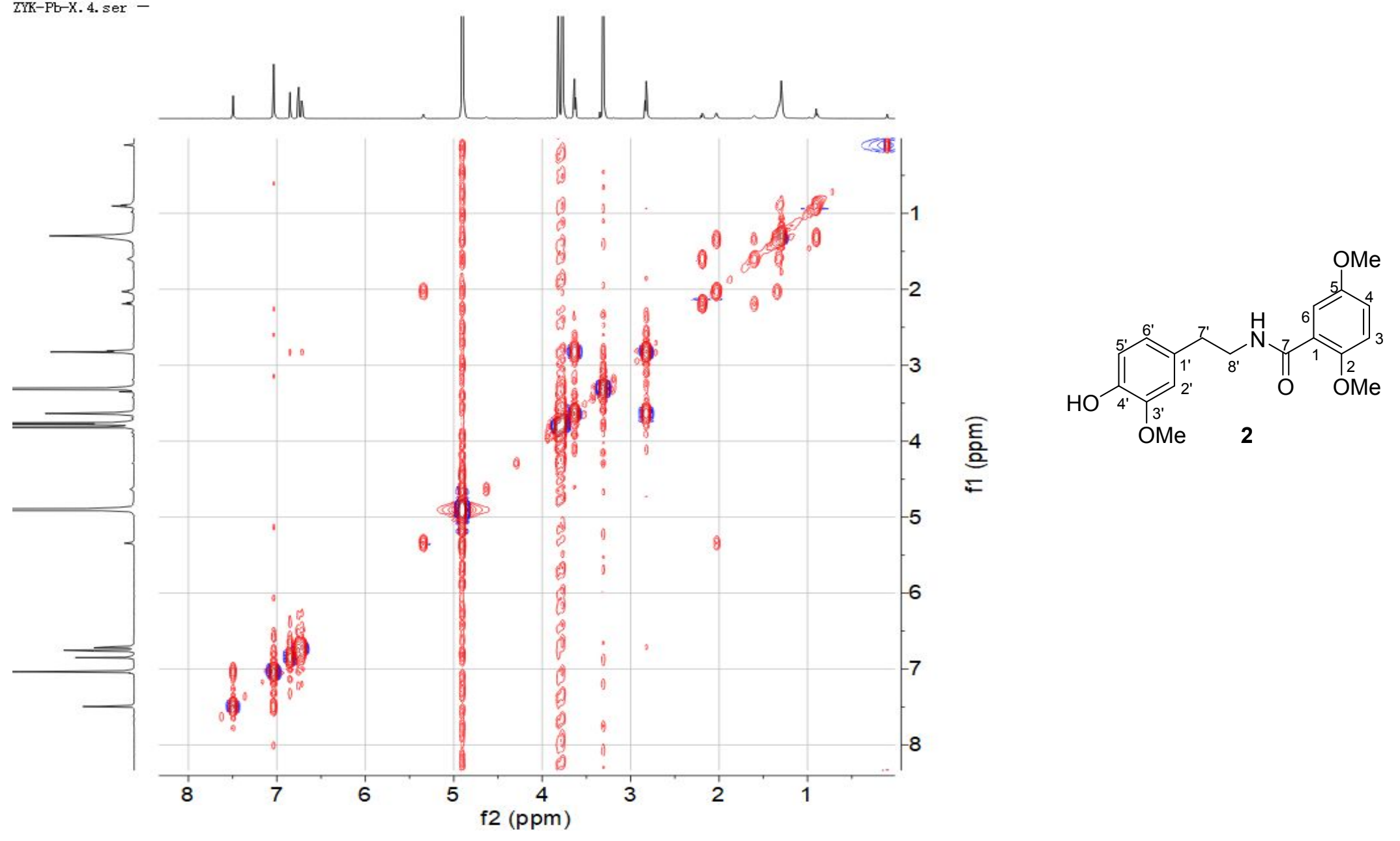


Figure S13. HSQC Spectrum of Compound 2 in $\mathrm{MeOH}-d_{4}$ ZJK-Pb-97. 6. ser -
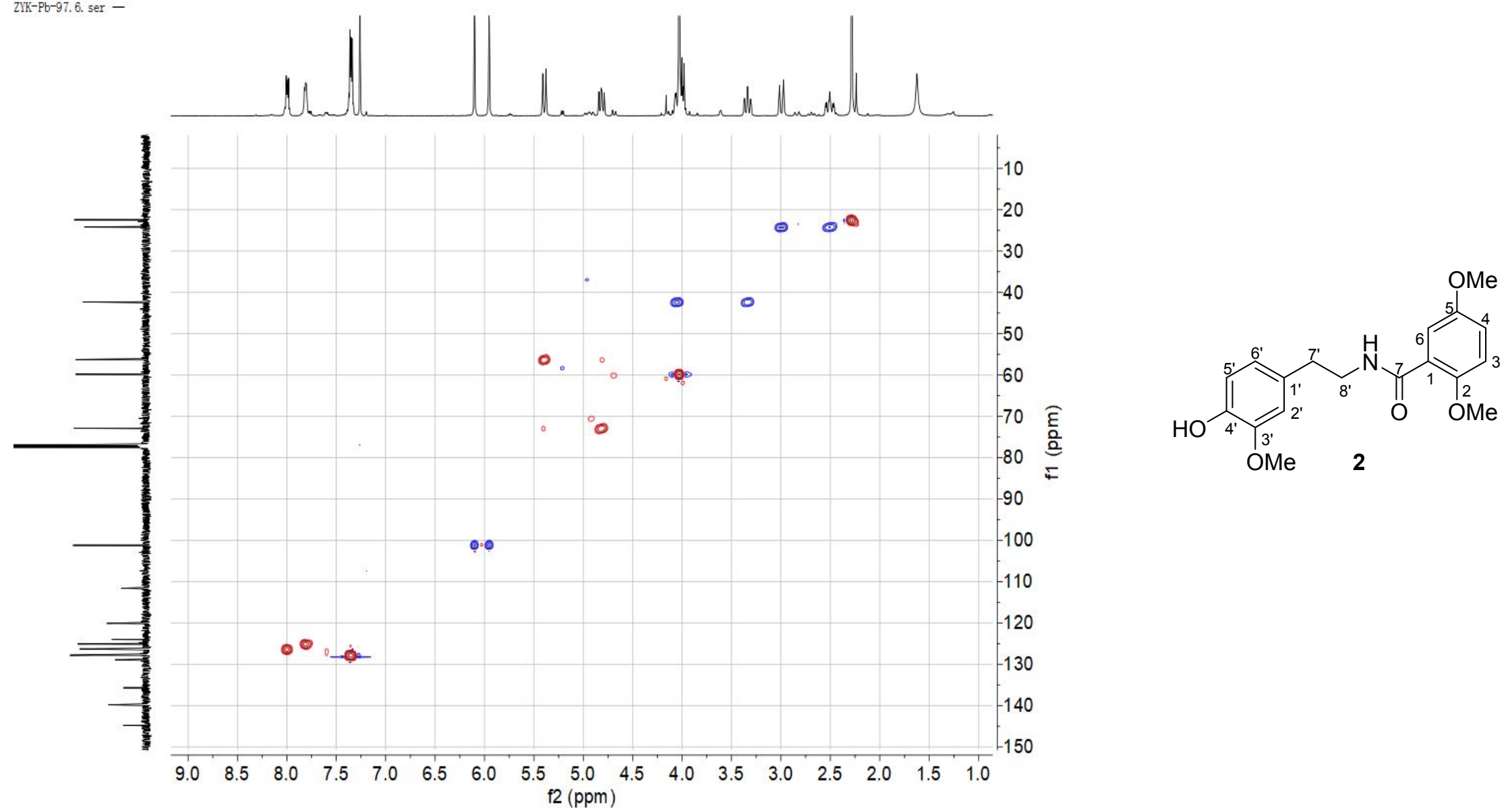
Figure S14. HMBC Spectrum of Compound 2 in $\mathrm{MeOH}-d_{4}$ ZJK-Pb-X. 6. ser -
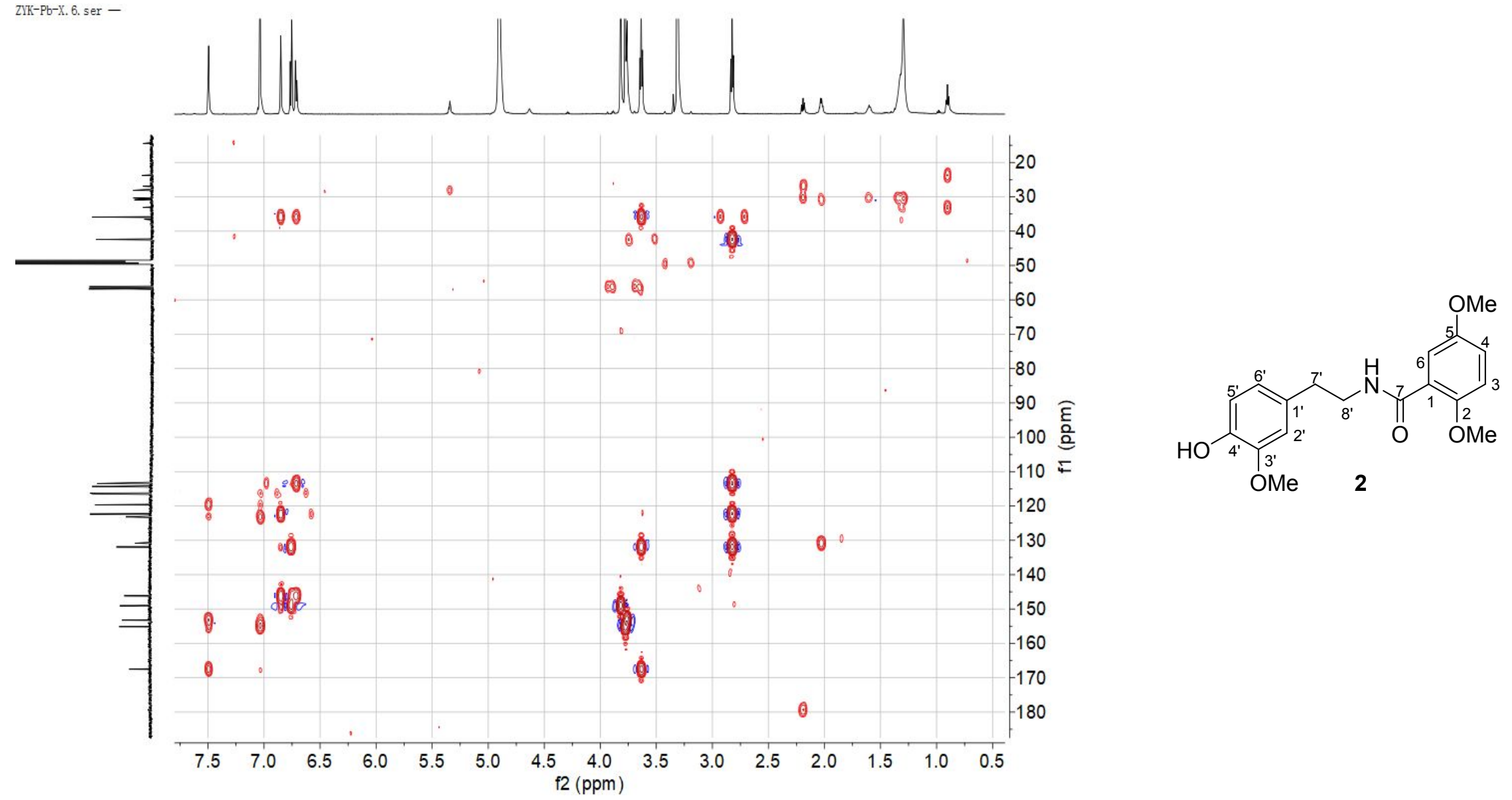
Figure S15. (+) HRESIMS Spectrum of Compound 2

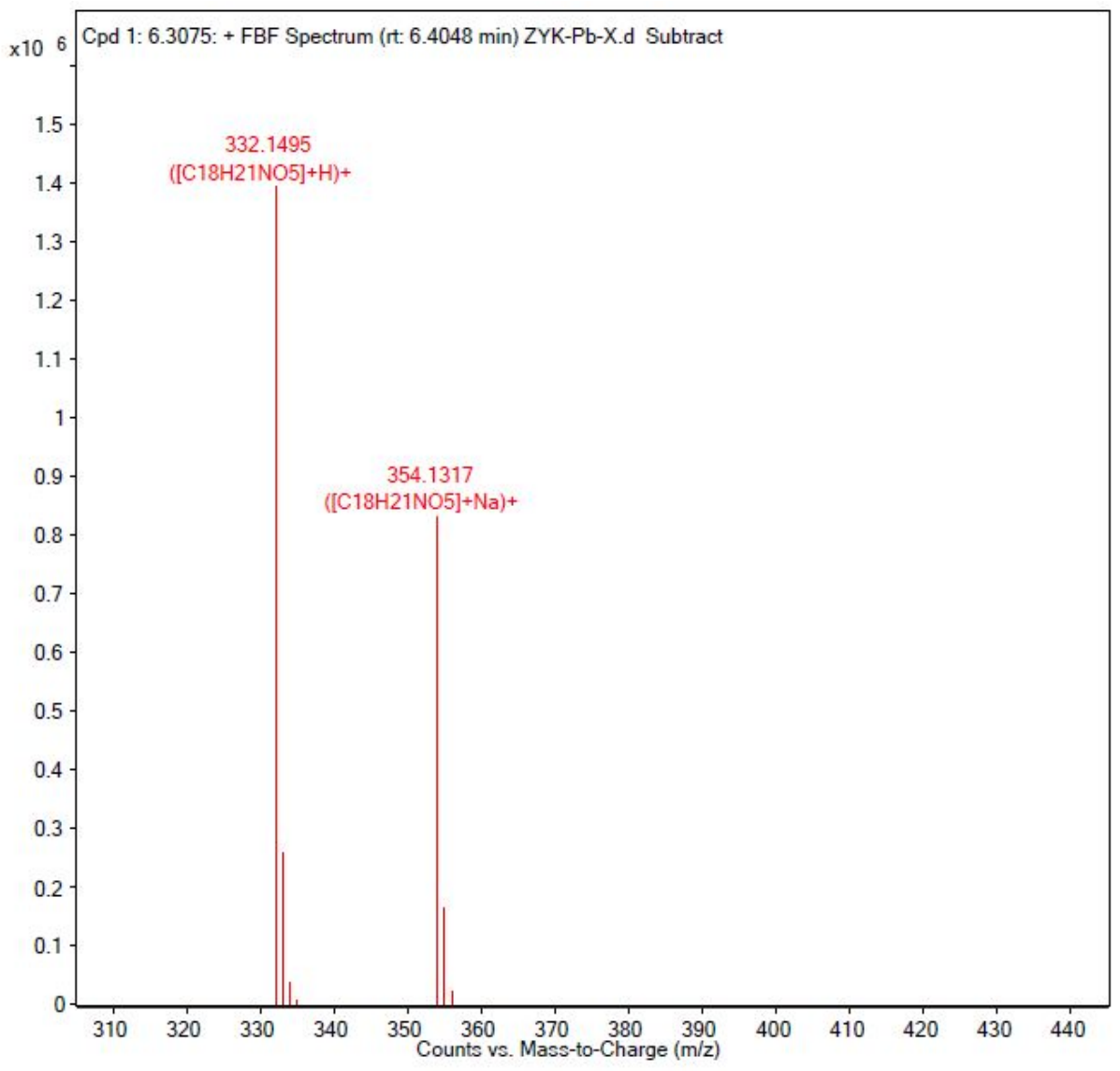


Figure S16. UV Spectrum of Compound 2
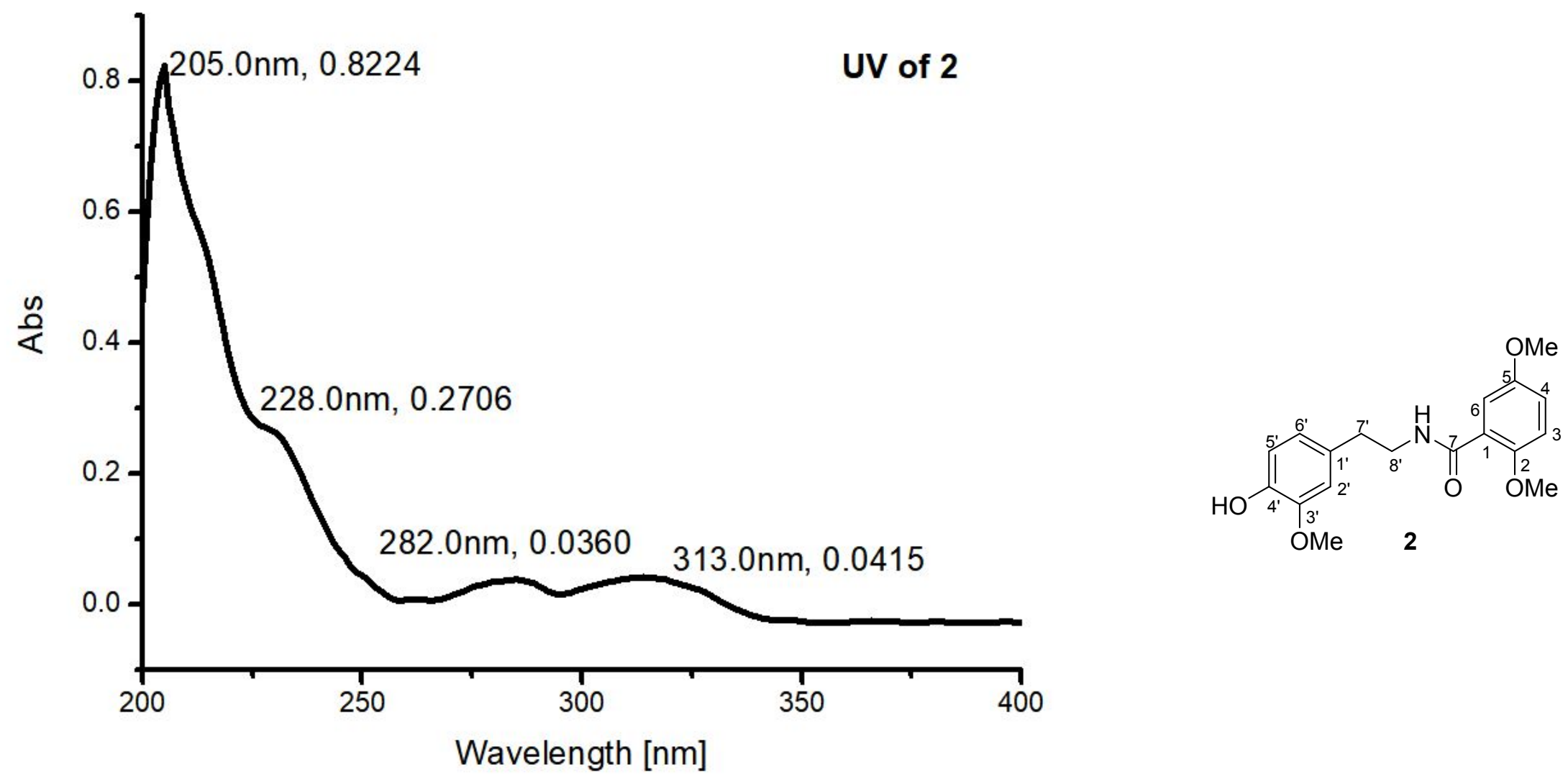
Figure S17. IR ( $\mathrm{KBr}$ disc) Spectrum of Compound 2

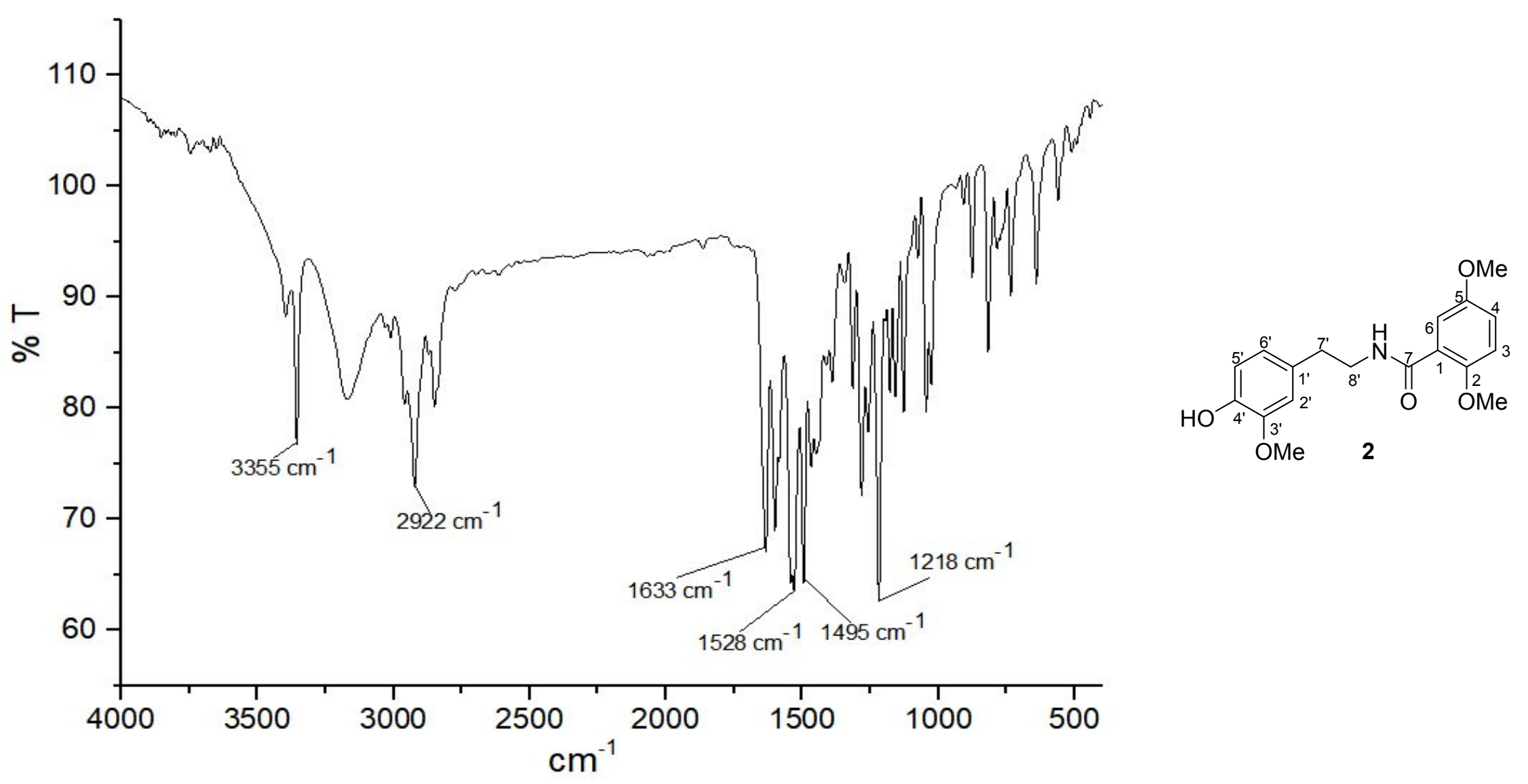


Figure S18. ${ }^{1} \mathrm{H}$ NMR Spectrum of Compound 3 in $\mathrm{CDCl}_{3}$

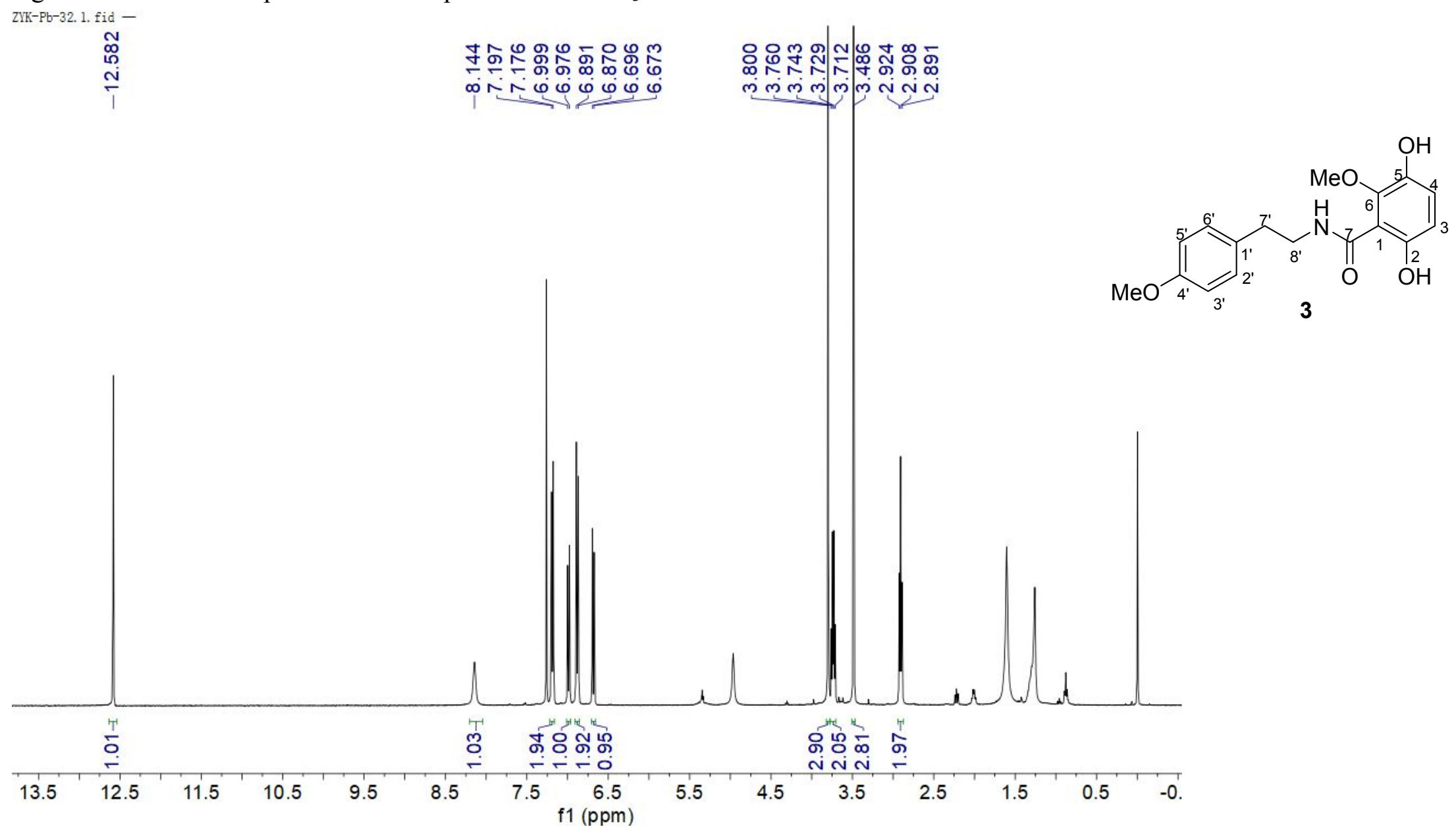


Figure S19. ${ }^{13} \mathrm{C}$ NMR Spectrum of Compound 3 in $\mathrm{CDCl}_{3}$

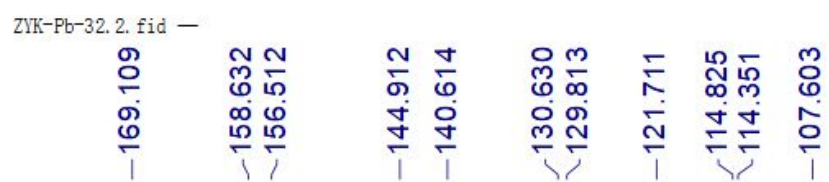

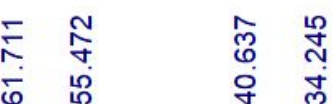

एं
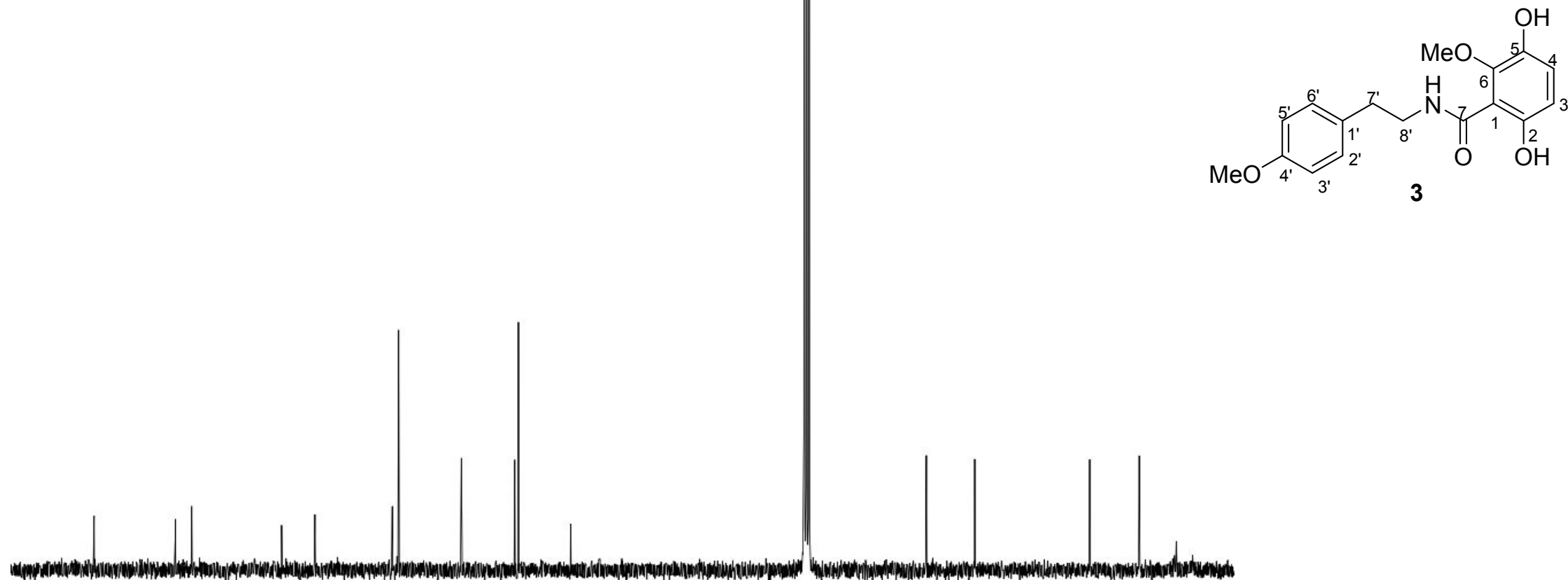

$10 \quad 100$

90

80

70

60

50 
Figure S20. ${ }^{1} \mathrm{H}-{ }^{1} \mathrm{H}$ COSY Spectrum of Compound 3 in $\mathrm{CDCl}_{3}$ TTK-Pt-32. 4. ser -
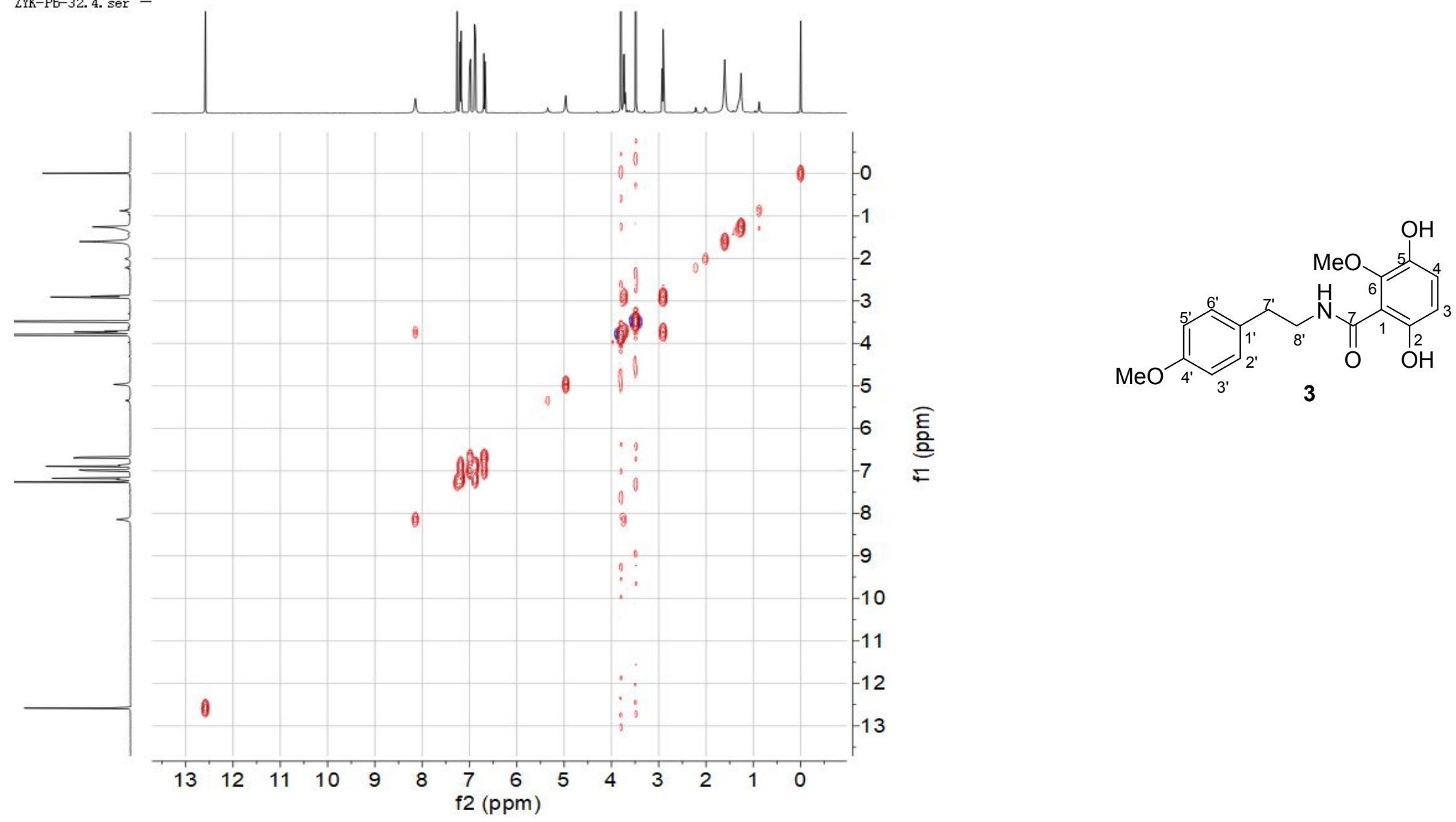
Figure S21. HSQC Spectrum of Compound 3 in $\mathrm{CDCl}_{3}$
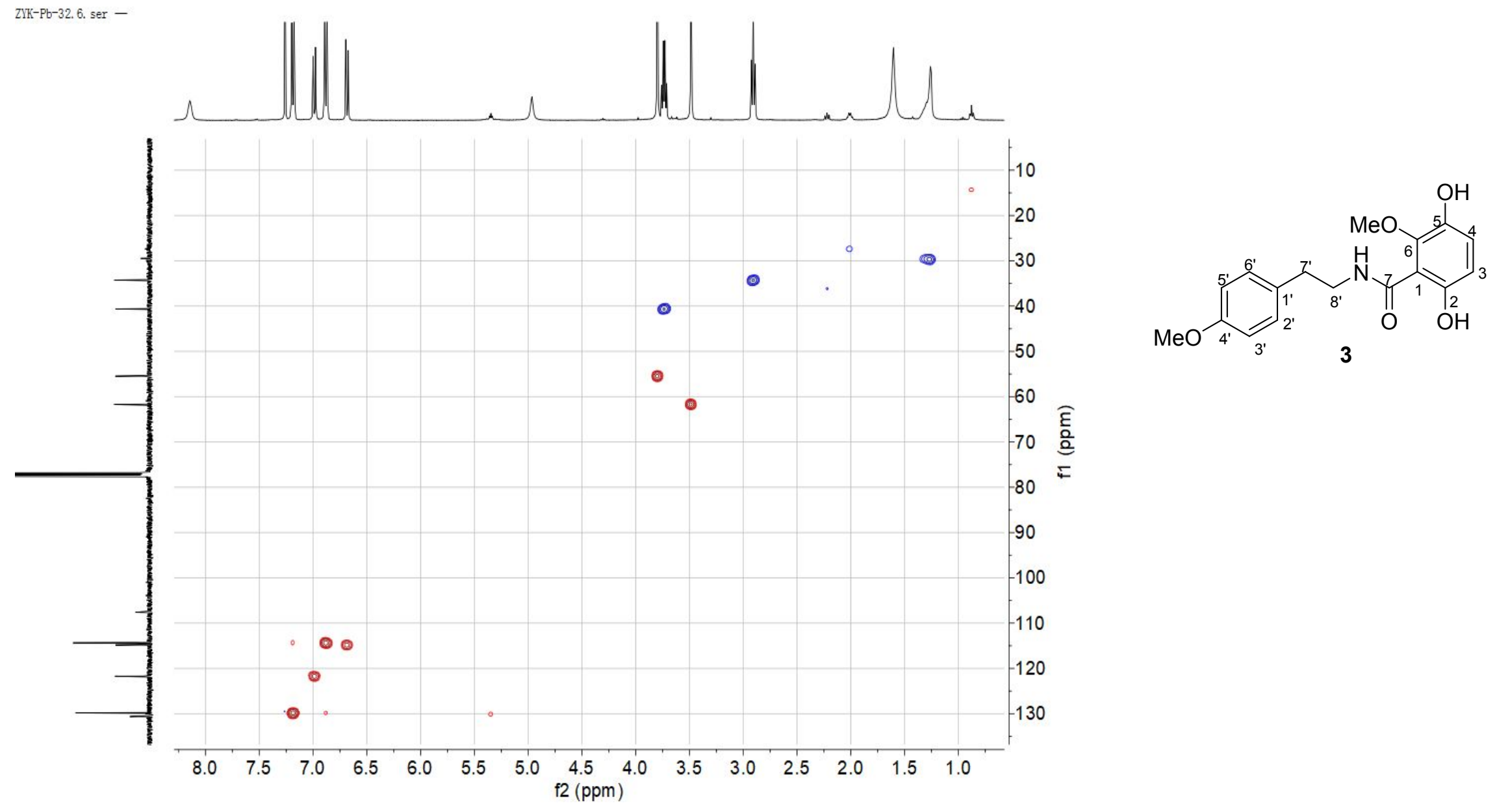
Figure S22. HMBC Spectrum of Compound $\mathbf{3}$ in $\mathrm{CDCl}_{3}$ zTK-Pb-32. 5. ser -
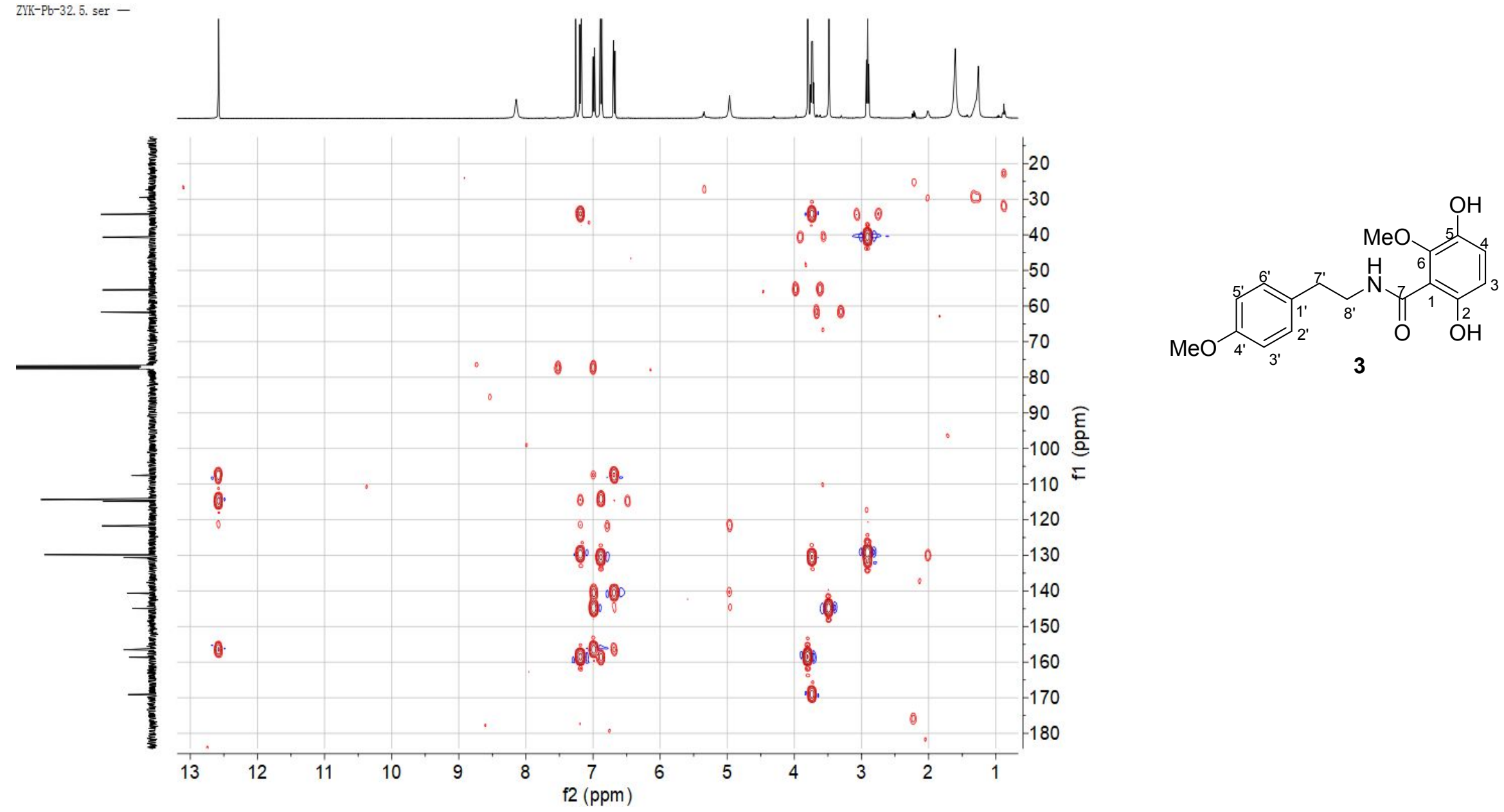
Figure S23. (+) HRESIMS Spectrum of Compound 3
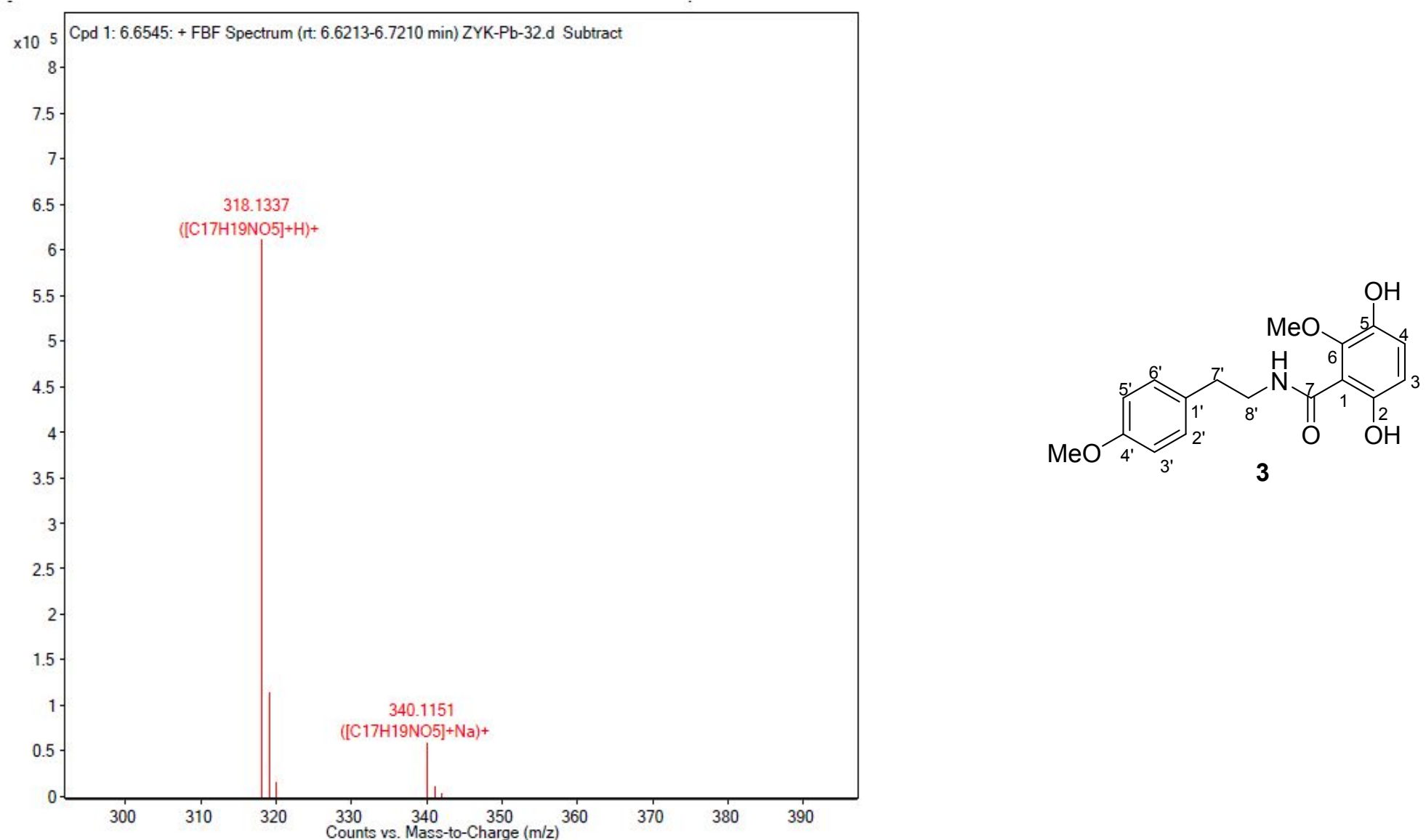
Figure S24. UV Spectrum of Compound 3

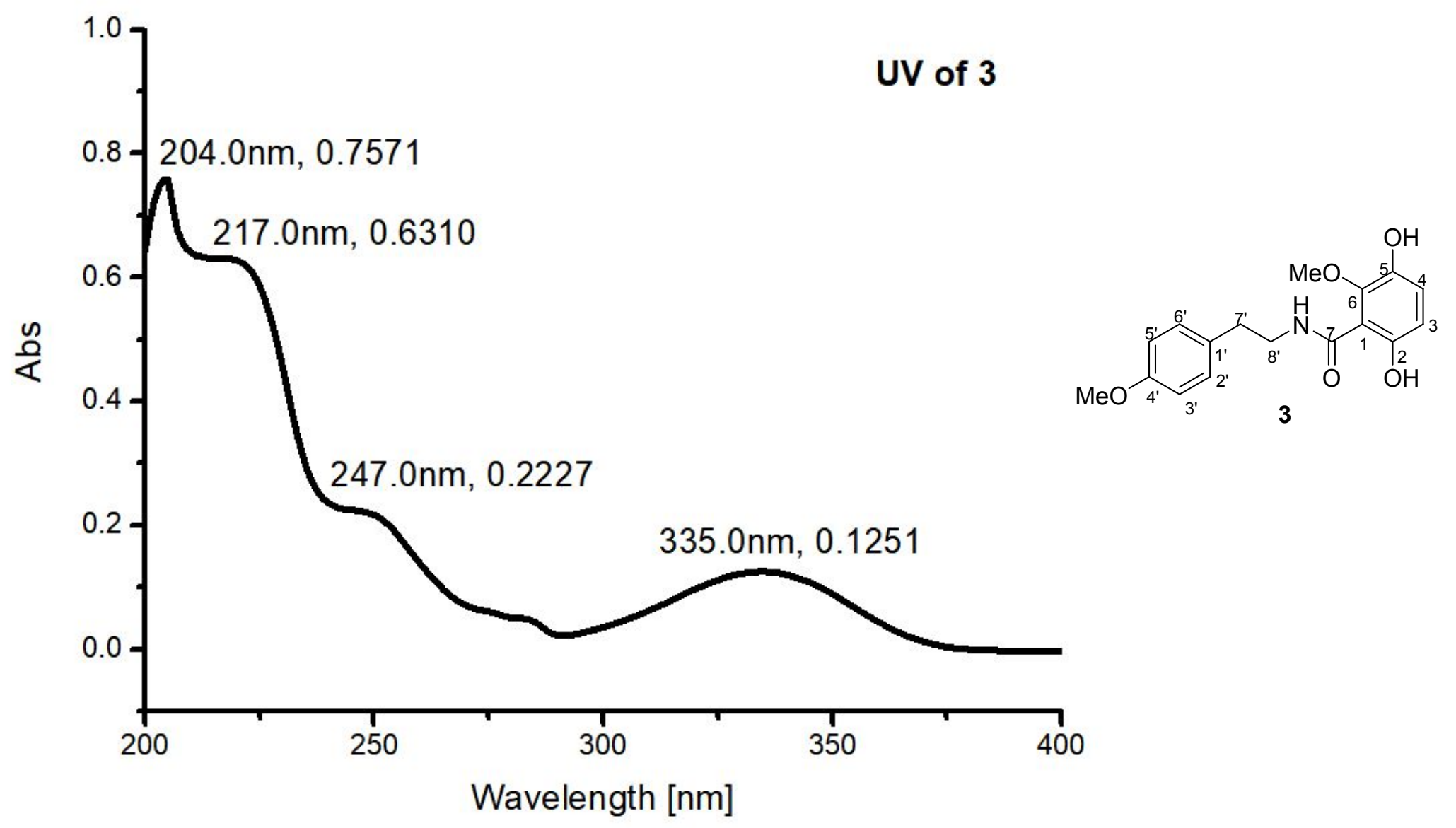


Figure S25. IR (KBr disc) Spectrum of Compound 3
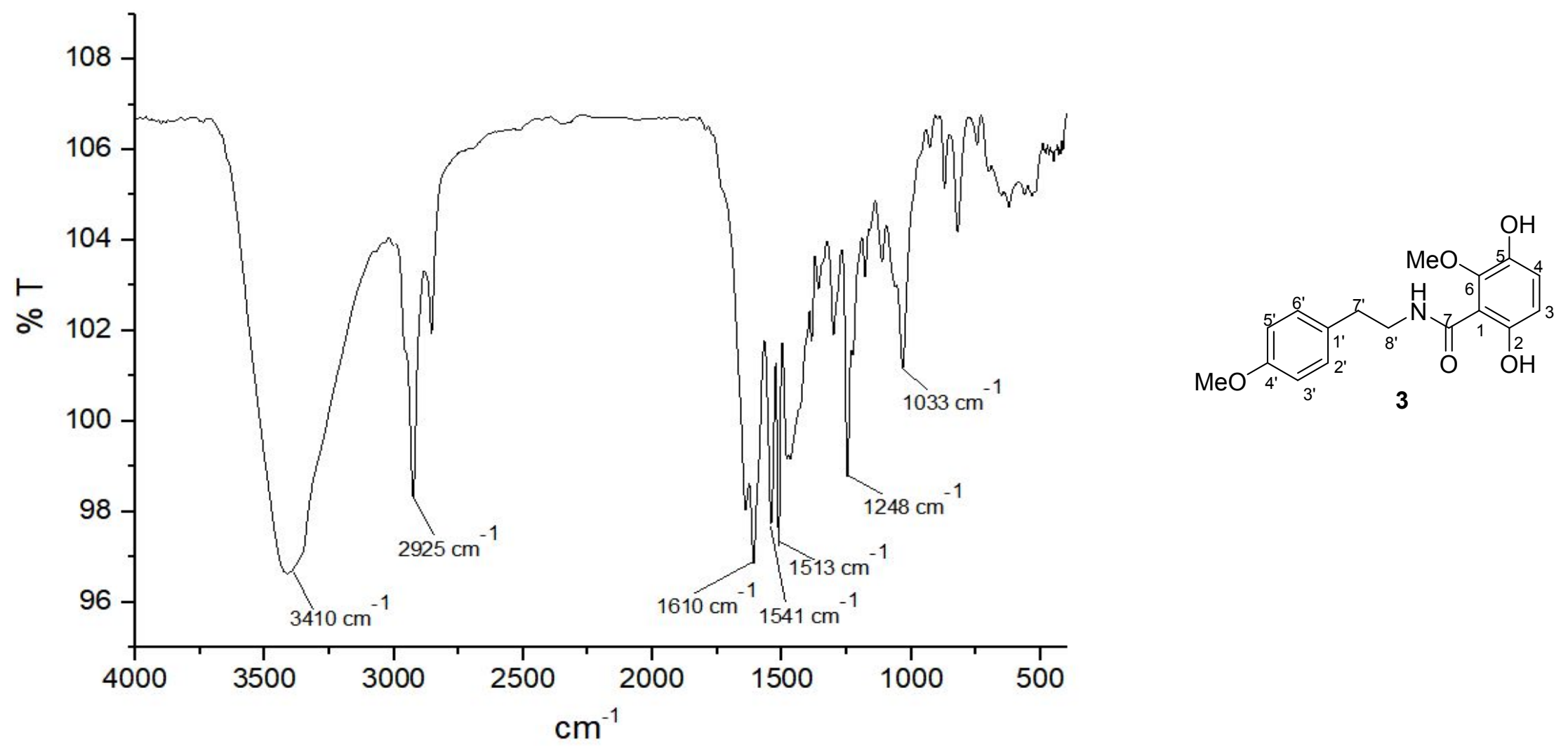
Figure S26. ${ }^{1} \mathrm{H}$ NMR Spectrum of Compound 4 in $\mathrm{MeOH}-d_{4}$ ZYK-Pb-103. 1. fid -

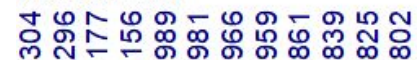

NNN

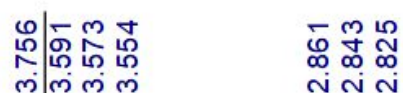

잉

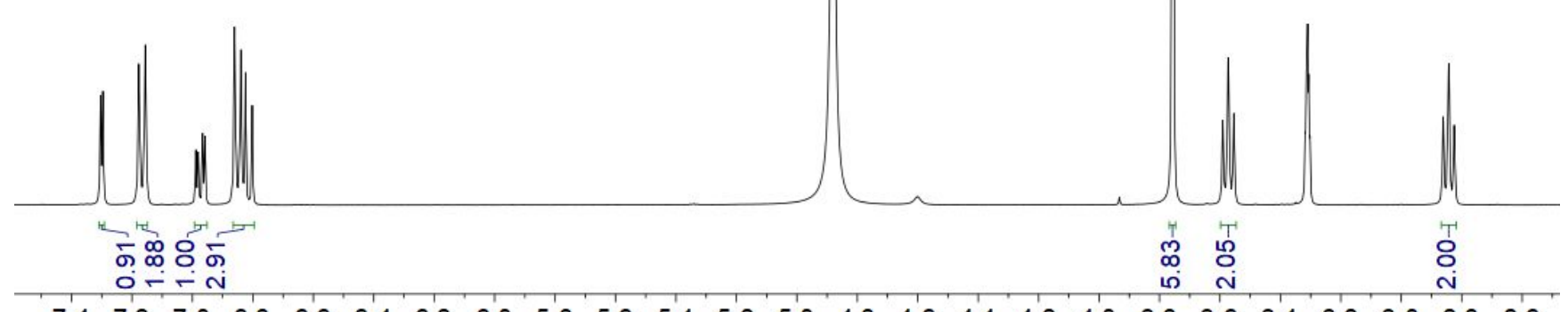

$\begin{array}{lllllllllllllllllllllllllllll}7.4 & 7.2 & 7.0 & 6.8 & 6.6 & 6.4 & 6.2 & 6.0 & 5.8 & 5.6 & 5.4 & 5.2 & 5.0 & 4.8 & 4.6 & 4.4 & 4.2 & 4.0 & 3.8 & 3.6 & 3.4 & 3.2 & 3.0 & 2.8 & 2.6\end{array}$

$$
\text { f1 (ppm) }
$$


Figure S27. ${ }^{13} \mathrm{C}$ NMR Spectrum of Compound $\mathbf{4}$ in $\mathrm{MeOH}-d_{4}$

$$
\begin{aligned}
& \begin{array}{ccc}
\text { ZTK-Pb-103.2. fid - } \\
\text { N. }
\end{array}
\end{aligned}
$$

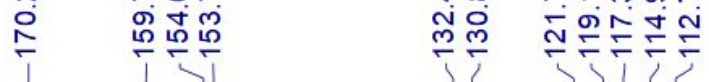
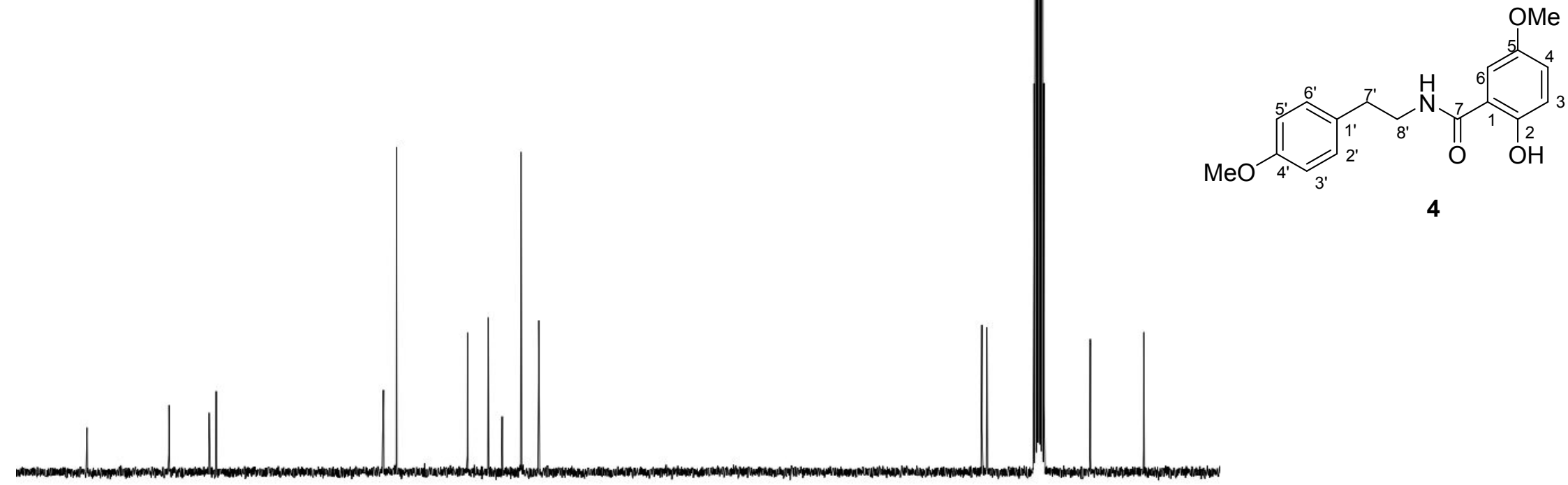

$170 \quad 160 \quad 150$

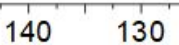

120

$10 \quad 100$

90

80

70

60 
Figure S28. ${ }^{1} \mathrm{H}-{ }^{1} \mathrm{H}$ COSY Spectrum of Compound 4 in $\mathrm{MeOH}-d_{4}$ ZTK-Pt-103.4. ser -
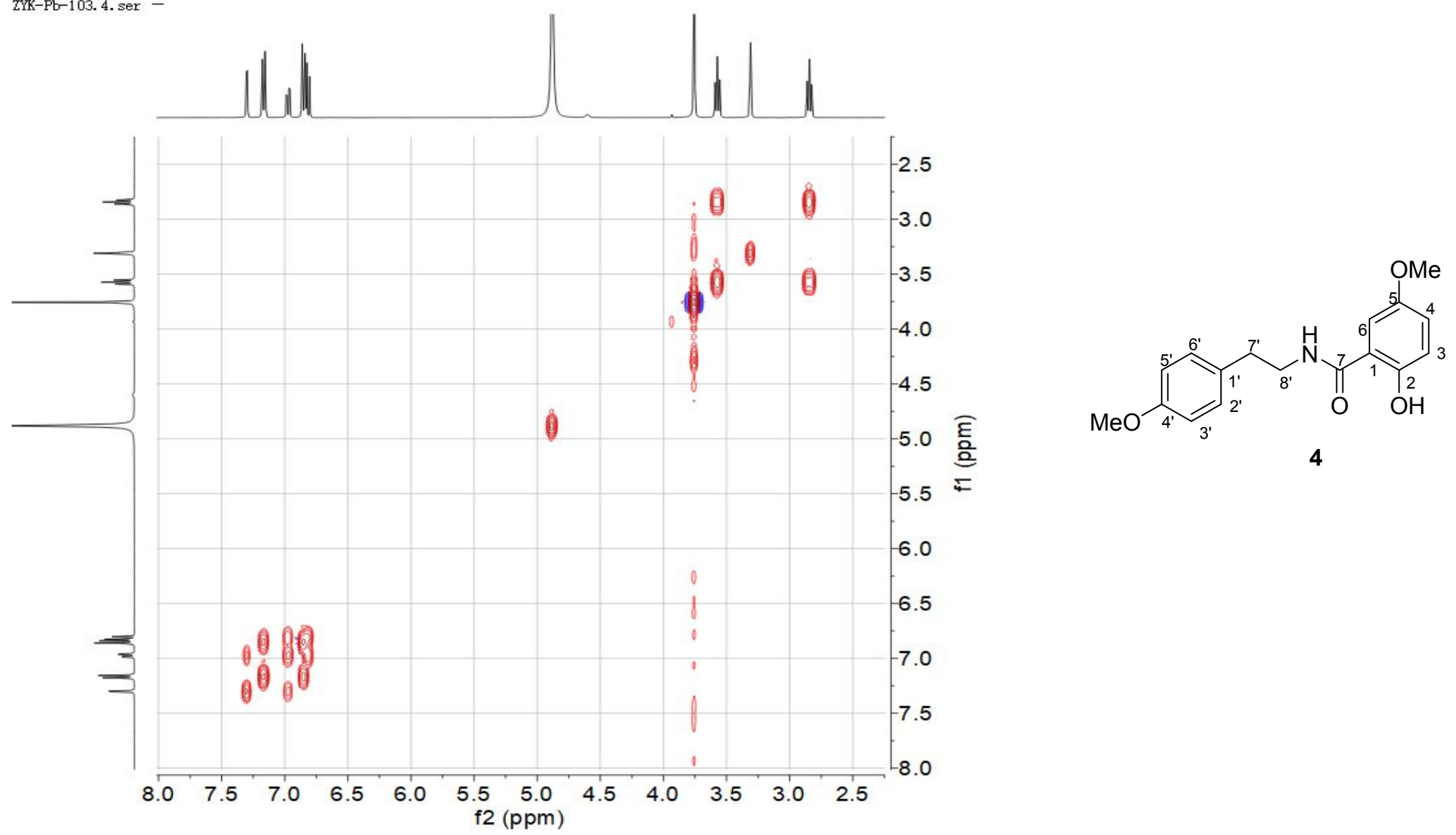
Figure S29. HSQC Spectrum of Compound 4 in $\mathrm{MeOH}-d_{4}$

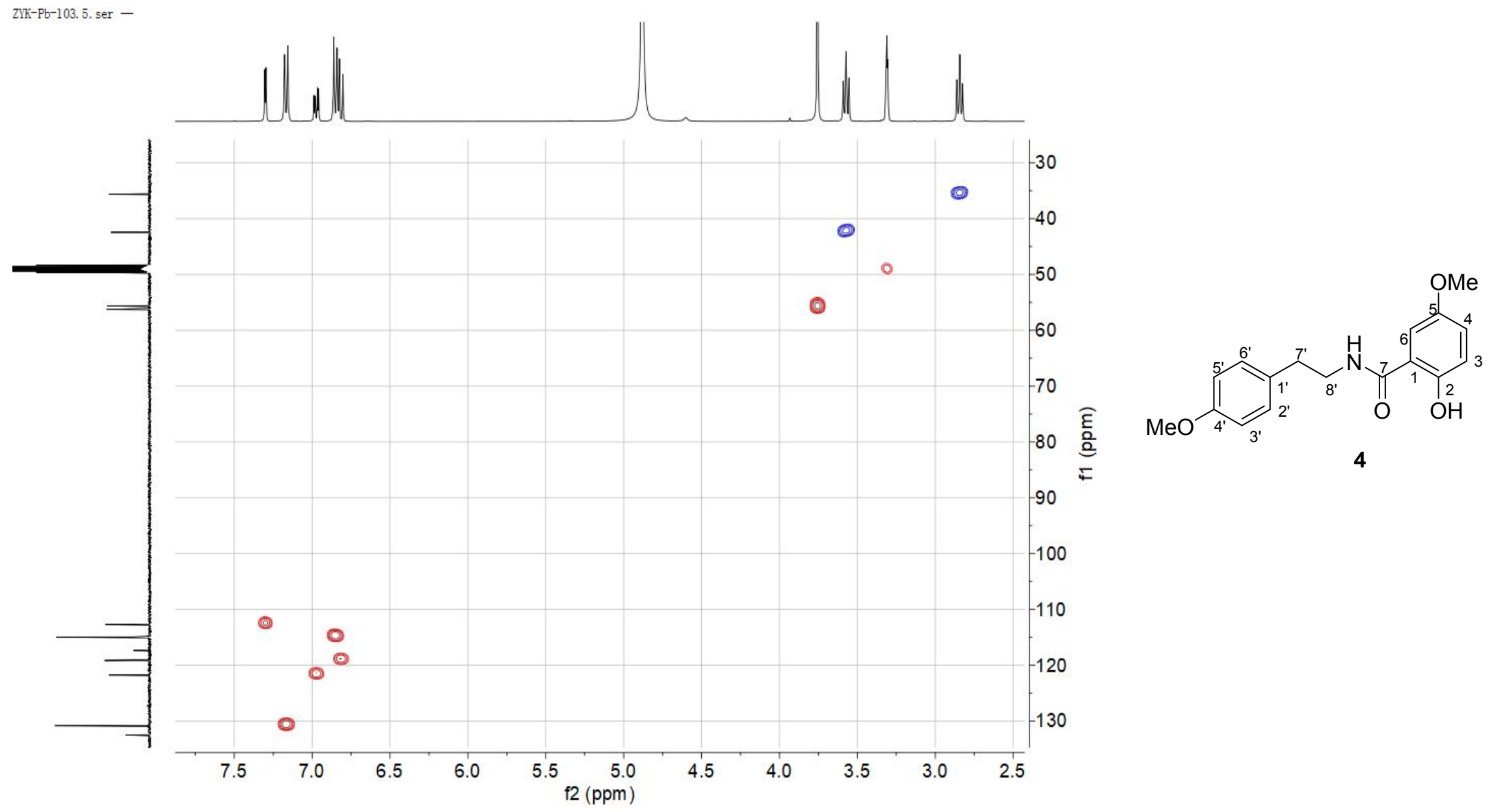


Figure S30. HMBC Spectrum of Compound 4 in $\mathrm{MeOH}-d_{4}$
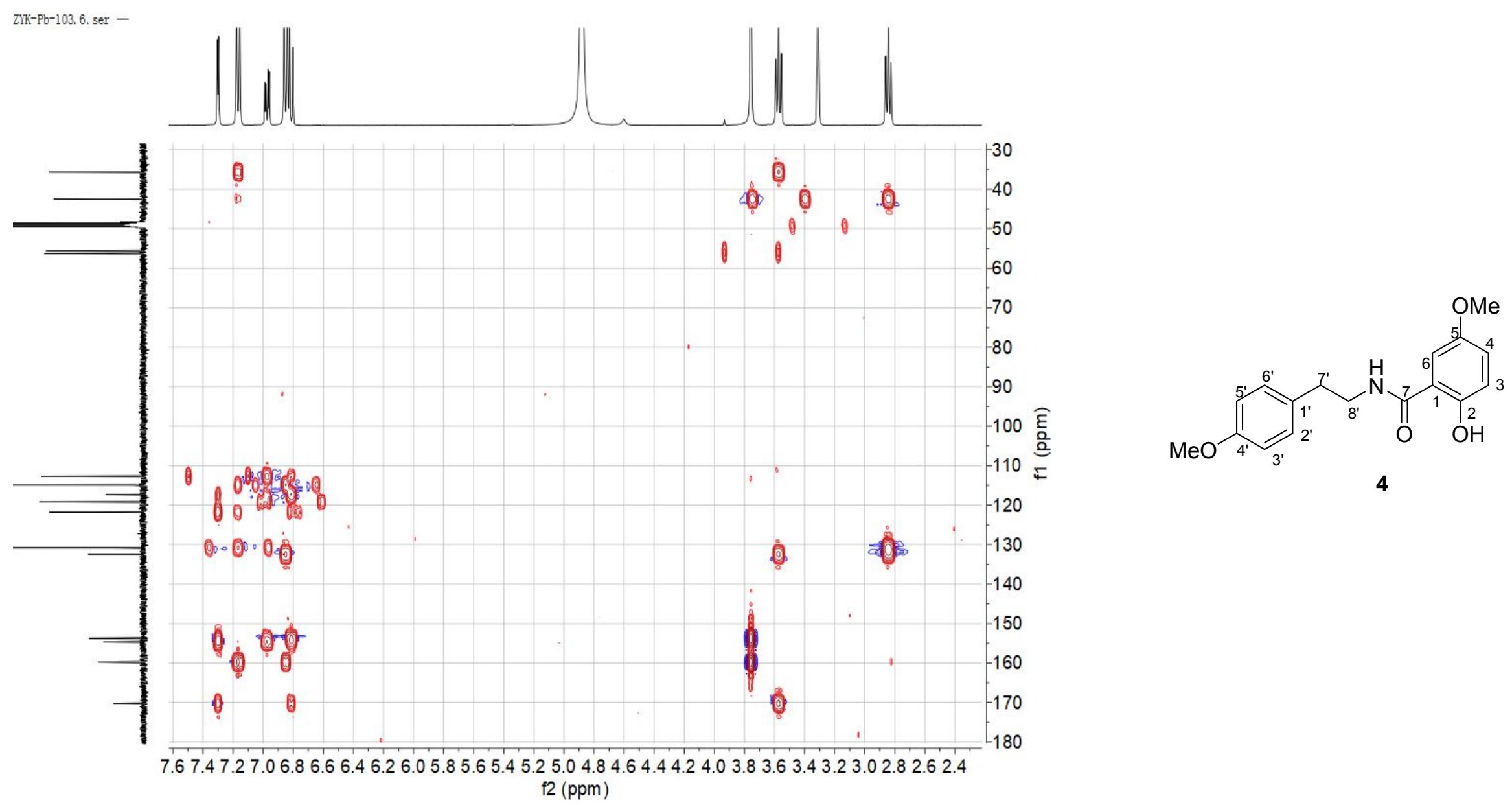
Figure S31. (+) HRESIMS Spectrum of Compound 4

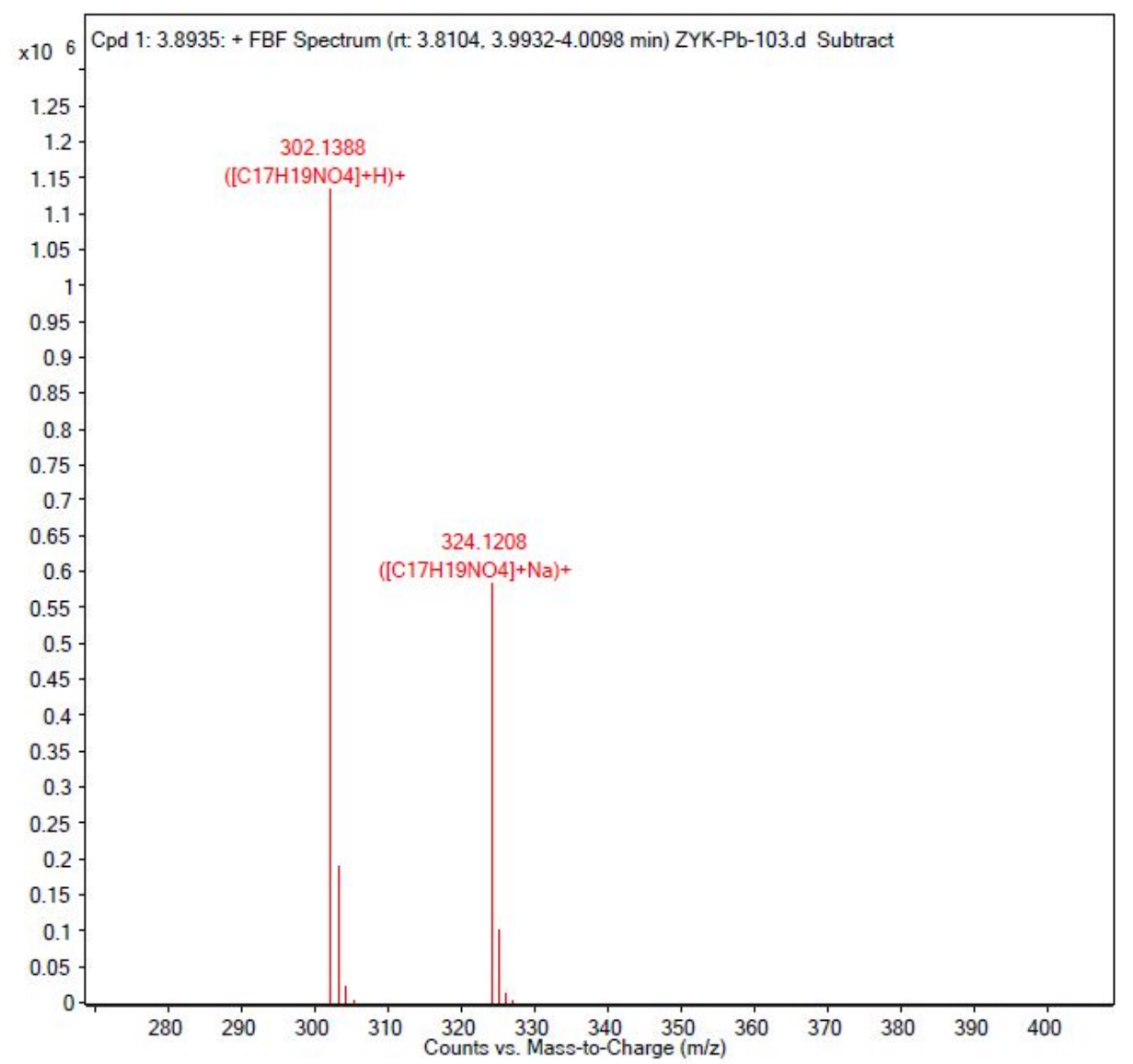

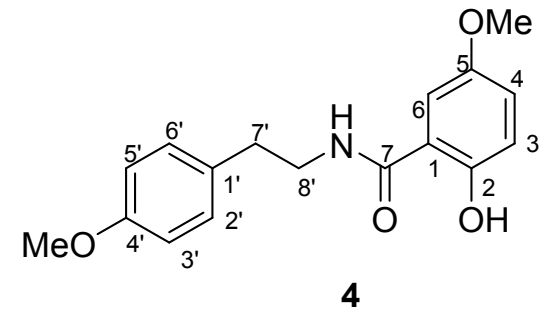


Figure S32. UV Spectrum of Compound 4

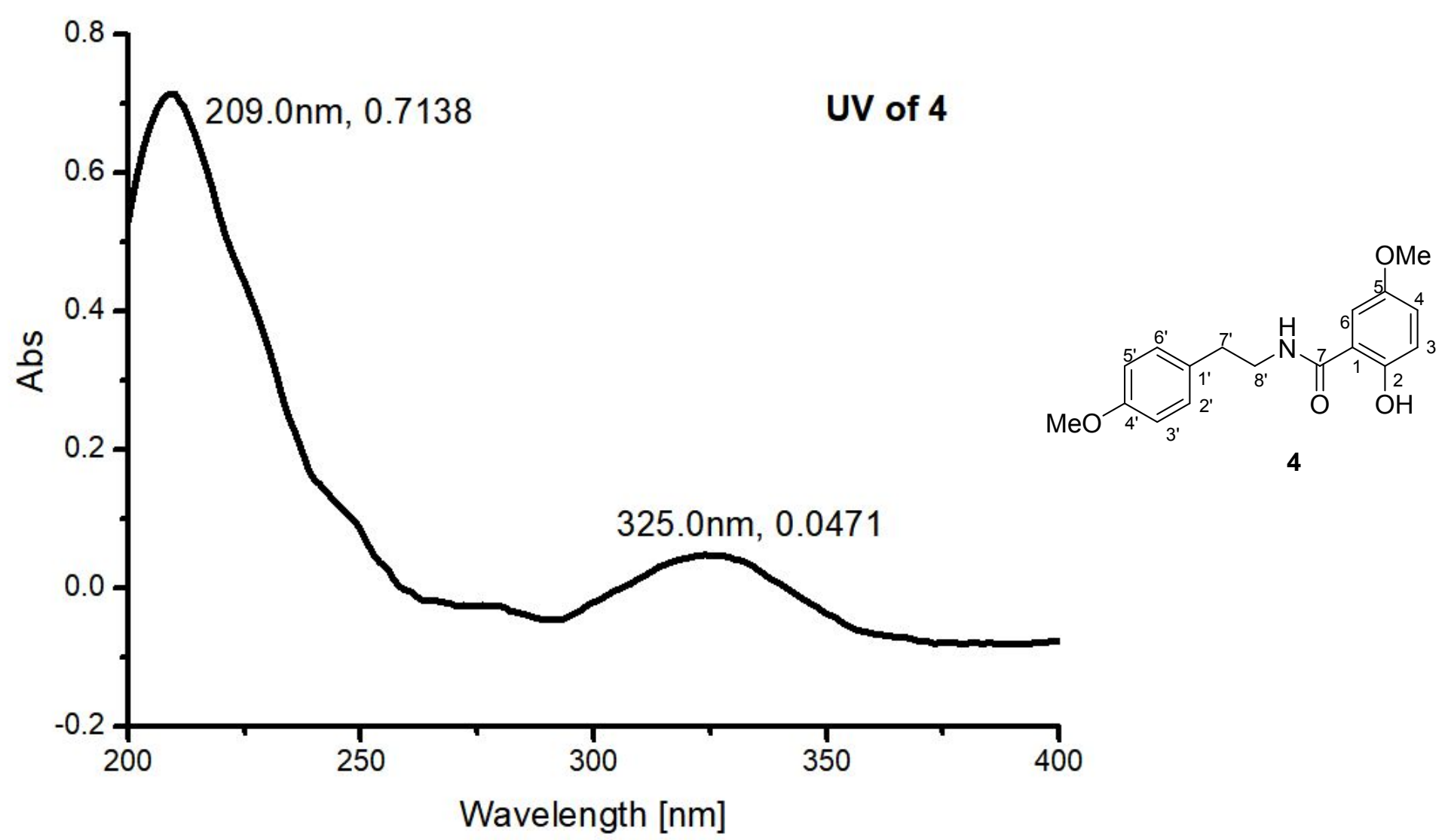


Figure S33. IR ( $\mathrm{KBr}$ disc) Spectrum of Compound 4

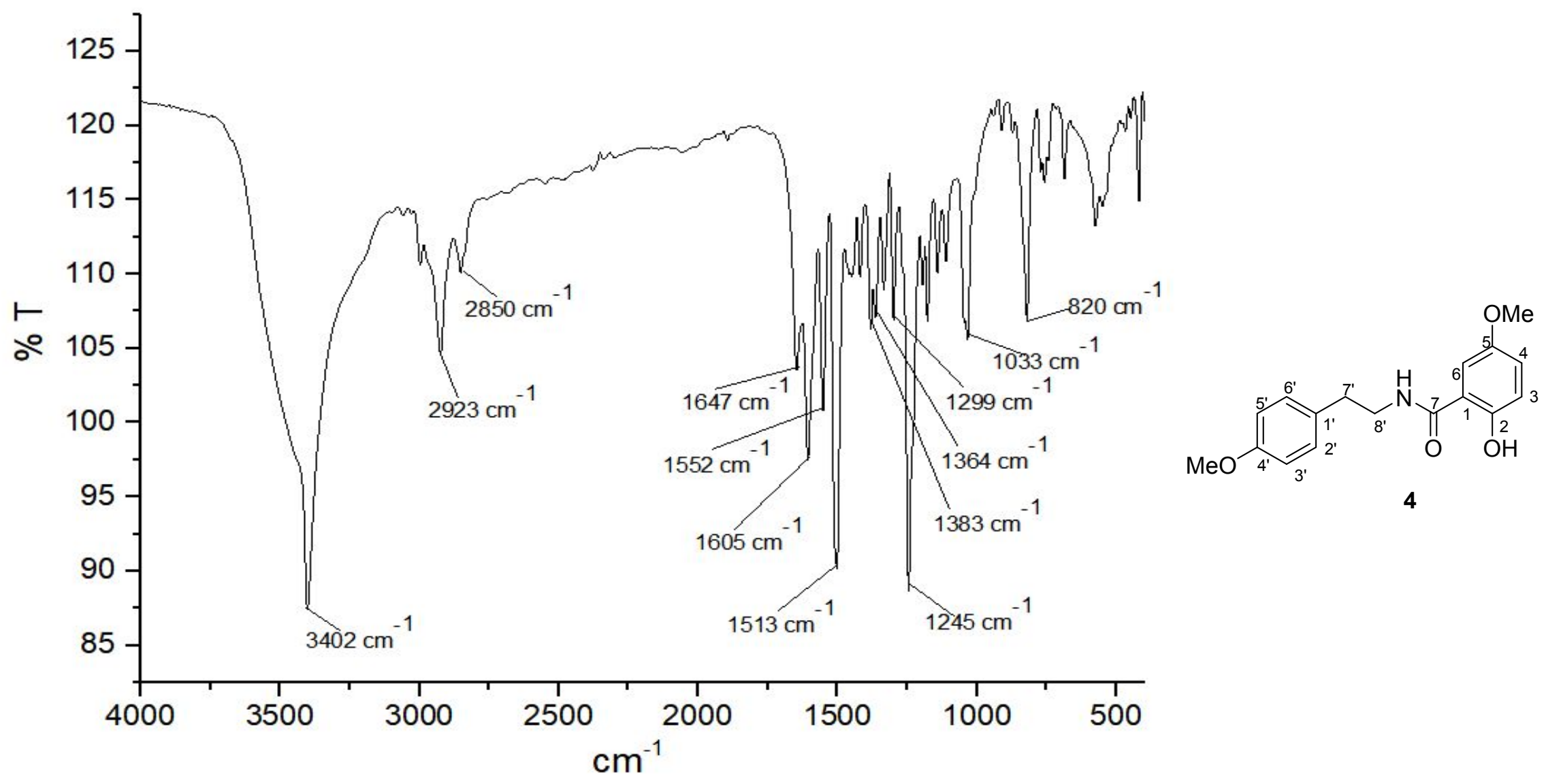


Figure S34. ${ }^{1} \mathrm{H}$ NMR Spectrum of Compound $5 \mathrm{CDCl}_{3}$ ZJK-Pb-31. 1. fid -

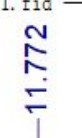

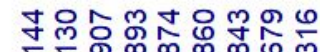

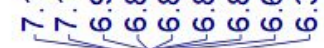

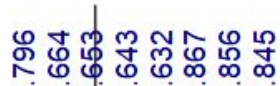

نंiूn

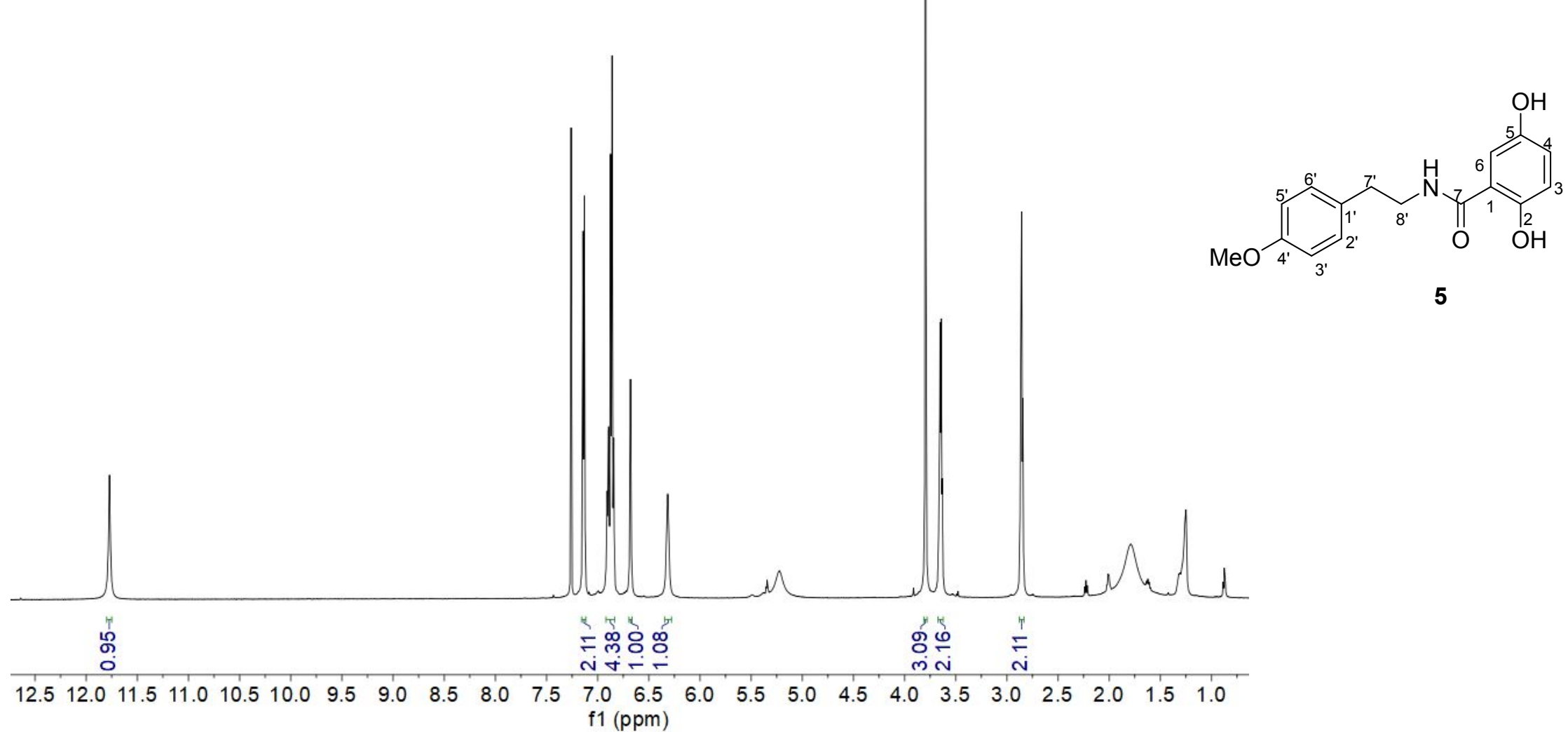


Figure S35. ${ }^{13} \mathrm{C}$ NMR Spectrum of Compound $\mathbf{5}$ in $\mathrm{CDCl}_{3}$

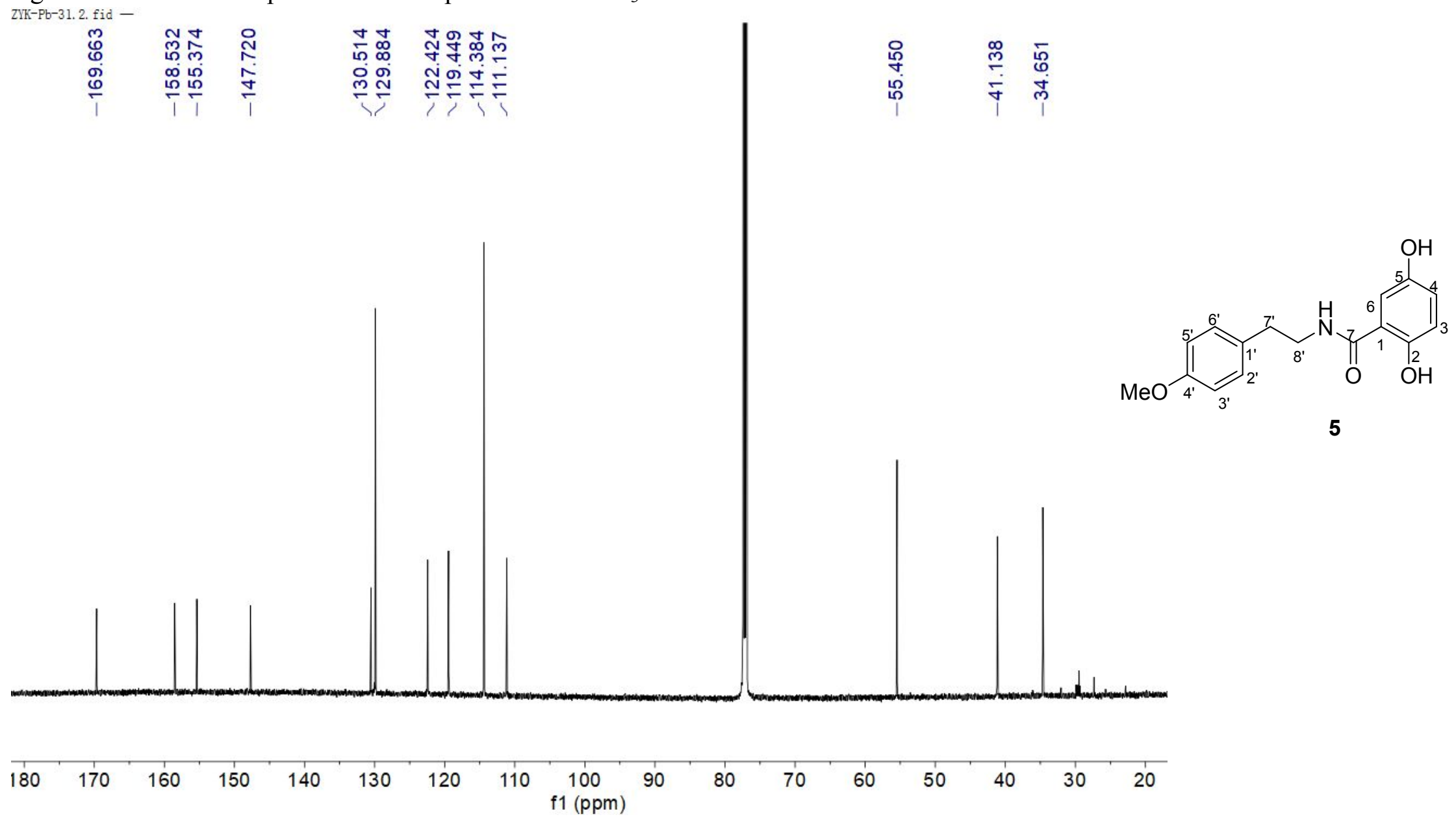


Figure S36. ${ }^{1} \mathrm{H}-{ }^{1} \mathrm{H}$ COSY Spectrum of Compound 5 in $\mathrm{CDCl}_{3}$ TKK-Ft-31. 7. ser -
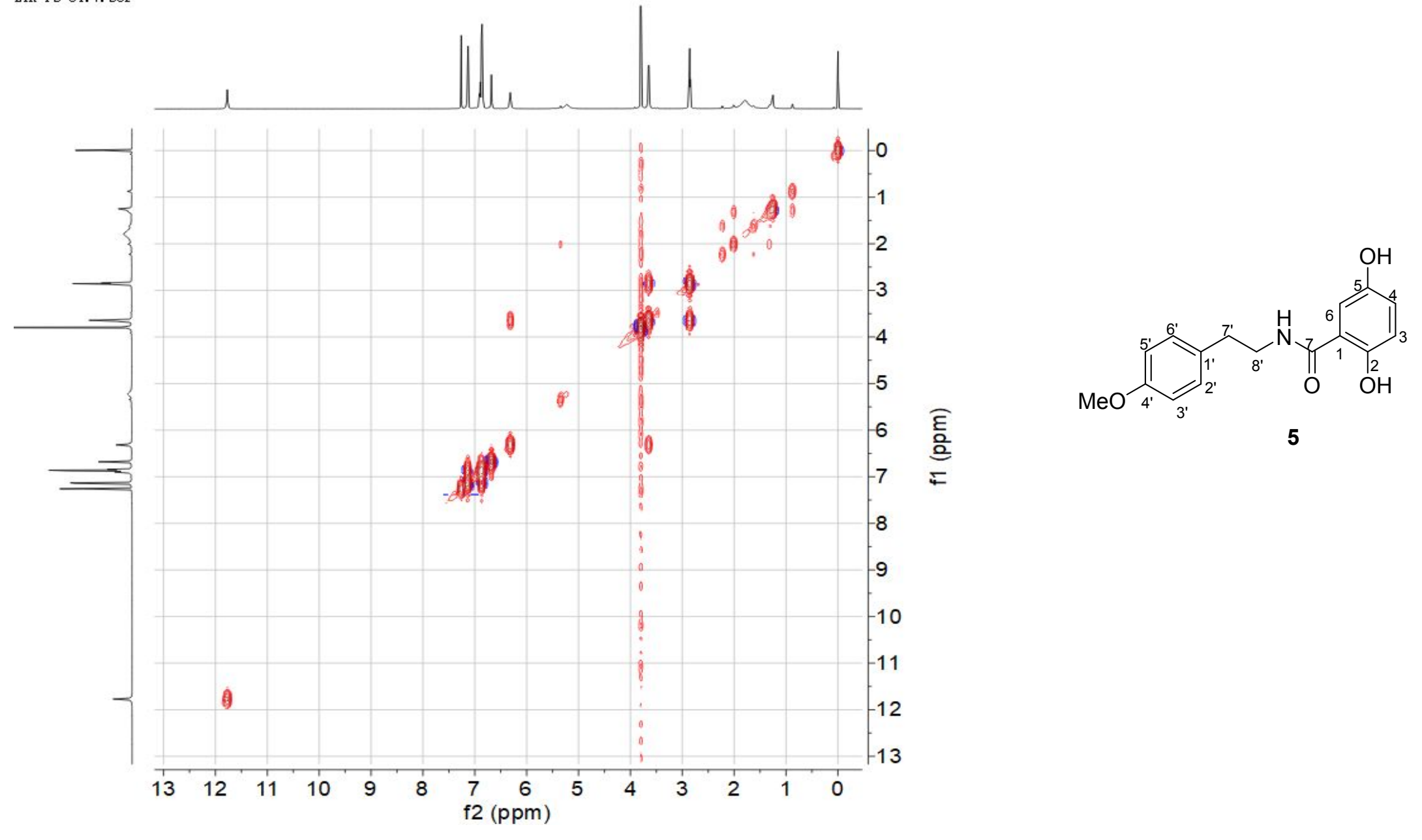
Figure S37. HSQC Spectrum of Compound $\mathbf{5}$ in $\mathrm{CDCl}_{3}$
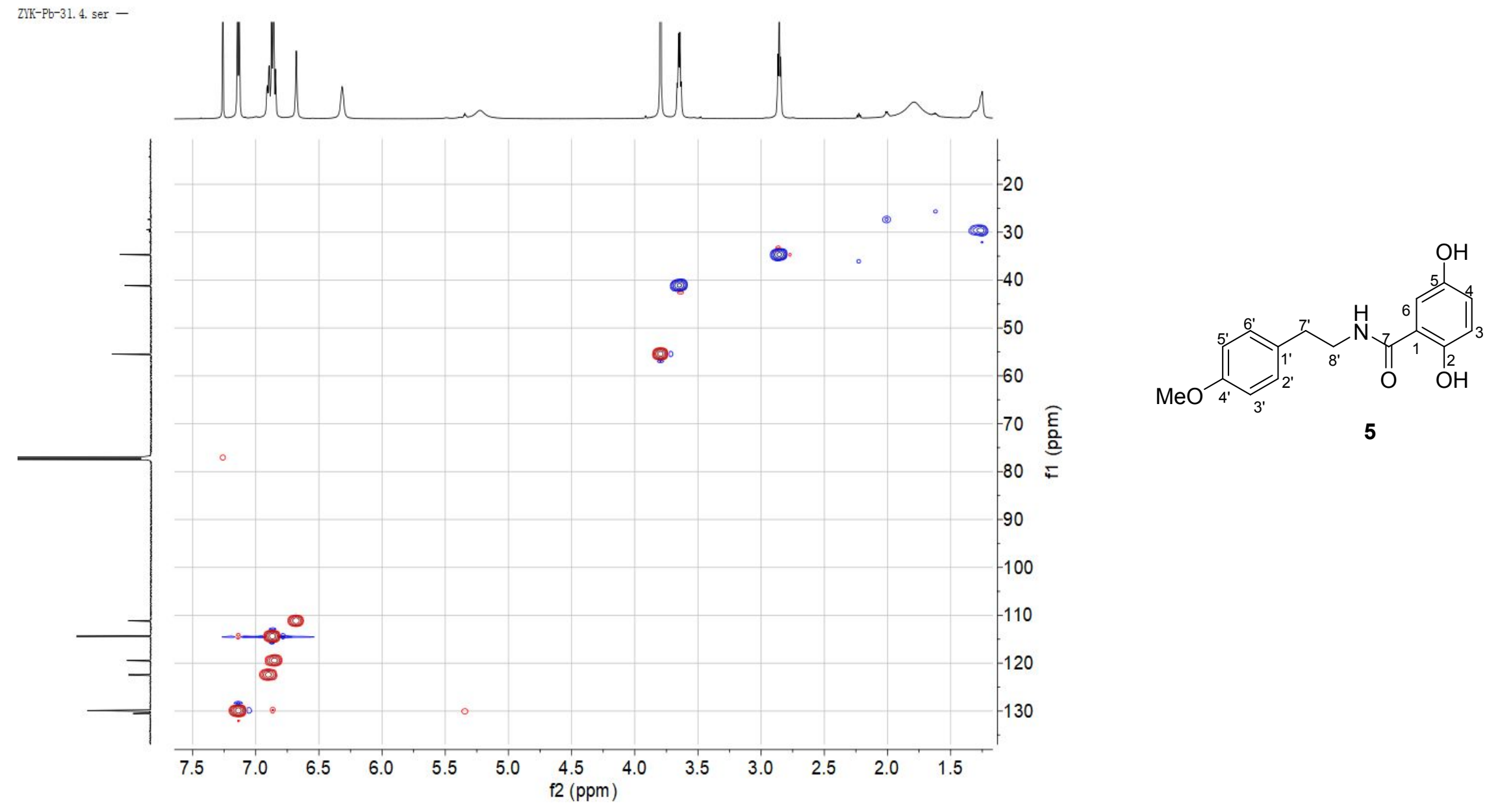
Figure S38. HMBC Spectrum of Compound $\mathbf{5}$ in $\mathrm{CDCl}_{3}$

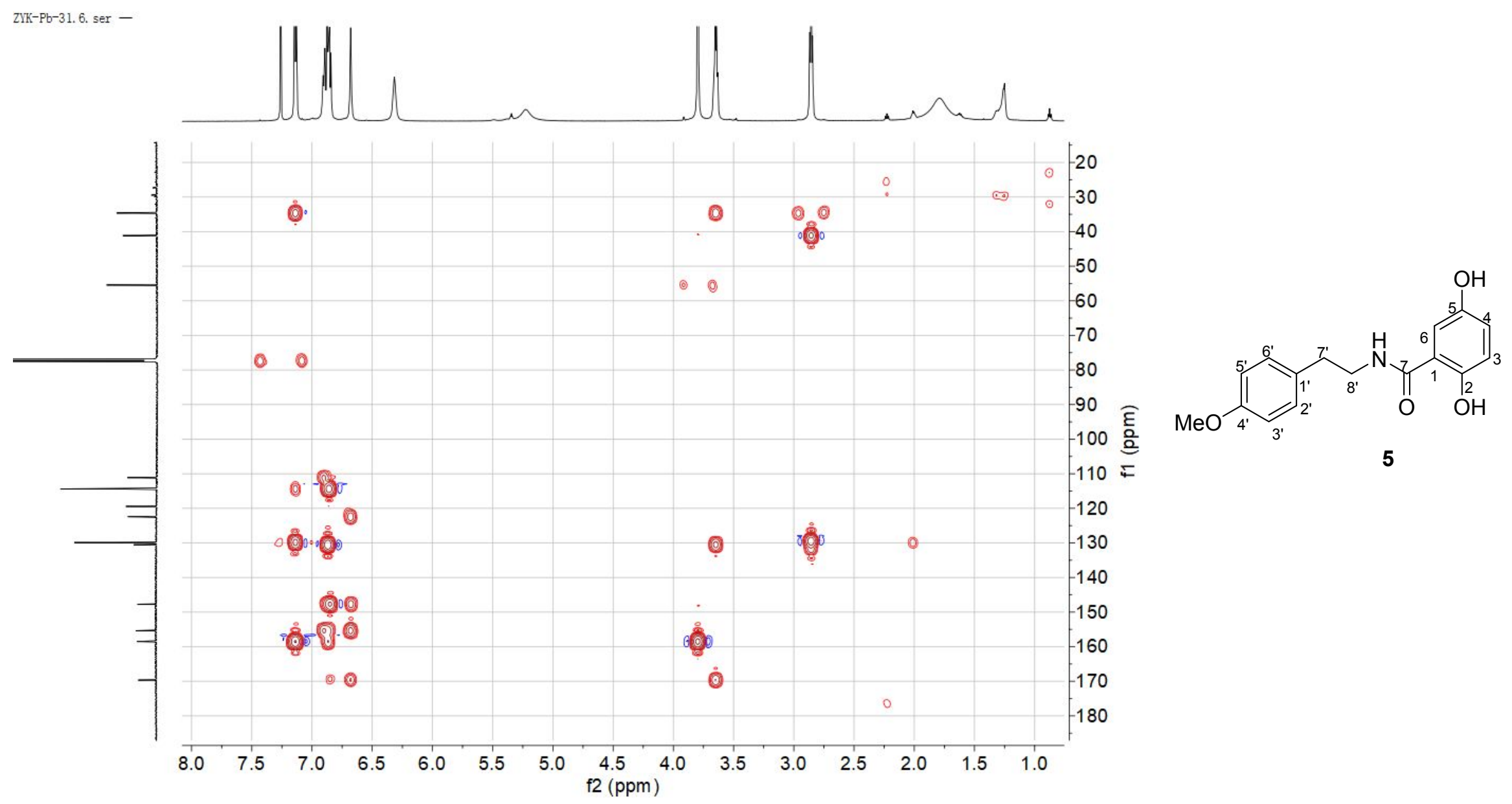


Figure S39. (+) HRESIMS Spectrum of Compound 5

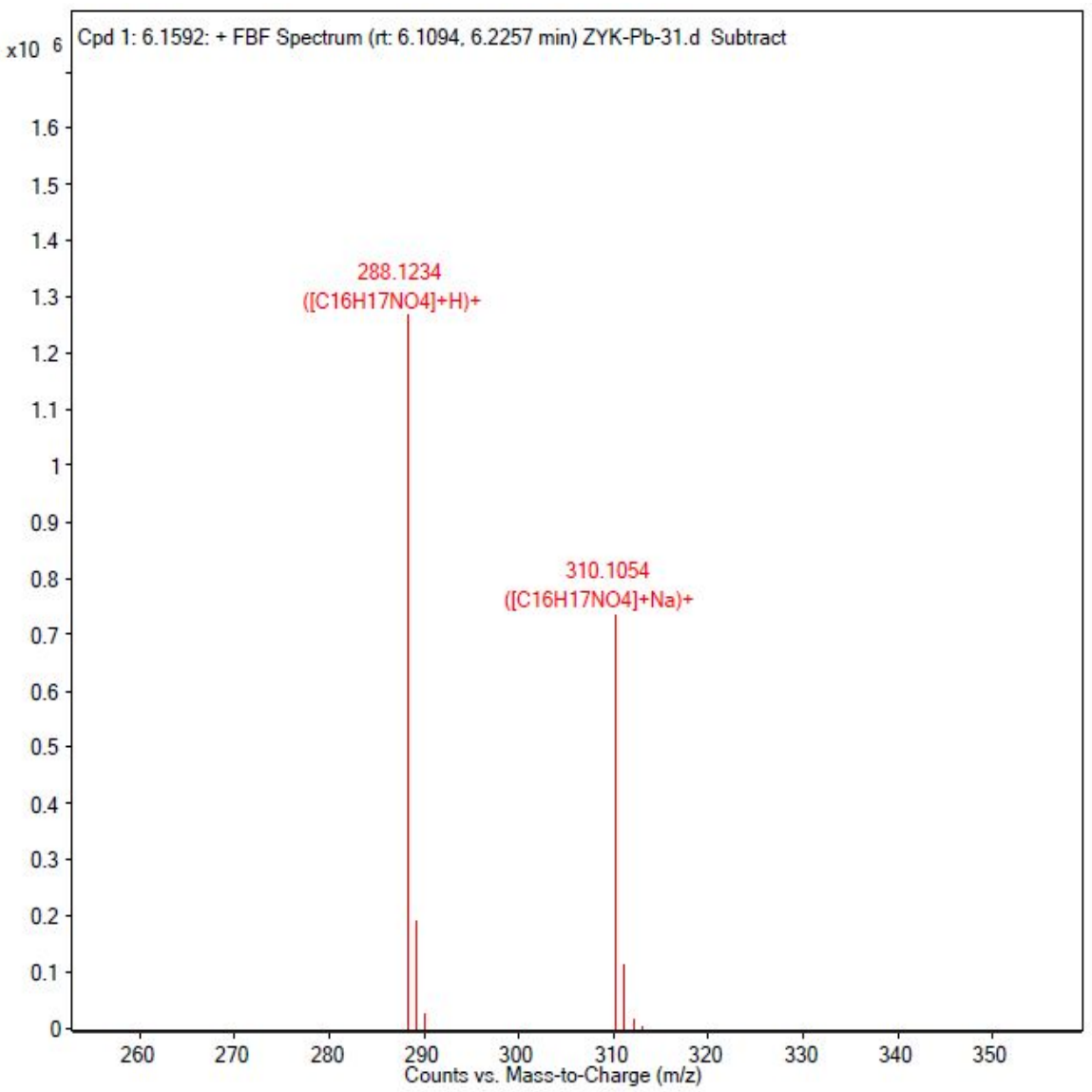


Figure S40. UV Spectrum of Compound 5
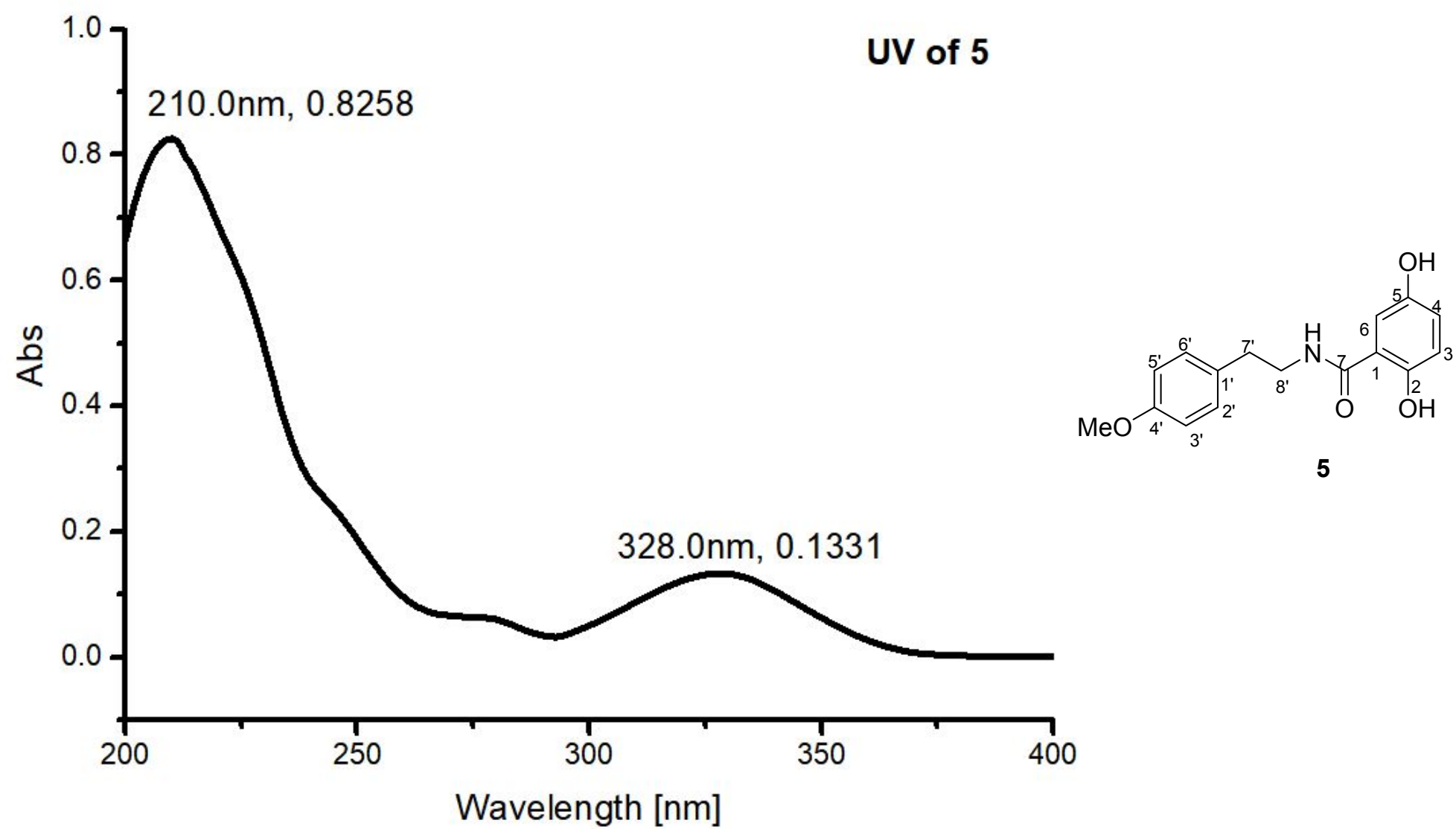
Figure S41. IR (KBr disc) Spectrum of Compound 5

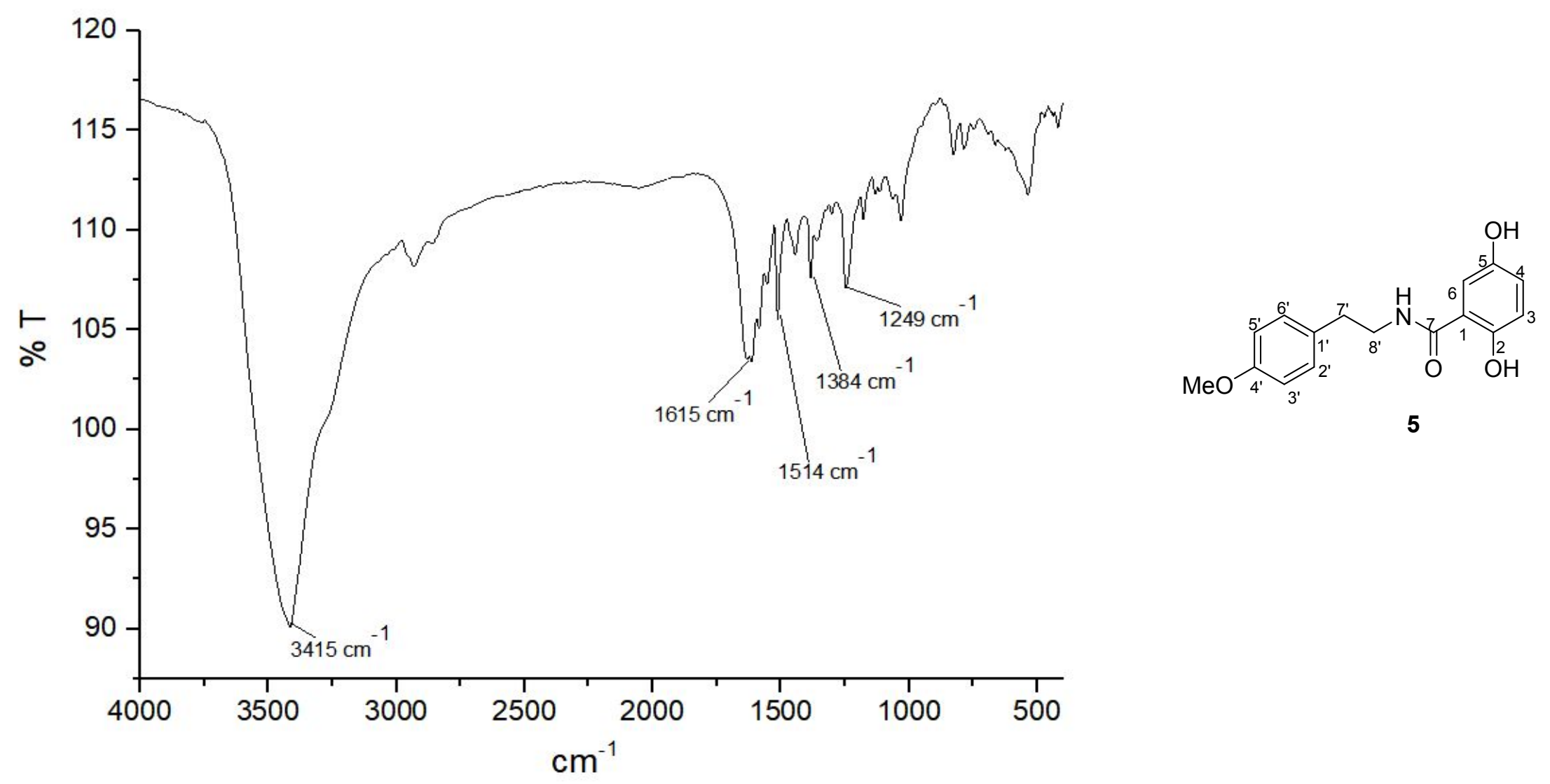


Figure S42. ${ }^{1} \mathrm{H}$ NMR Spectrum of Compound 6 in $\mathrm{CDCl}_{3}$

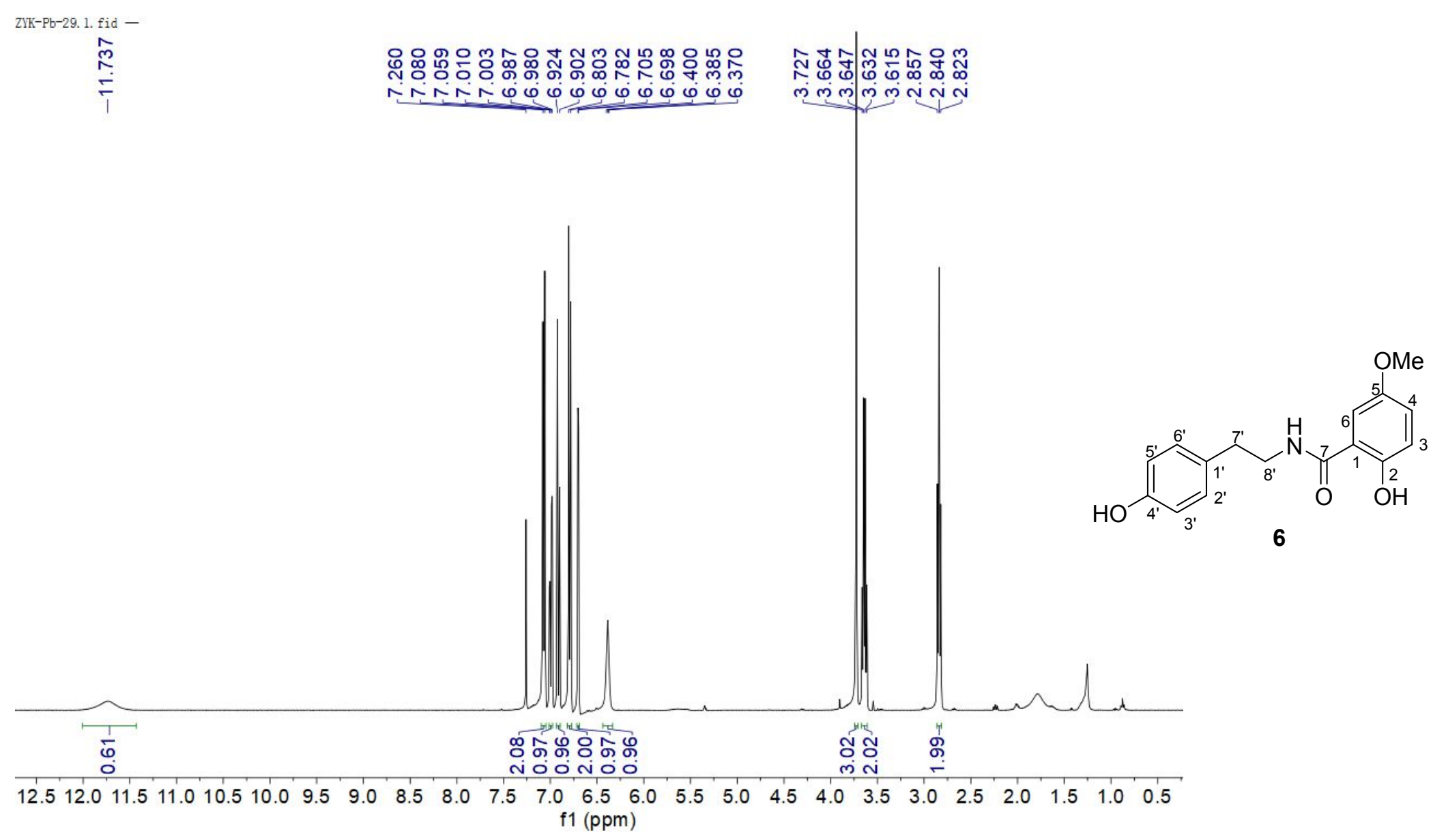


Figure S43. ${ }^{13} \mathrm{C}$ NMR Spectrum of Compound 6 in $\mathrm{CDCl}_{3}$ ZTK-Pb-29. 2. fid -

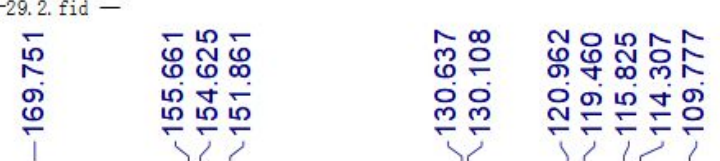

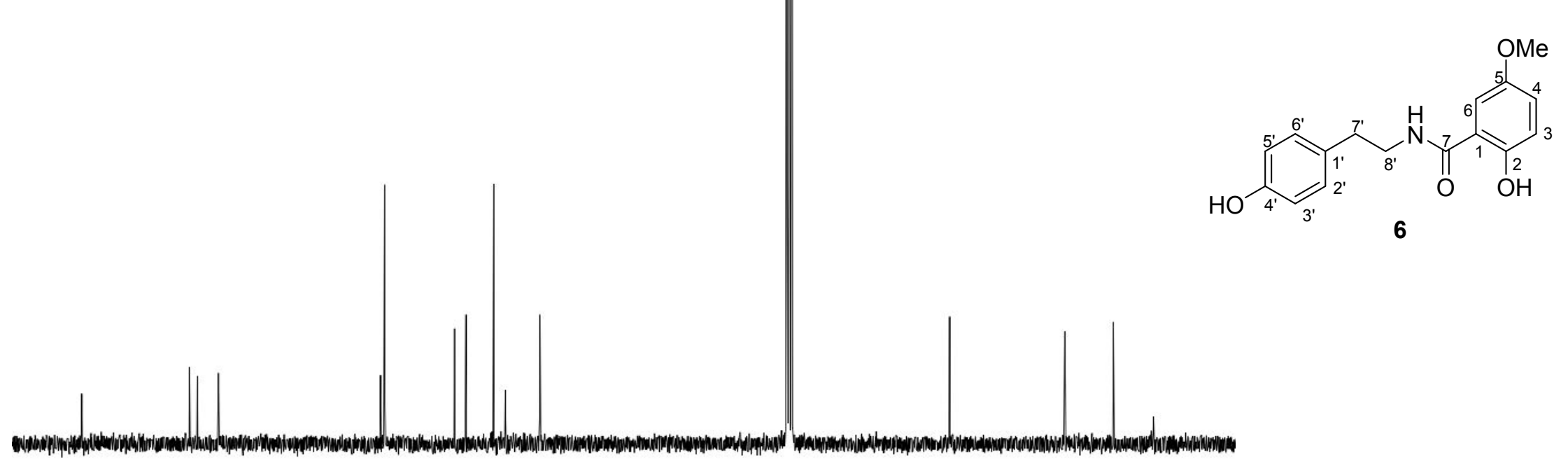

170

$150 \quad 150$

$130 \quad 120$

$110 \quad 100$ f1 $(\mathrm{ppm})$ 
Figure S44. ${ }^{1} \mathrm{H}-{ }^{1} \mathrm{H}$ COSY Spectrum of Compound 6 in $\mathrm{CDCl}_{3}$
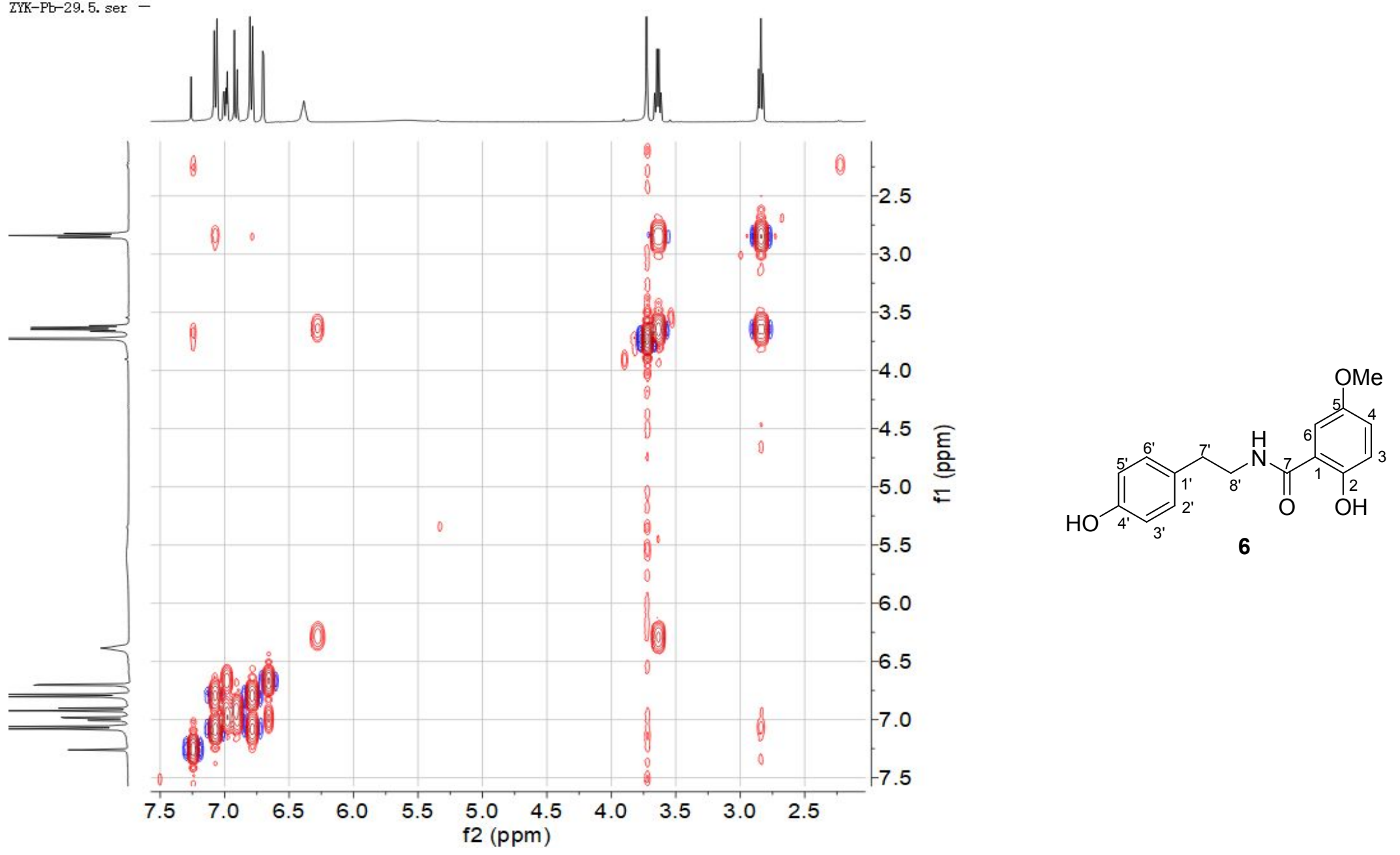
Figure S45. HSQC Spectrum of Compound $\mathbf{6}$ in $\mathrm{CDCl}_{3}$

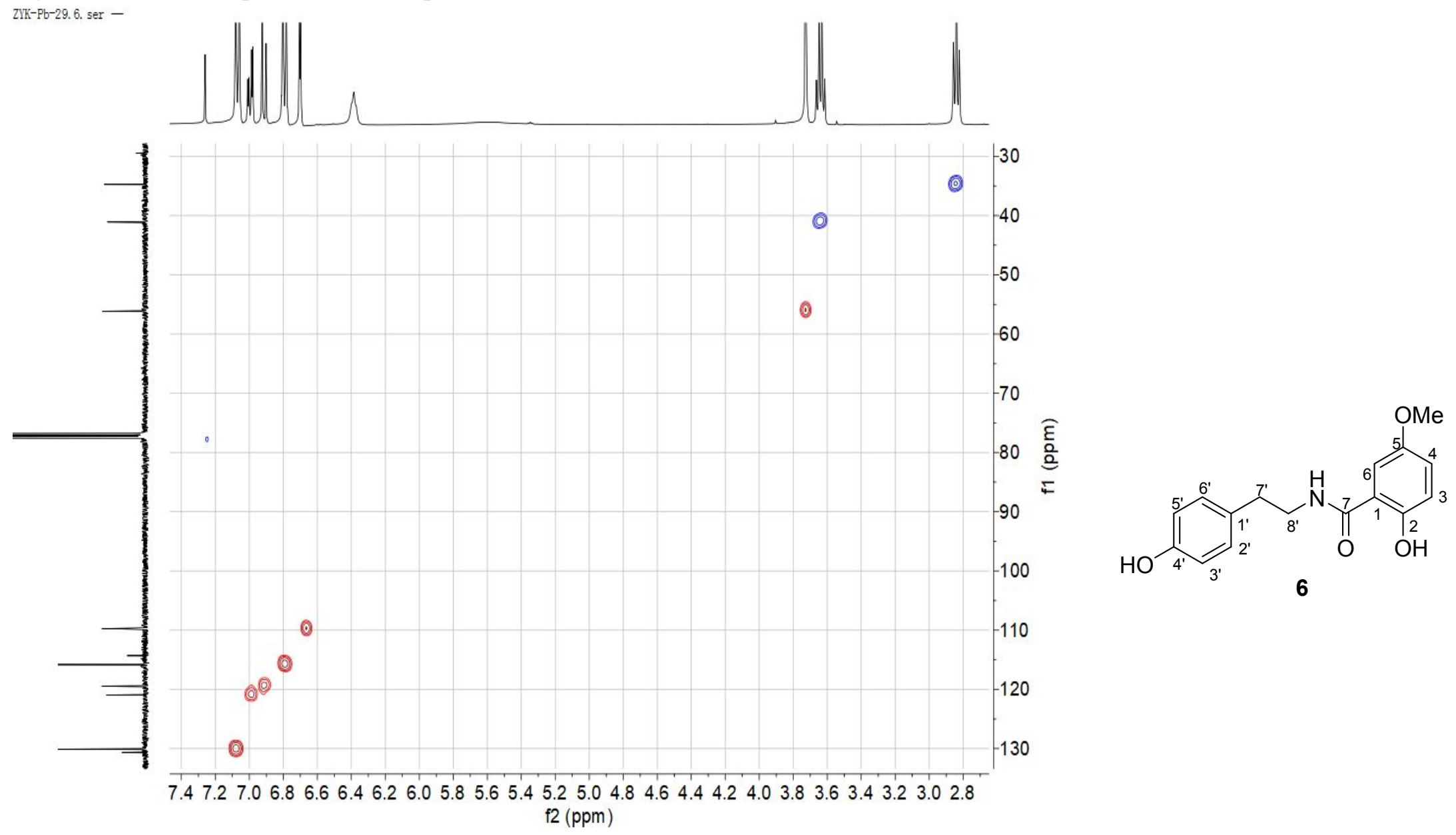


Figure S46. HMBC Spectrum of Compound 6 in $\mathrm{CDCl}_{3}$ ZJK-Pb-29.8. ser -
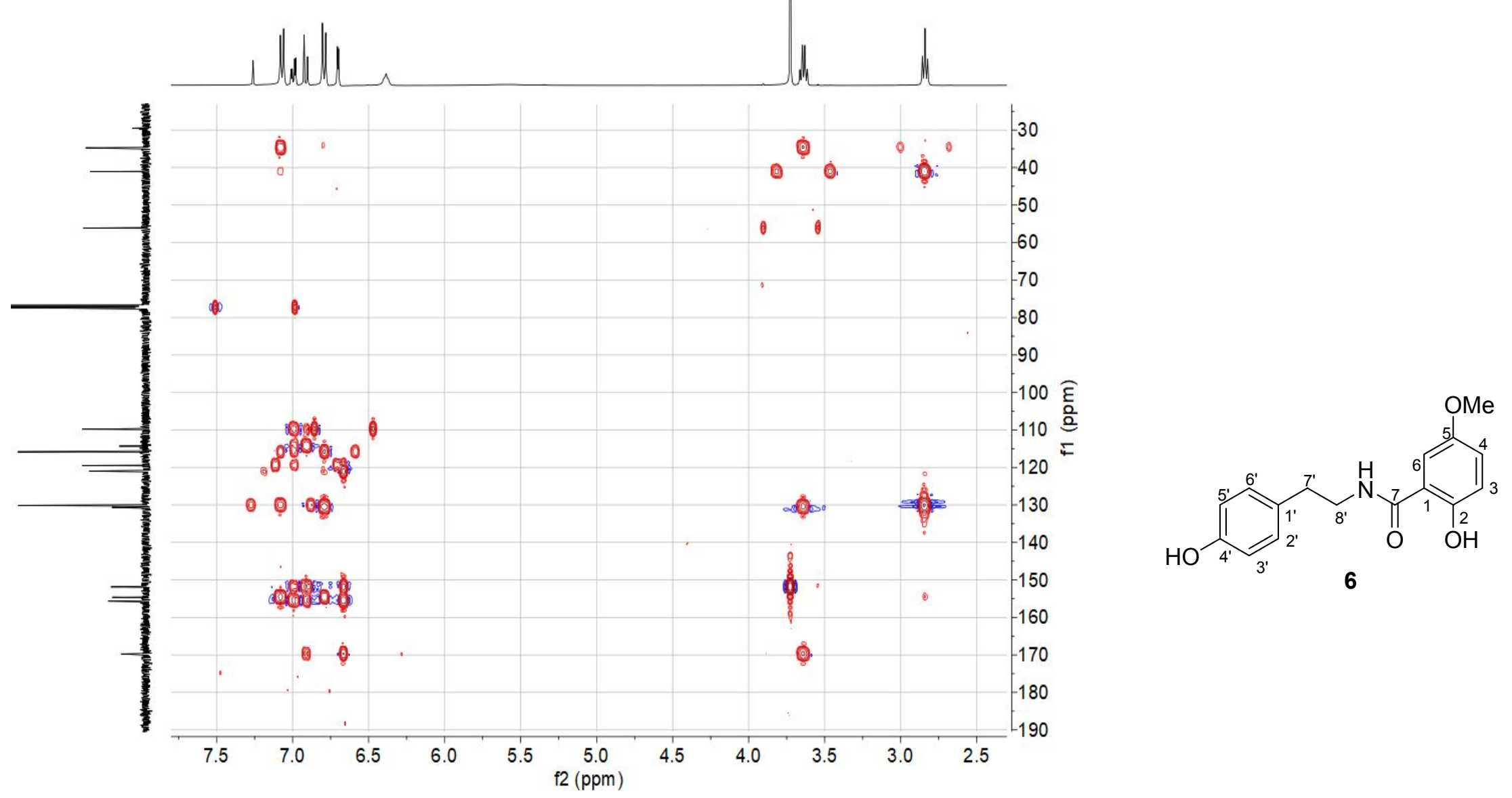
Figure S47. (+) HRESIMS Spectrum of Compound 6
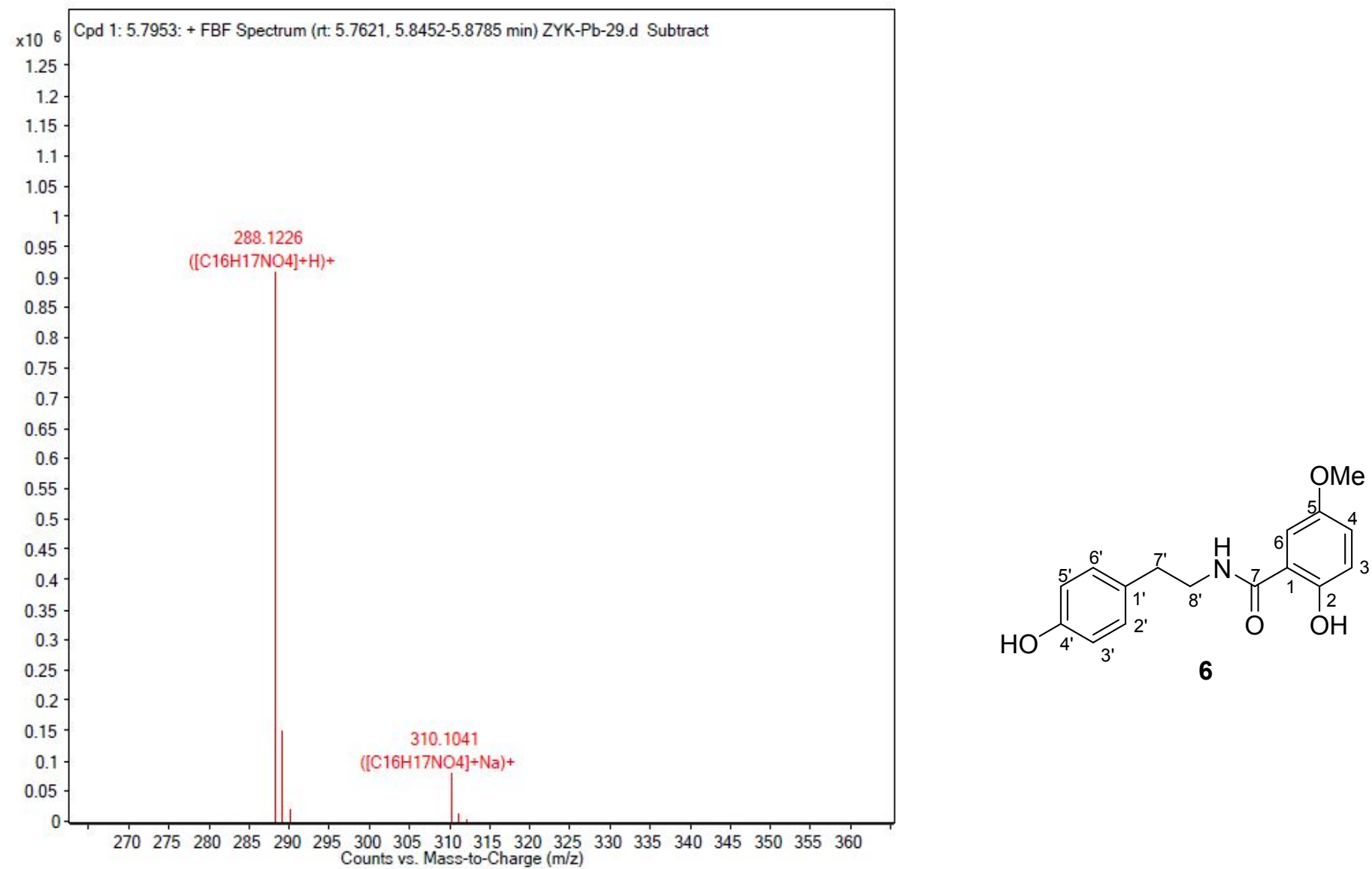
Figure S48. UV Spectrum of Compound 6

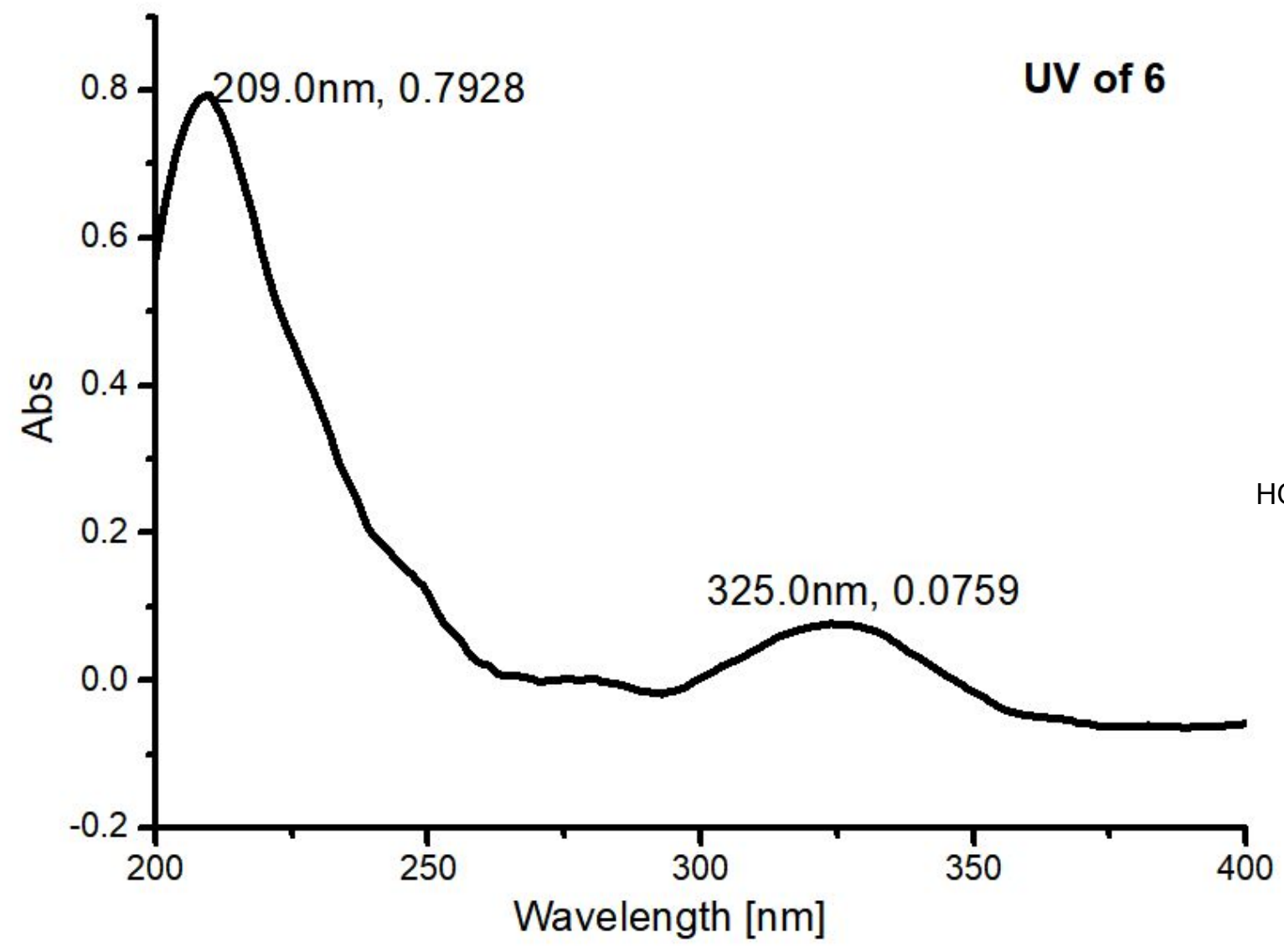


Figure S49. IR (KBr disc) Spectrum of Compound 6

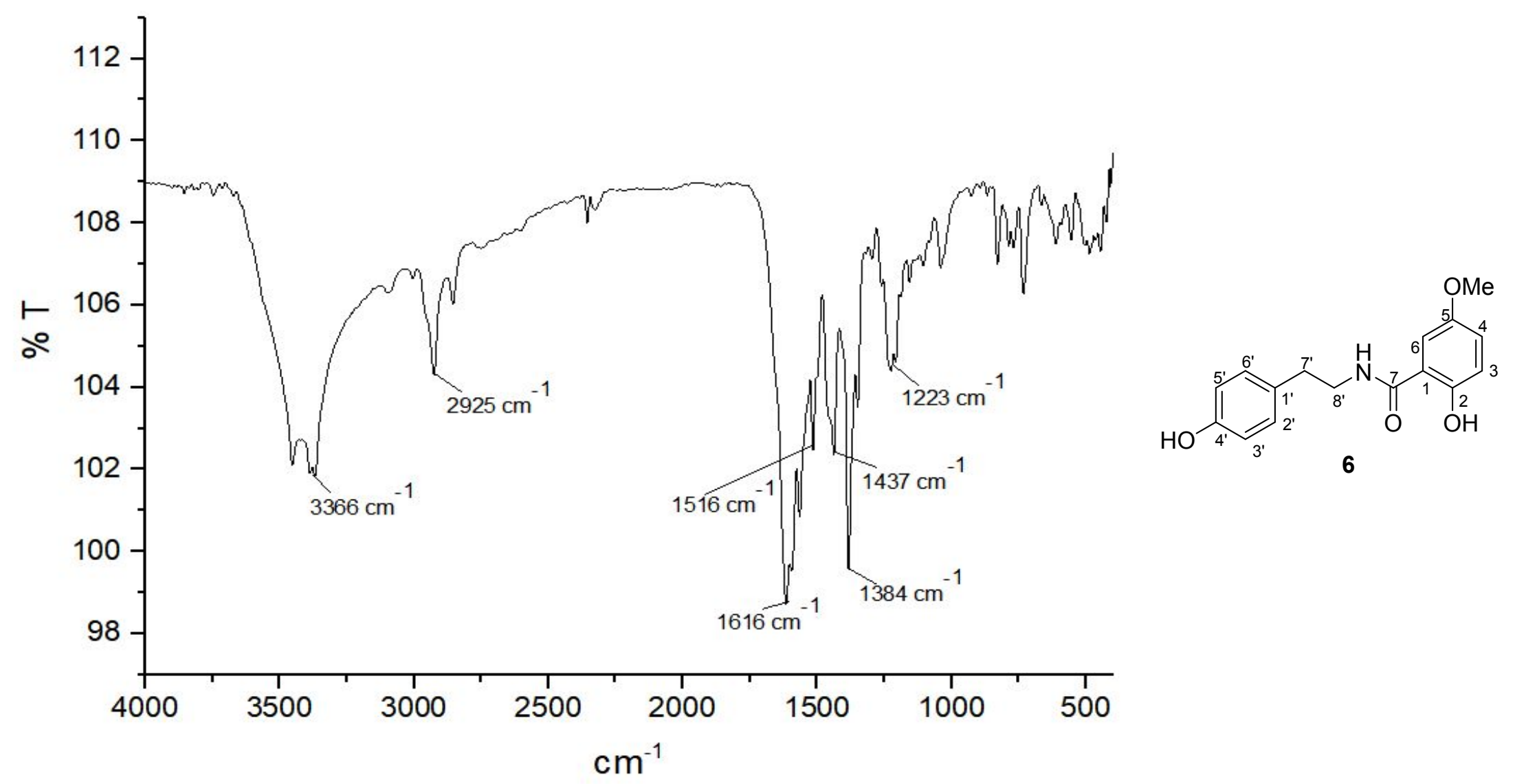


Figure S50. ${ }^{1} \mathrm{H}$ NMR Spectrum of Compound 7 in $\mathrm{CDCl}_{3}$ ZYK-Pb-50.1. fid -

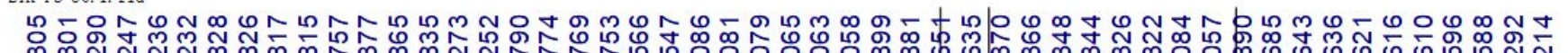
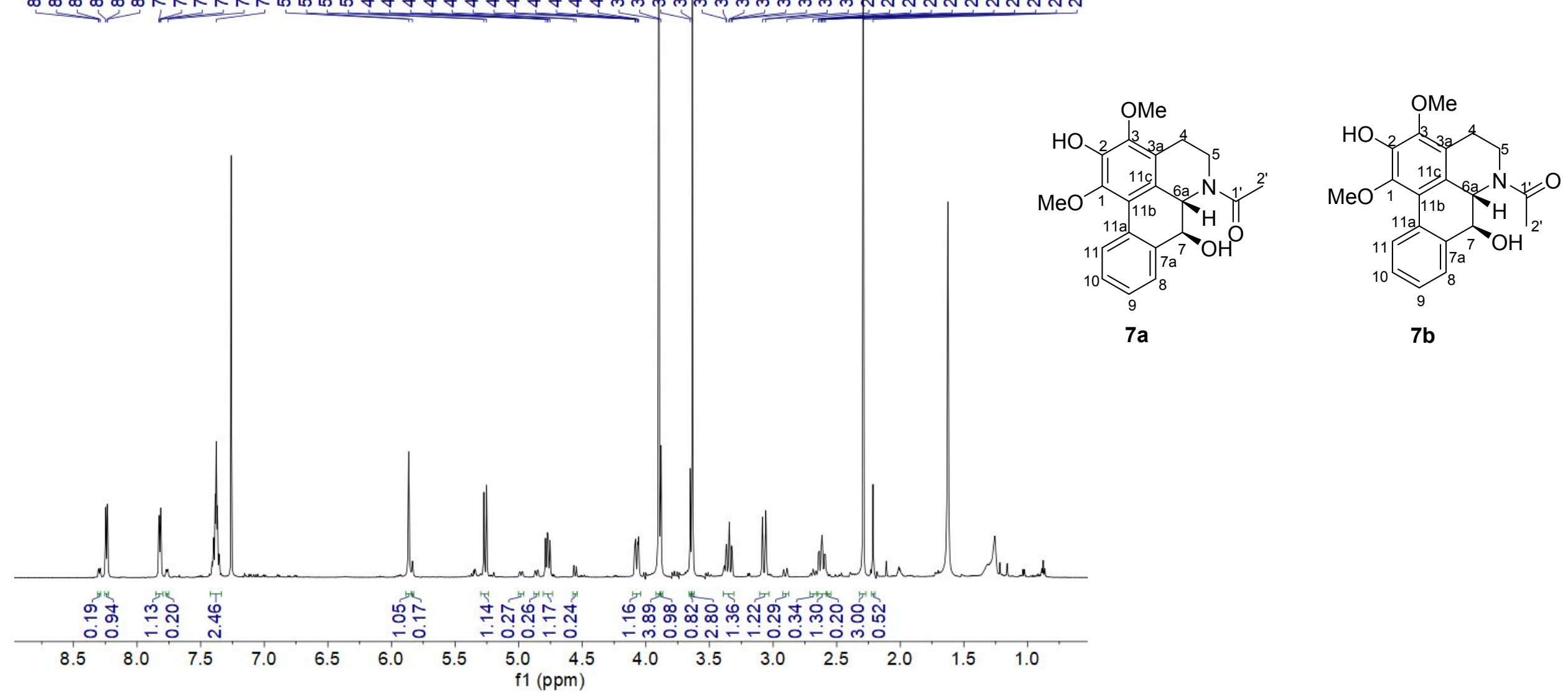
Figure S51. ${ }^{13} \mathrm{C}$ NMR Spectrum of Compound 7 in $\mathrm{CDCl}_{3}$ ZJK-Pb. 2. fid

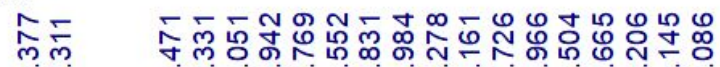

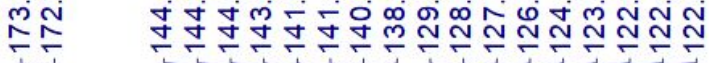

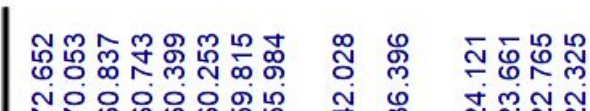

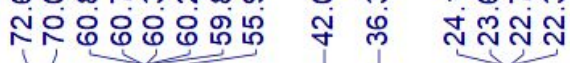

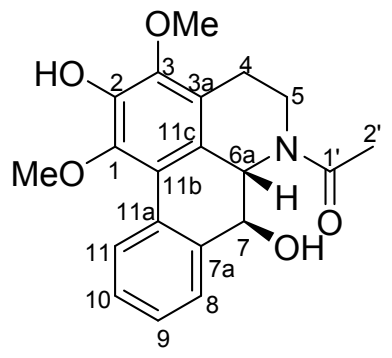

$7 a$

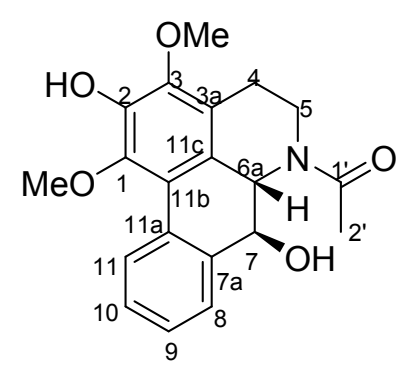

$7 b$

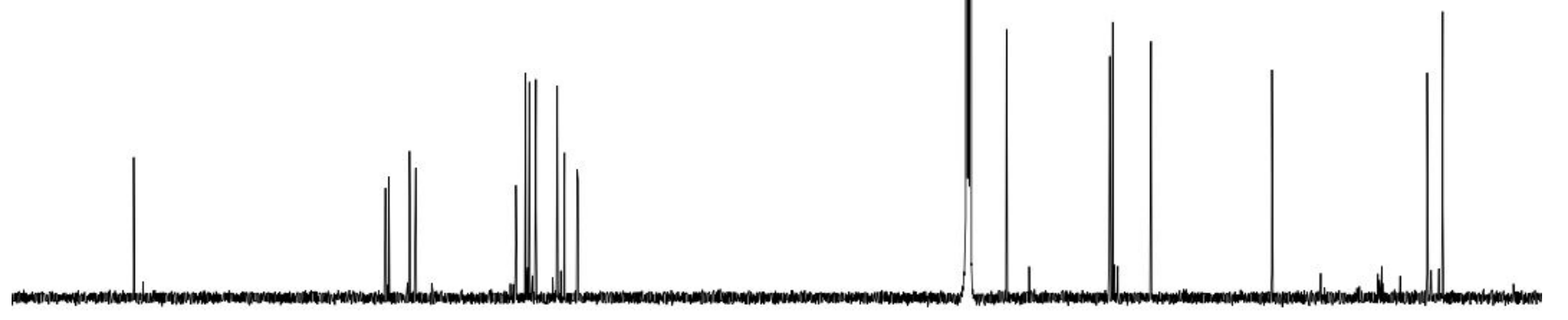

18

150

140

$30 \quad 120$

110100

f1 (ppm)

80

60

50

40

$30 \quad 20$ 
Figure S52. DEPT135 Spectrum of Compound 7 in $\mathrm{CDCl}_{3}$ z]K-Pb-50. 3. fid -
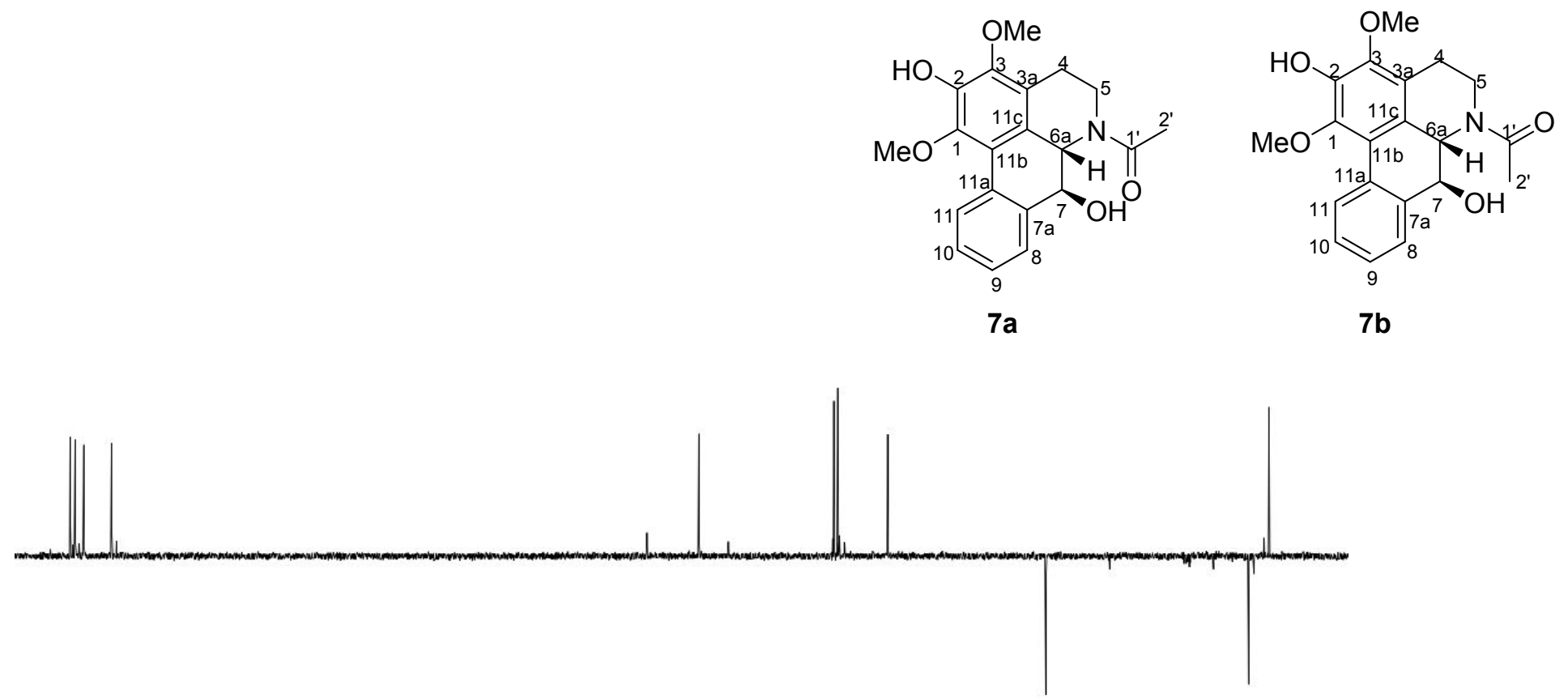

$\begin{array}{llllllllllllllllllllllllll}130 & 125 & 120 & 115 & 110 & 105 & 100 & 95 & 90 & 85 & 80 & \begin{array}{c}75 \\ \mathrm{f} 1(\mathrm{ppm})\end{array} & 65 & 60 & 55 & 50 & 45 & 40 & 35 & 30 & 25 & 20\end{array}$ 
Figure S53. ${ }^{1} \mathrm{H}-{ }^{1} \mathrm{H}$ COSY Spectrum of Compound 7 in $\mathrm{CDCl}_{3}$ TYK-Pb-50. 5. ser -

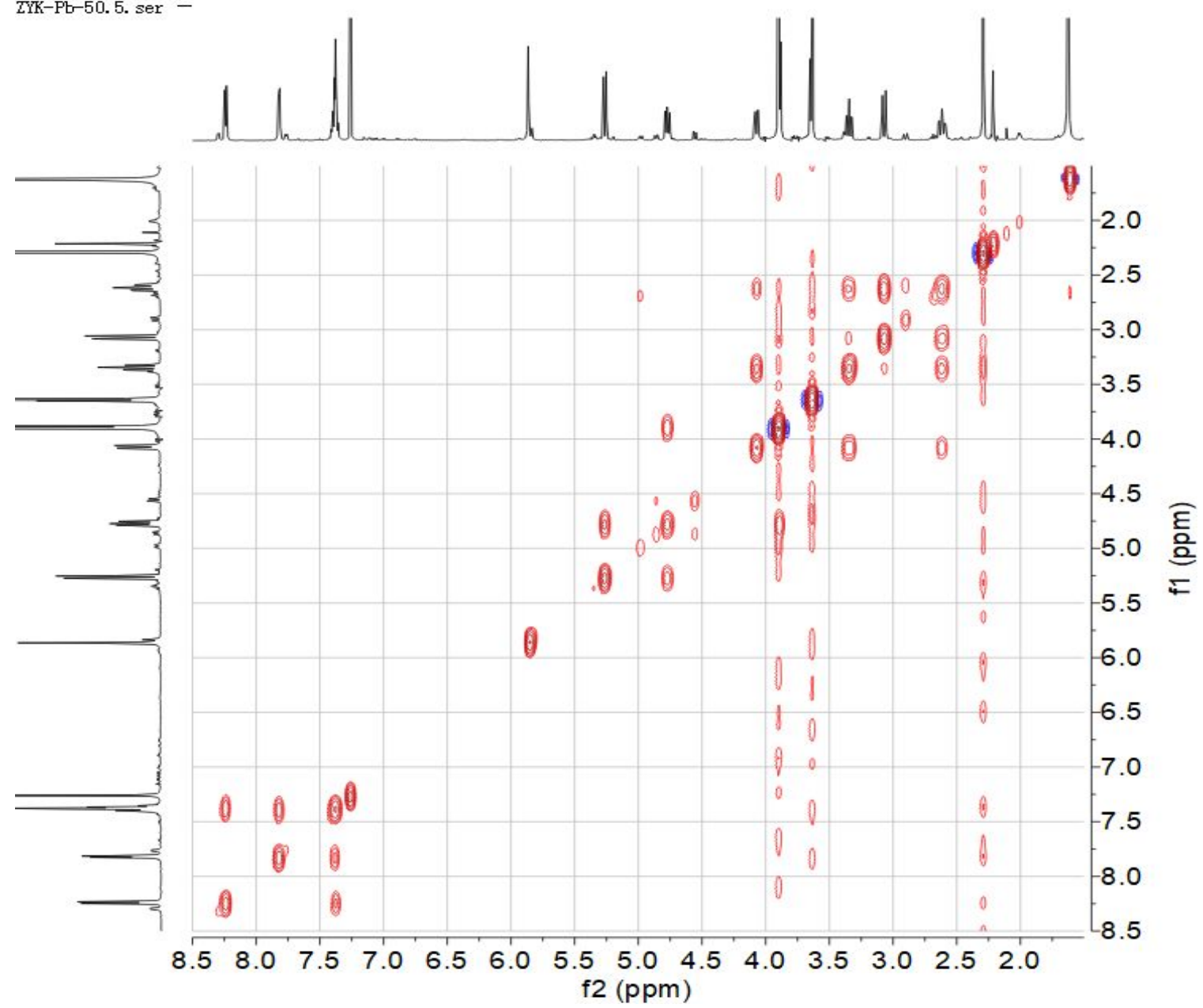

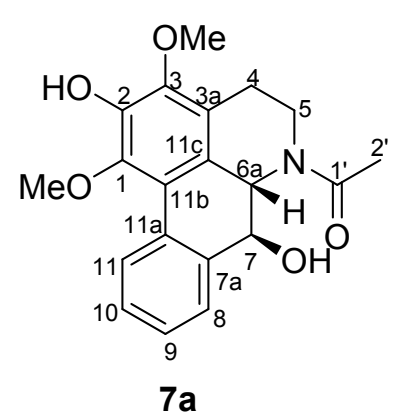

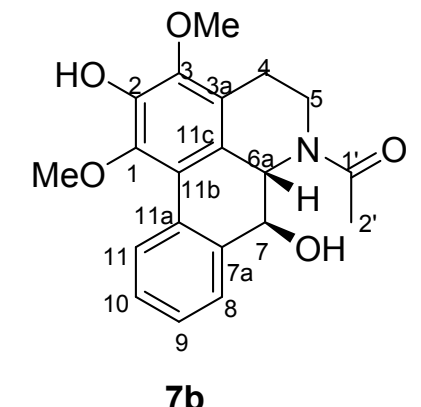


Figure S54. HSQC Spectrum of Compound 7 in $\mathrm{CDCl}_{3}$ ZIK-Pb-50.7. ser -
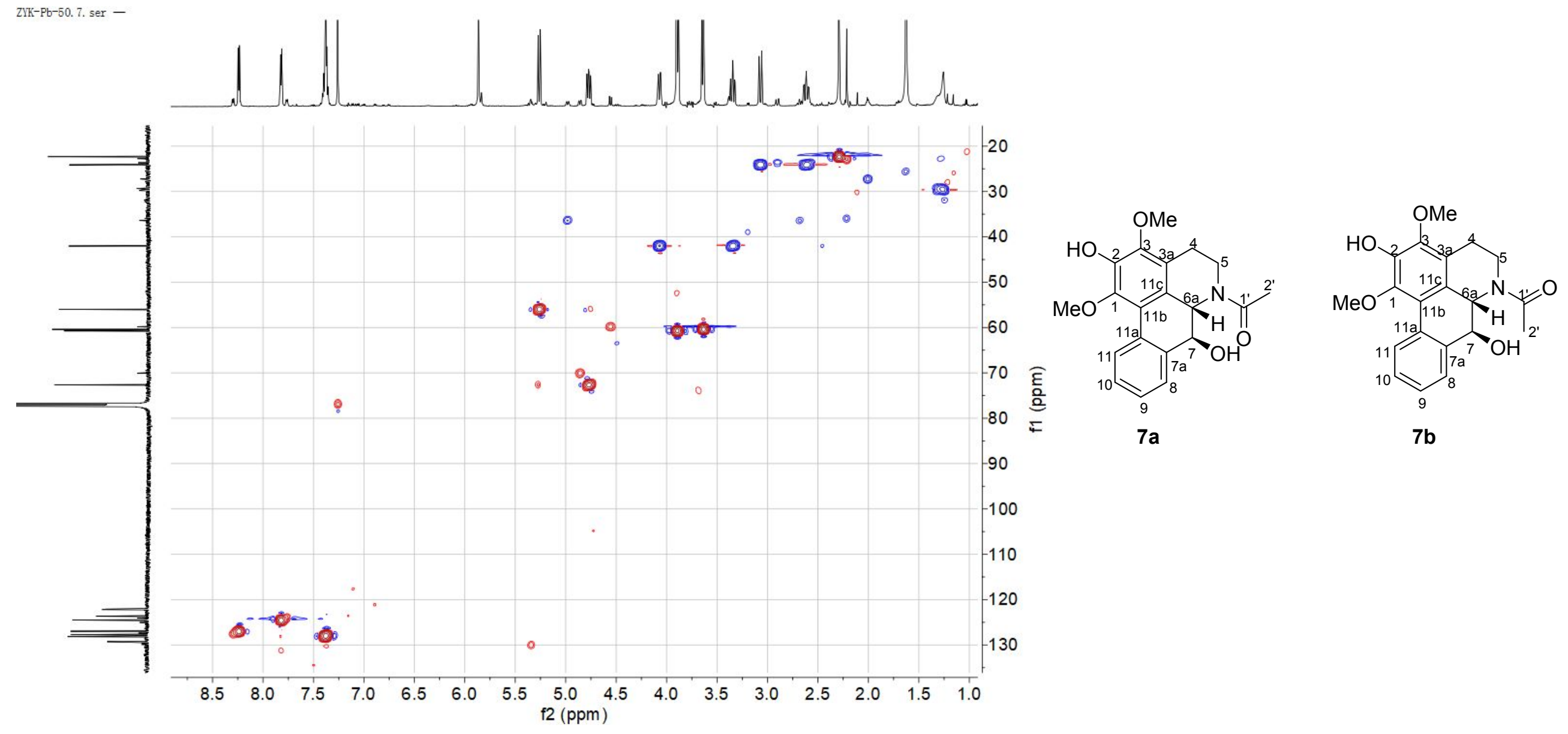
Figure S55. HMBC Spectrum of Compound 7 in $\mathrm{CDCl}_{3}$
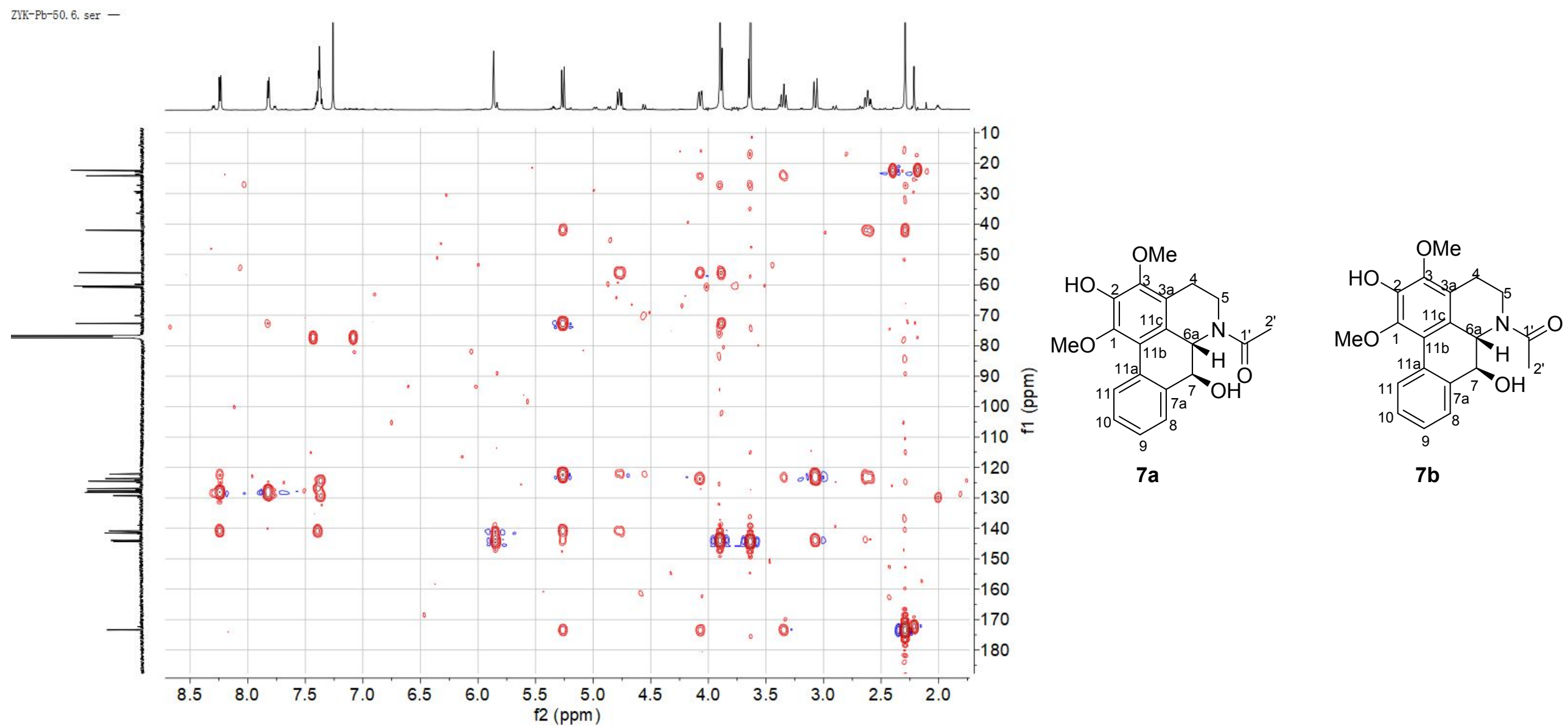
Figure S56. NOESY Spectrum of Compound 7 in $\mathrm{CDCl}_{3}$

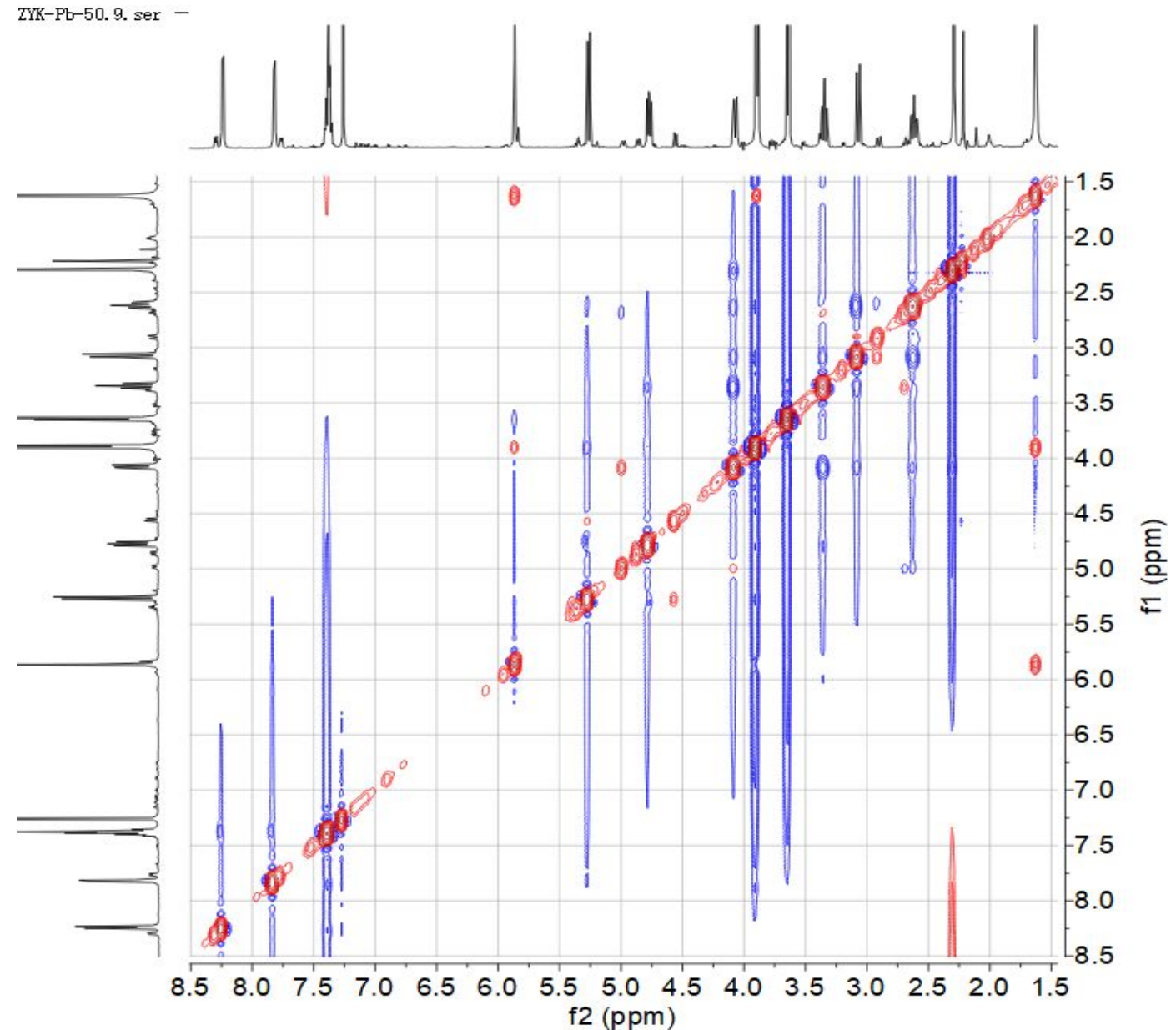

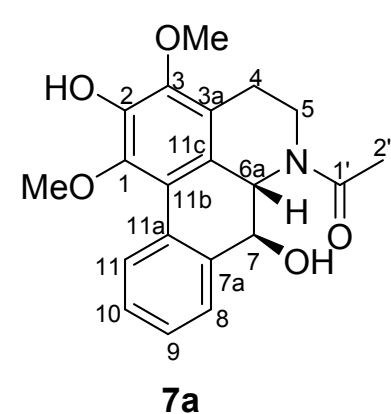

$7 a$

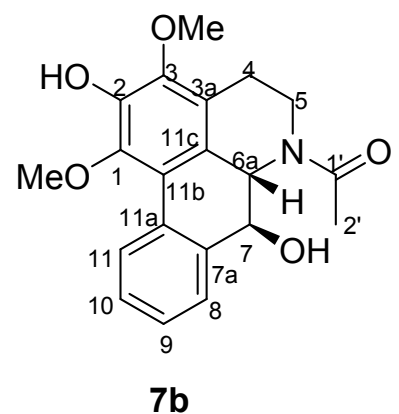


Figure S57. (+) HRESIMS Spectrum of Compound 7

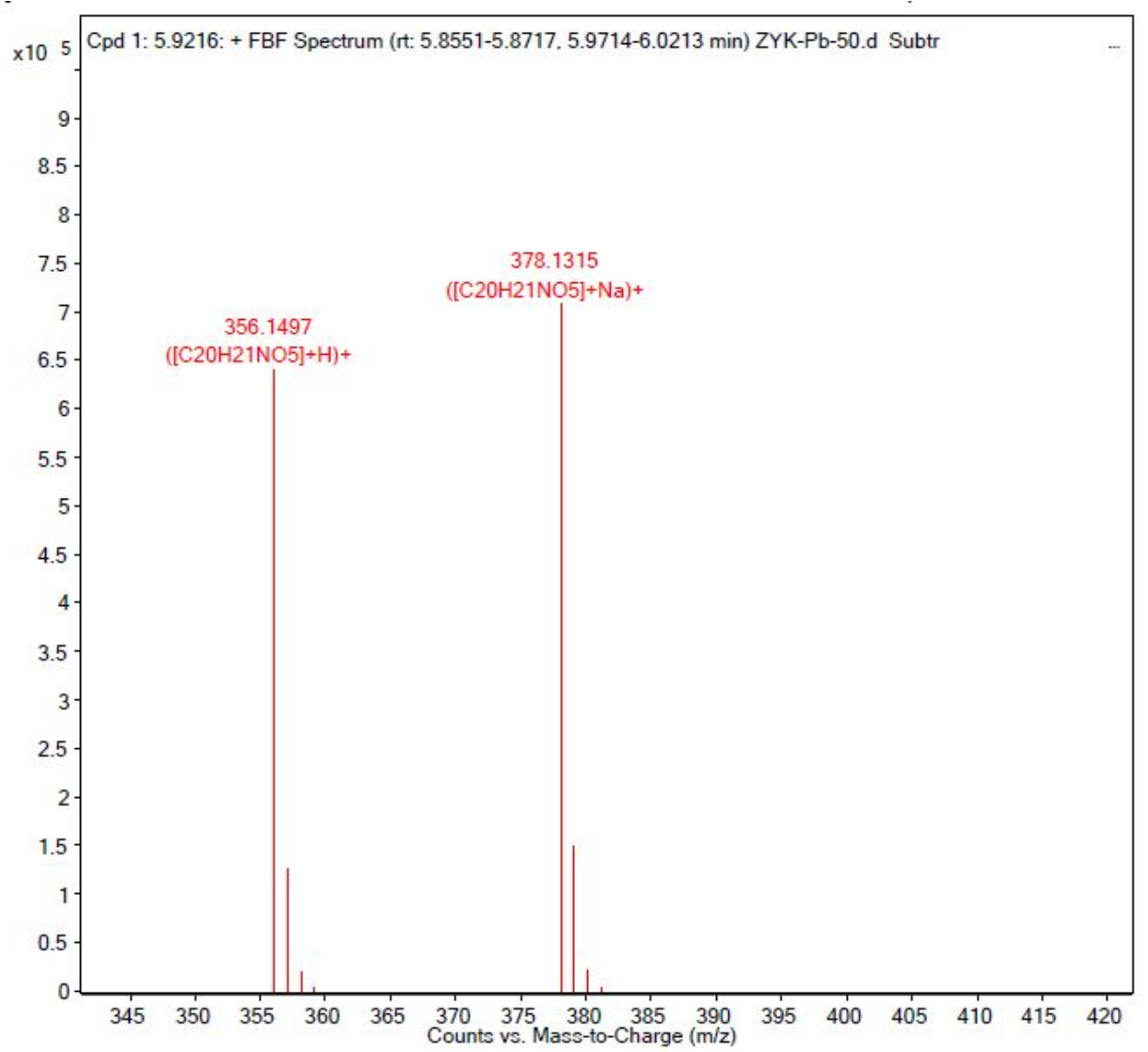

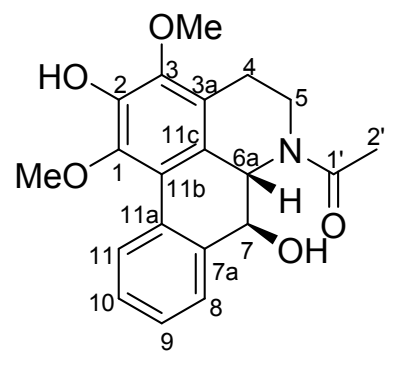

$7 a$

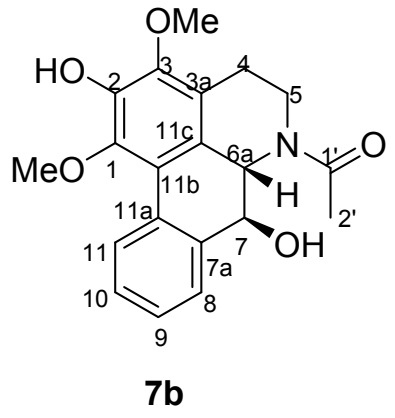


Figure S58. UV Spectrum of Compound 7

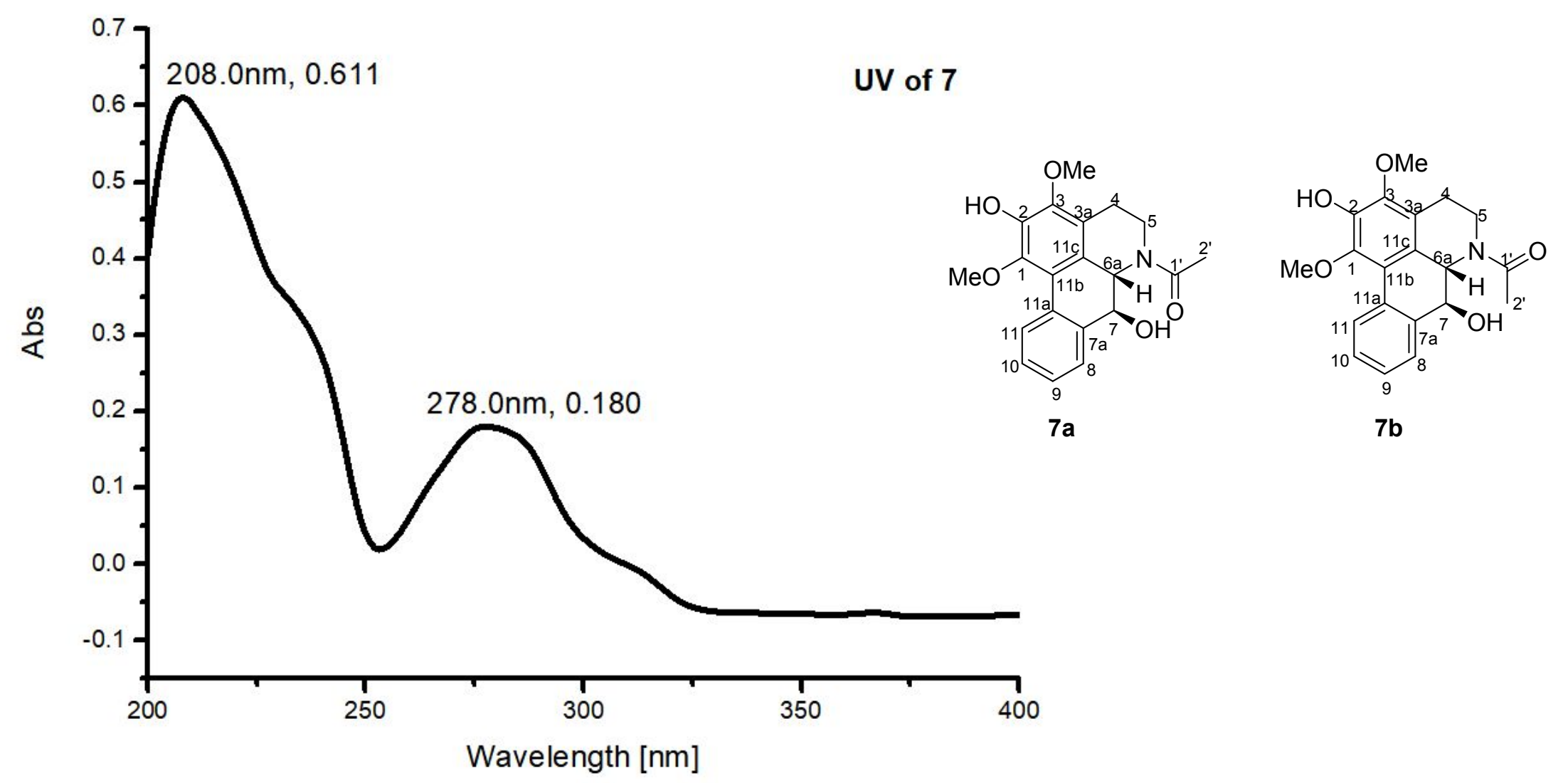


Figure S59. IR (KBr disc) Spectrum of Compound 7

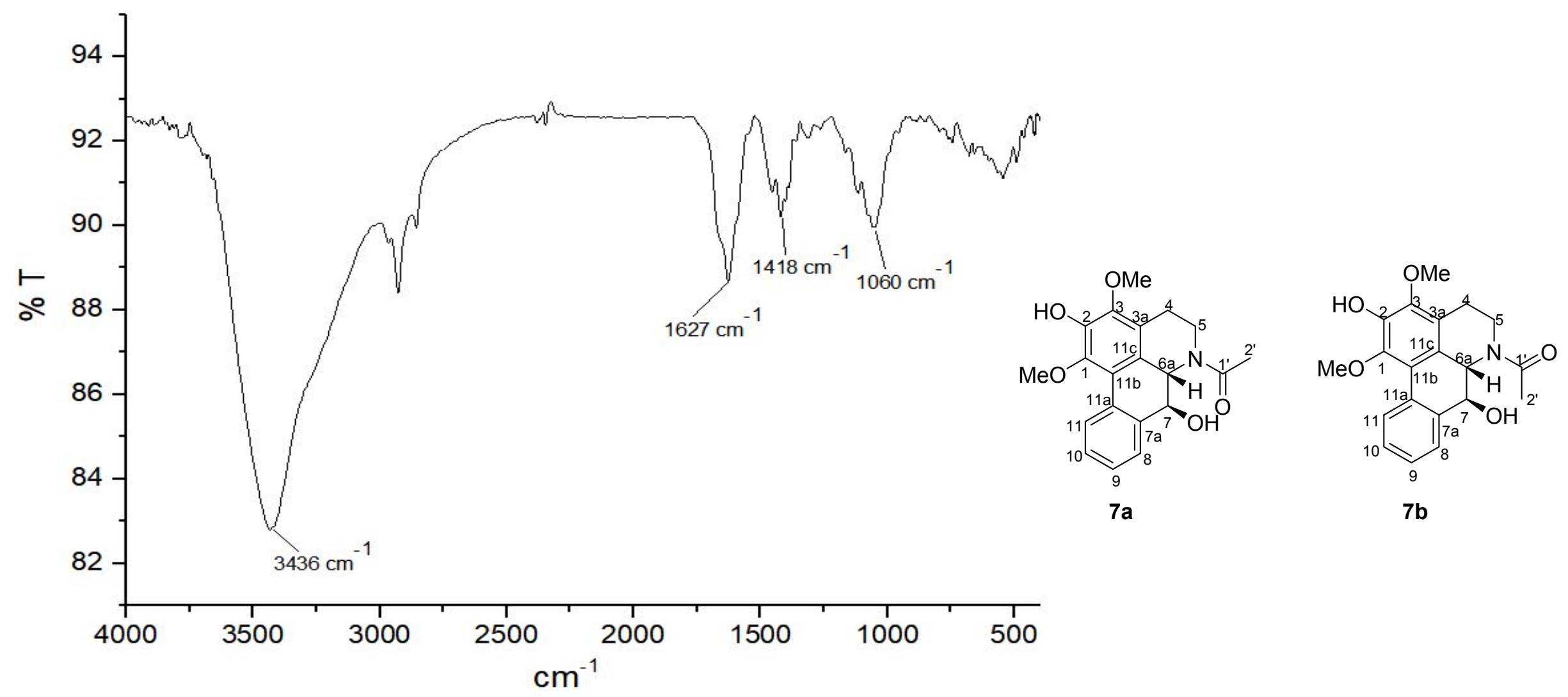


Figure S60. ECD Spectrum of 7

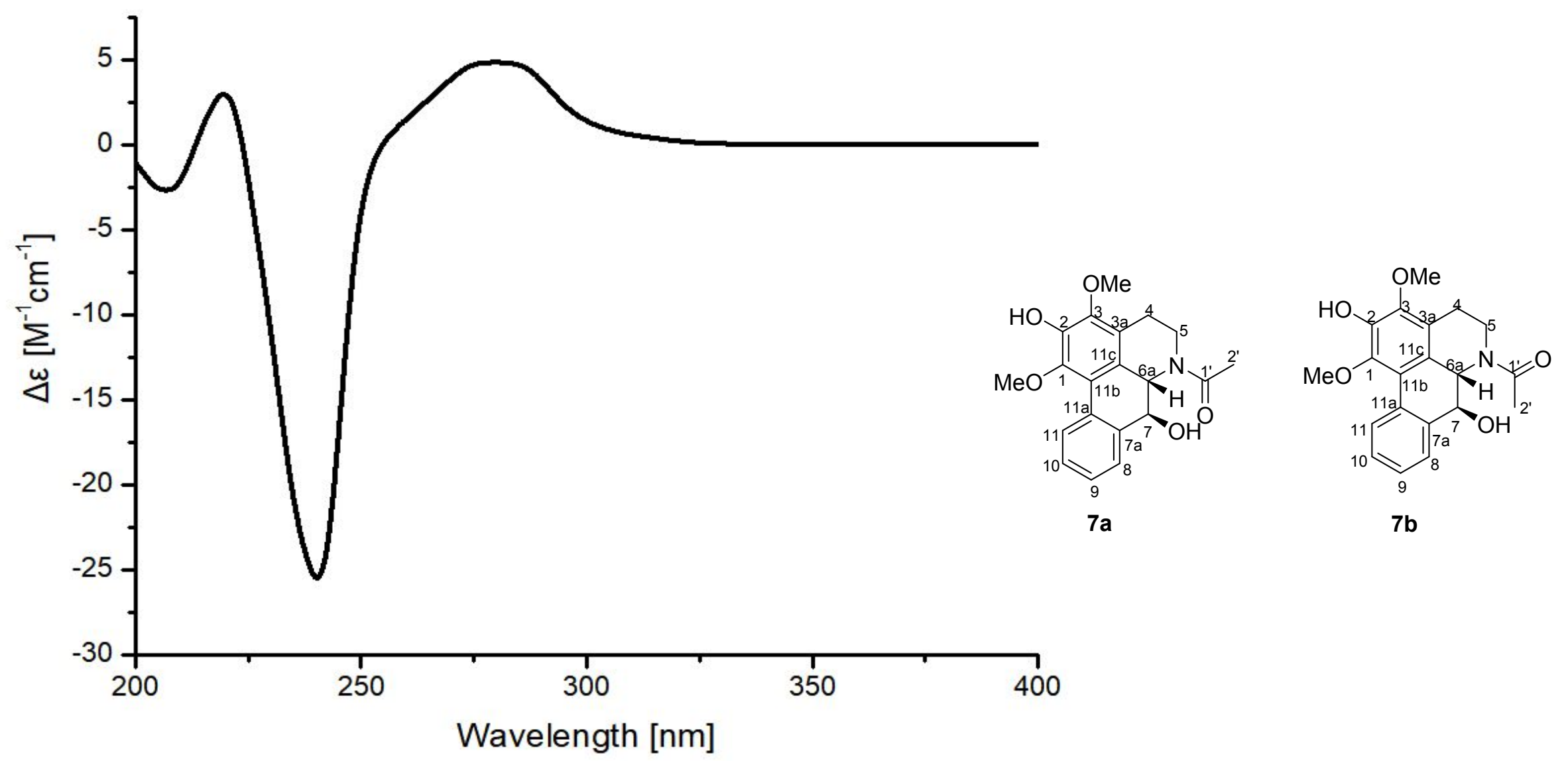


Figure S61. ${ }^{1} \mathrm{H}$ NMR Spectrum of Compound 8 in $\mathrm{CDCl}_{3}$

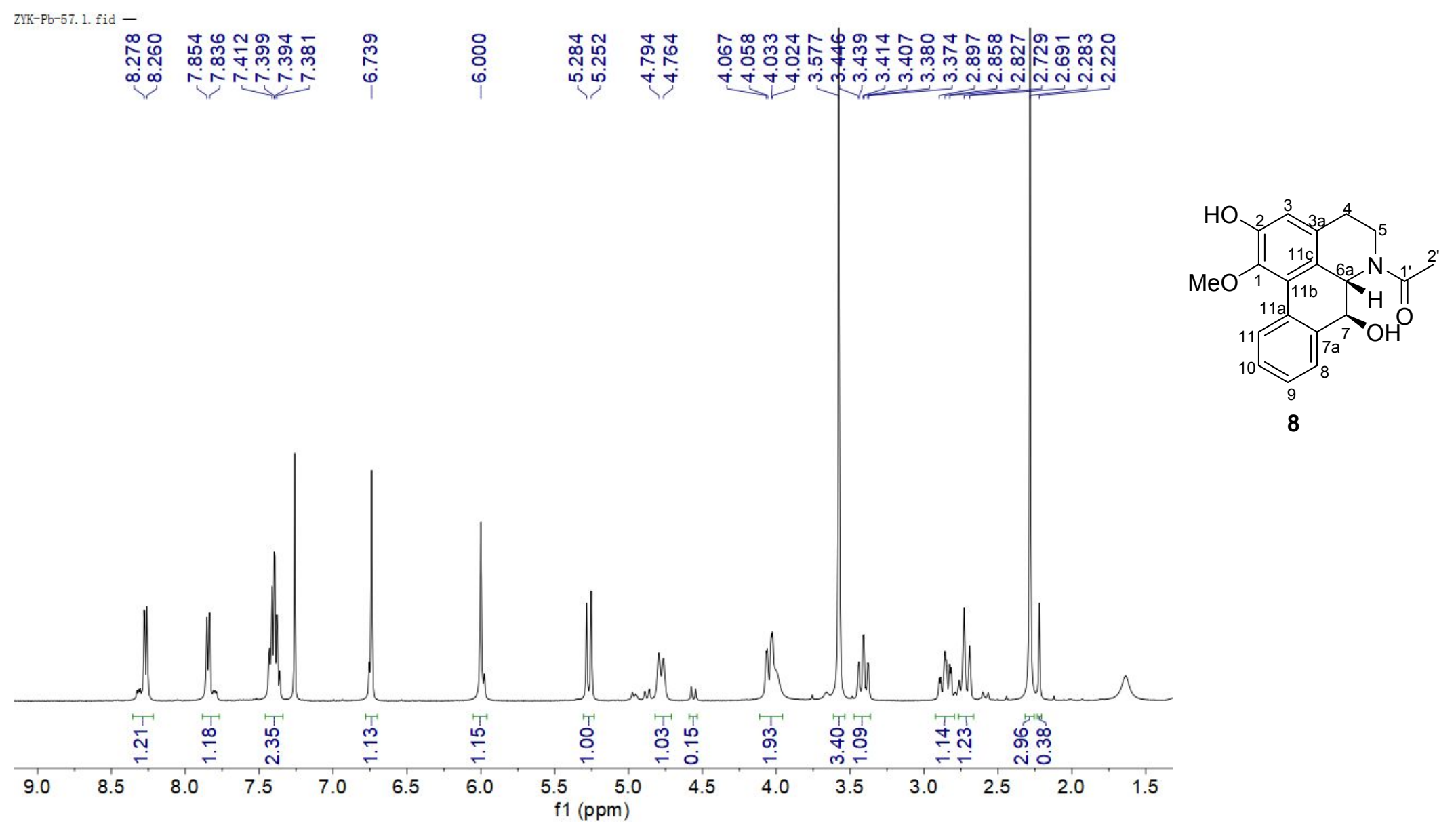


Figure S62. ${ }^{13} \mathrm{C}$ NMR Spectrum of Compound $\mathbf{8}$ in $\mathrm{CDCl}_{3}$
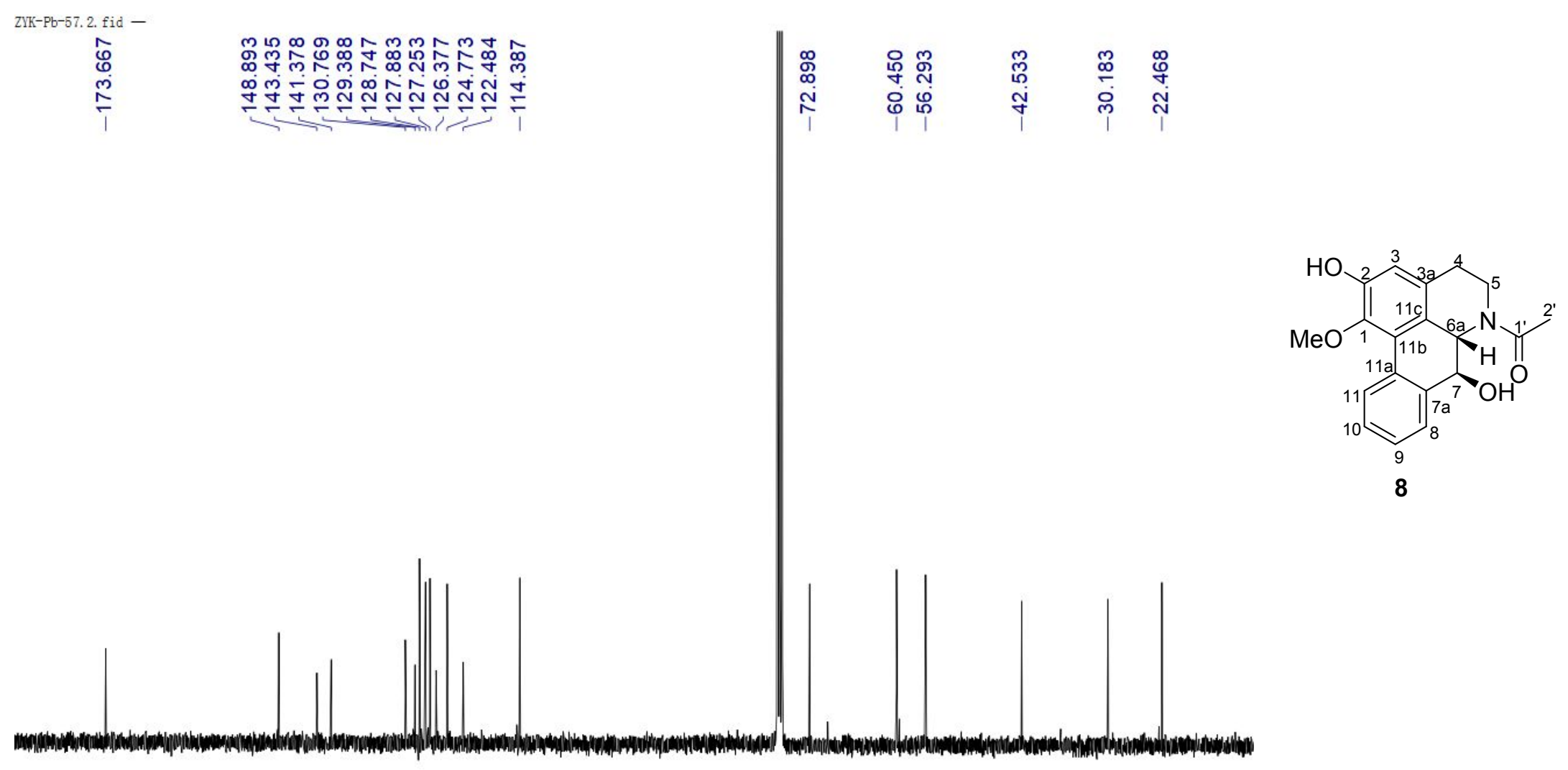

$\begin{array}{llll}180 & 170 & 160 & 150\end{array}$

140

130

20

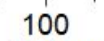

f1 (ppm)

60

50

30

$20 \quad 16$ 
Figure S64. ${ }^{1} \mathrm{H}-{ }^{1} \mathrm{H}$ COSY Spectrum of Compound 8 in $\mathrm{CDCl}_{3}$ ZYK-Pb-57. 4. ser -
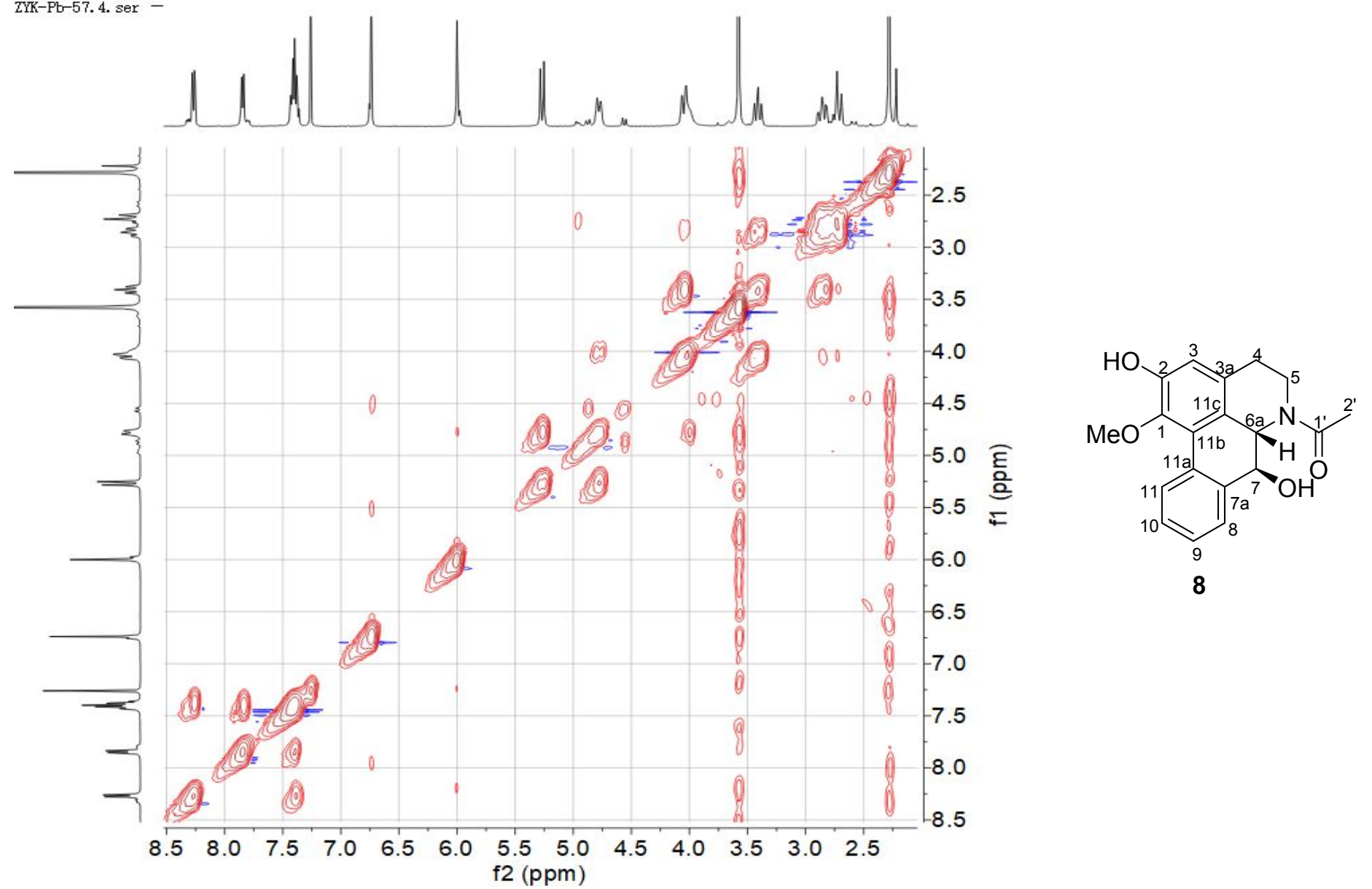
Figure S64. HSQC Spectrum of Compound $\mathbf{8}$ in $\mathrm{CDCl}_{3}$ ZTK-Pb-57. 5. ser -

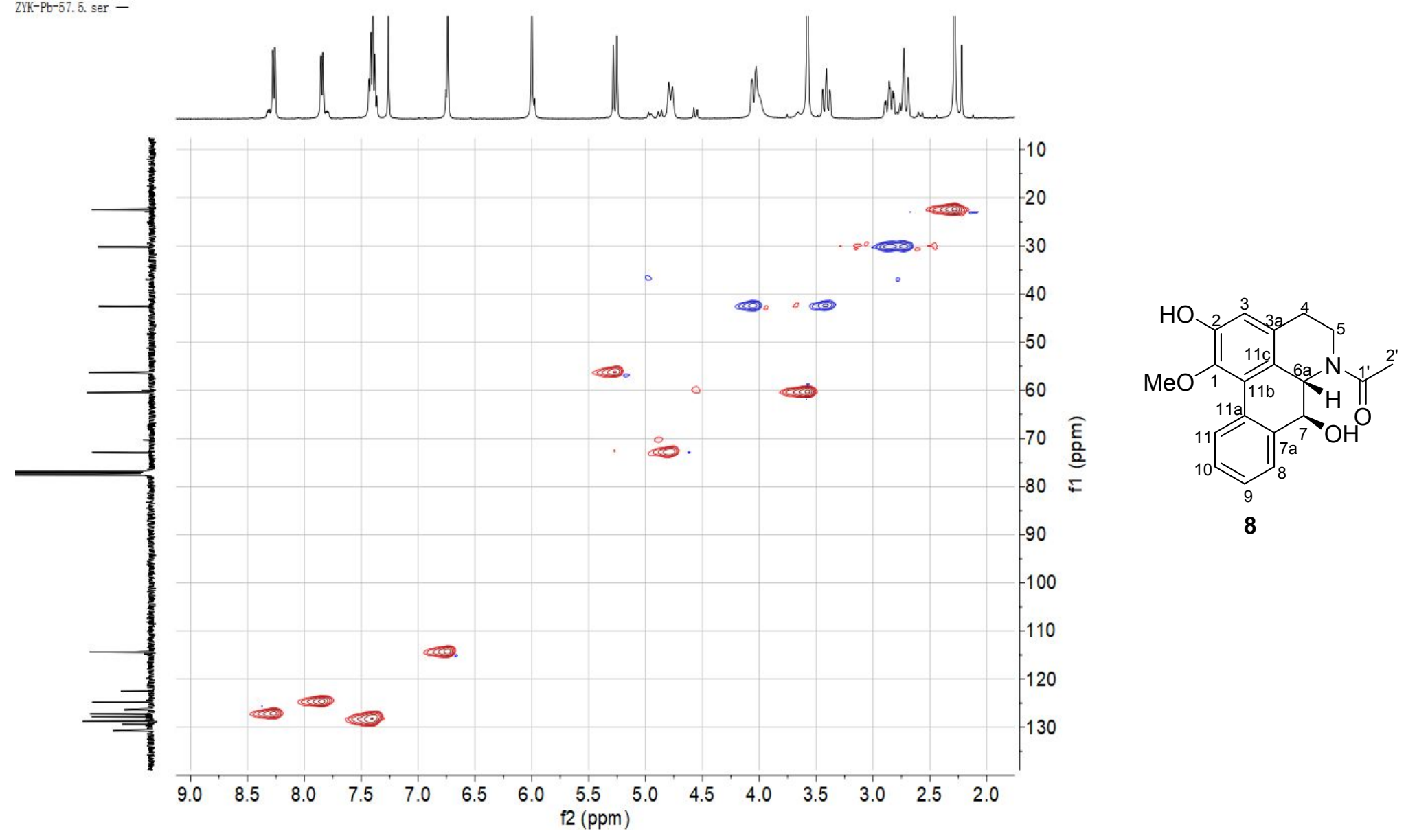


Figure S65. HMBC Spectrum of Compound 8 in $\mathrm{CDCl}_{3}$

ZTK-Pb-57. 6. ser -

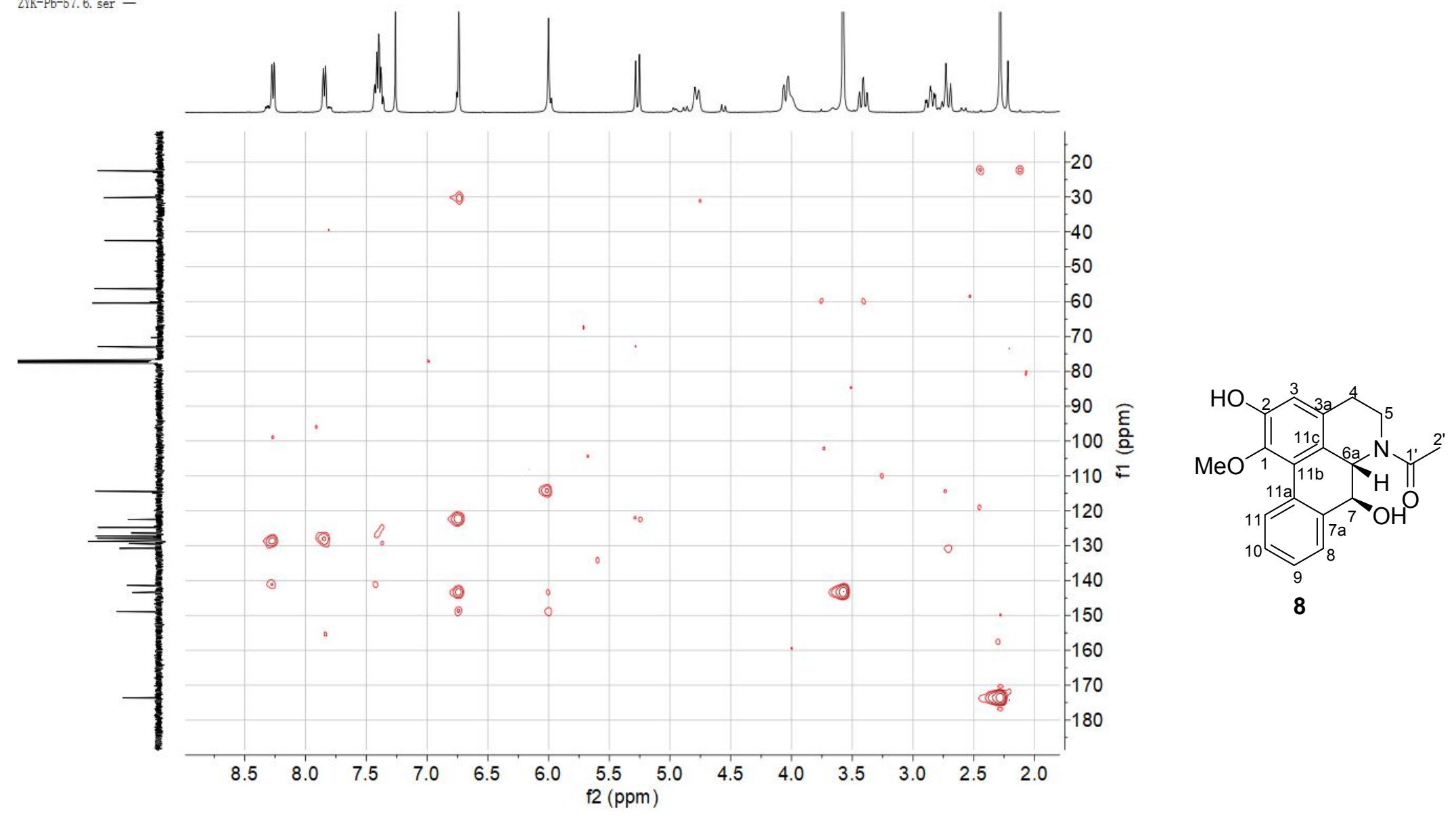


Figure S66. NOESY Spectrum of Compound $\mathbf{8}$ in $\mathrm{CDCl}_{3}$ ZYK-Ft-57.8. ser -

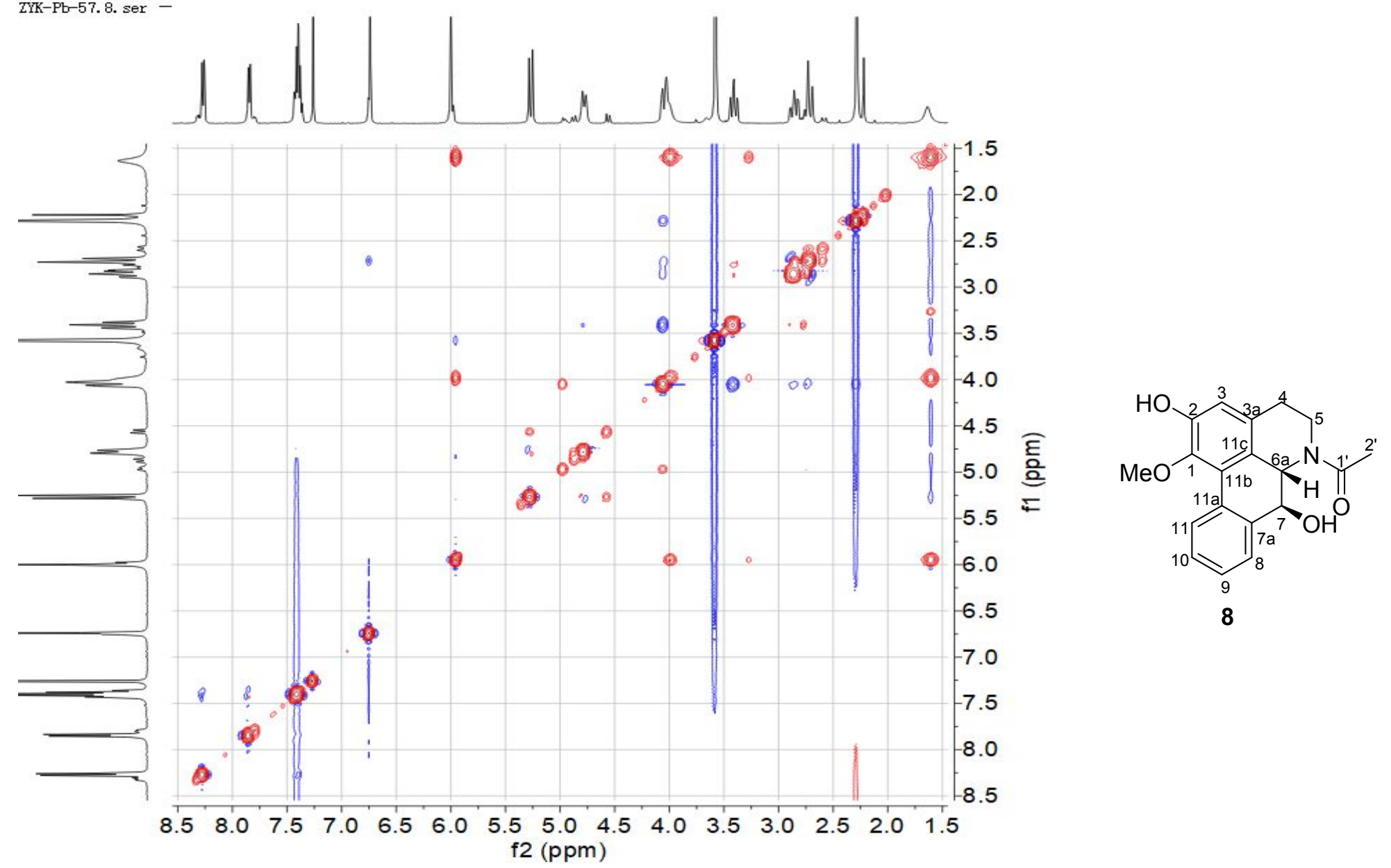


Figure S67. (+) HRESIMS Spectrum of Compound 8
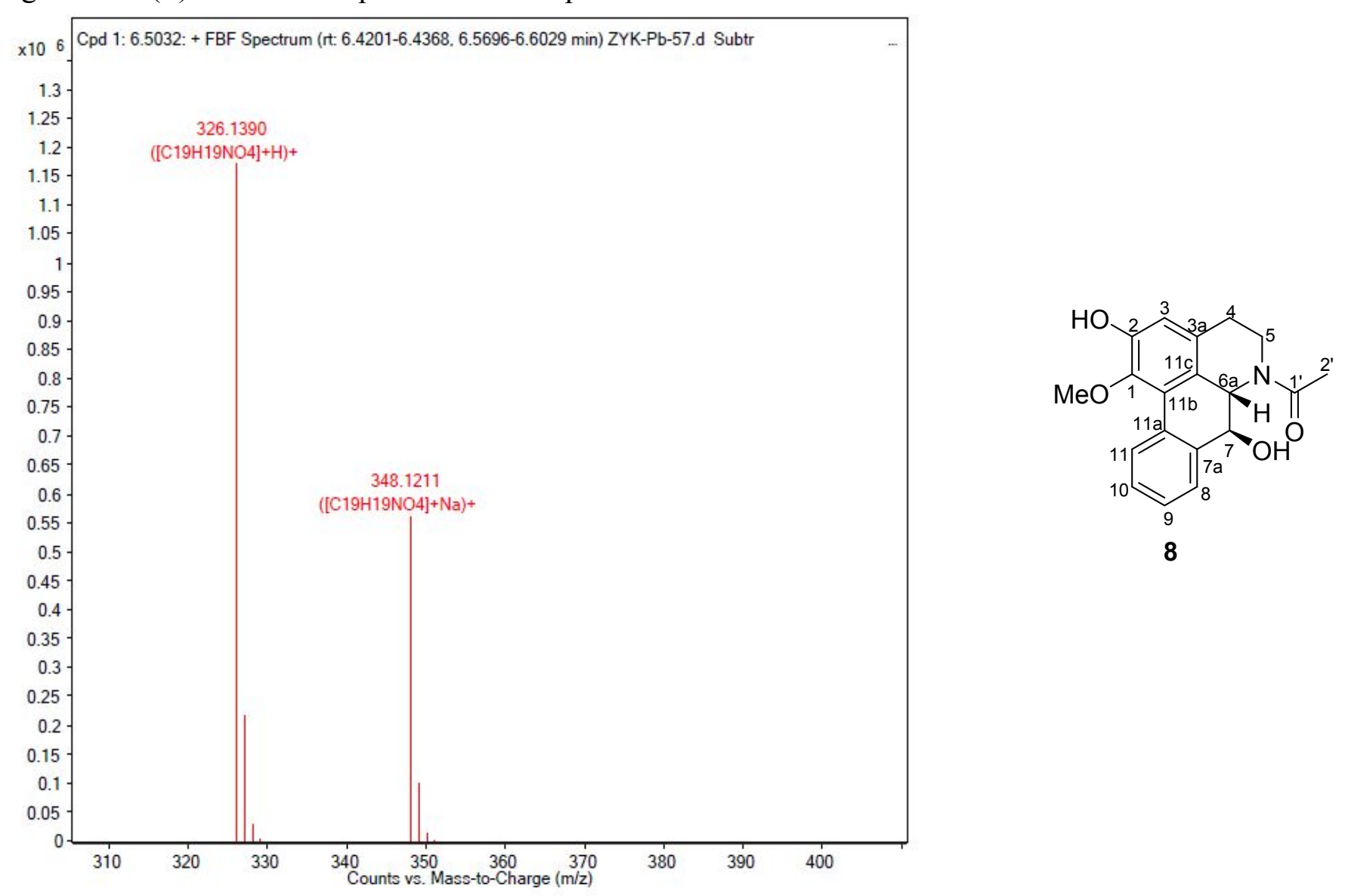
Figure S68. UV Spectrum of Compound 8
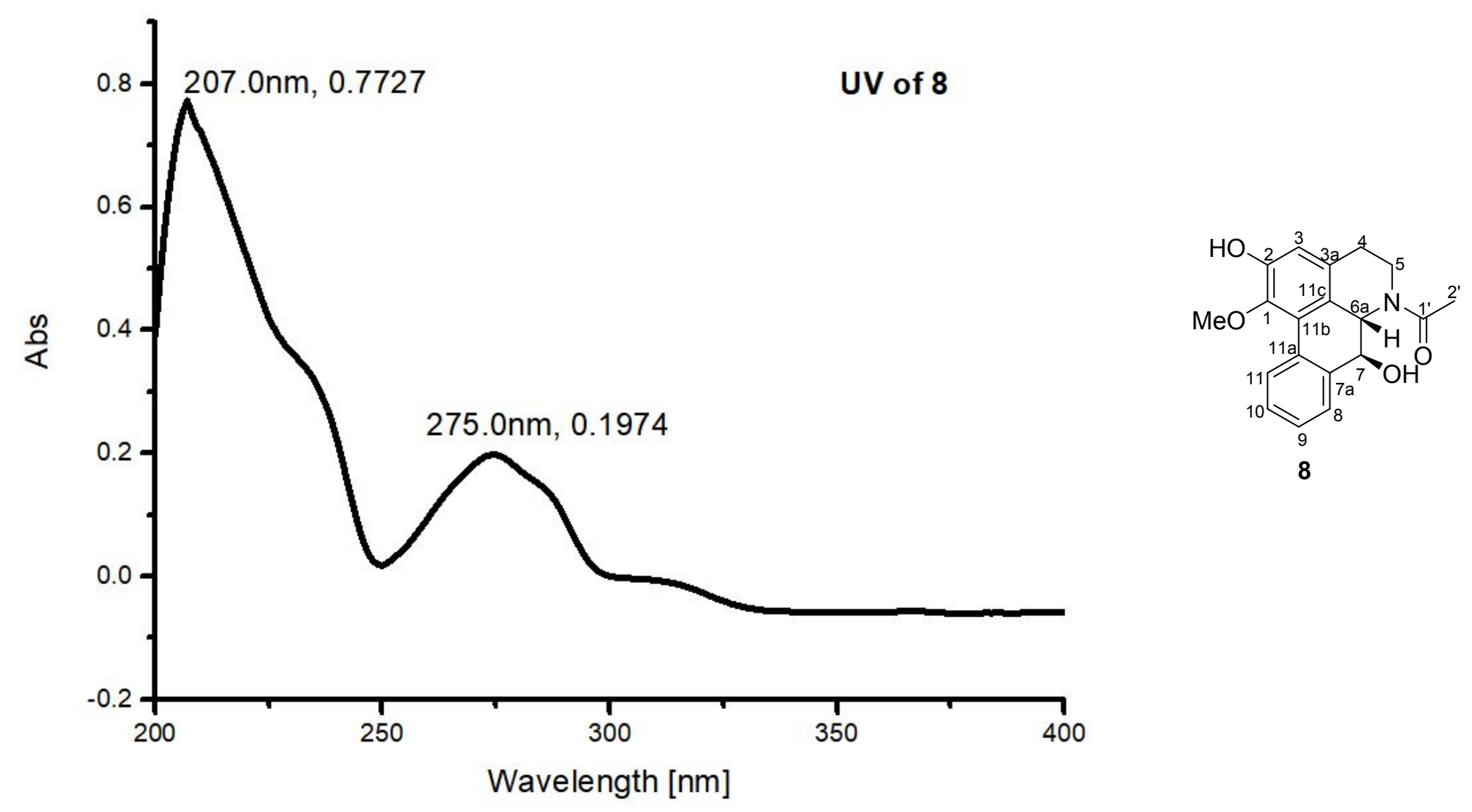
Figure S69. IR (KBr disc) Spectrum of Compound 8

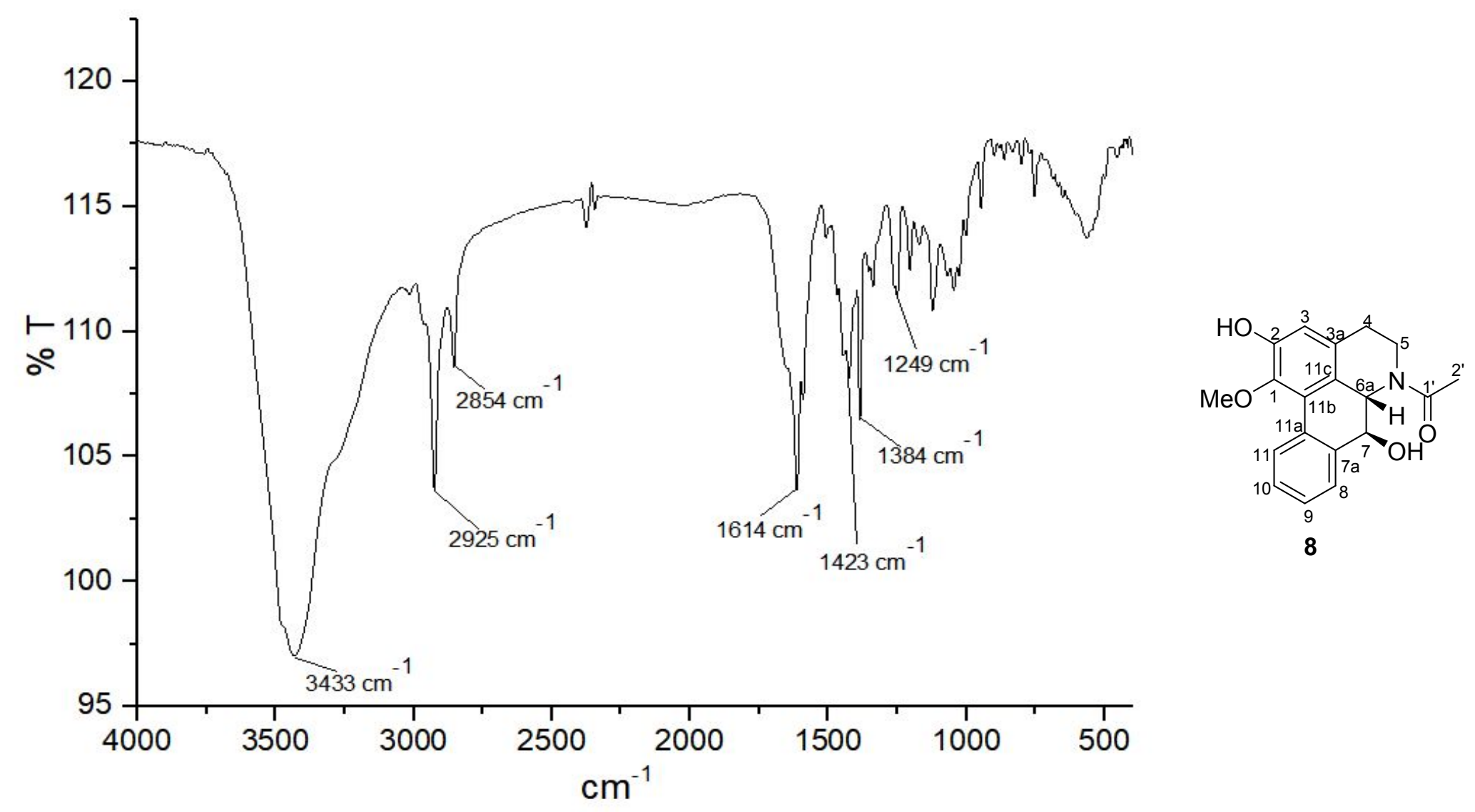


Figure S70. ECD Spectrum of 8

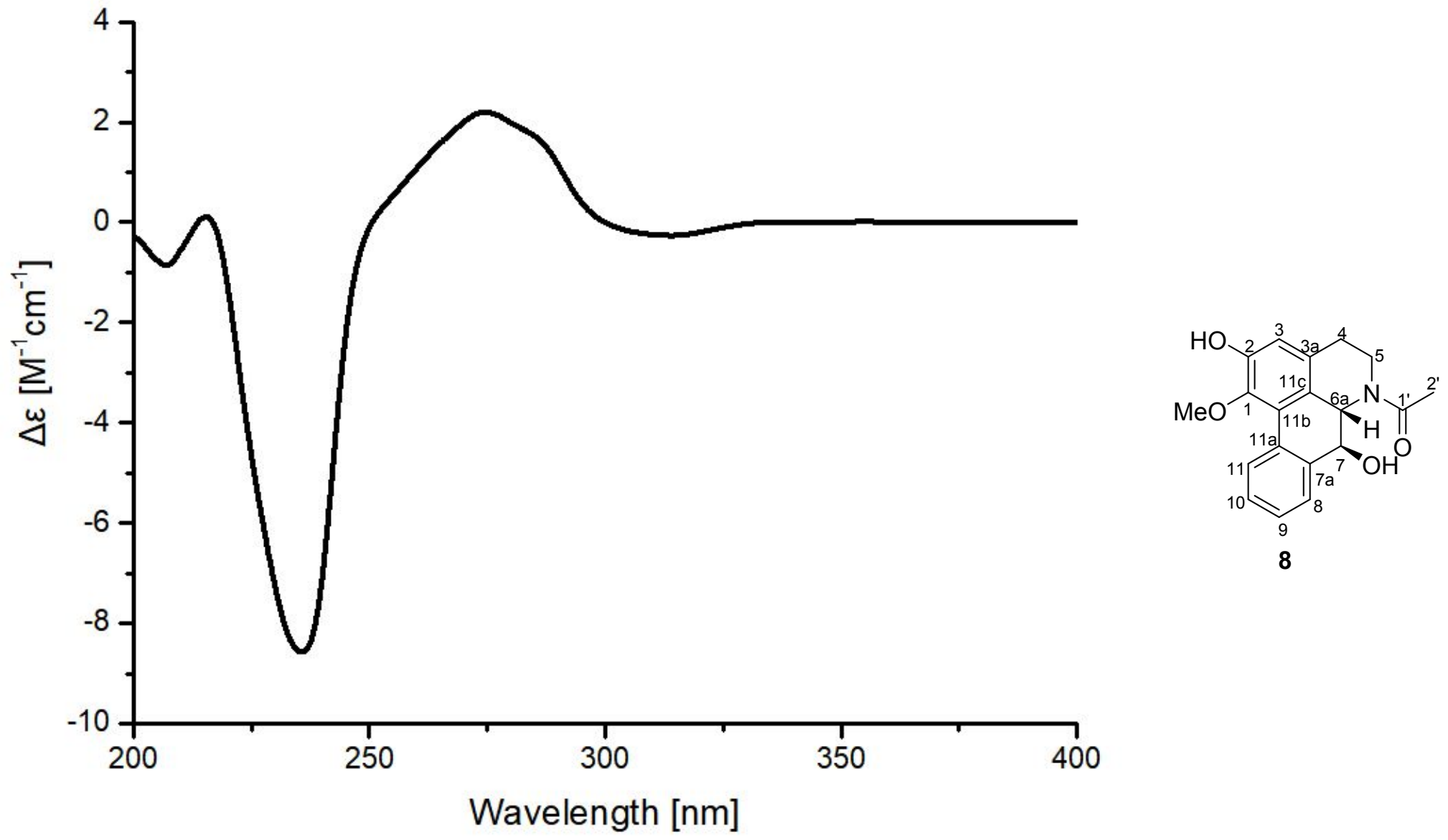


Figure S71. ${ }^{1} \mathrm{H}$ NMR Spectrum of Compound 9 in $\mathrm{MeOH}-d_{4}$

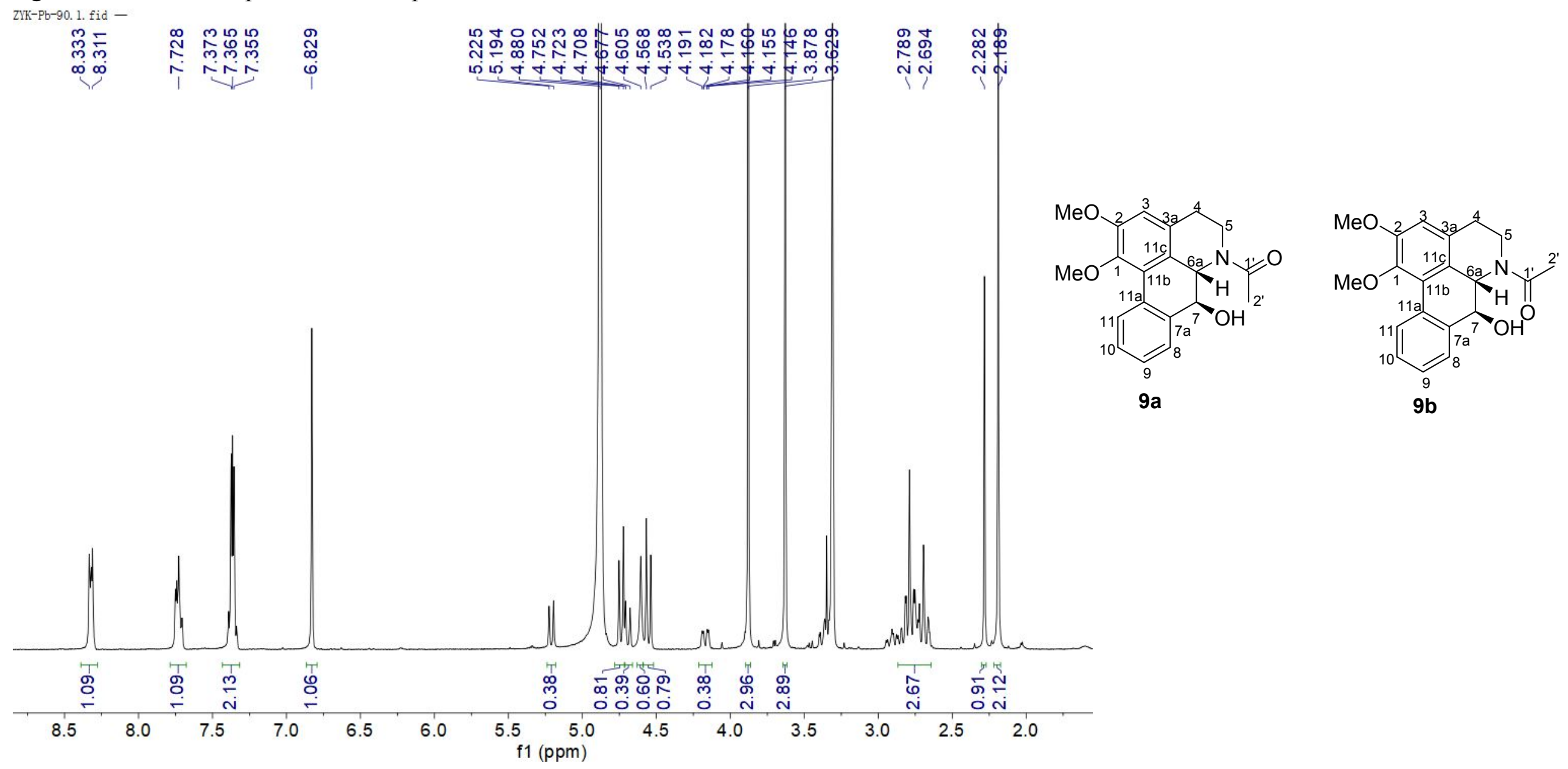


Figure S72. ${ }^{13} \mathrm{C}$ NMR Spectrum of Compound 9 in $\mathrm{MeOH}-d_{4}$ ZTK-Pb-90. 2. fid -

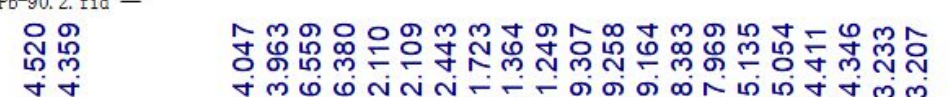

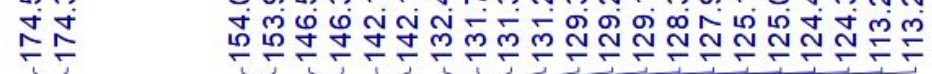

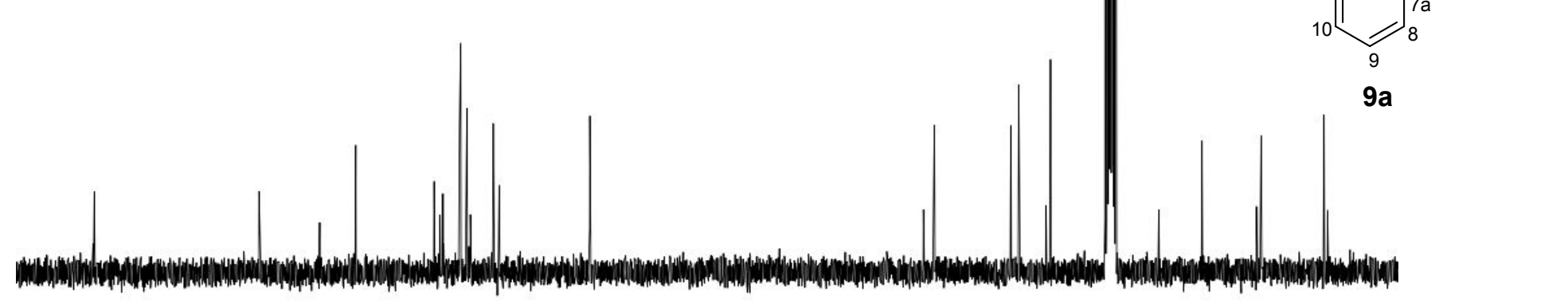

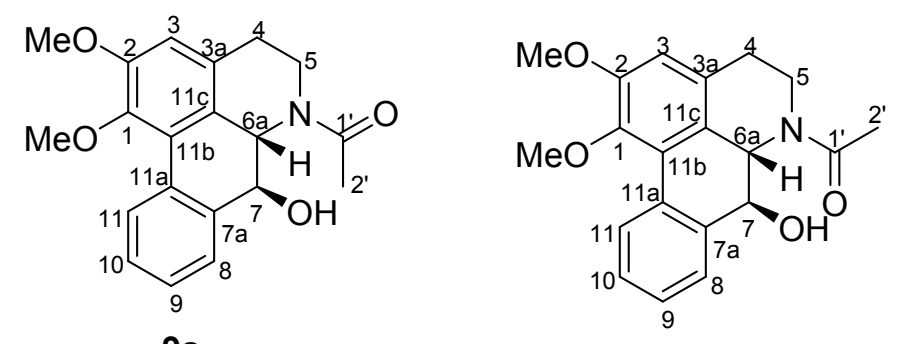

$9 b$

180

150

$40 \quad 130$

10100

90

70

60

$50 \quad 40$ 
Figure S73. ${ }^{1} \mathrm{H}-{ }^{1} \mathrm{H}$ COSY Spectrum of Compound 9 in $\mathrm{MeOH}-d_{4}$ ZTK-Pt-90. 4. ser -
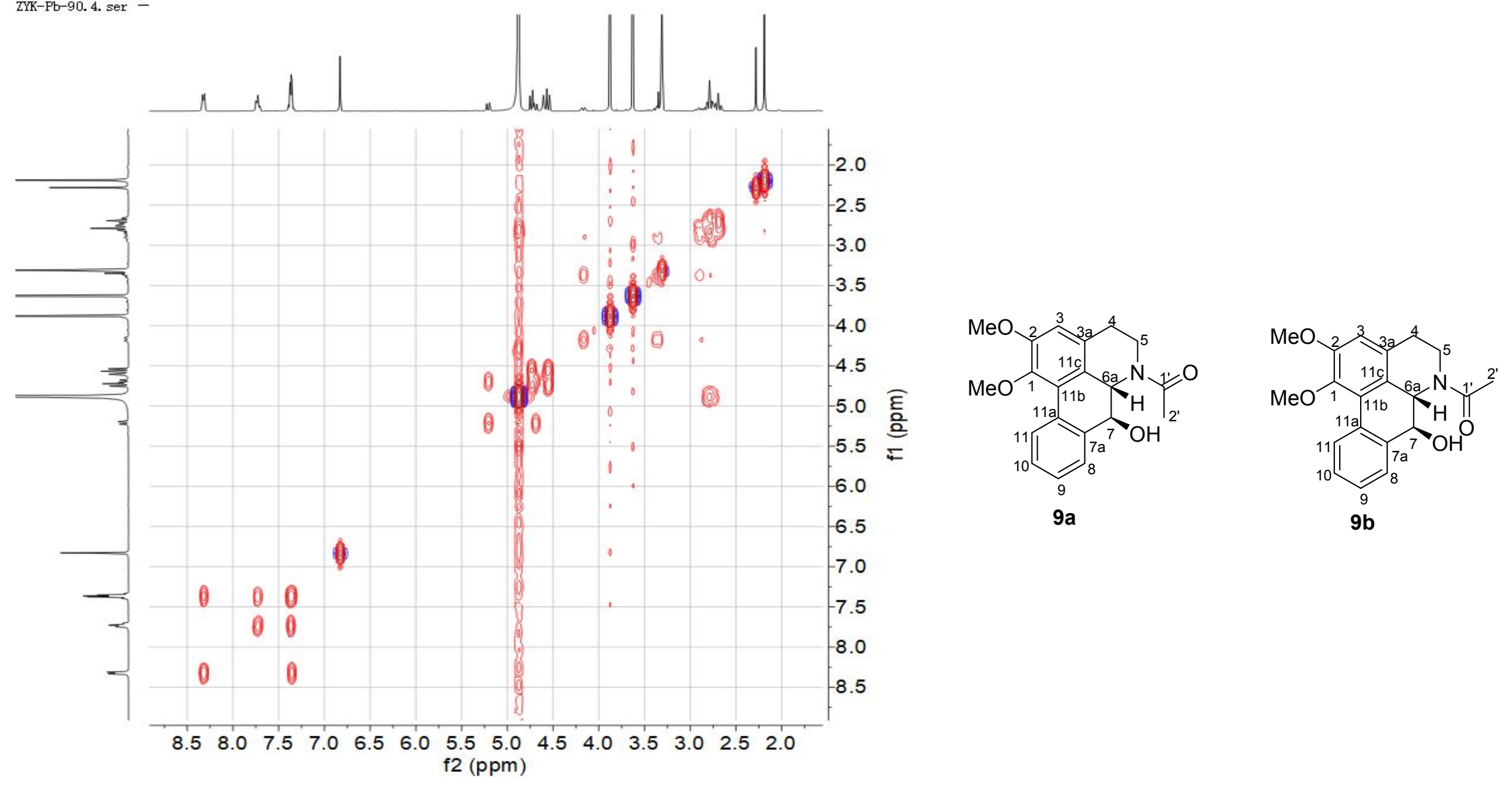
Figure S74. HSQC Spectrum of Compound 9 in $\mathrm{MeOH}-d_{4}$ zJK-Pb-90.5. ser -
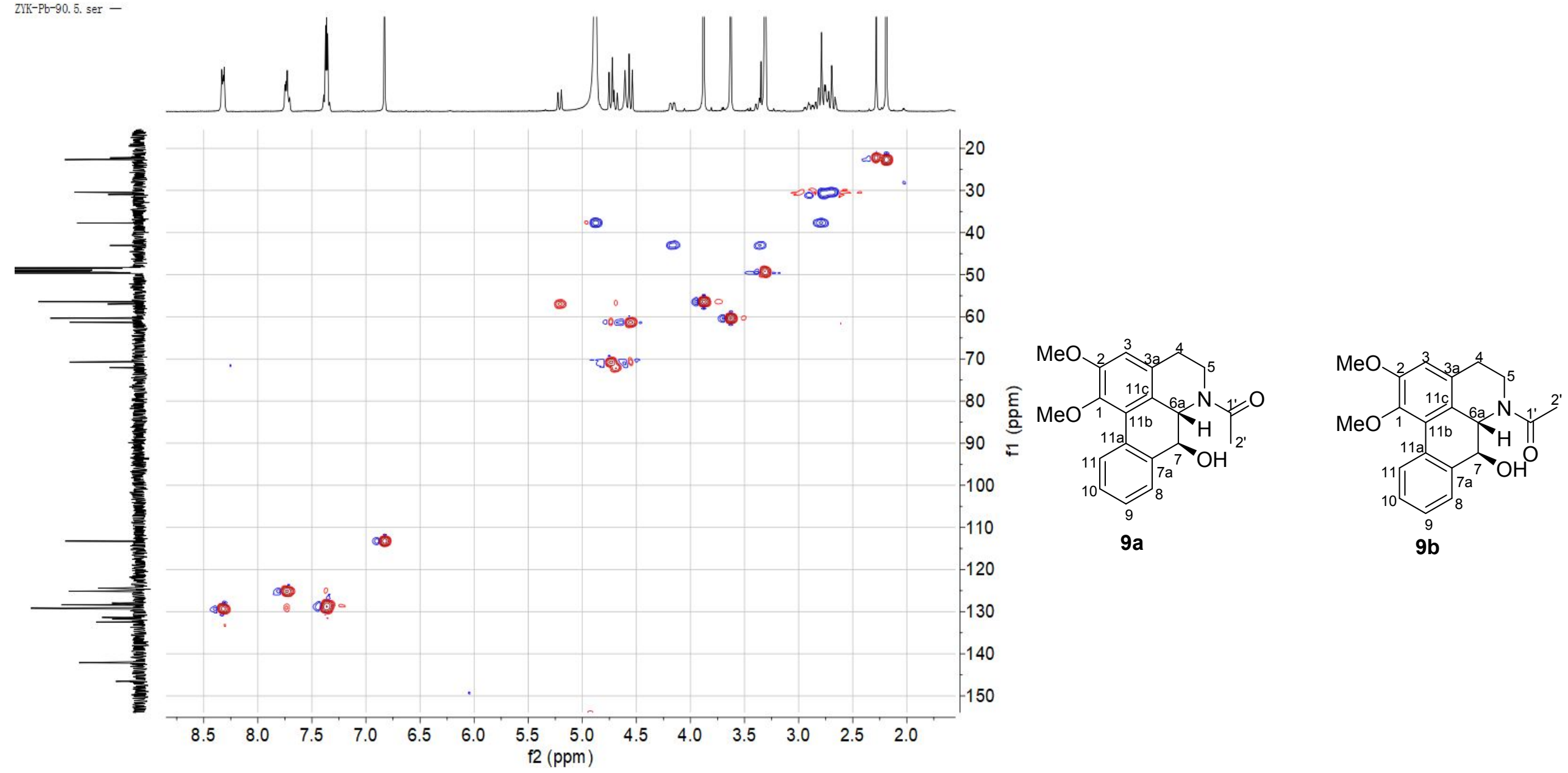
Figure S75. HMBCSpectrum of Compound 9 in $\mathrm{MeOH}-d_{4}$ Z7K-Pb-90. 6. ser -
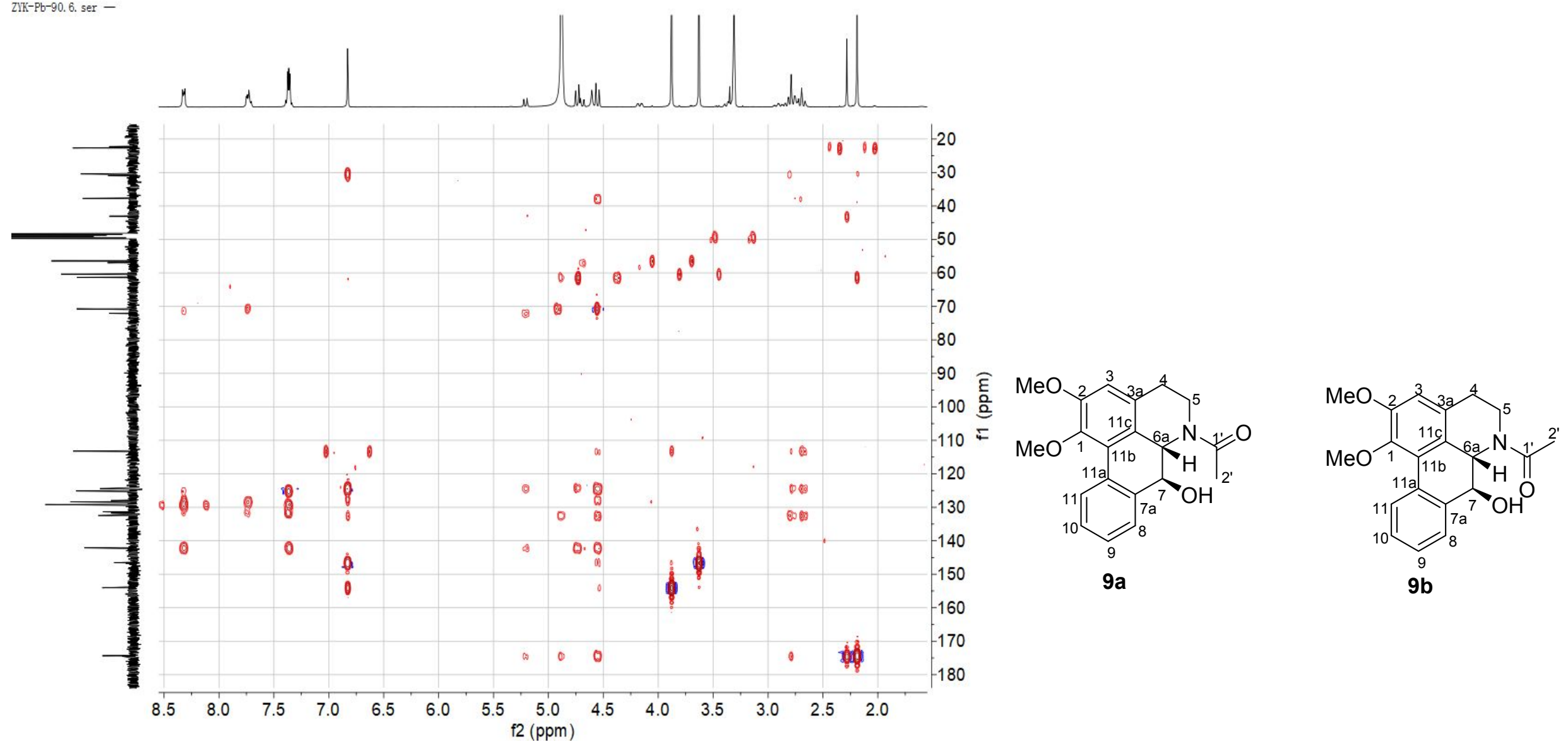
Figure S76. NOESY Spectrum of Compound 9 in $\mathrm{MeOH}-d_{4}$ TYK-Pb-90. 7. ser -

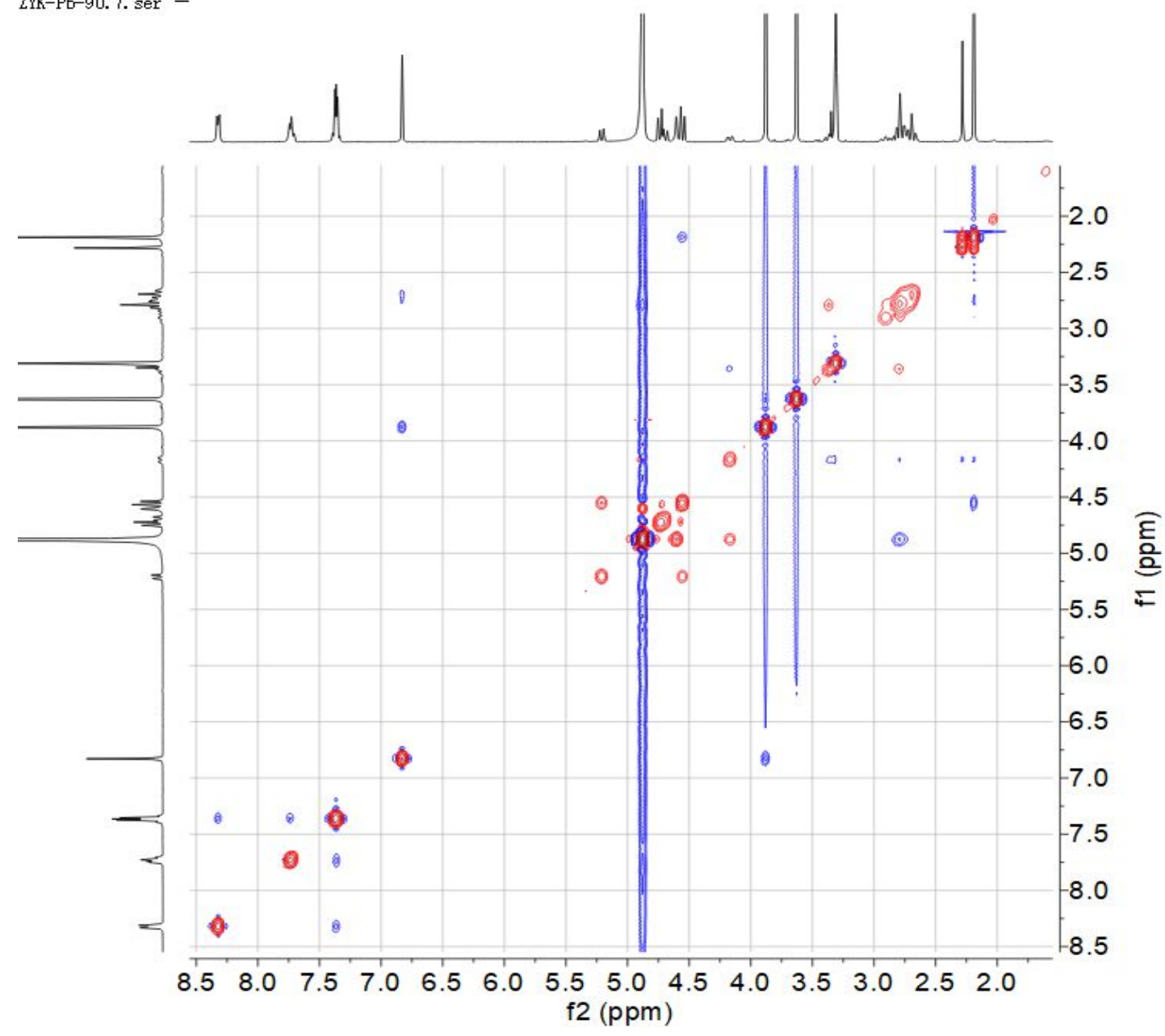

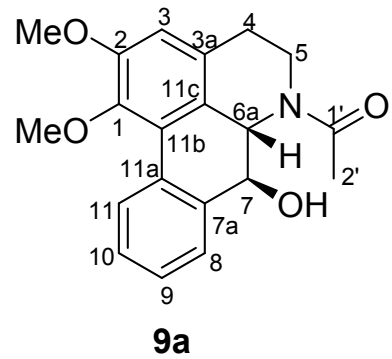

$9 a$

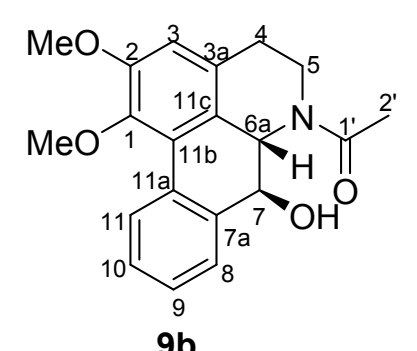


Figure S77. (+) HRESIMS Spectrum of Compound 9

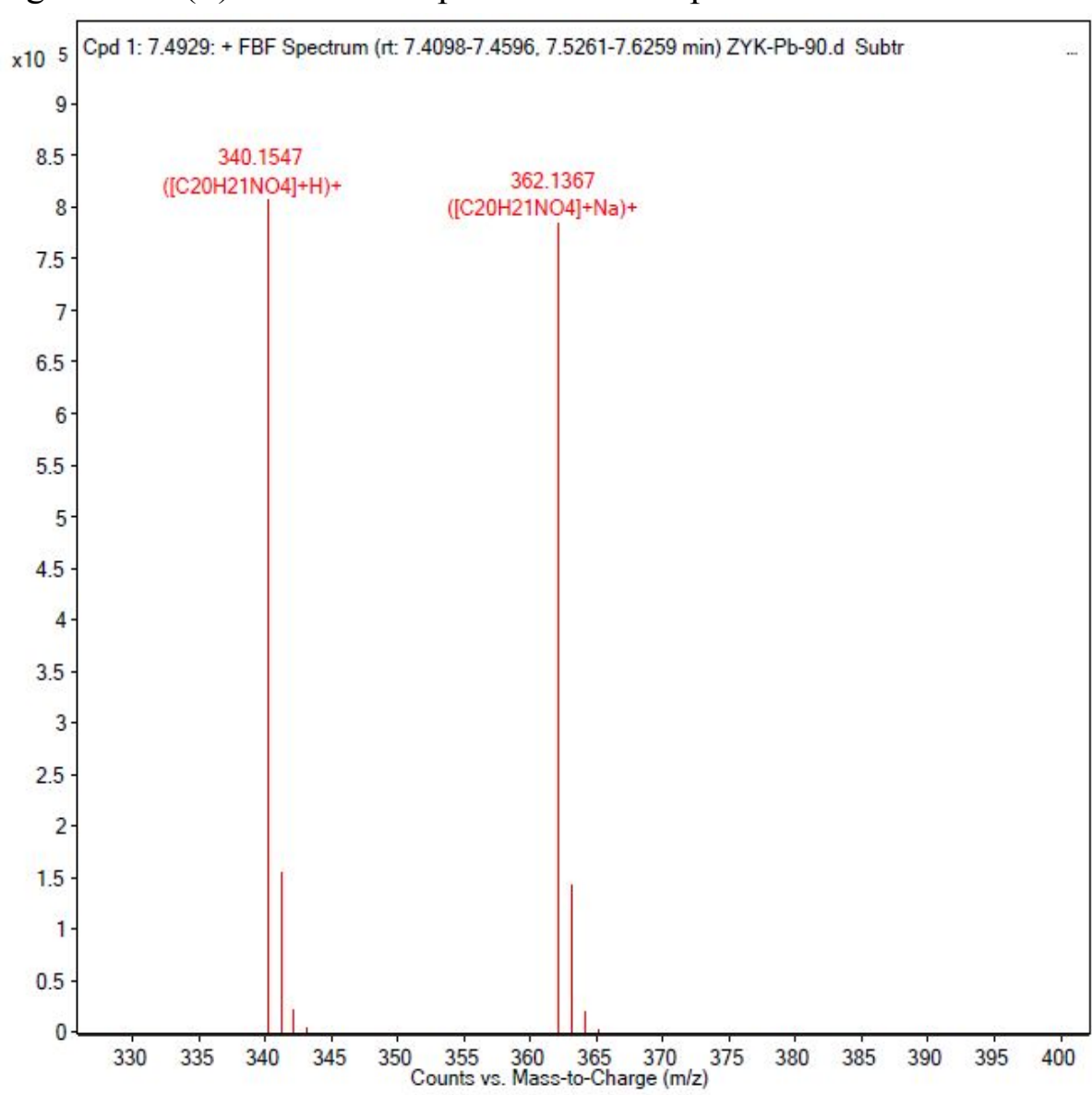

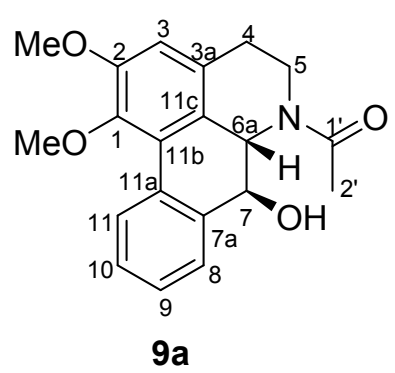

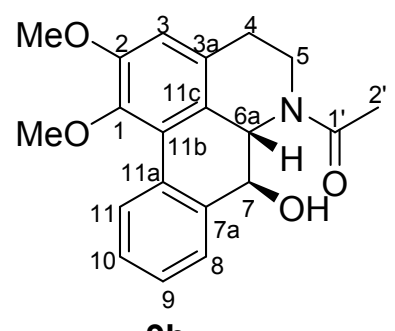


Figure S78. UV Spectrum of Compound 9
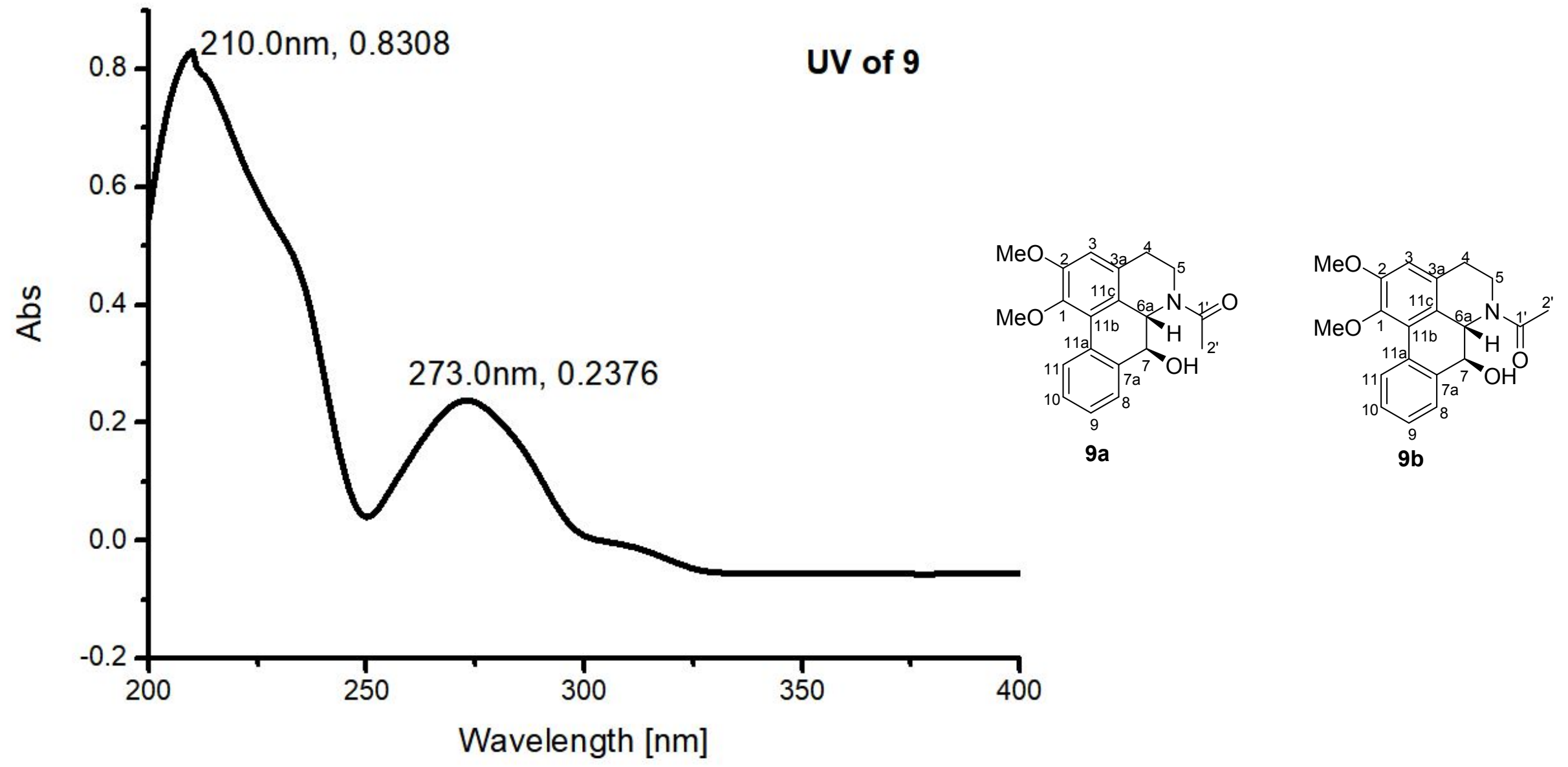
Figure S89. IR (KBr disc) Spectrum of Compound 9
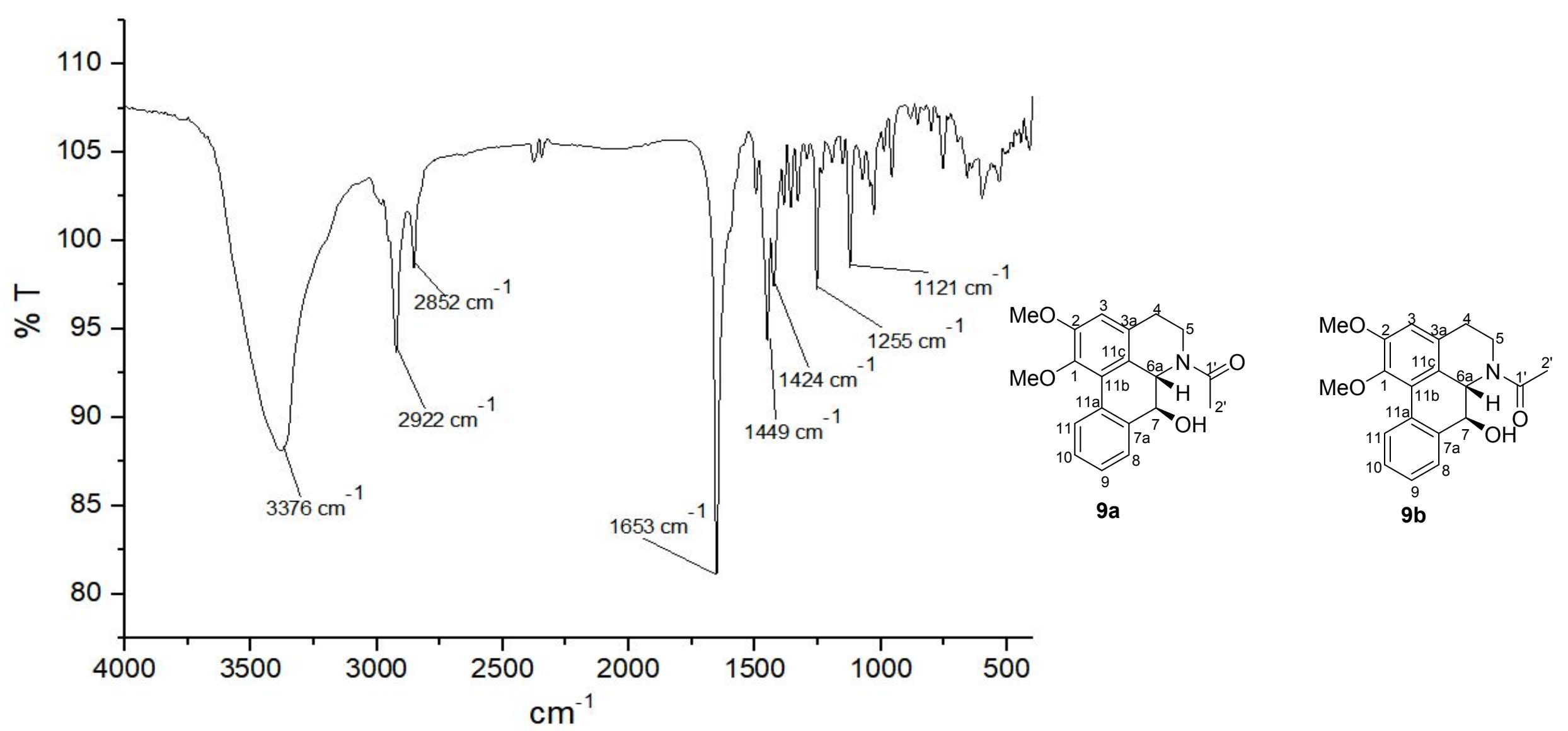
Figure S80. ECD Spectrum of 9

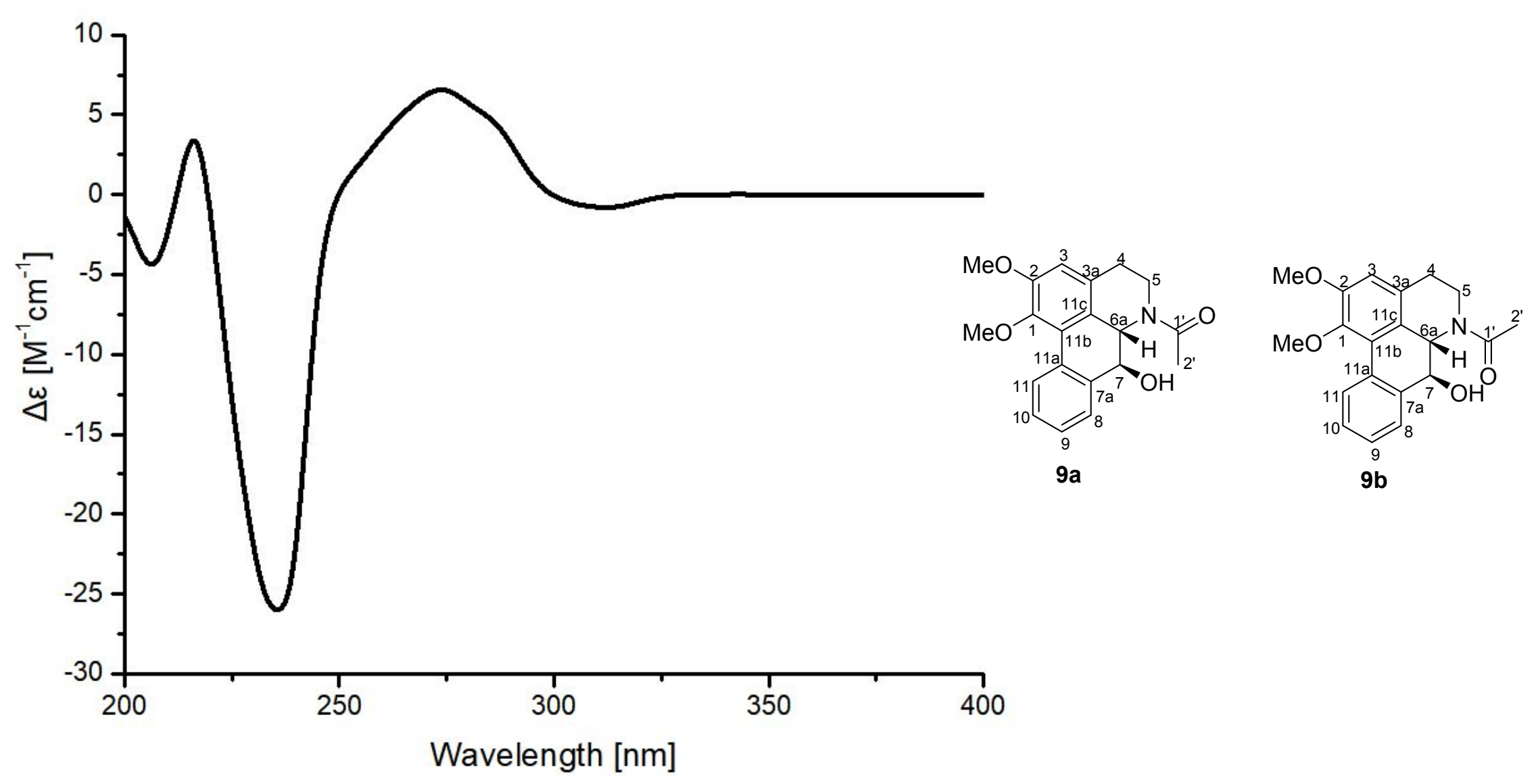


Figure S81. ${ }^{1} \mathrm{H}$ NMR Spectrum of Compound $\mathbf{1 0}$ in $\mathrm{MeOH}-d_{4}$

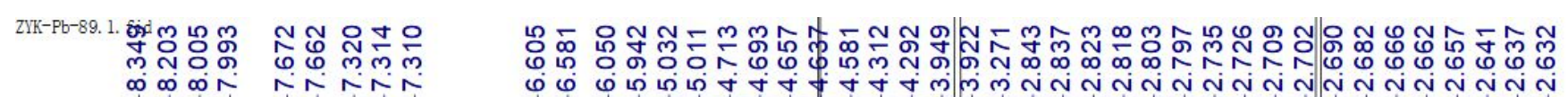

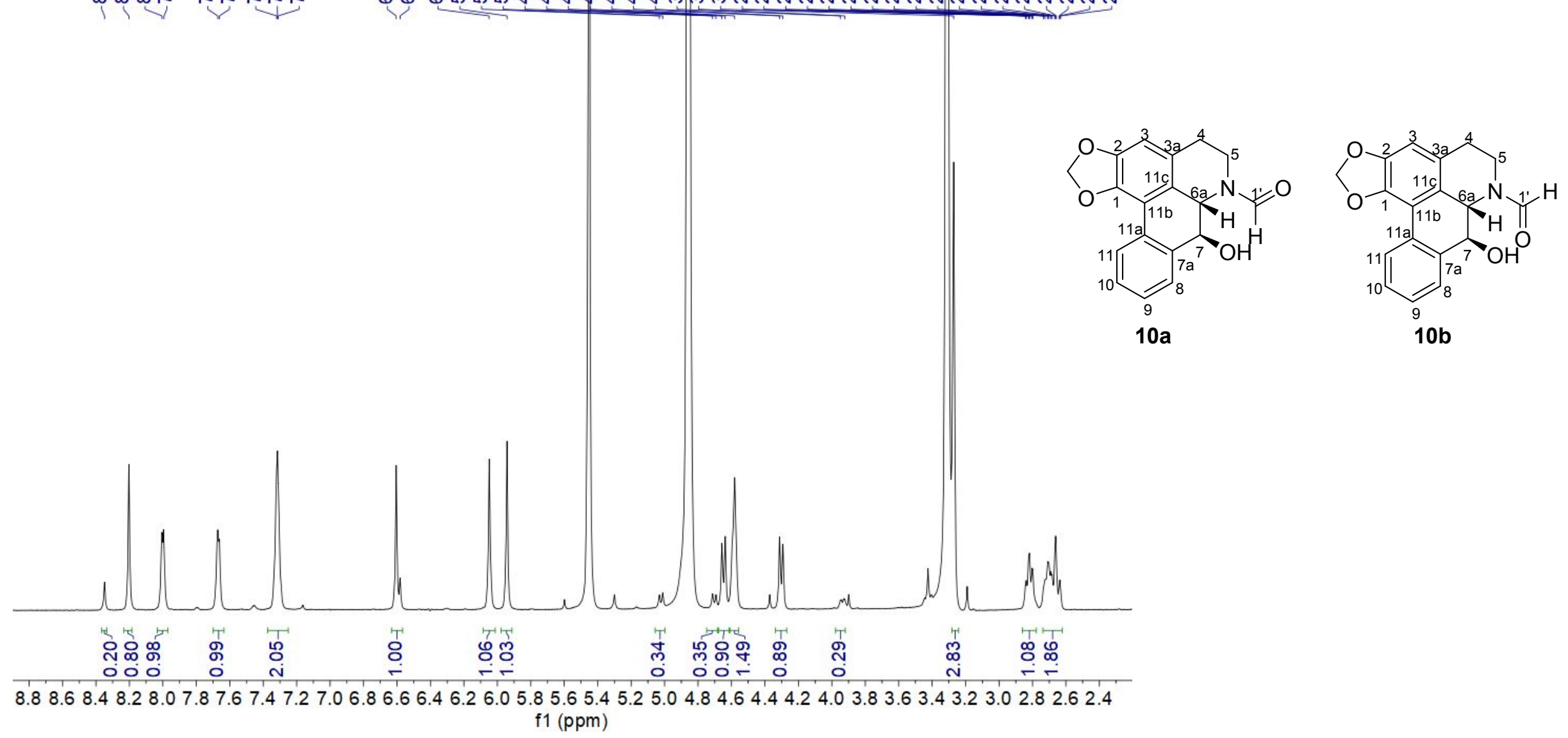


Figure S82. ${ }^{13} \mathrm{C}$ NMR Spectrum of Compound $\mathbf{1 0}$ in $\mathrm{MeOH}-d_{4}$

ZTK-Pb-89.

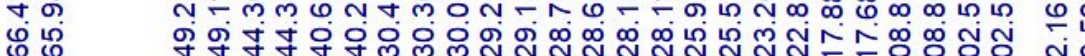

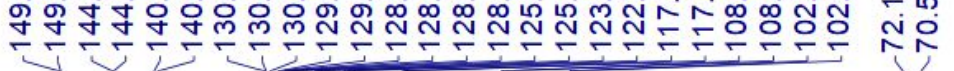
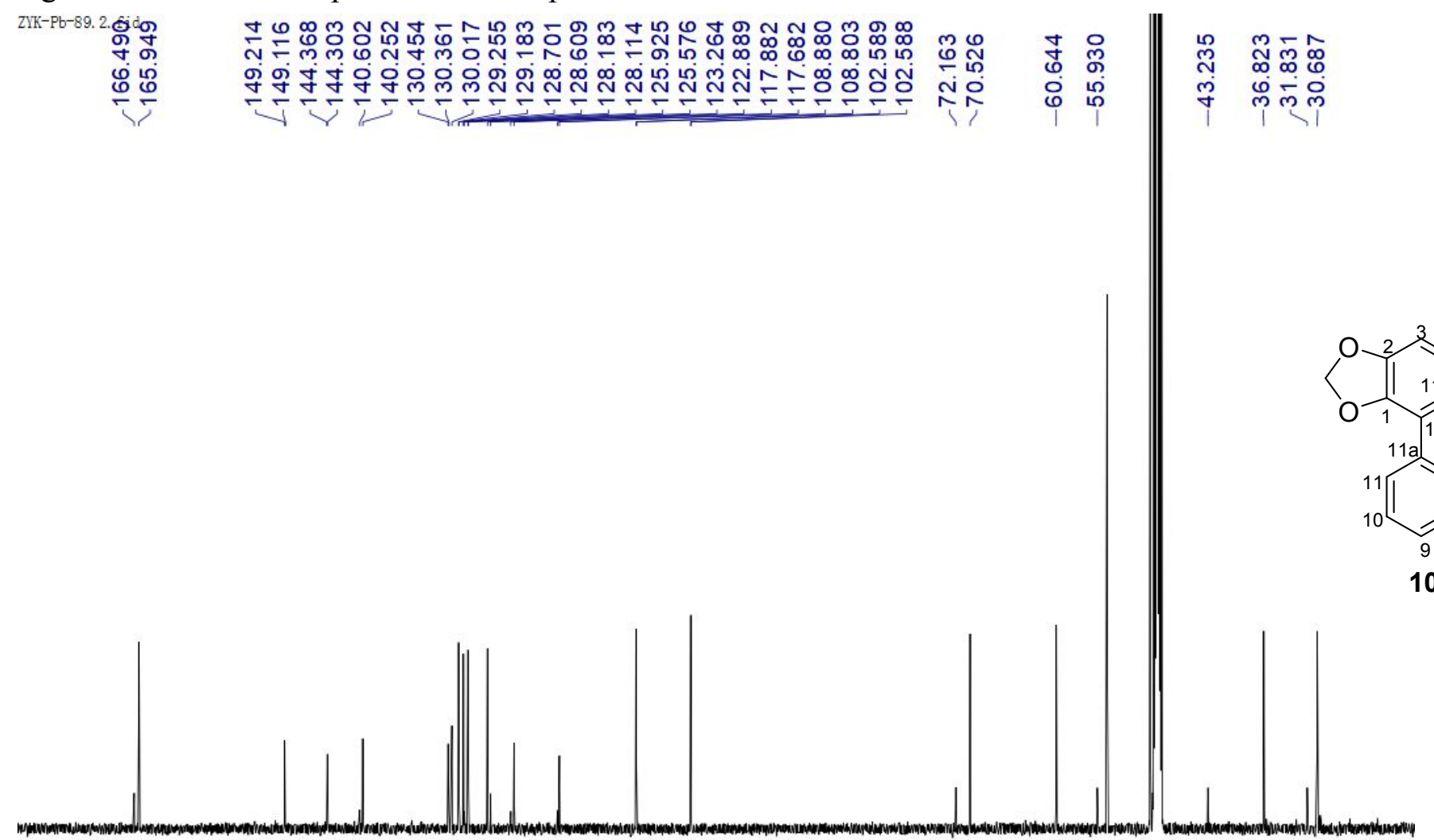

$170 \quad 160$

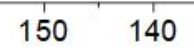

$130 \quad 120$

$110 \quad 100$ 100
f1 $(\mathrm{ppm})$

70

60

50

40

$30 \quad 21$ 
Figure S83. ${ }^{1} \mathrm{H}-{ }^{1} \mathrm{H}$ COSY Spectrum of Compound $\mathbf{1 0}$ in $\mathrm{MeOH}-d_{4}$

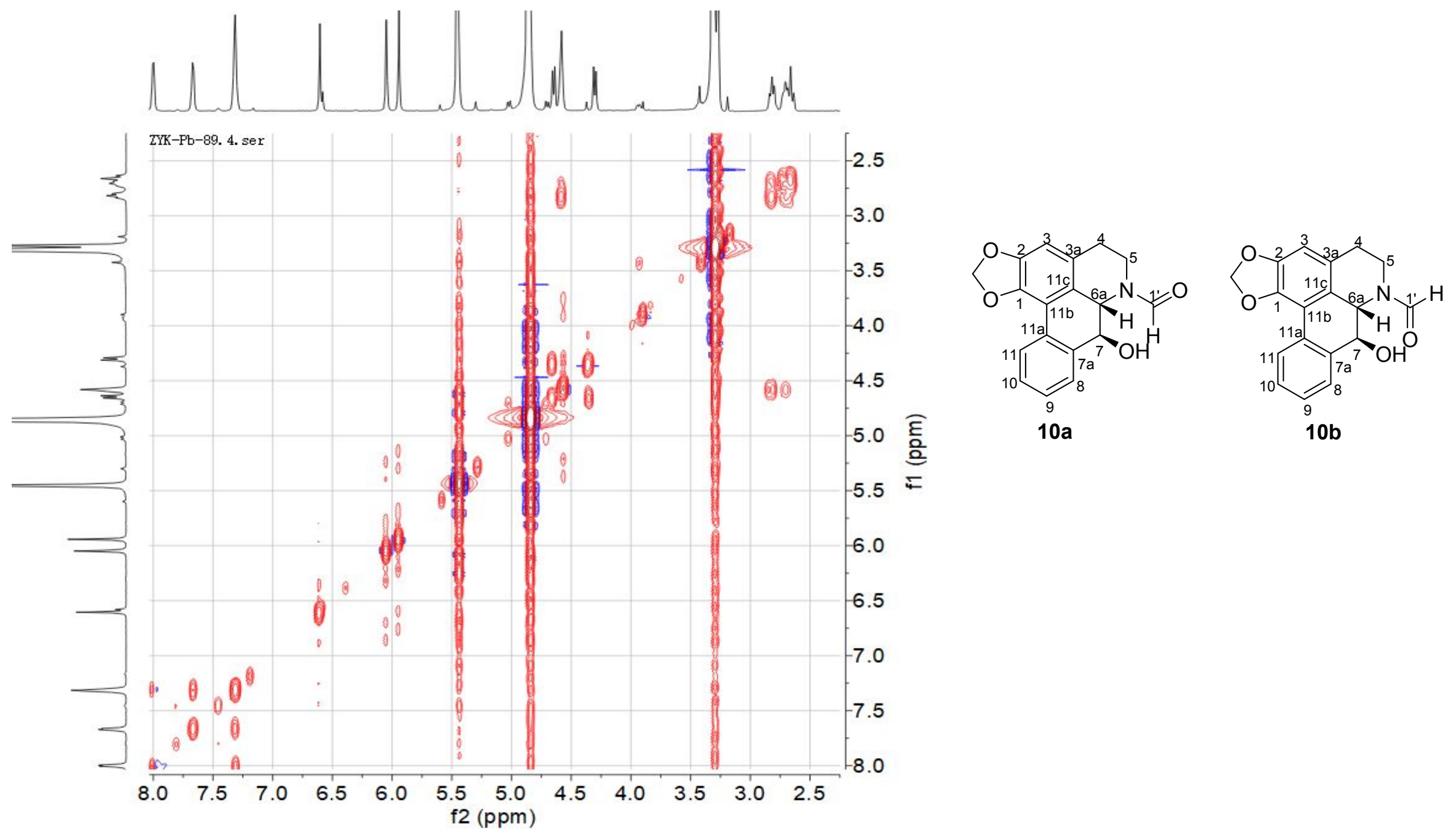


Figure S84. HSQC Spectrum of Compound $\mathbf{1 0}$ in $\mathrm{MeOH}-d_{4}$

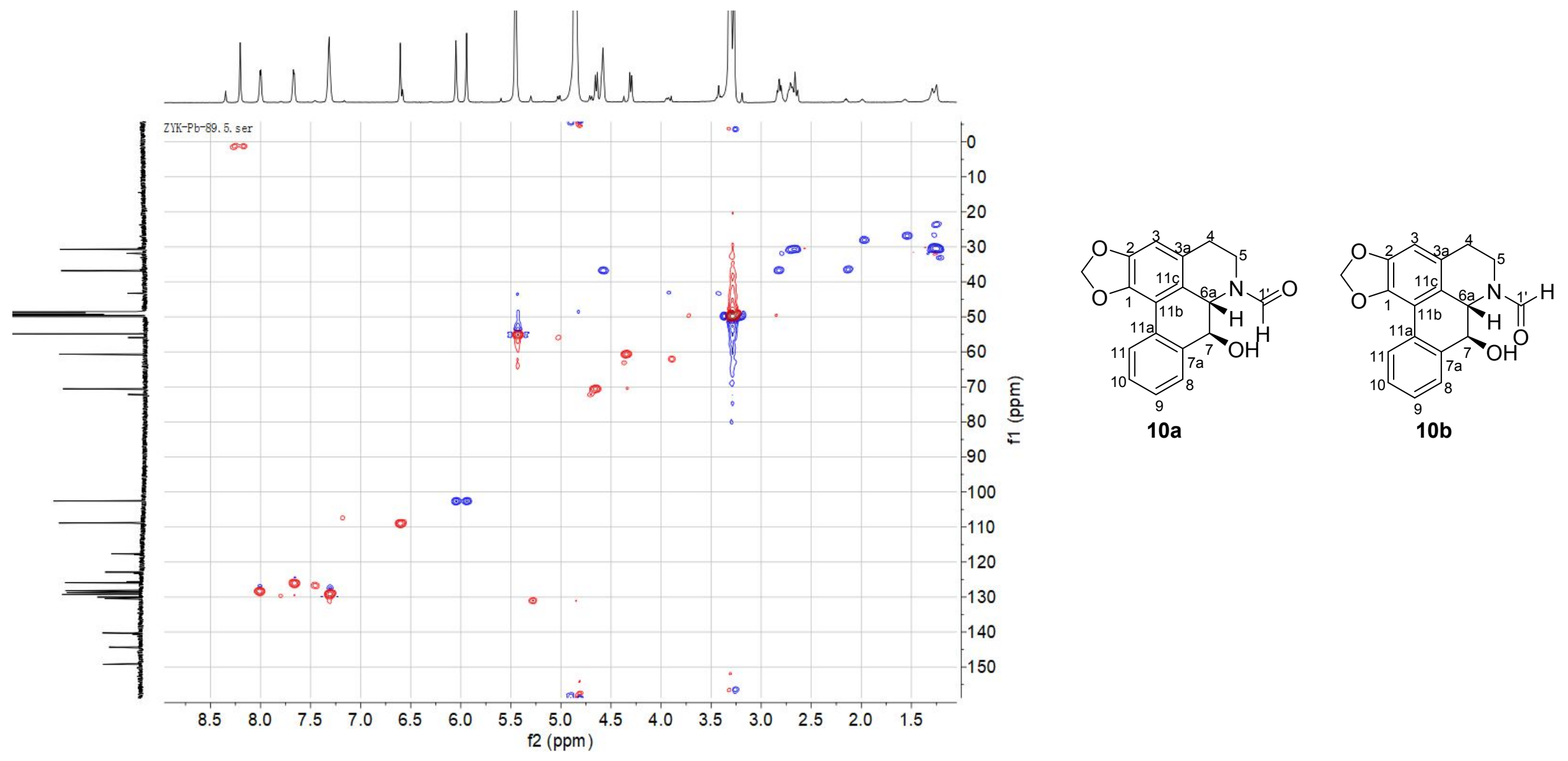


Figure S85. HMBC Spectrum of Compound $\mathbf{1 0}$ in $\mathrm{MeOH}-d_{4}$

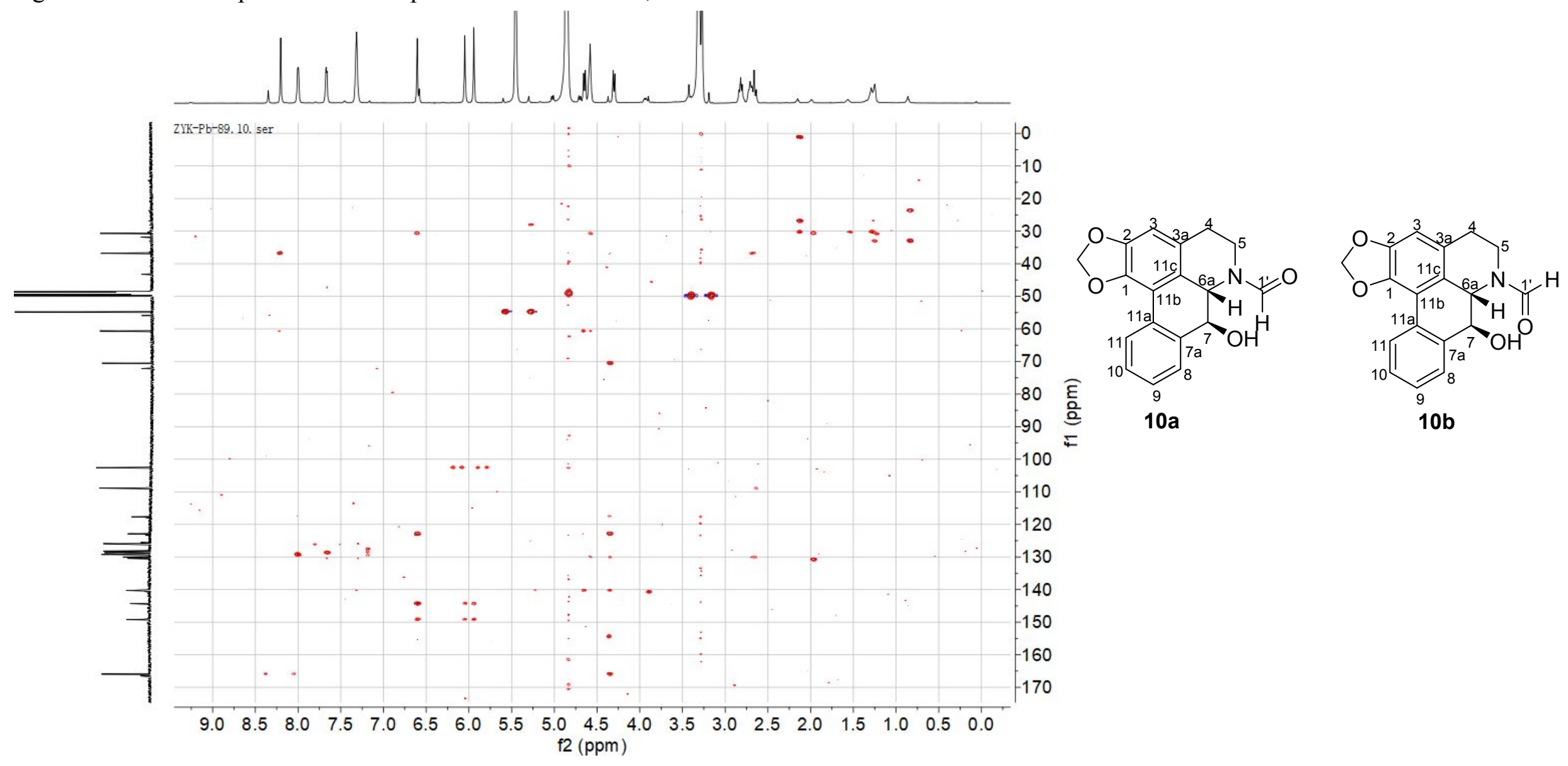


Figure S86. NOESY Spectrum of Compound $\mathbf{1 0}$ in $\mathrm{MeOH}-d_{4}$

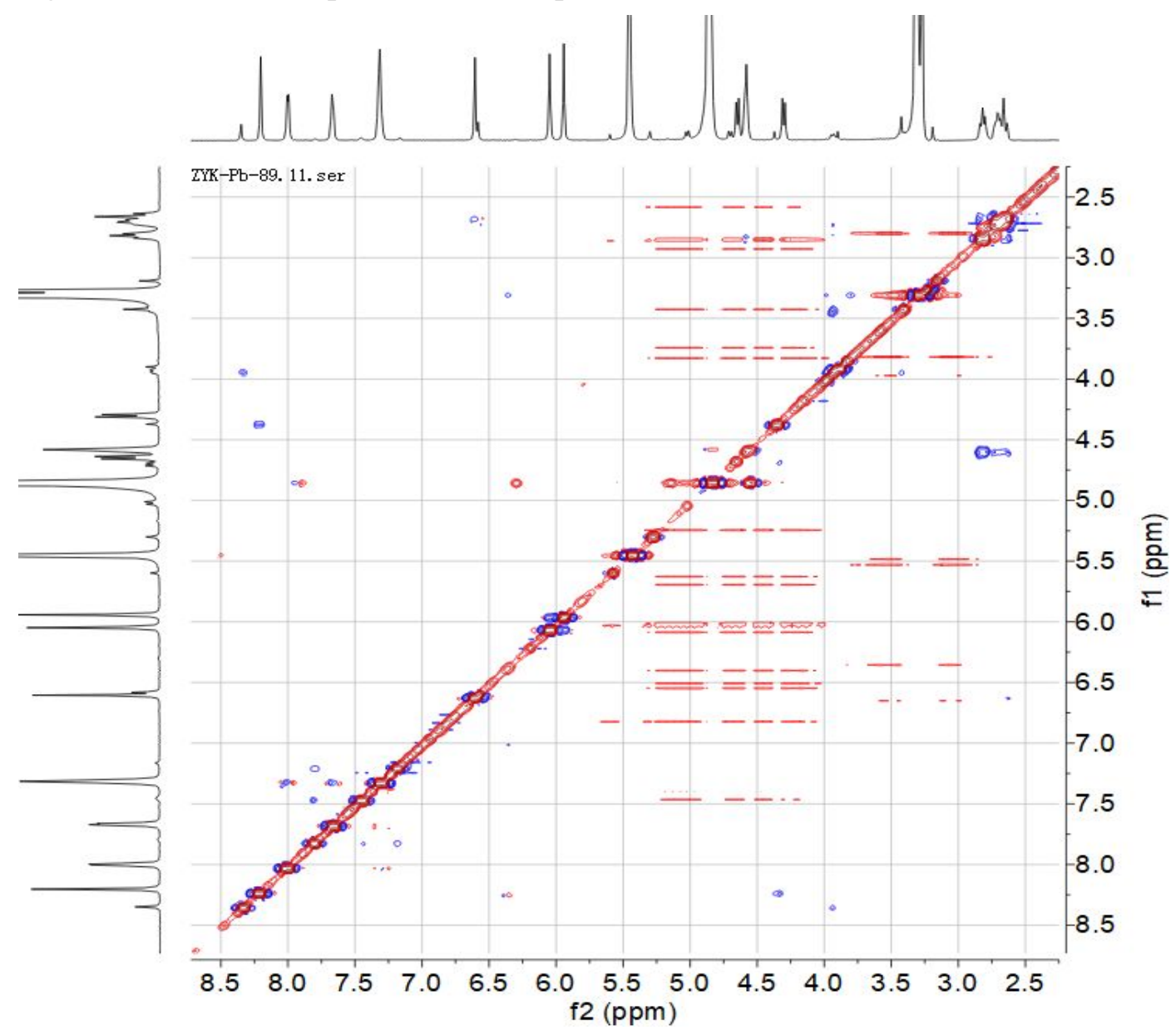

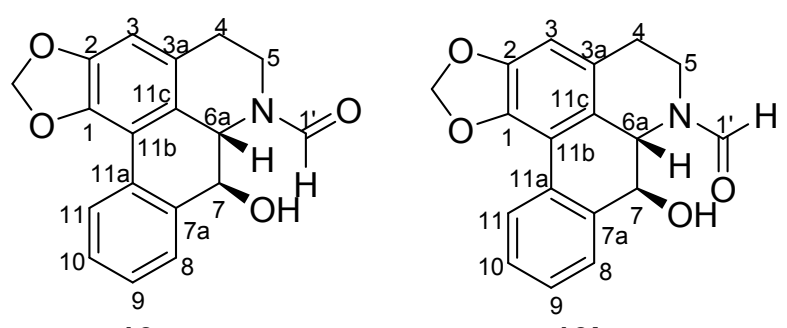

$10 a$
$10 \mathrm{~b}$ 
Figure S87. (+) HRESIMS Spectrum of Compound 10

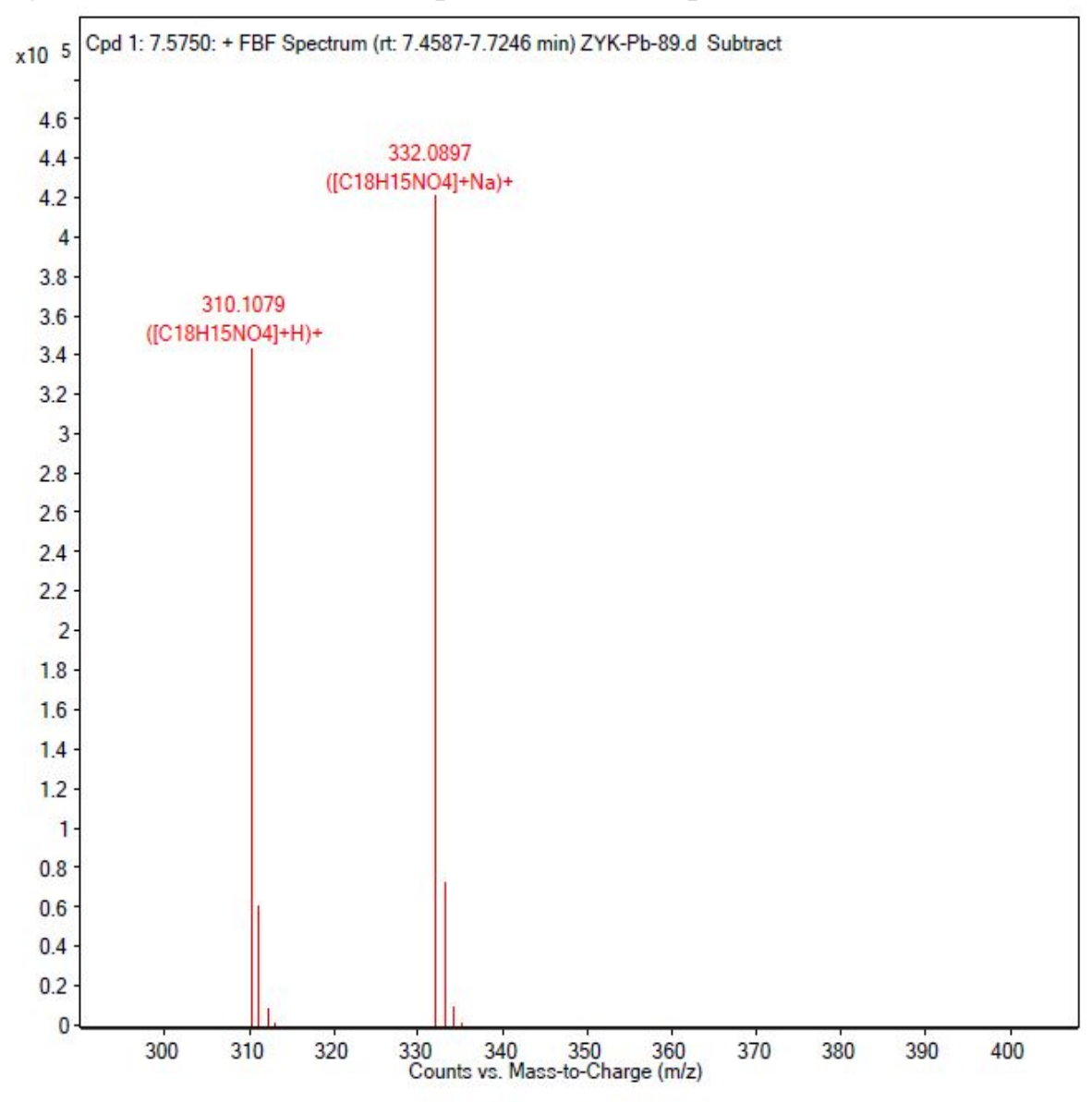

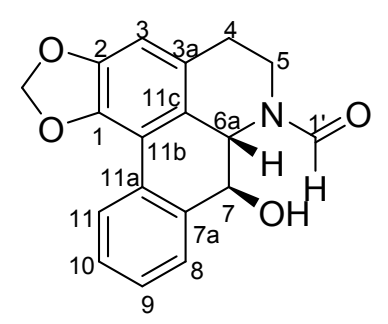

$10 a$

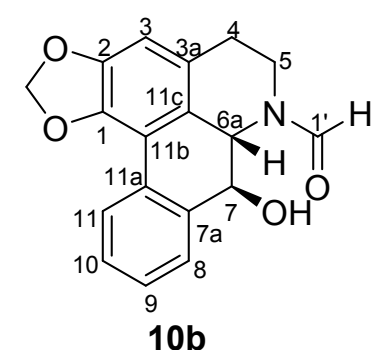

$10 \mathrm{~b}$ 
Figure S88. UV Spectrum of Compound 10

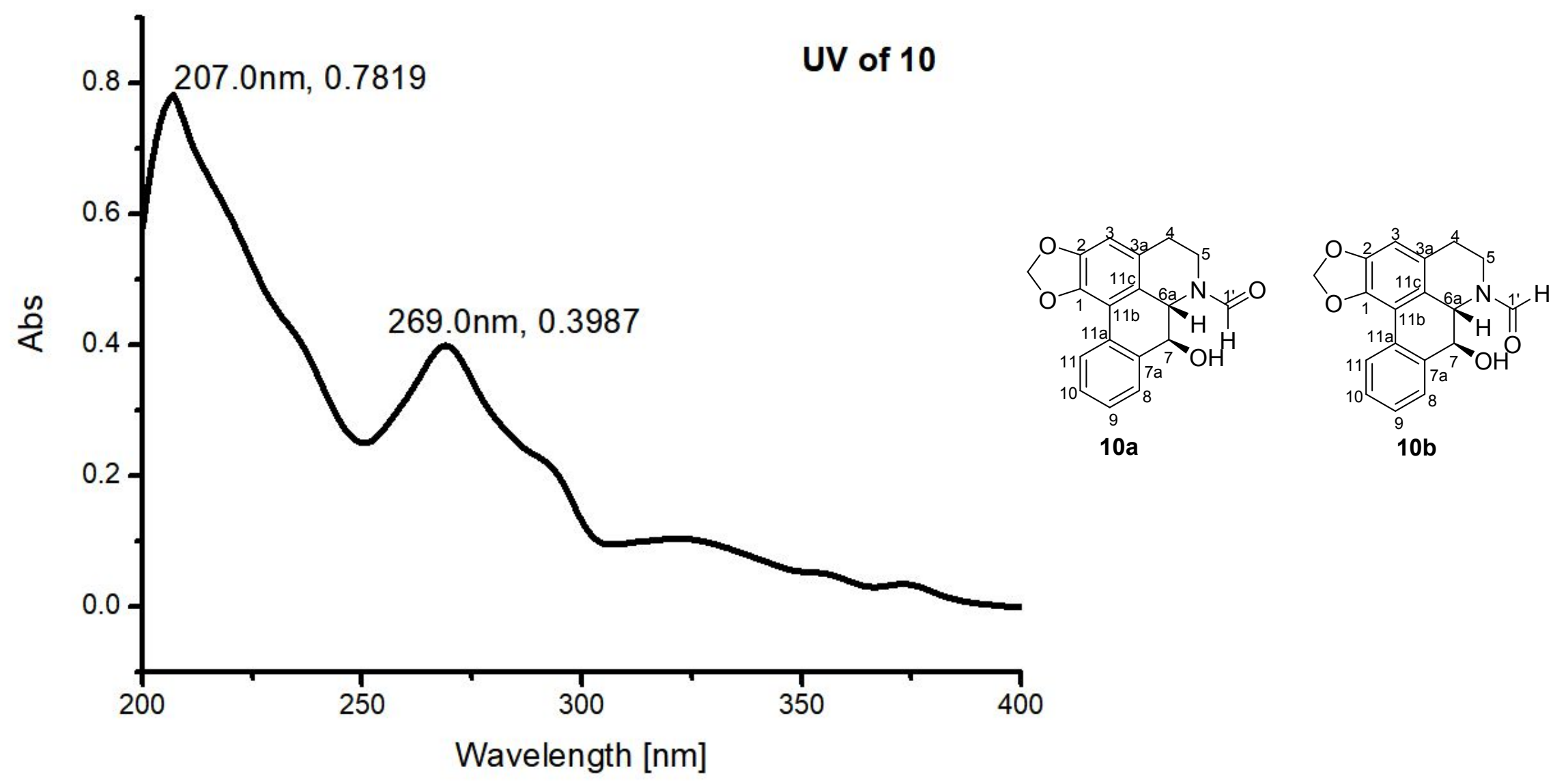


Figure S89. IR (KBr disc) Spectrum of Compound 10

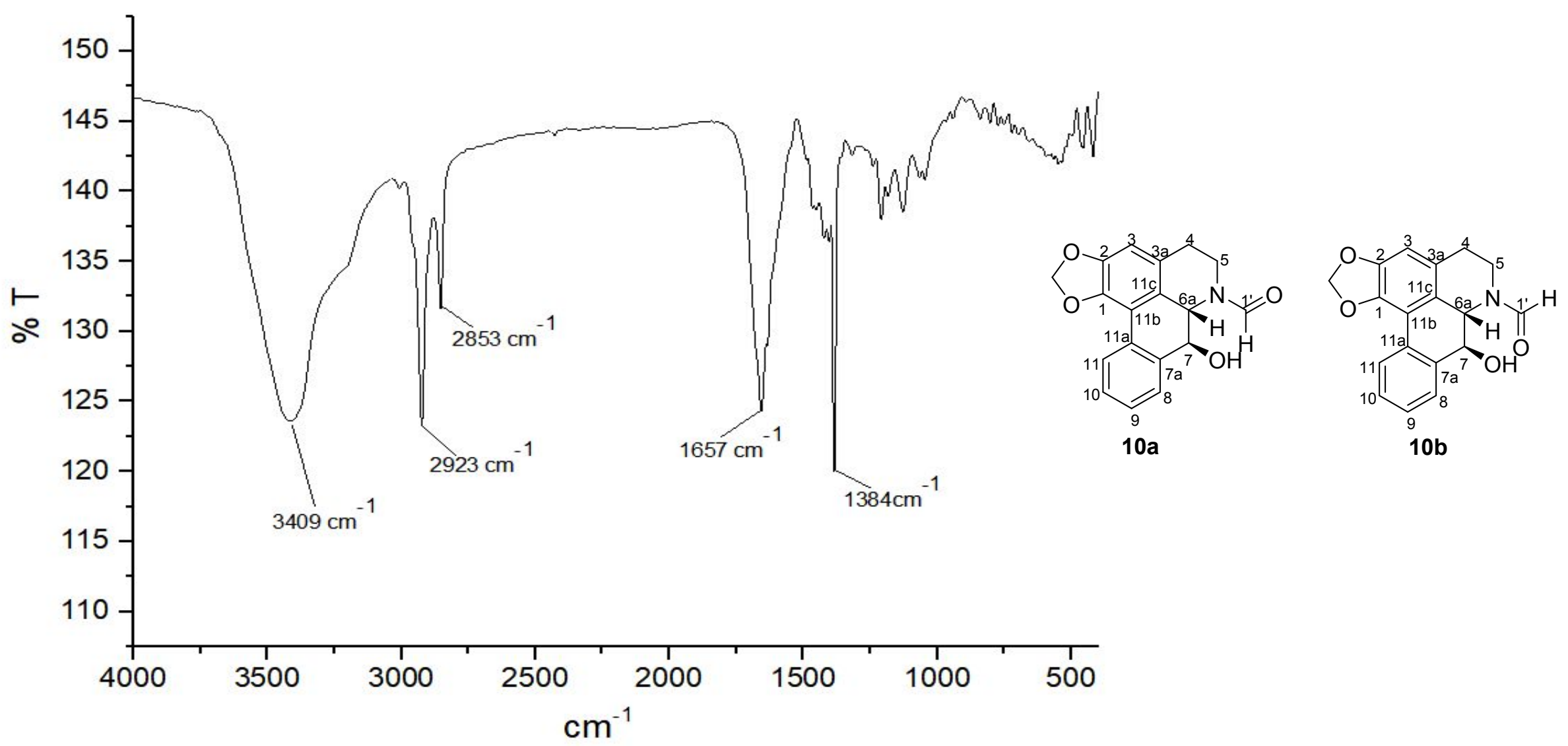


Figure S90. ECD Spectrum of $\mathbf{1 0}$

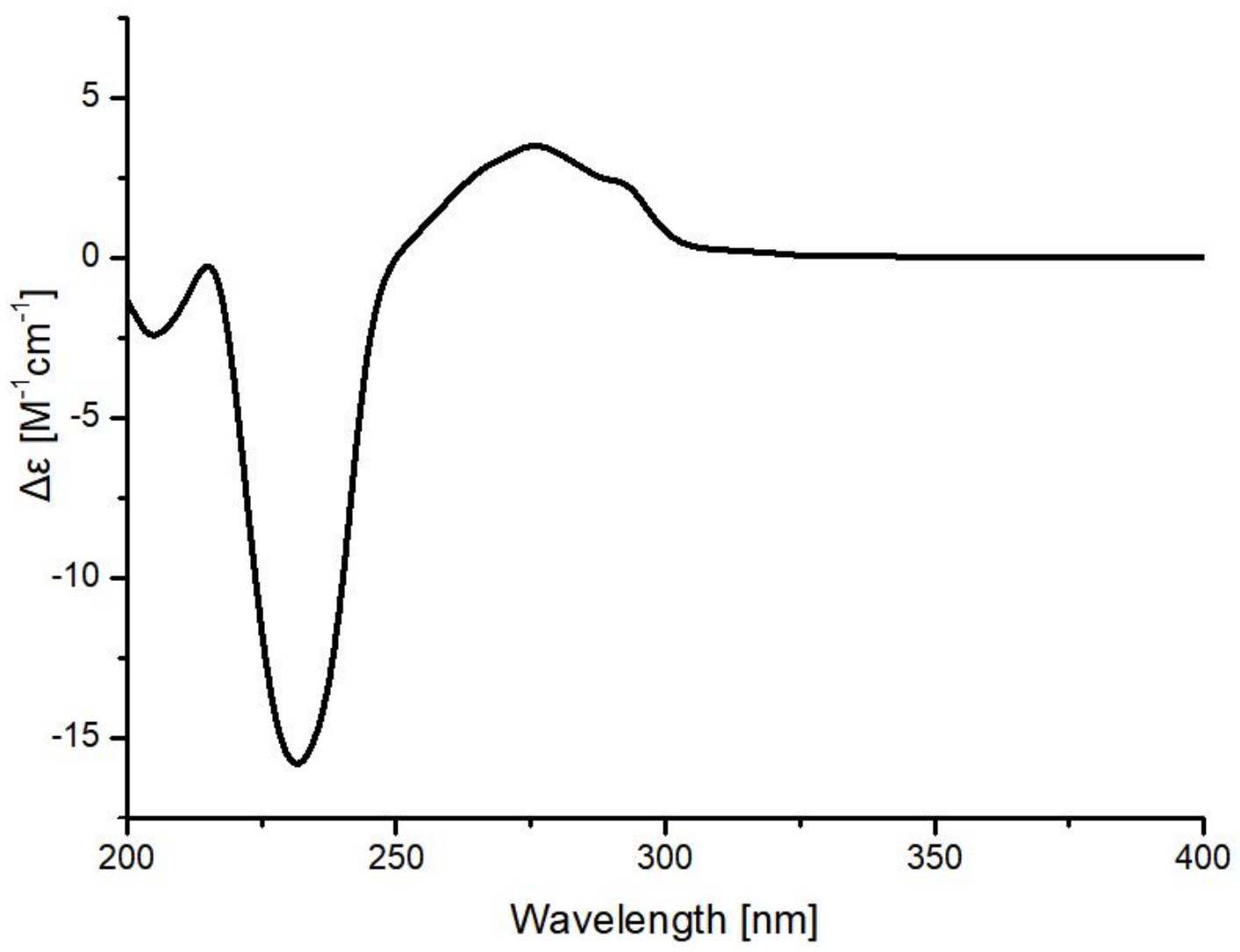

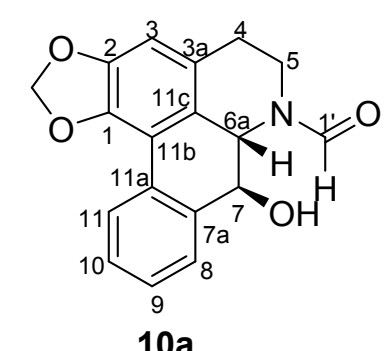

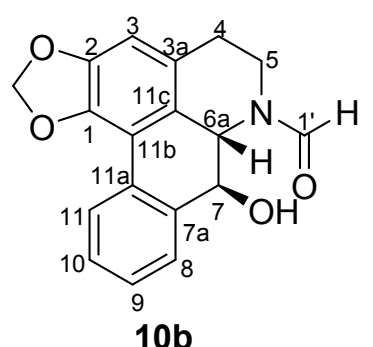


Figure S91. ${ }^{1} \mathrm{H}$ NMR Spectrum of Compound 11 in $\mathrm{CDCl}_{3}$

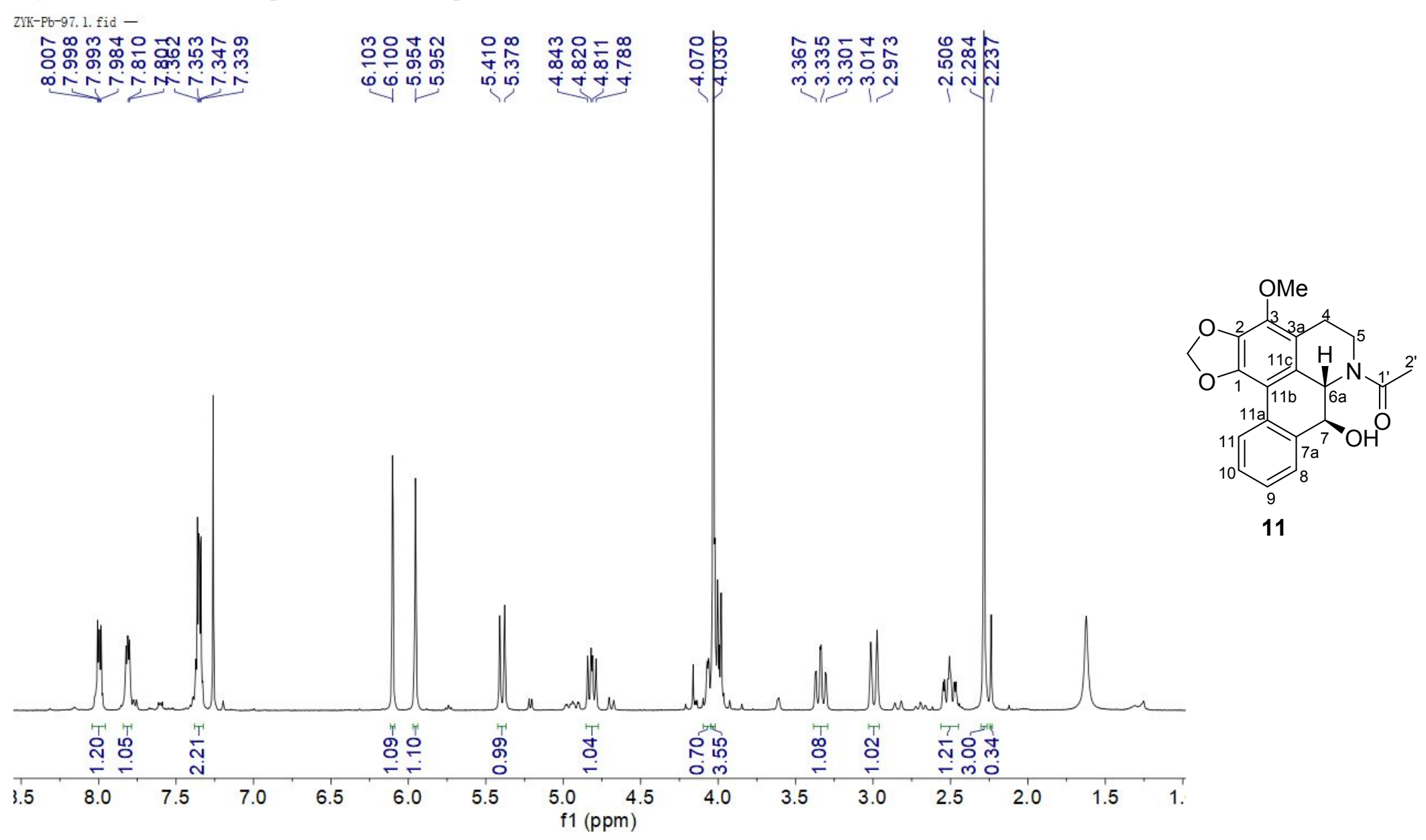


Figure S92. ${ }^{13} \mathrm{C}$ NMR Spectrum of Compound 11 in $\mathrm{CDCl}_{3}$
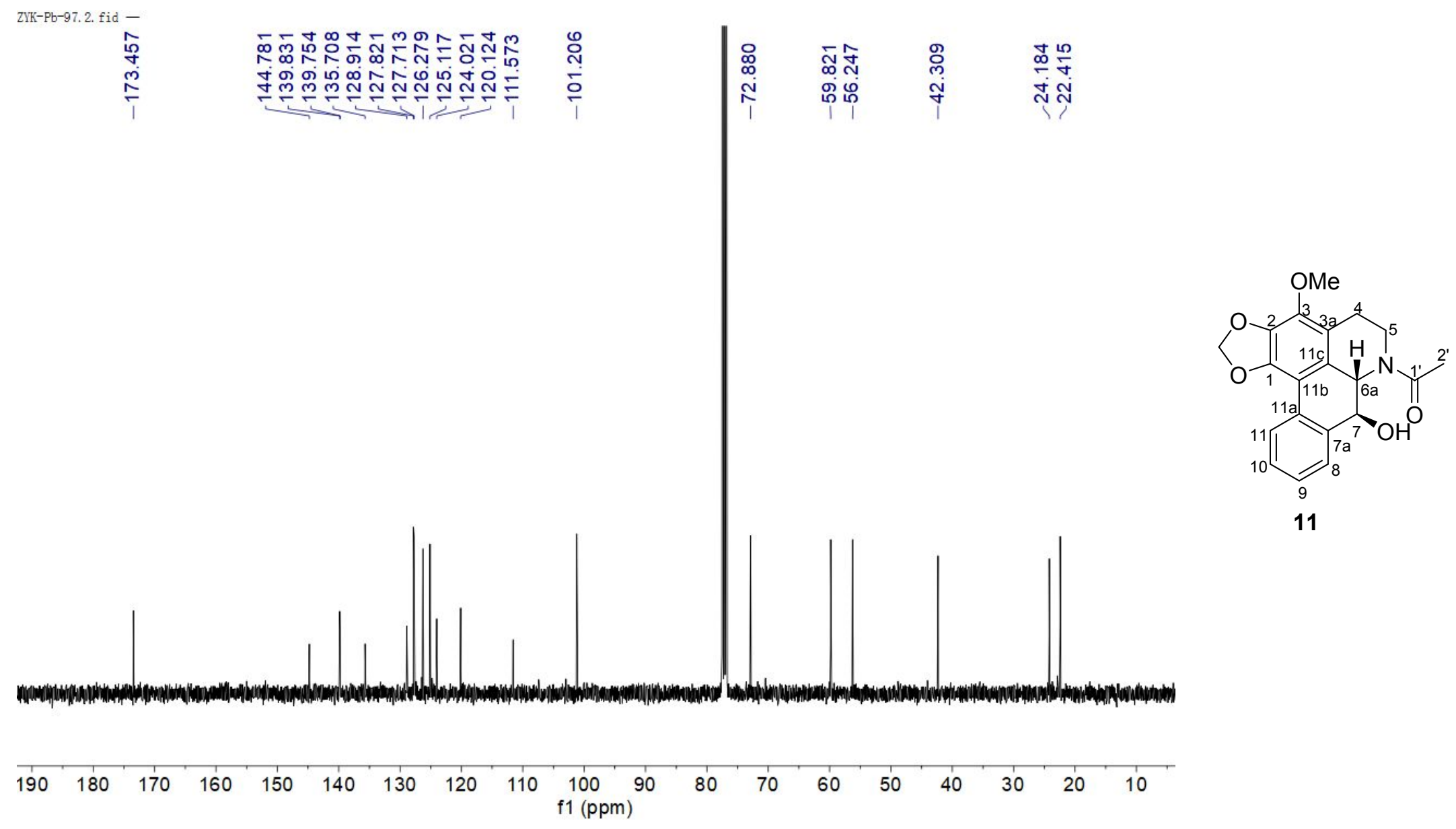
Figure S93. DEPT135 Spectrum of Compound 11 in $\mathrm{CDCl}_{3}$ ZTK-Pb-97. 3. . fic
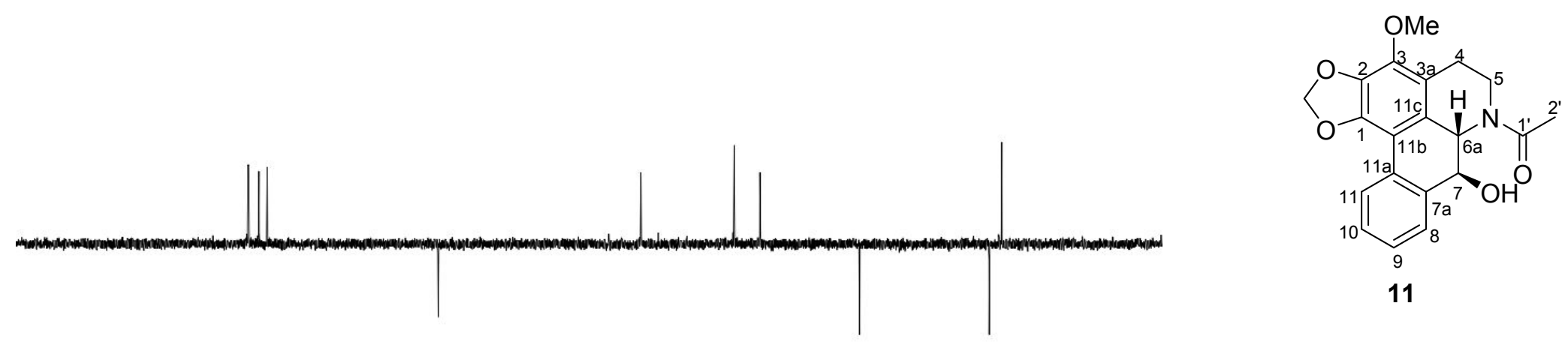

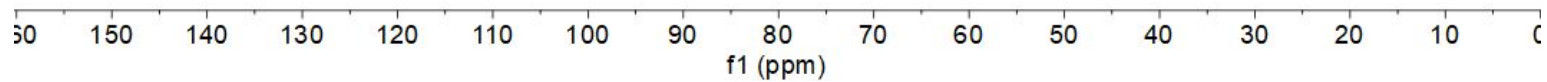


Figure S94. ${ }^{1} \mathrm{H}-{ }^{1} \mathrm{H}$ COSY Spectrum of Compound 11 in $\mathrm{CDCl}_{3}$ TYK-Ft-97. 5. ser -
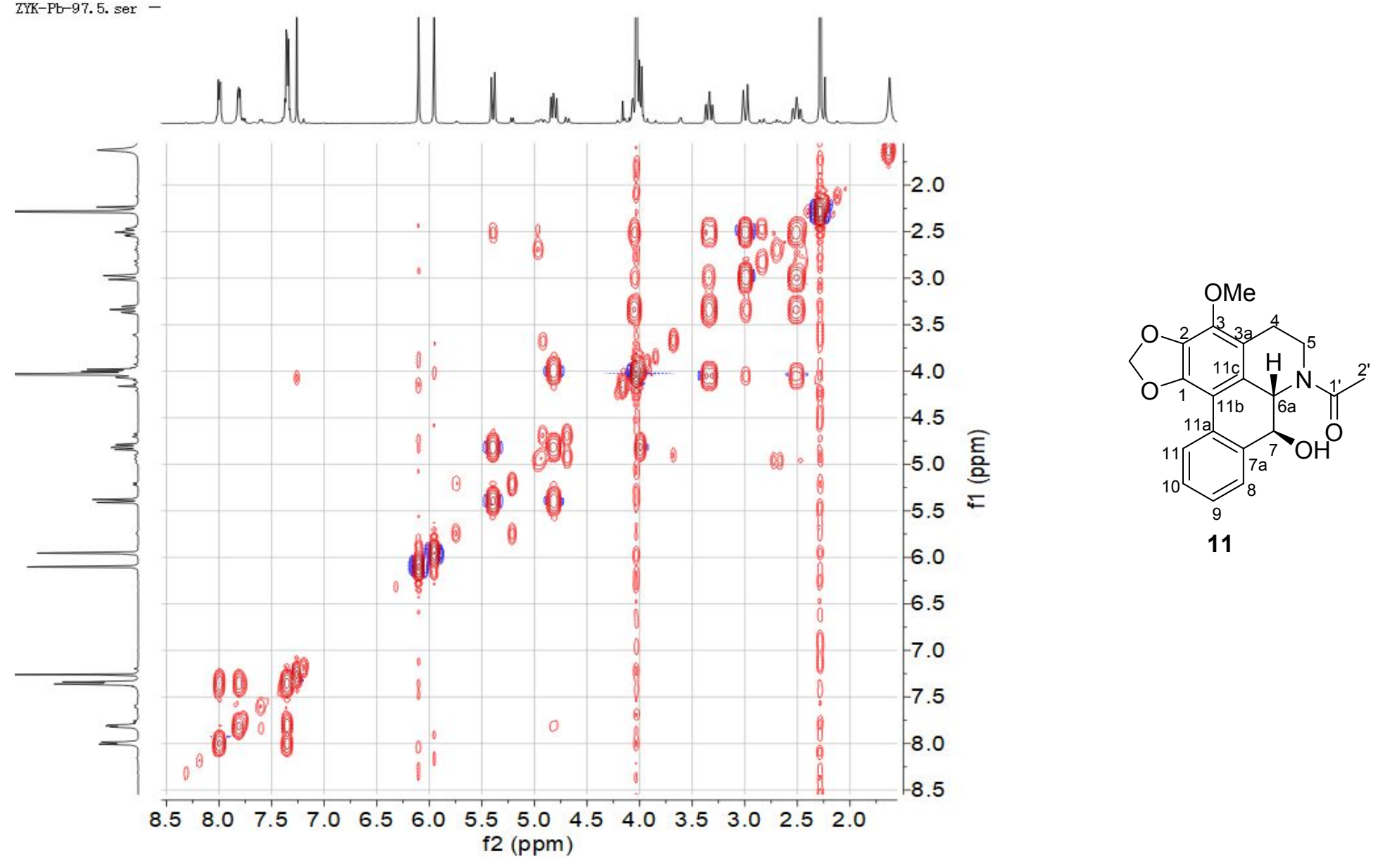
Figure S95. HSQC Spectrum of Compound 11 in $\mathrm{CDCl}_{3}$
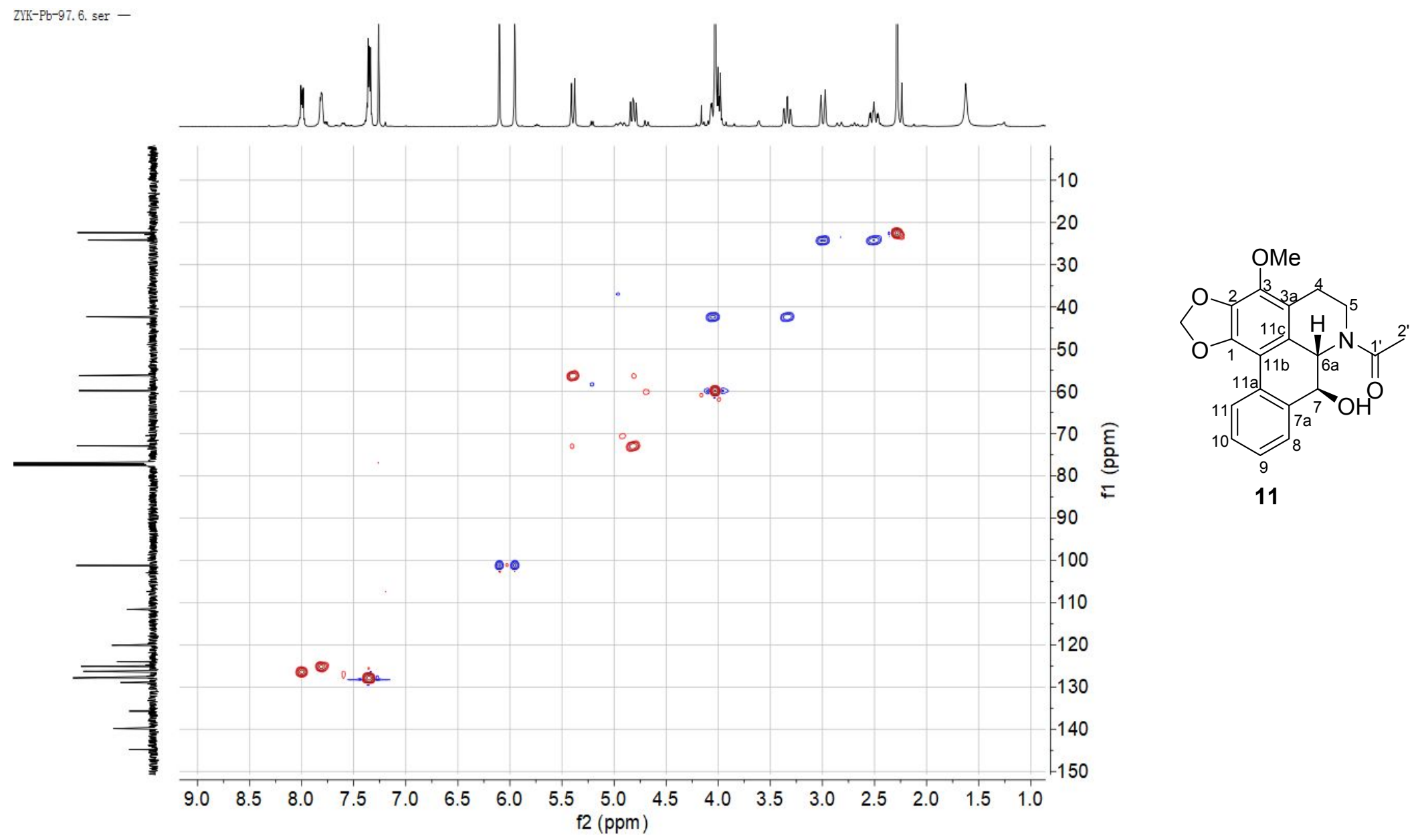
Figure S96. HMBC Spectrum of Compound 11 in $\mathrm{CDCl}_{3}$

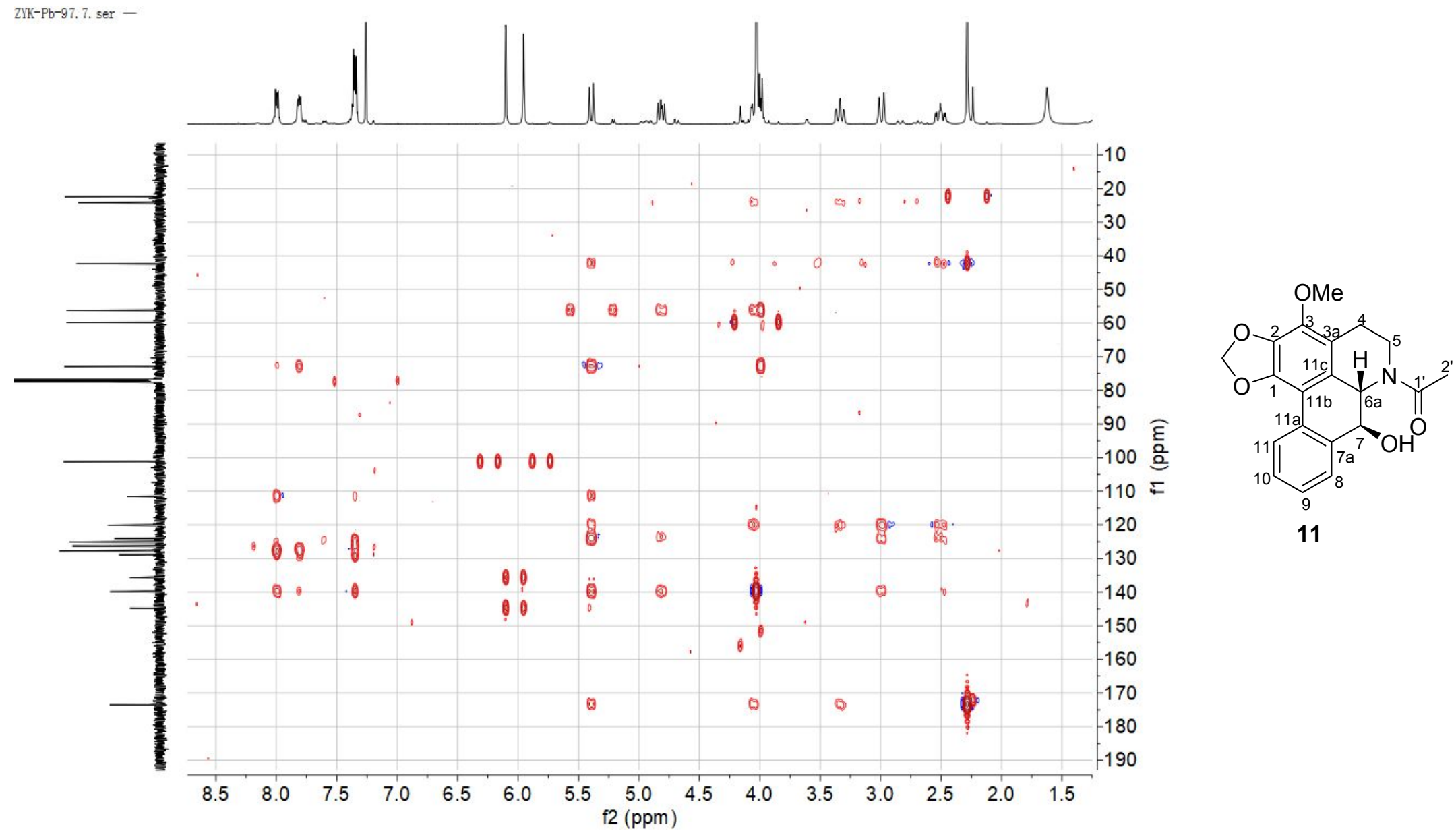


Figure S97. NOESY Spectrum of Compound 11 in $\mathrm{CDCl}_{3}$

ZTK-Pb-97. 9. ser -
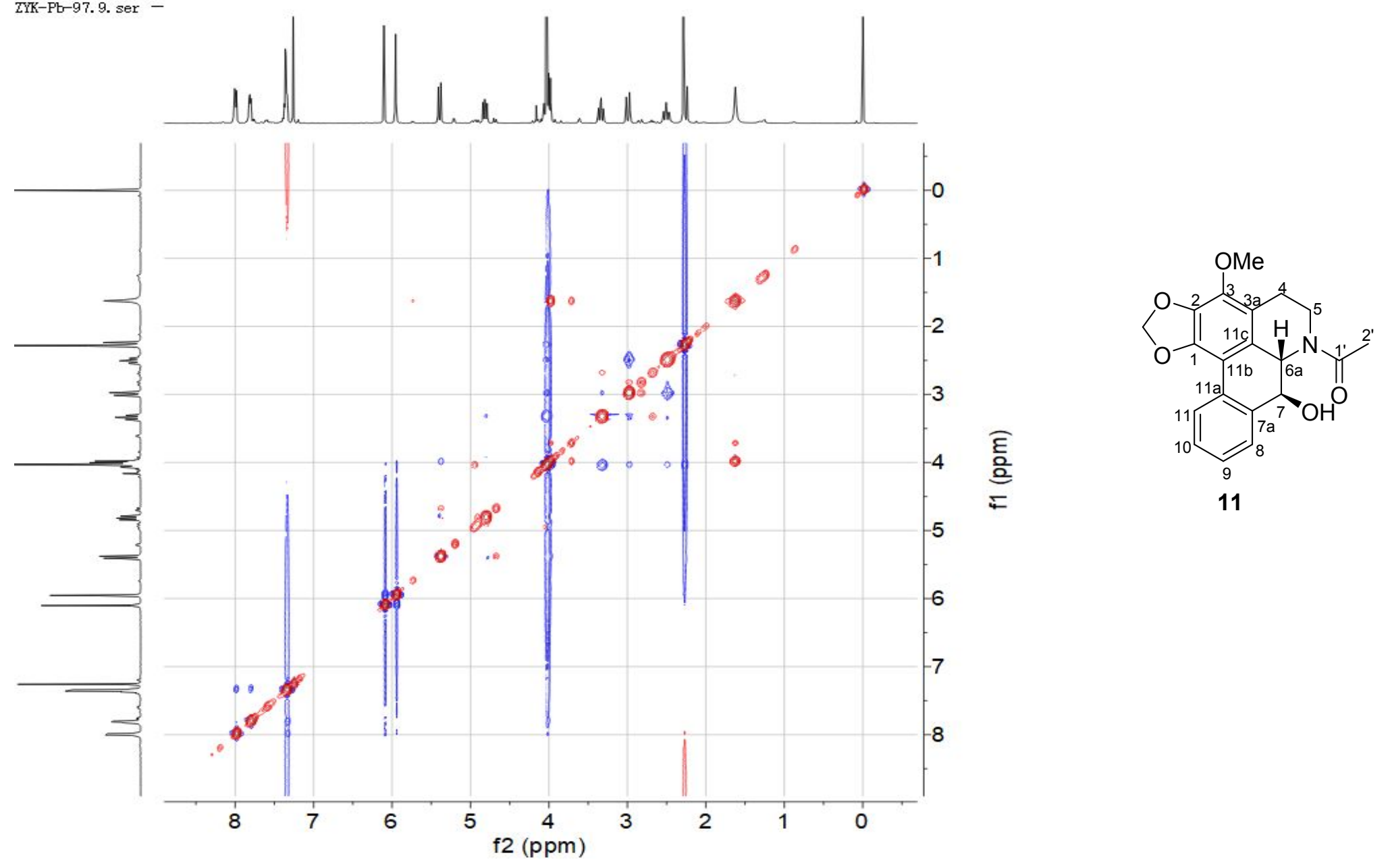
Figure S98. (+) HRESIMS Spectrum of Compound 11
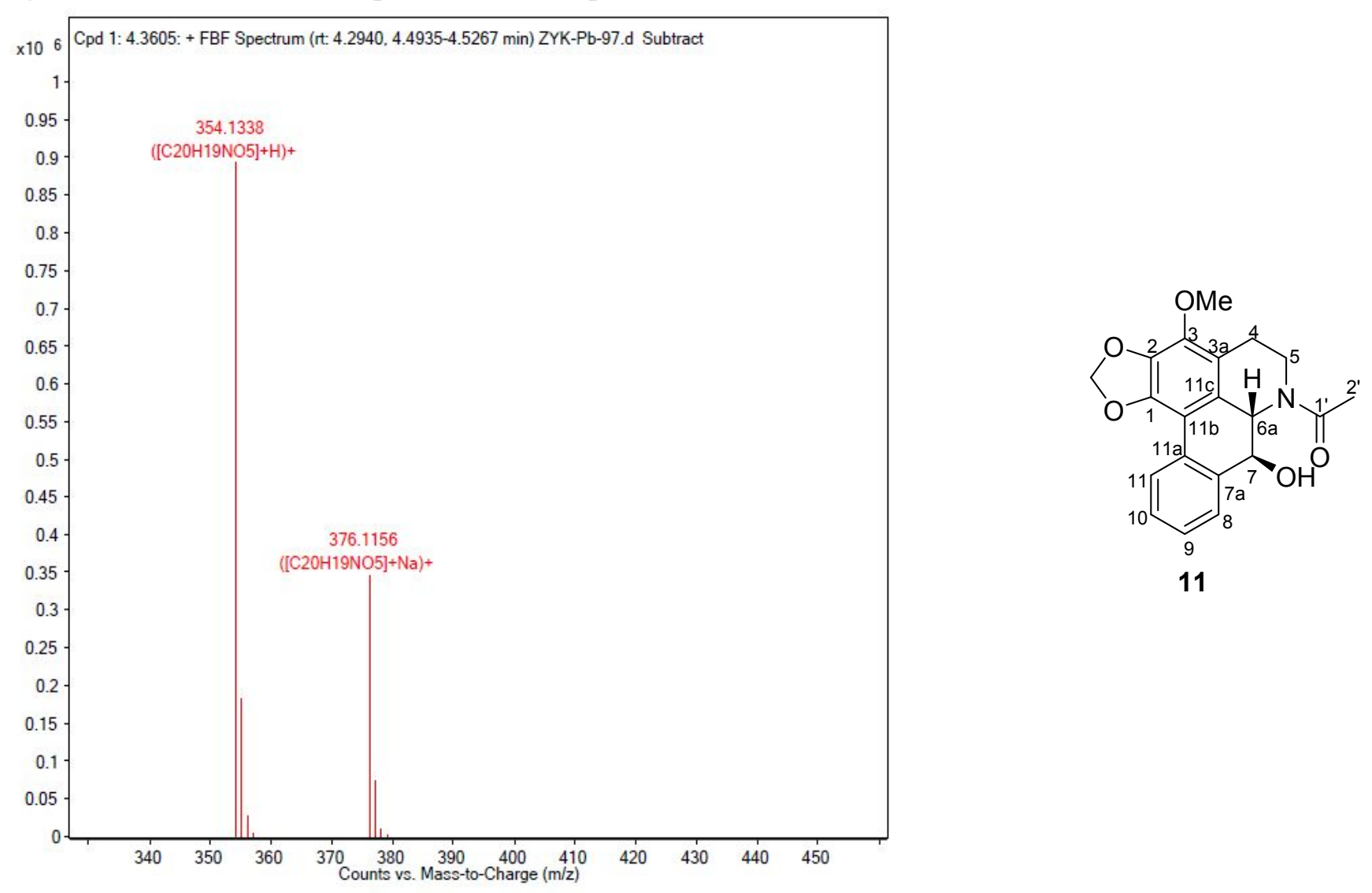
Figure S99. UV Spectrum of Compound 11
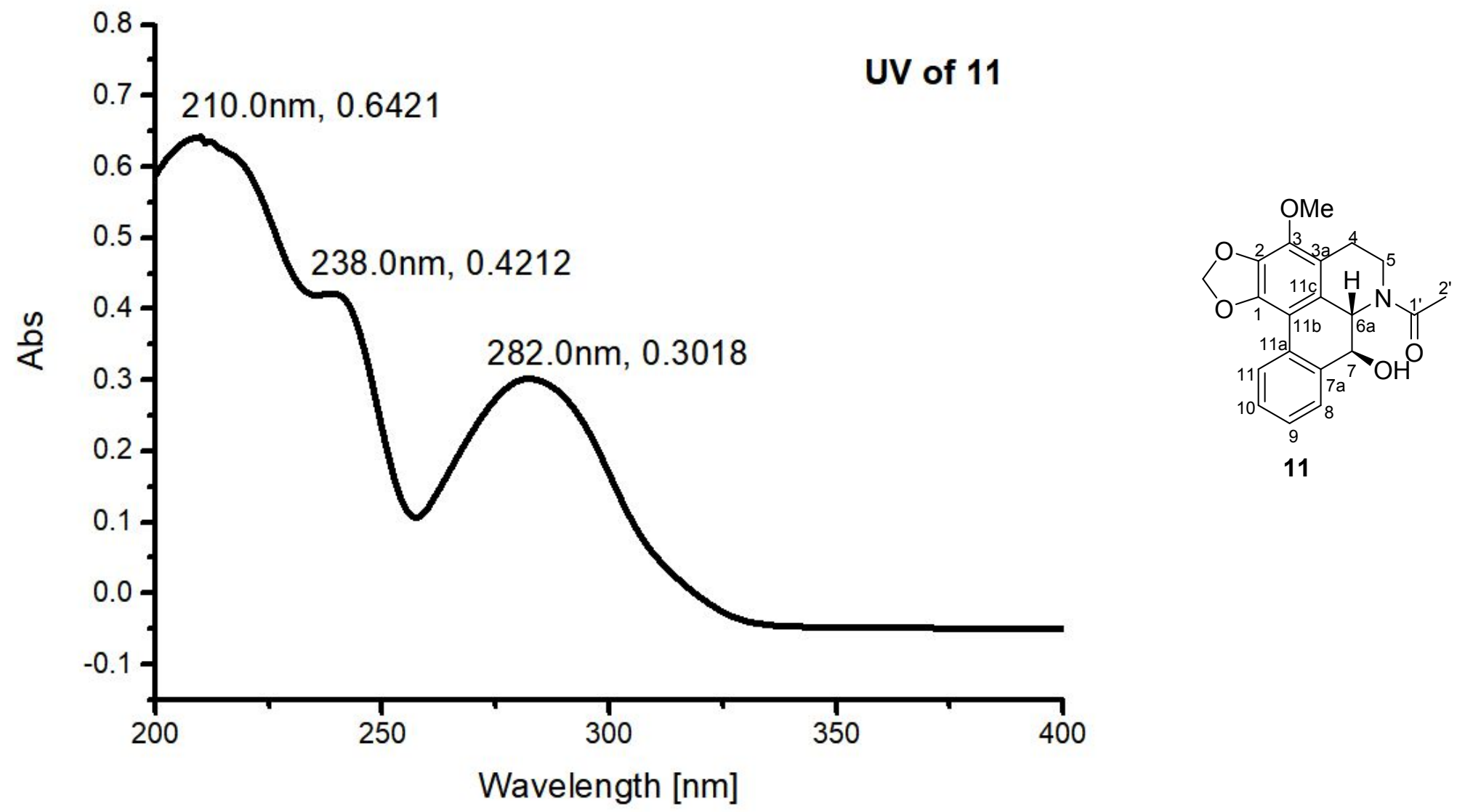
Figure S100. IR (KBr disc) Spectrum of Compound 11
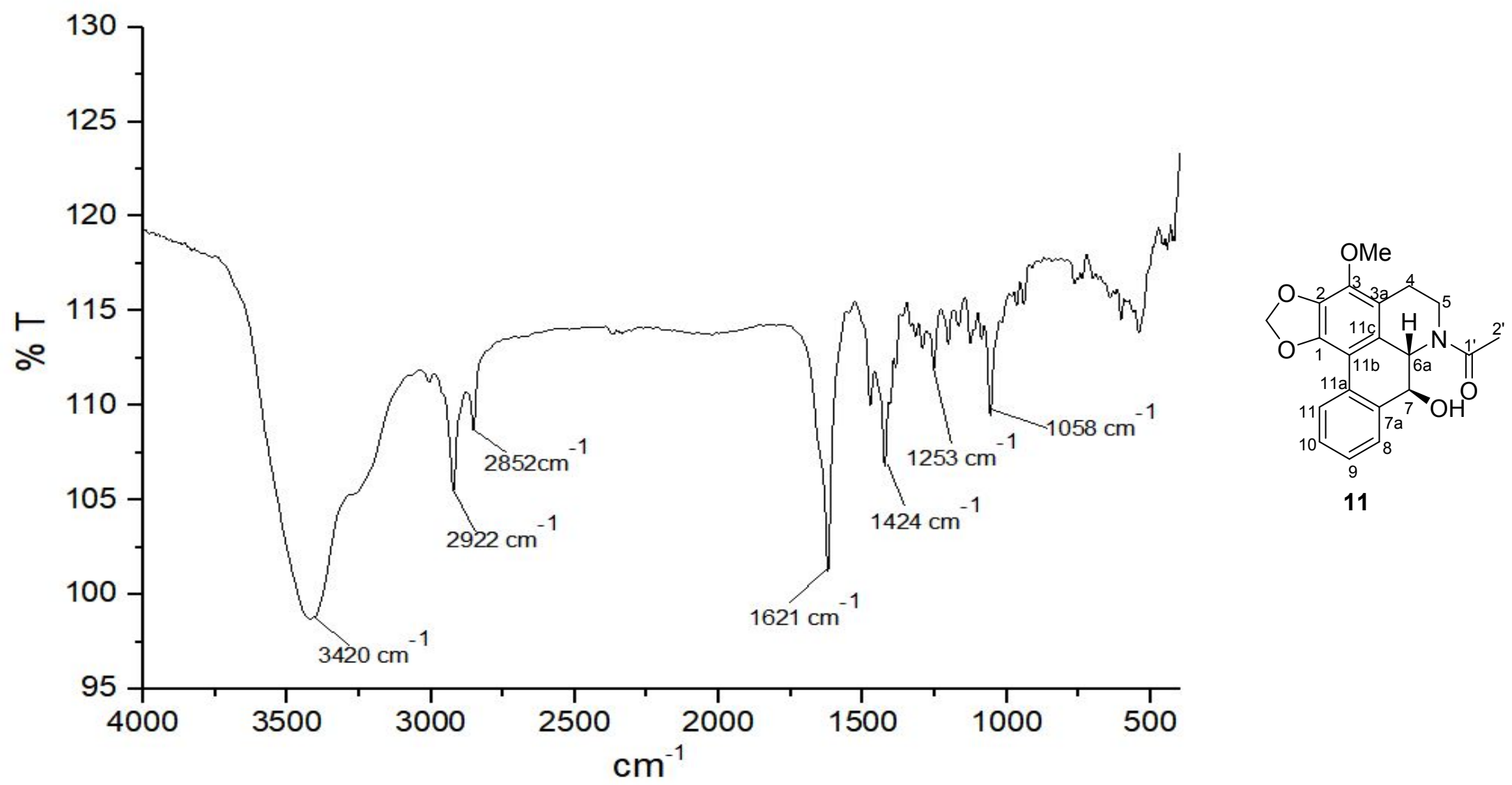
Figure S101. ECD Spectrum of 11
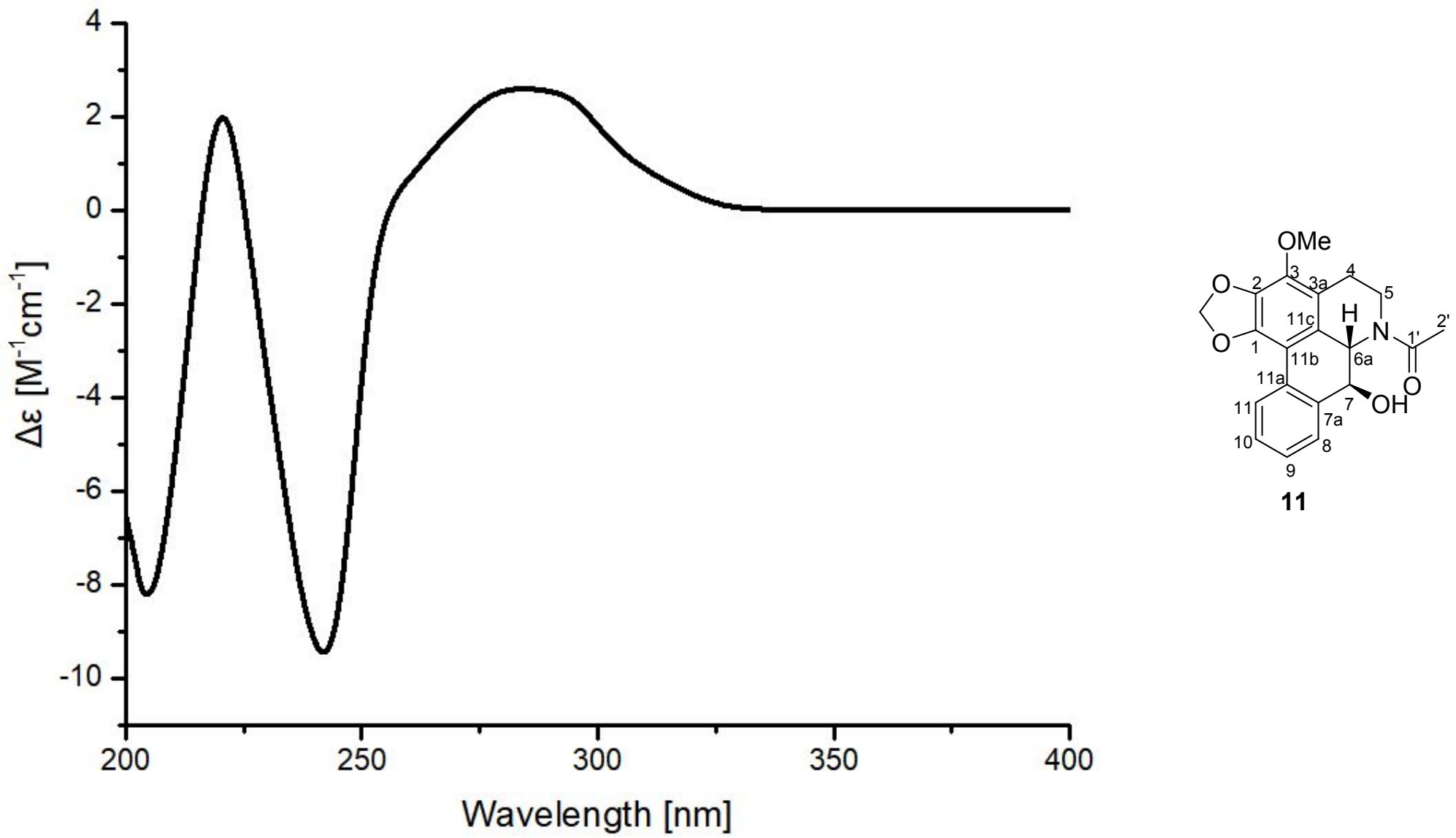
Figure S102. ${ }^{1} \mathrm{H}$ NMR Spectrum of Compound 12 in $\mathrm{CDCl}_{3}$

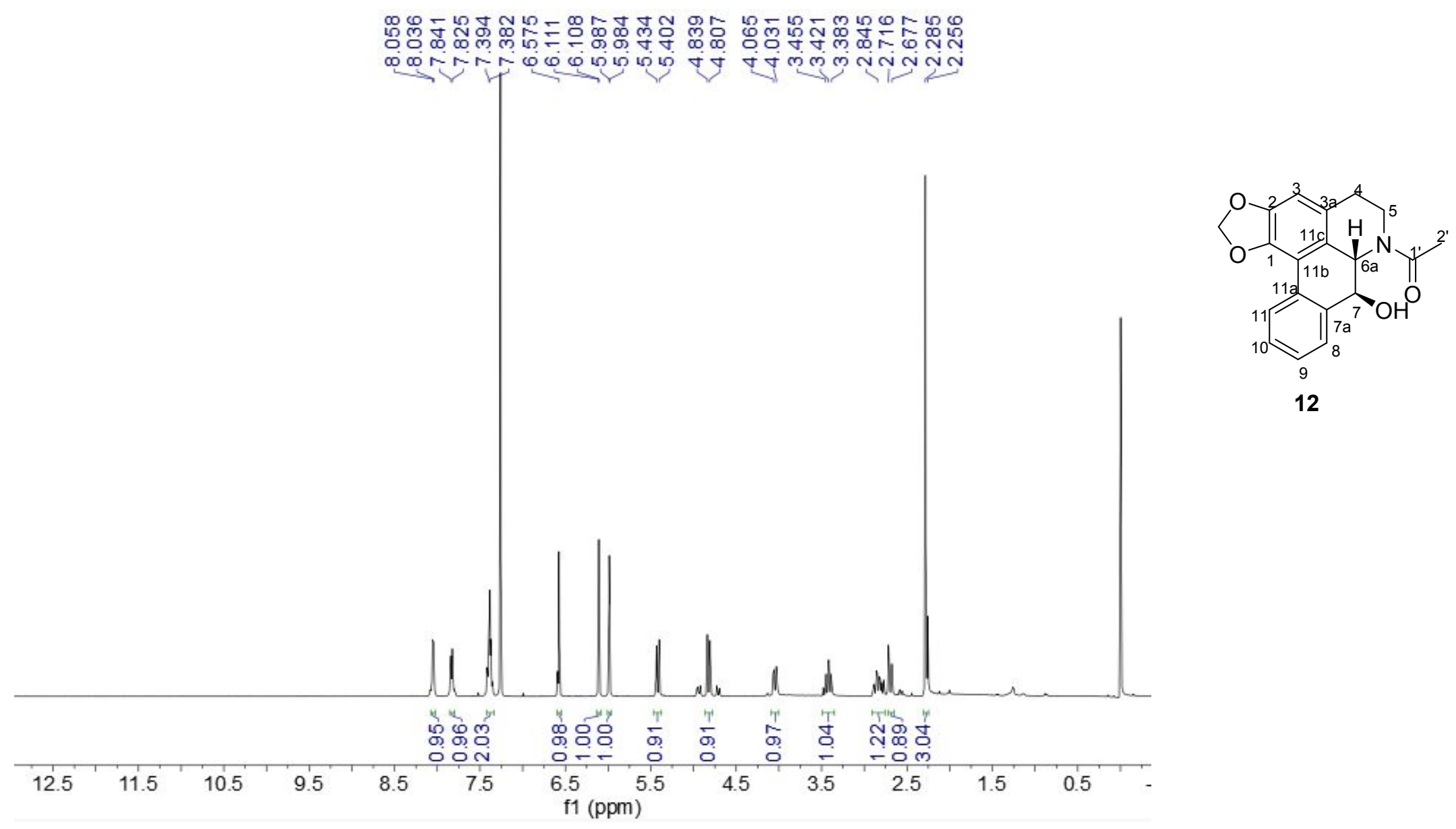


Figure S103. ${ }^{13} \mathrm{C}$ NMR Spectrum of Compound 12 in $\mathrm{CDCl}_{3}$
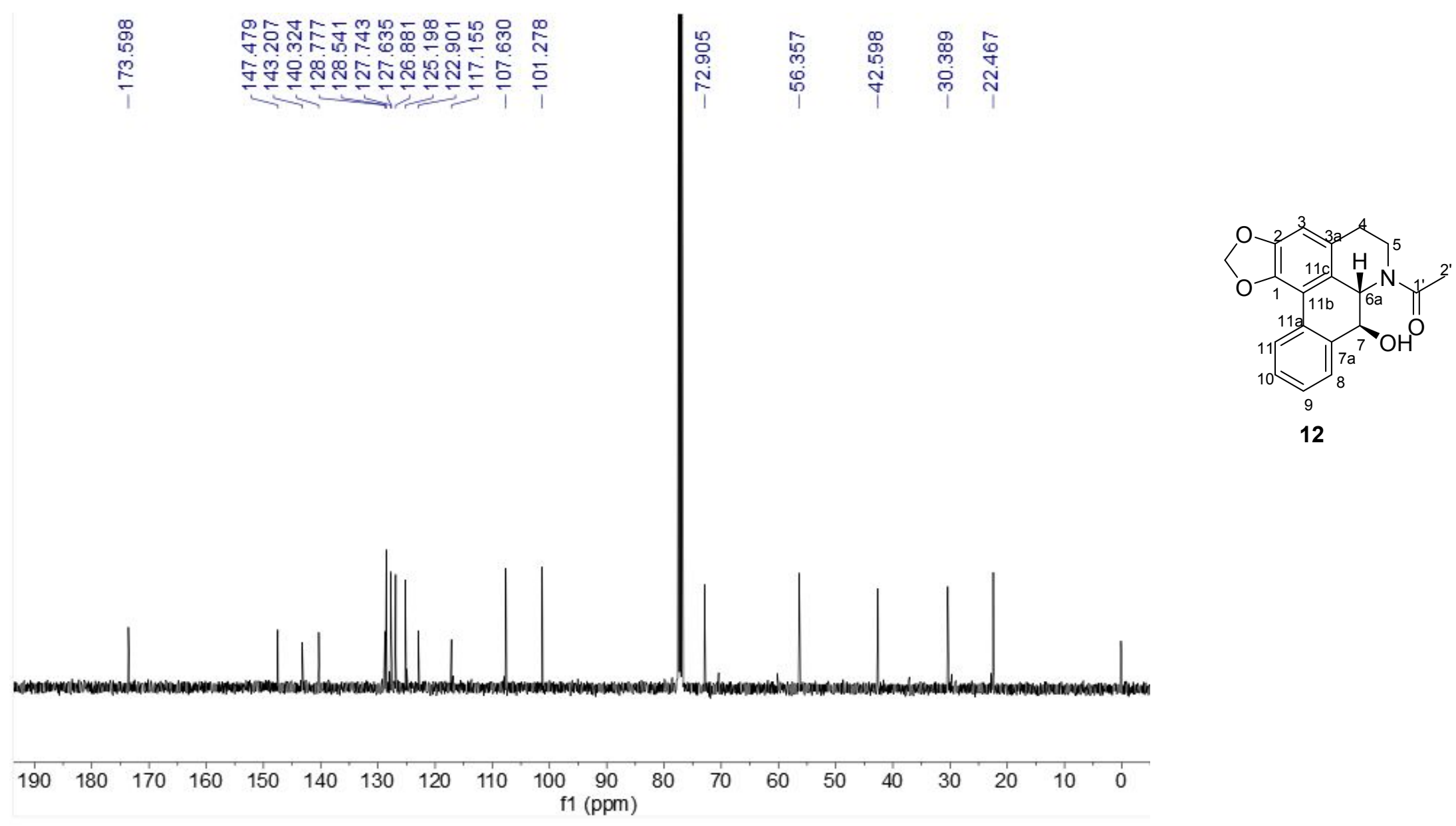
Figure S104. (+) HRESIMS Spectrum of Compound 12
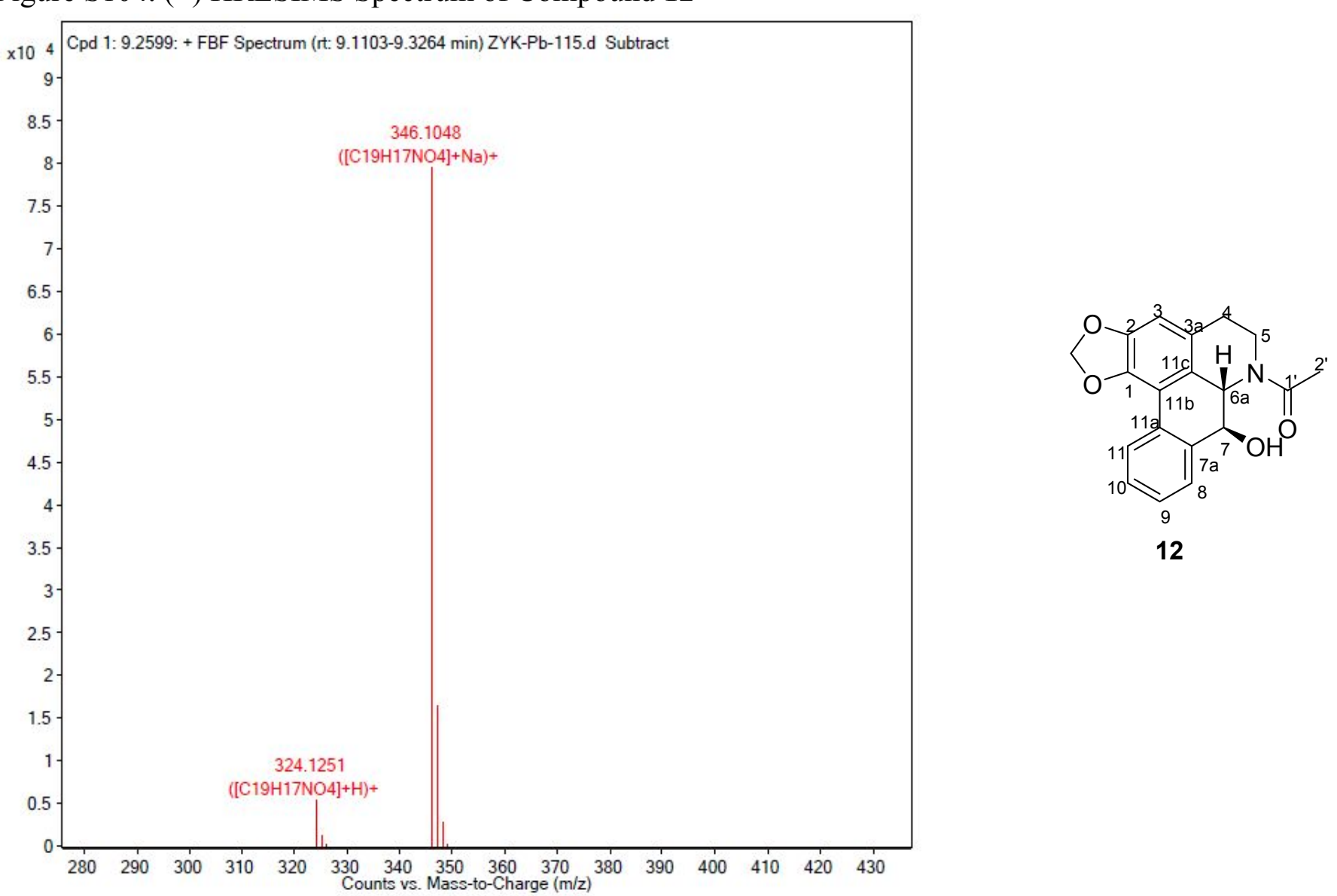
Figure S105. ${ }^{1} \mathrm{H}$ NMR Spectrum of Compound 13 in $\mathrm{CDCl}_{3}$

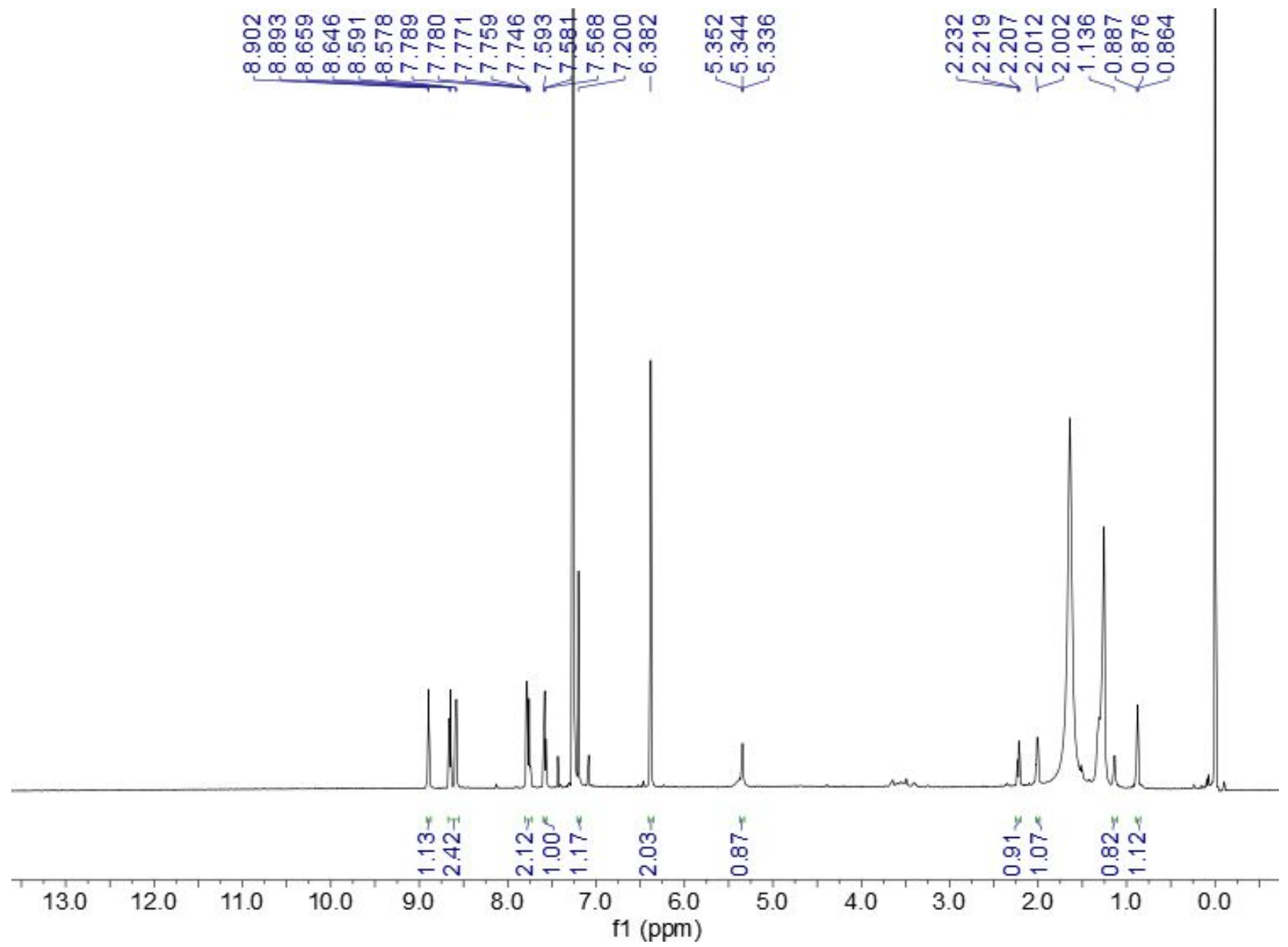


Figure S106. ${ }^{13} \mathrm{C}$ NMR Spectrum of Compound 13 in $\mathrm{CDCl}_{3}$

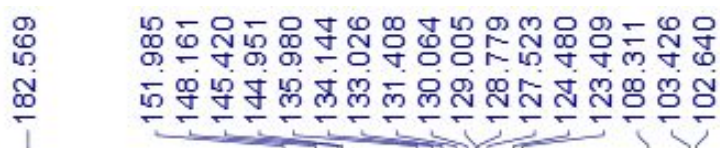

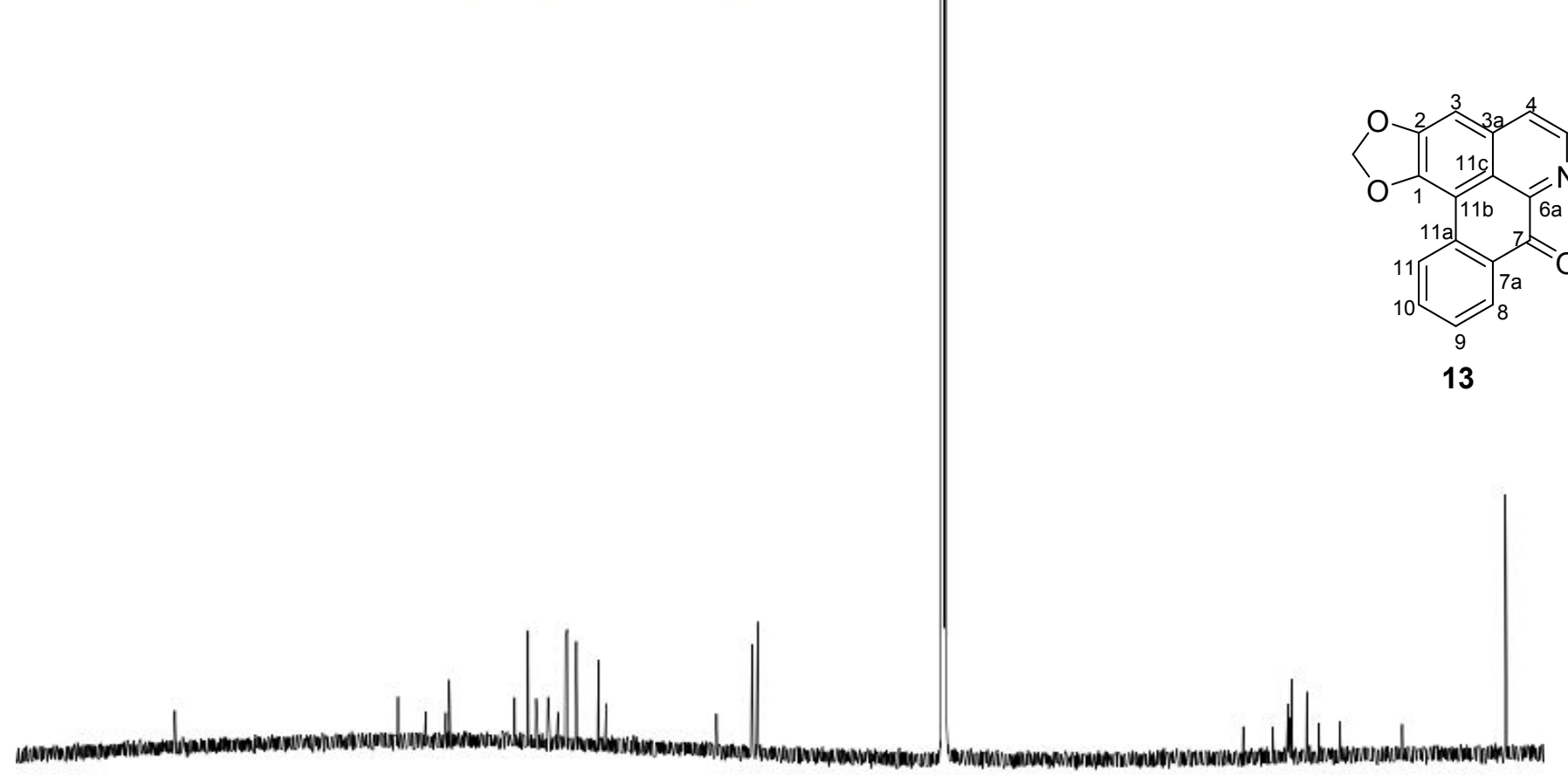


Figure S107. (+) HRESIMS Spectrum of Compound 13
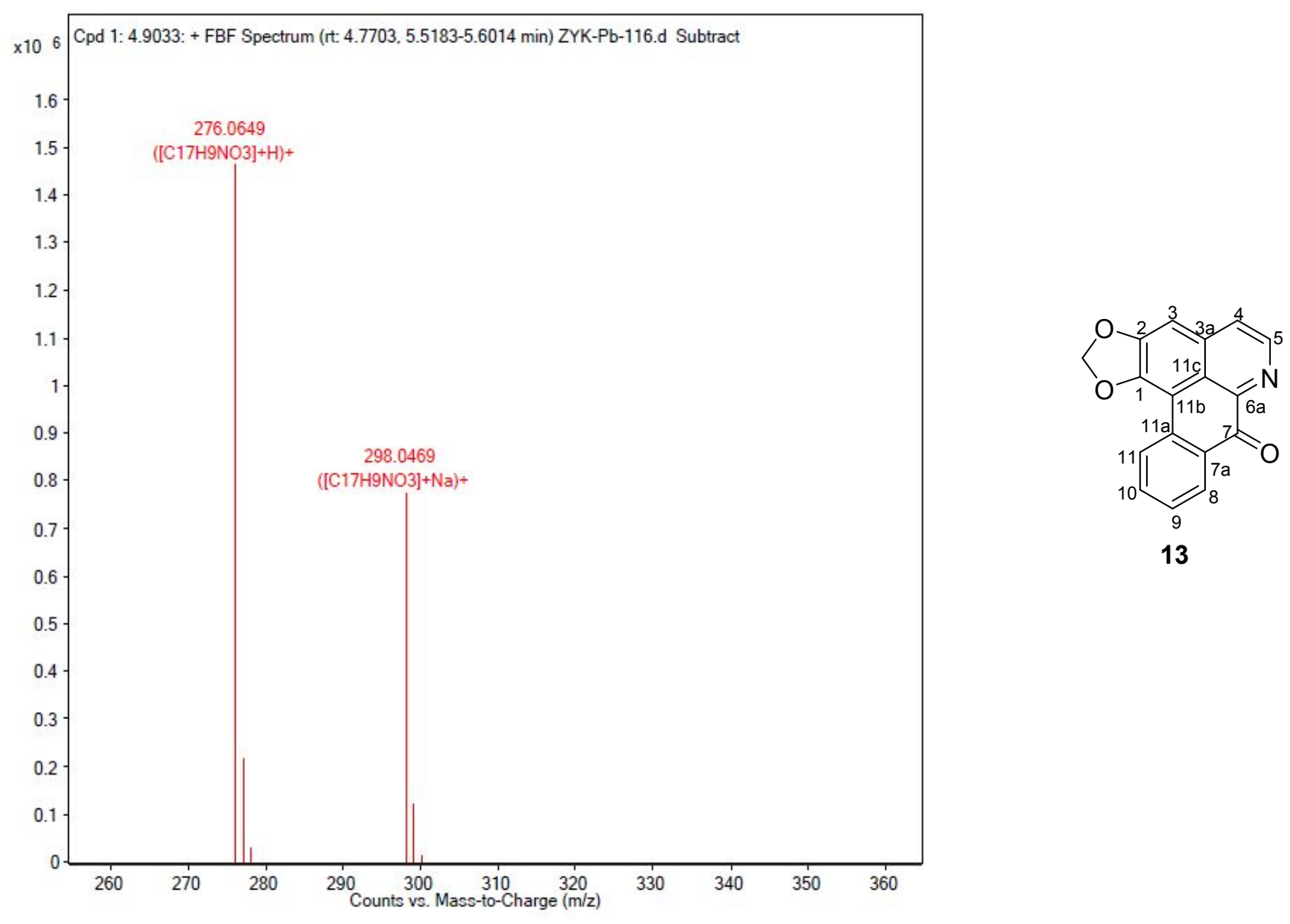

13 
Figure S108. ${ }^{1} \mathrm{H}$ NMR Spectrum of Compound 14 in DMSO- $d_{6}$

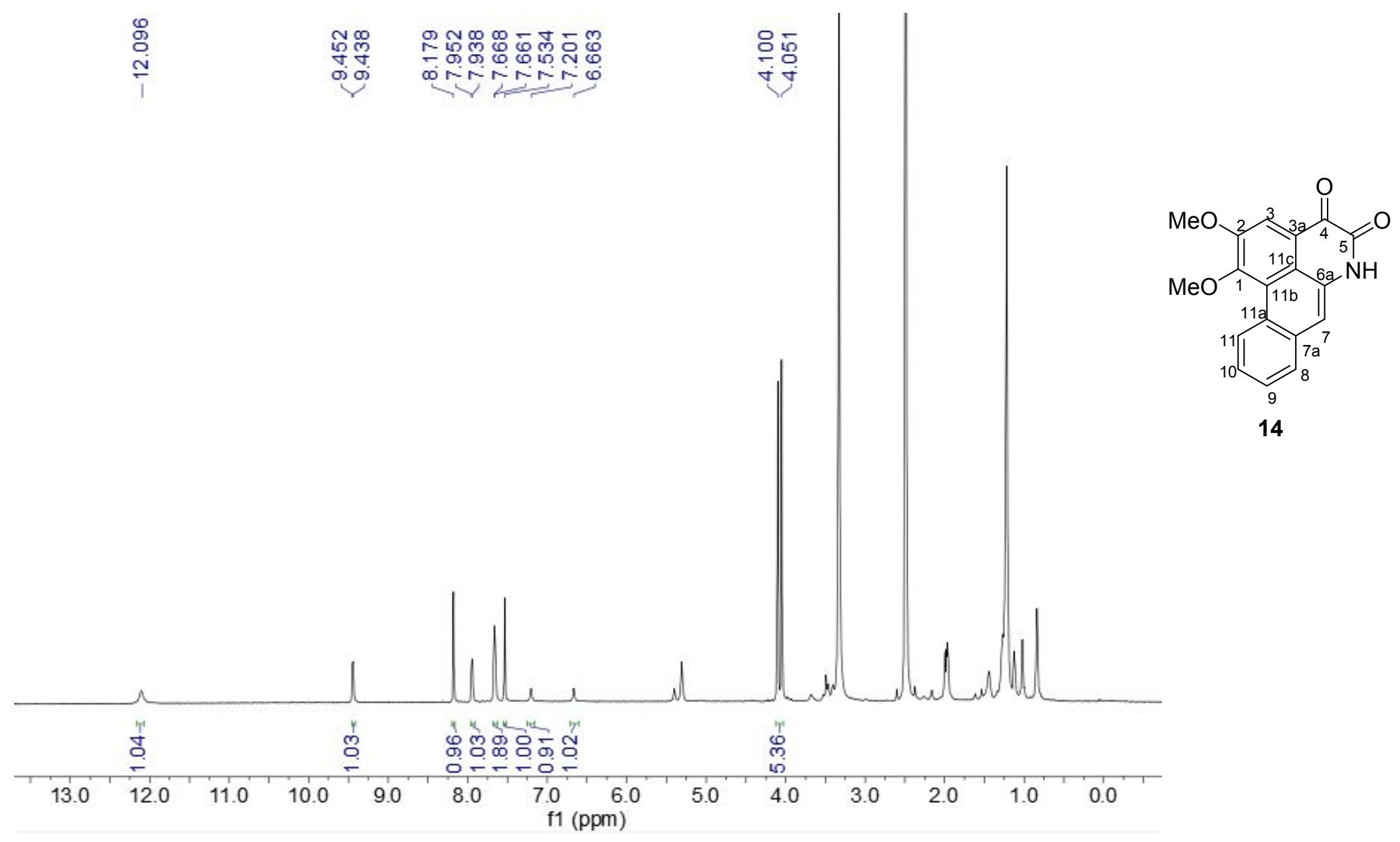


Figure S109. ${ }^{13} \mathrm{C}$ NMR Spectrum of Compound 14 in DMSO- $d_{6}$

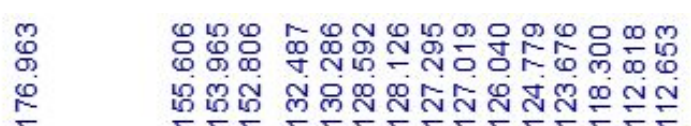

年

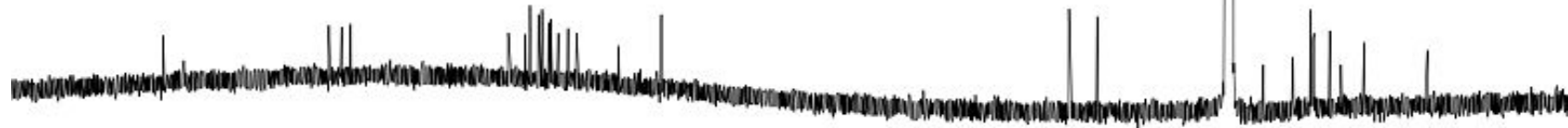

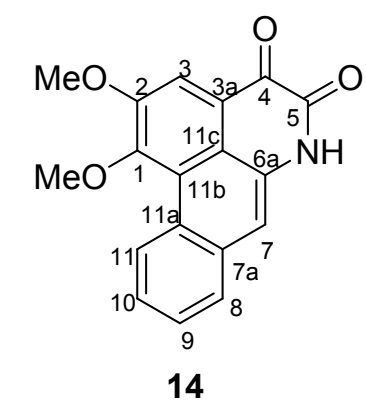

$\begin{array}{lllllllllll}190 & 180 & 170 & 160 & 150 & 140 & 130 & 120 & 110 & 100 & 90\end{array}$

$\mathrm{f} 1$ (ppm) 
Figure S110. (+) HRESIMS Spectrum of Compound 14

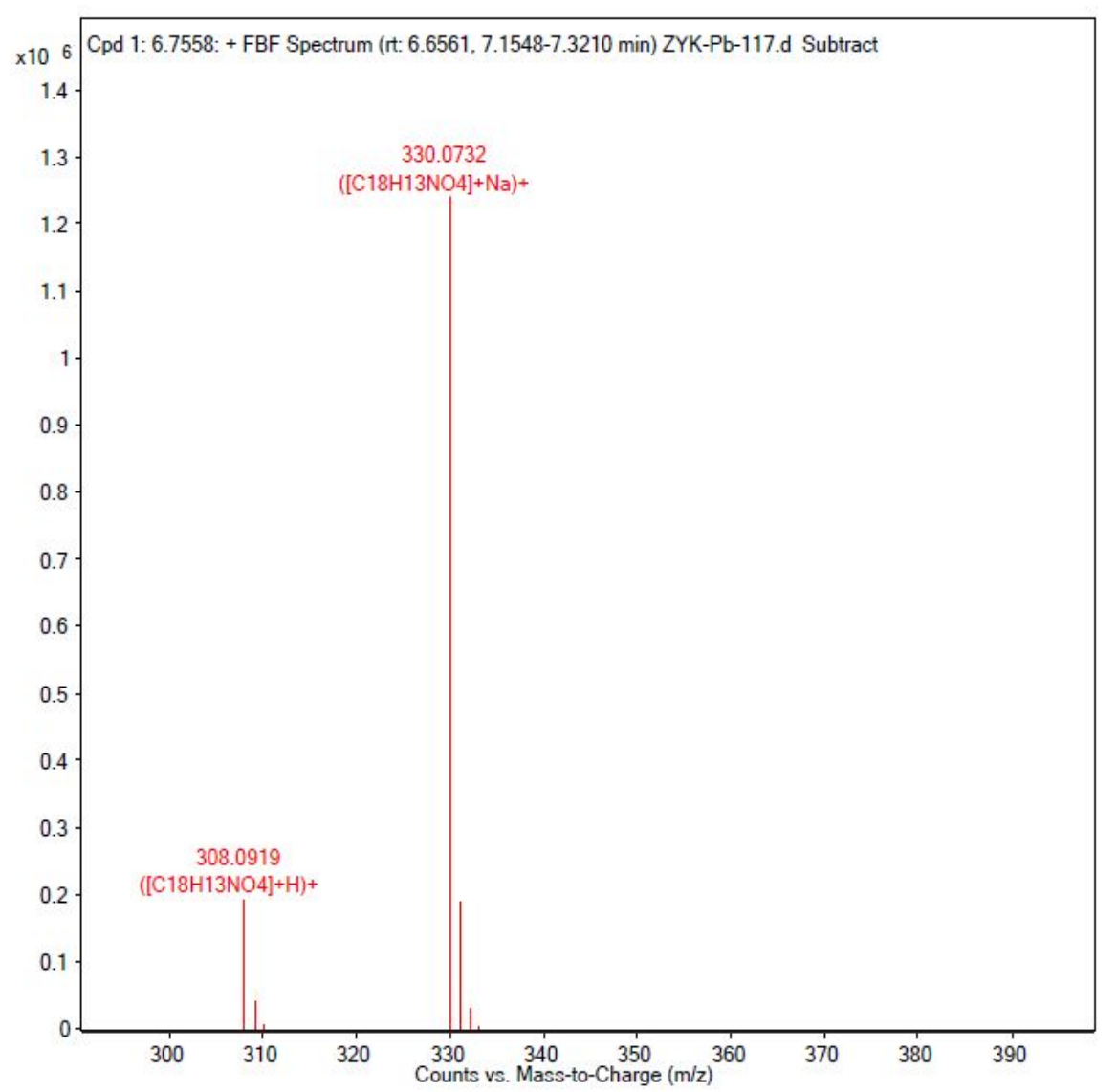


Figure S111. ${ }^{1} \mathrm{H}$ NMR Spectrum of Compound 15 in $\mathrm{MeOH}-d_{4}$

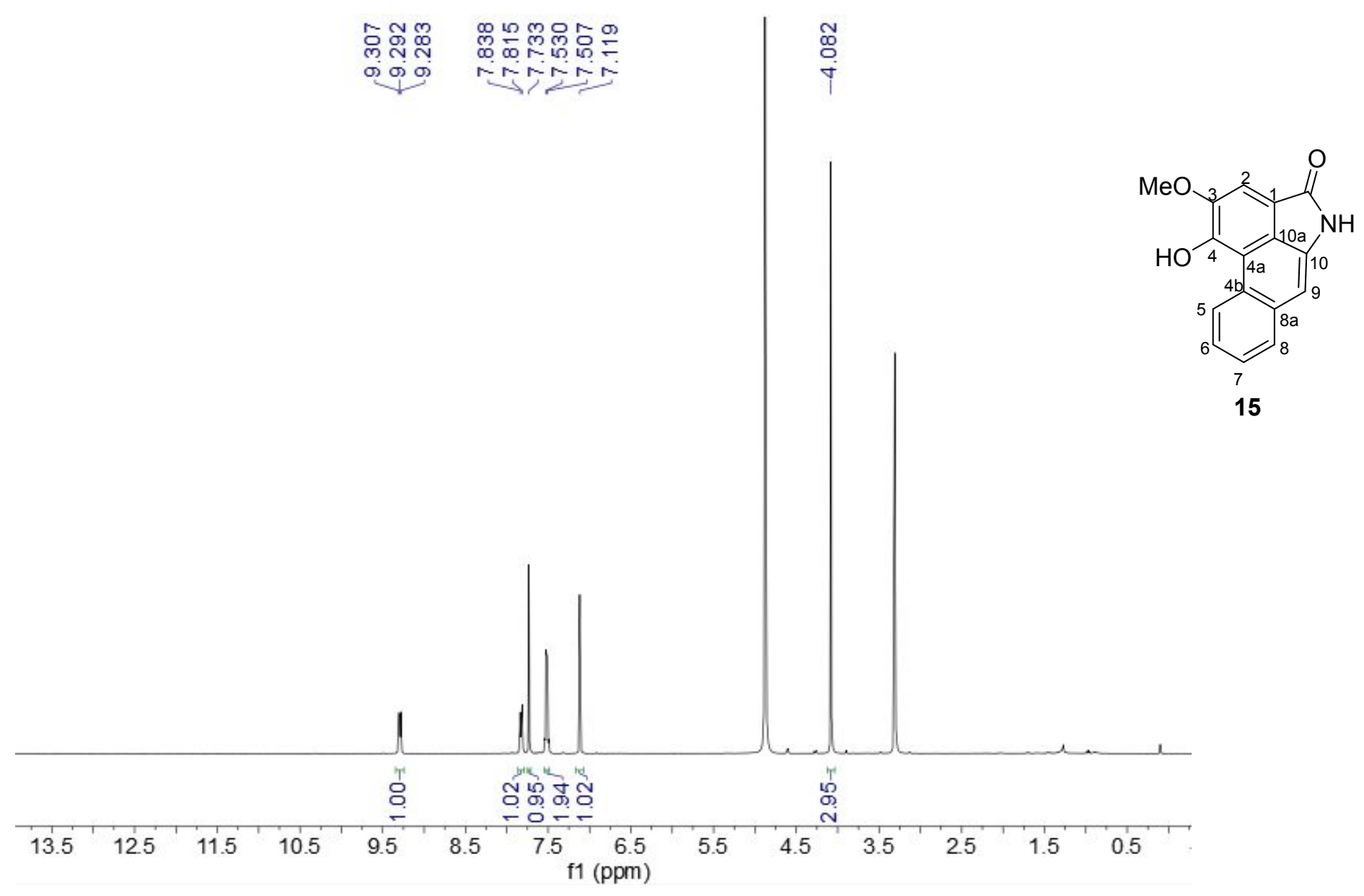


Figure S112. ${ }^{13} \mathrm{C}$ NMR Spectrum of Compound 15 in $\mathrm{MeOH}-d_{4}$

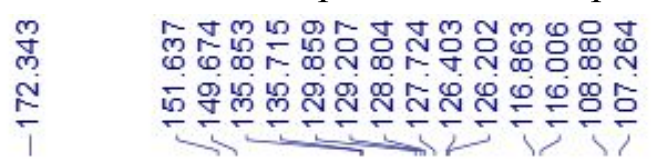

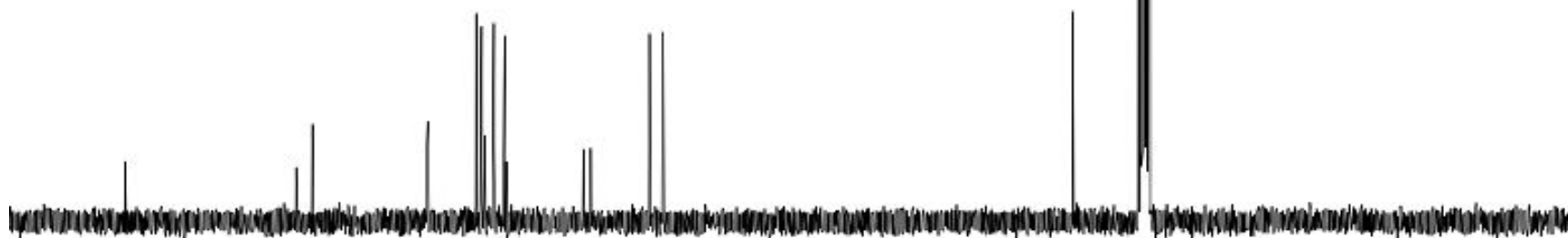

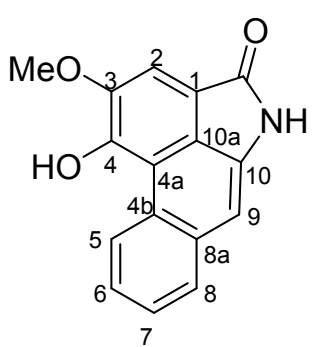

15

180

$\begin{array}{lll}170 & 160 & 150\end{array}$

$140 \quad 130$

$120 \quad 110$

$100 \quad 90$ f1 (ppm) 
Figure S113. (+) HRESIMS Spectrum of Compound 15

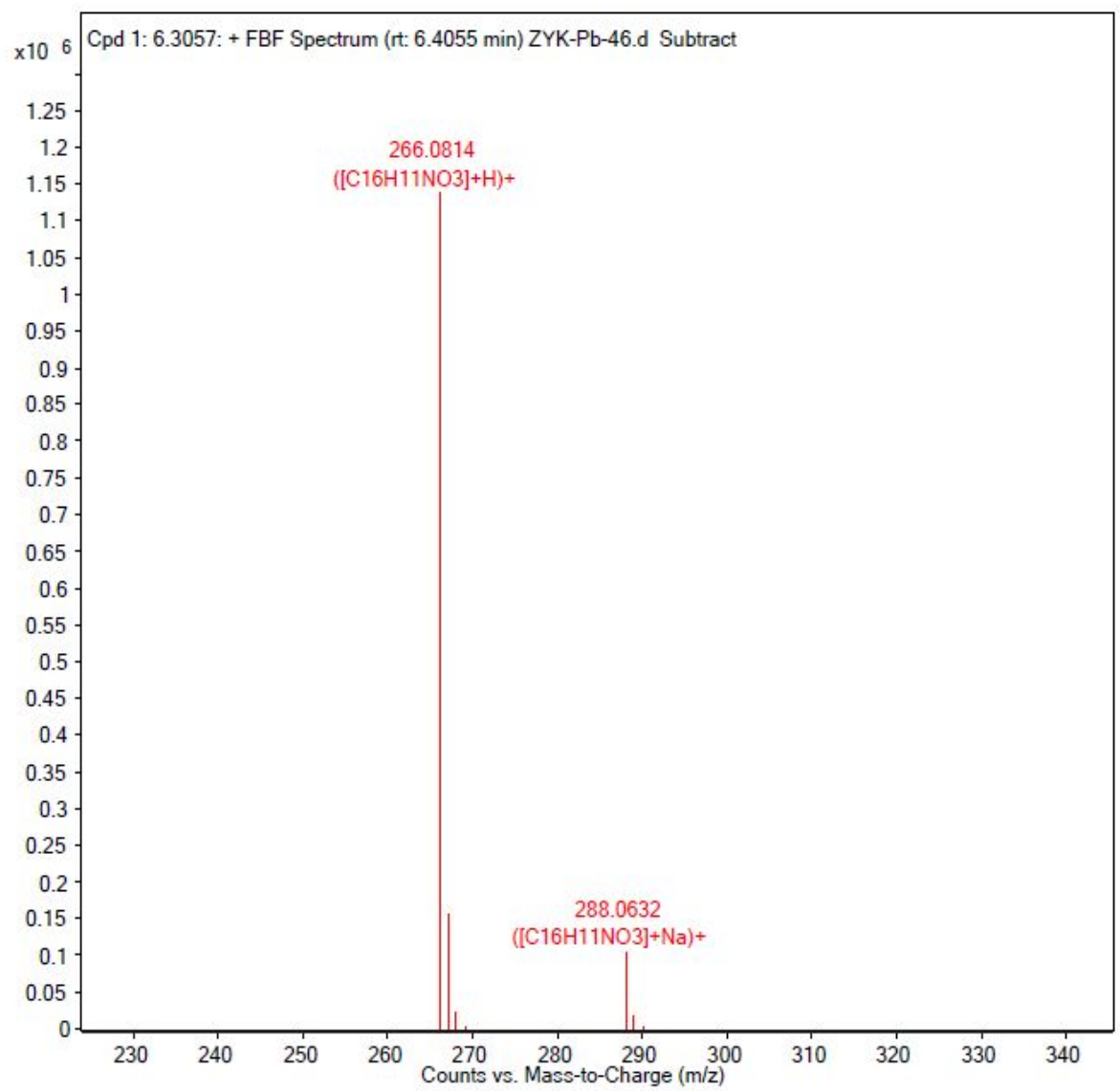

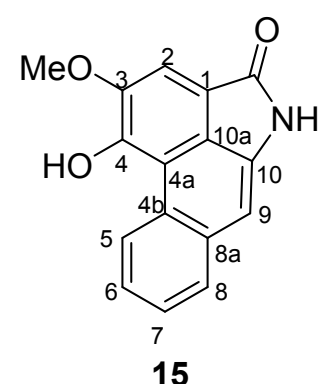


Figure S114. ${ }^{1} \mathrm{H}$ NMR Spectrum of Compound 16 in DMSO- $d_{6}$

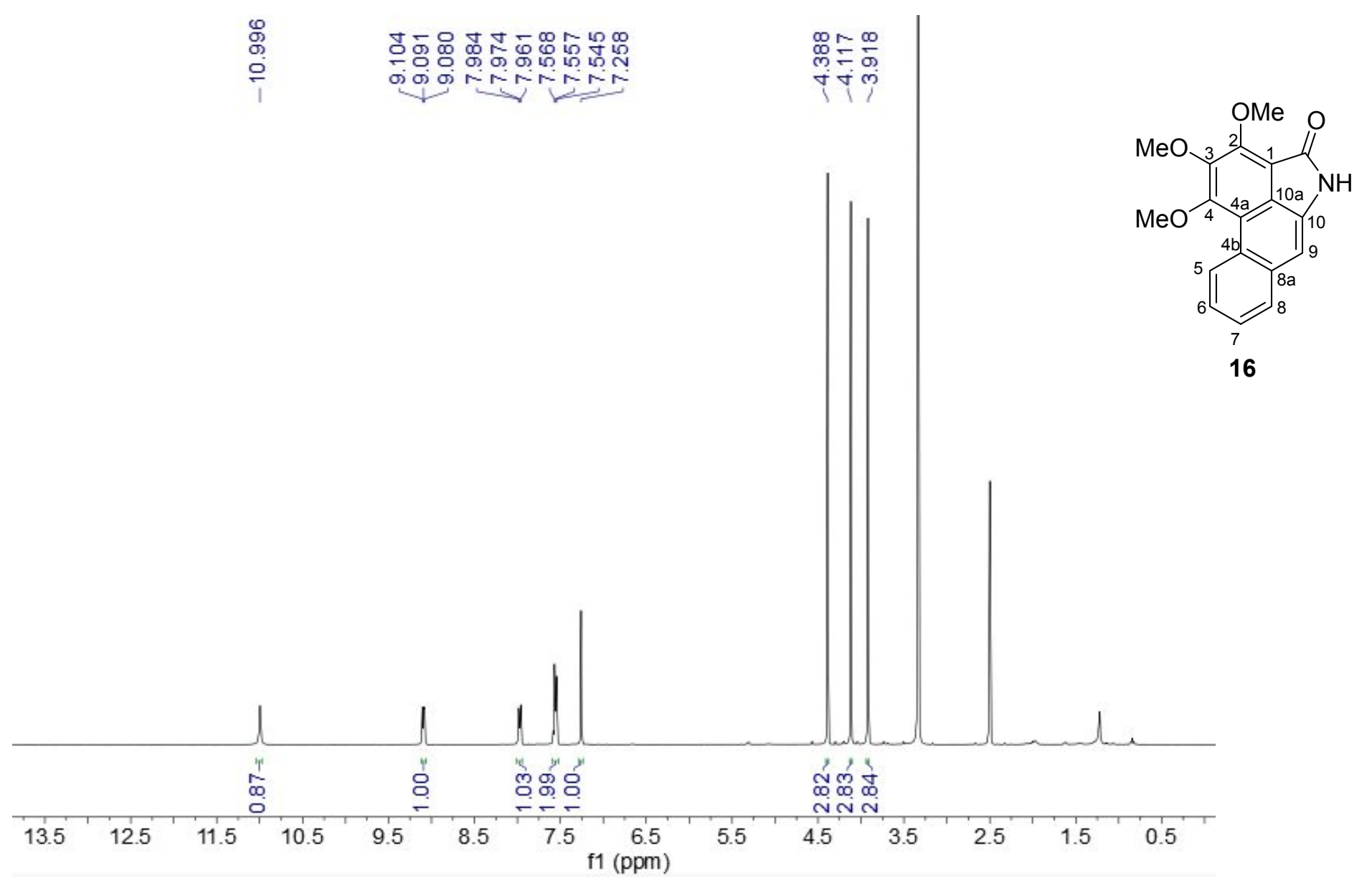


Figure S115. ${ }^{13} \mathrm{C}$ NMR Spectrum of Compound 16 in DMSO- $d_{6}$

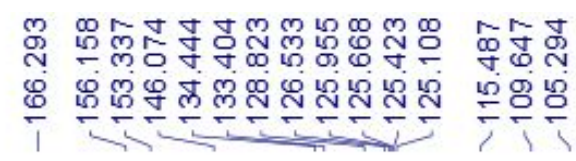

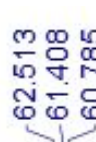

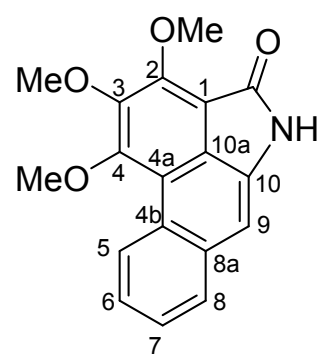

16

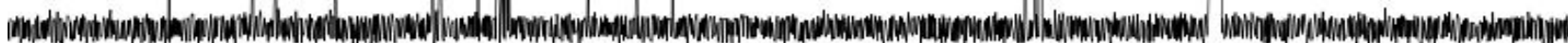

$\begin{array}{lllllllllllllllllll}180 & 170 & 160 & 150 & 140 & 130 & 120 & 110 & \begin{array}{l}100 \\ \mathrm{f} 1(\mathrm{ppm})\end{array} & 80 & 70 & 60 & 50 & 40 & 30 & 20 & 10 & 0\end{array}$


Figure S116. (+) HRESIMS Spectrum of Compound 16
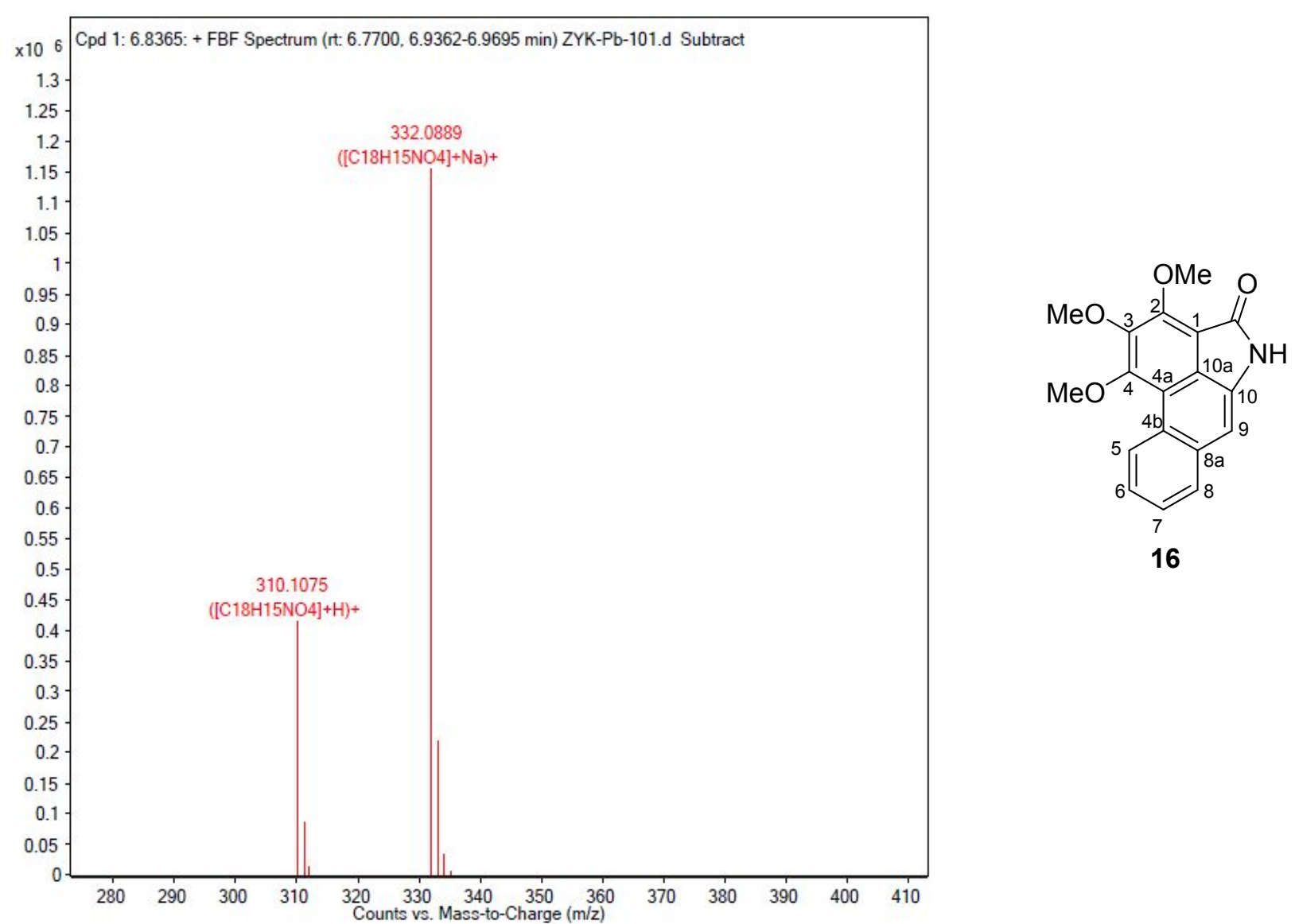
Figure S117. ${ }^{1} \mathrm{H}$ NMR Spectrum of Compound 17 in DMSO- $d_{6}$
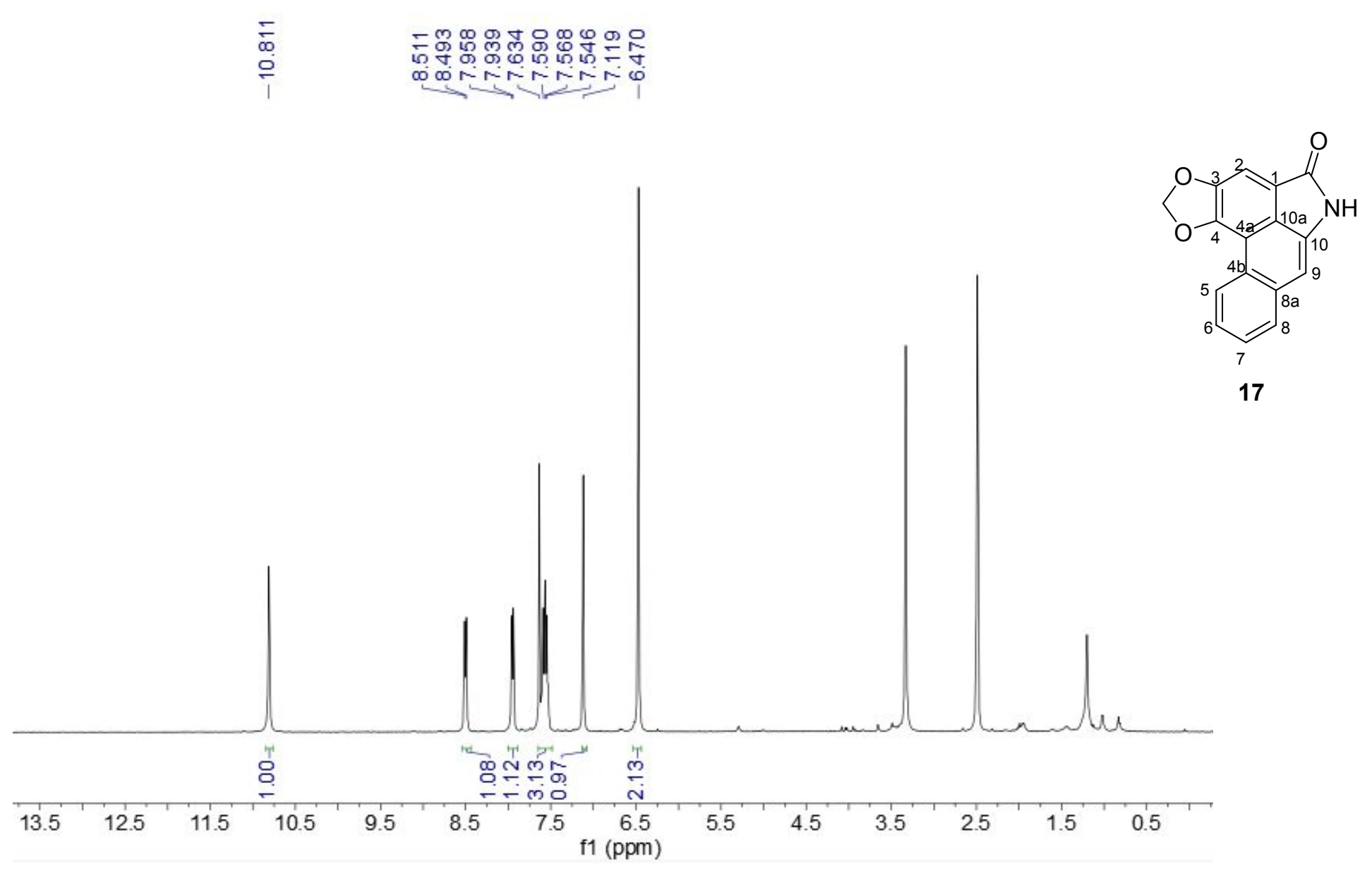
Figure S118. ${ }^{13} \mathrm{C}$ NMR Spectrum of Compound 17 in DMSO- $d_{6}$

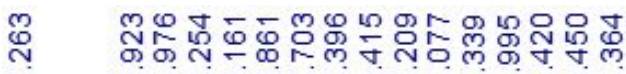

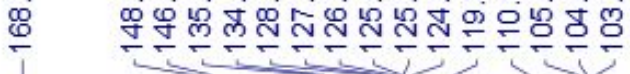

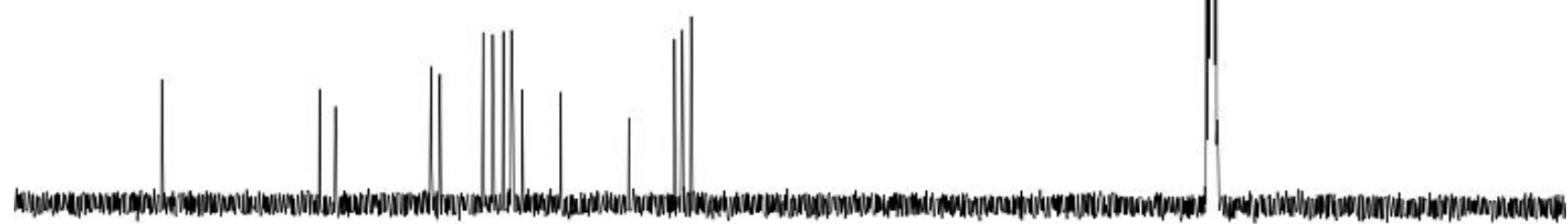

180

$170 \quad 160$

$150 \quad 140$

$130 \quad 120$

$\begin{array}{lll}110 & 100 \quad 90\end{array}$

f1 (ppm)

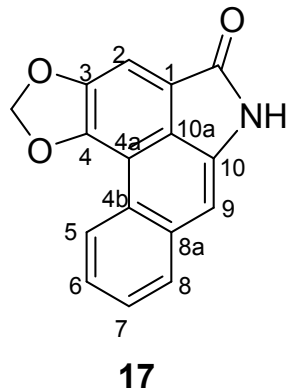

17 
Figure S119. (+) HRESIMS Spectrum of Compound 17

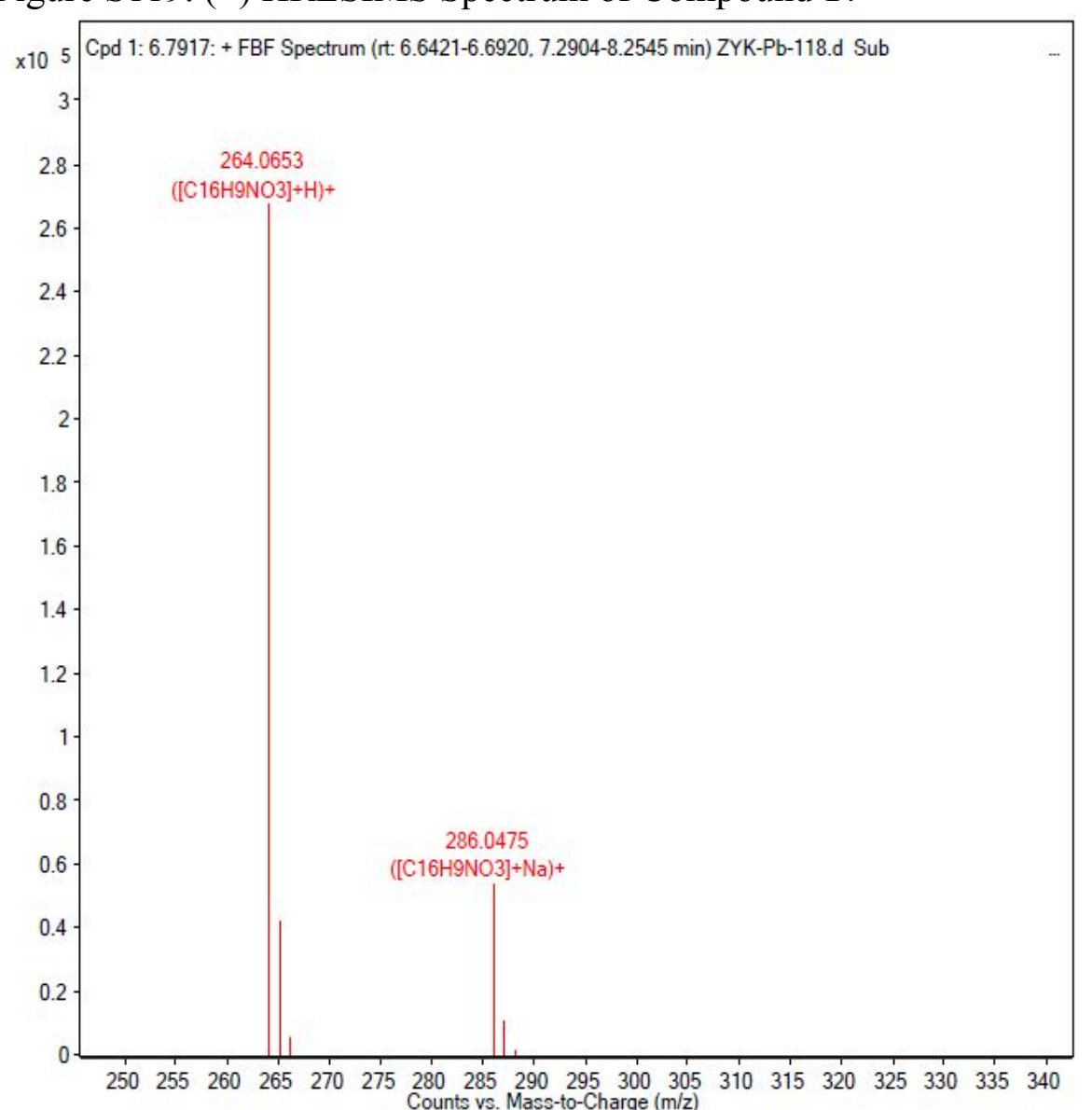

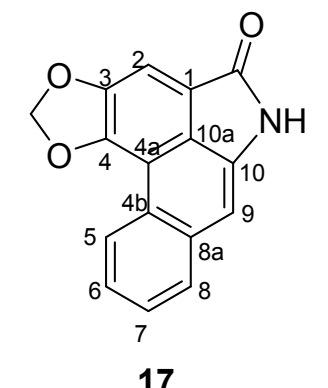

17 
Figure S120. ${ }^{1} \mathrm{H}$ NMR Spectrum of Compound 18 in $\mathrm{CDCl}_{3}$

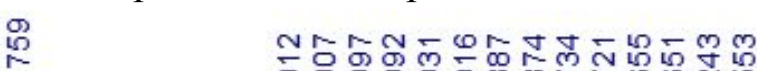
=

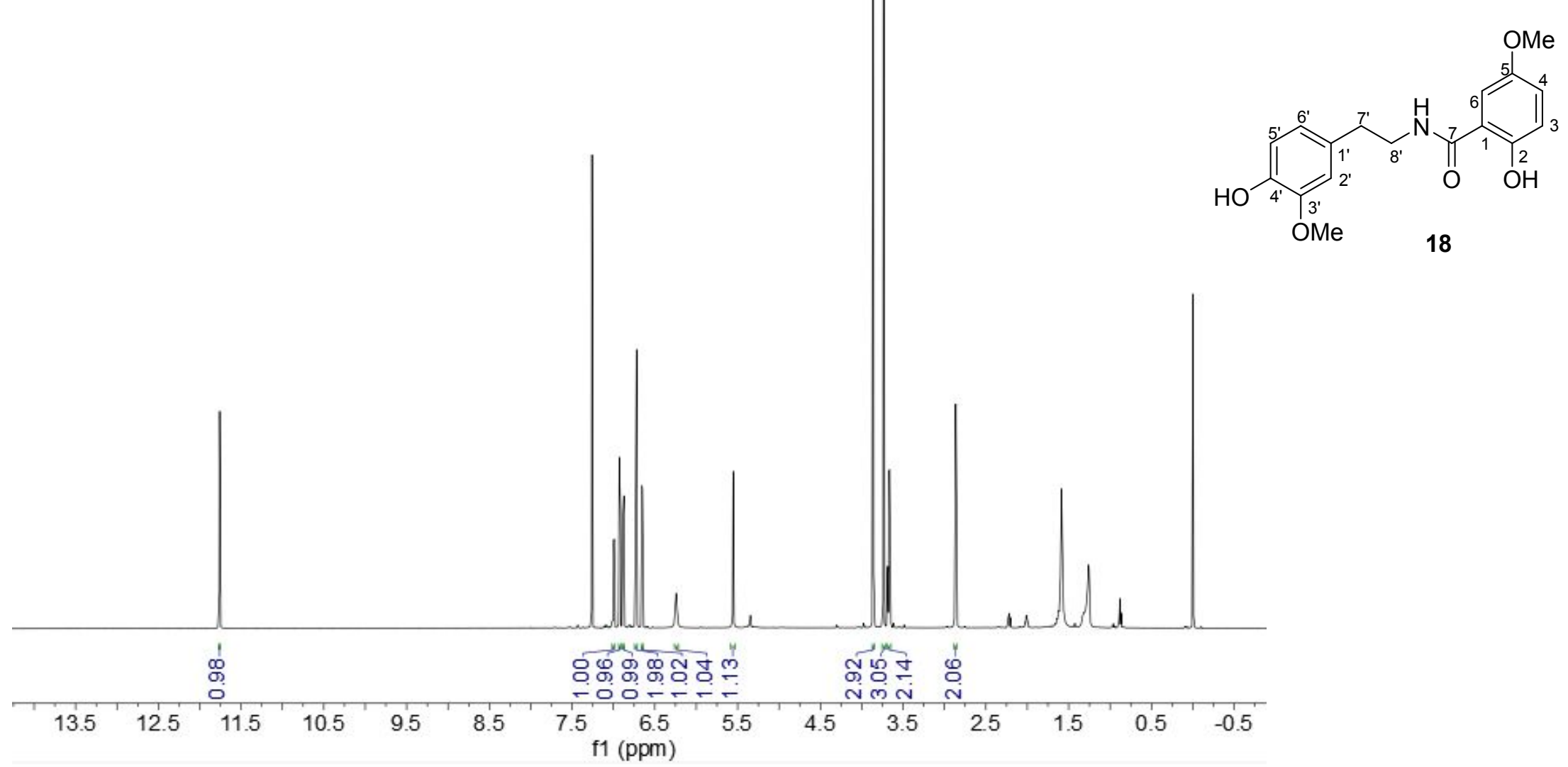


Figure S121. ${ }^{13} \mathrm{C}$ NMR Spectrum of Compound 18 in $\mathrm{CDCl}_{3}$

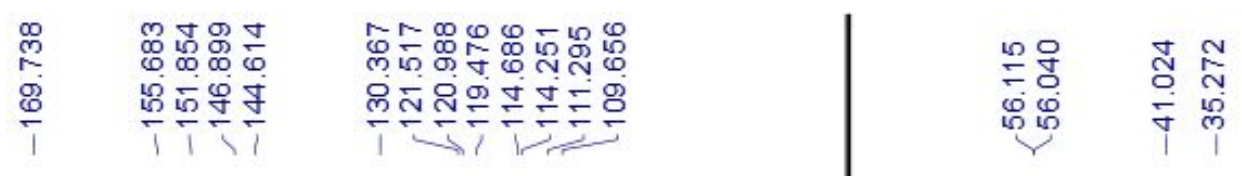

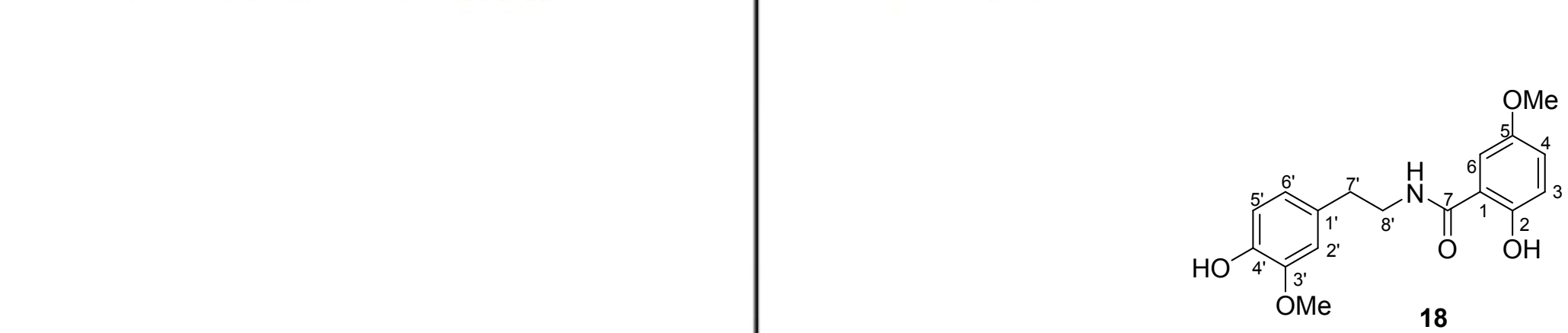

$\begin{array}{lllllllllllllllllll}180 & 170 & 160 & 150 & 140 & 130 & 120 & 110 & 100 & 90 & 80 & 70 & 60 & 50 & 40 & 30 & 20 & 10 & 0\end{array}$ 
Figure S122. (+) HRESIMS Spectrum of Compound 18

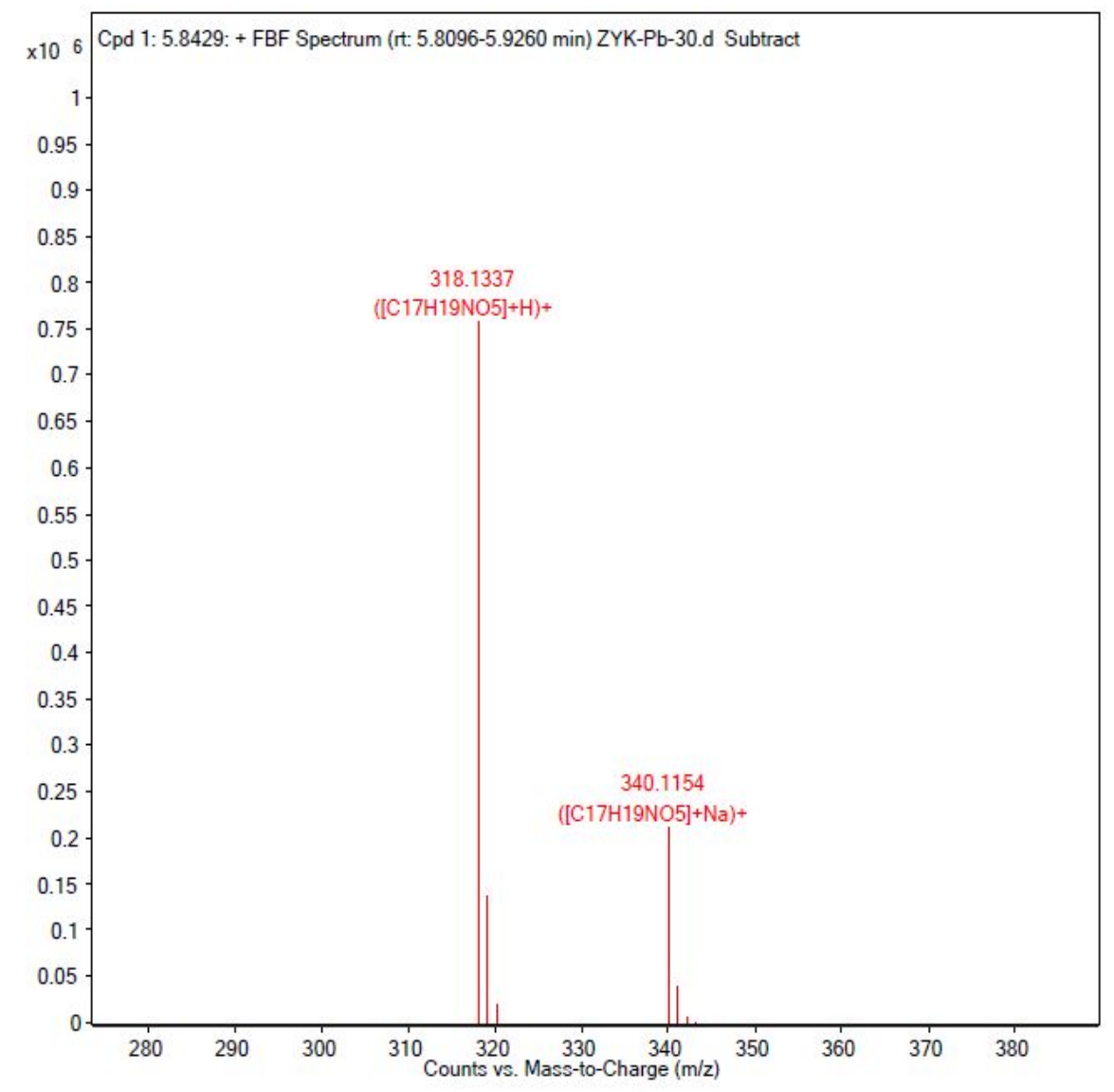


Figure S123. ${ }^{1} \mathrm{H}$ NMR Spectrum of Compound 19 in $\mathrm{MeOH}-d_{4}$

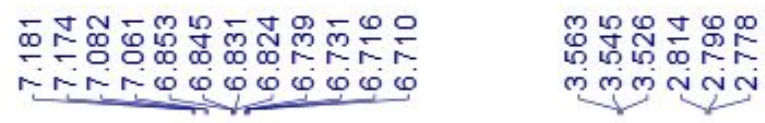

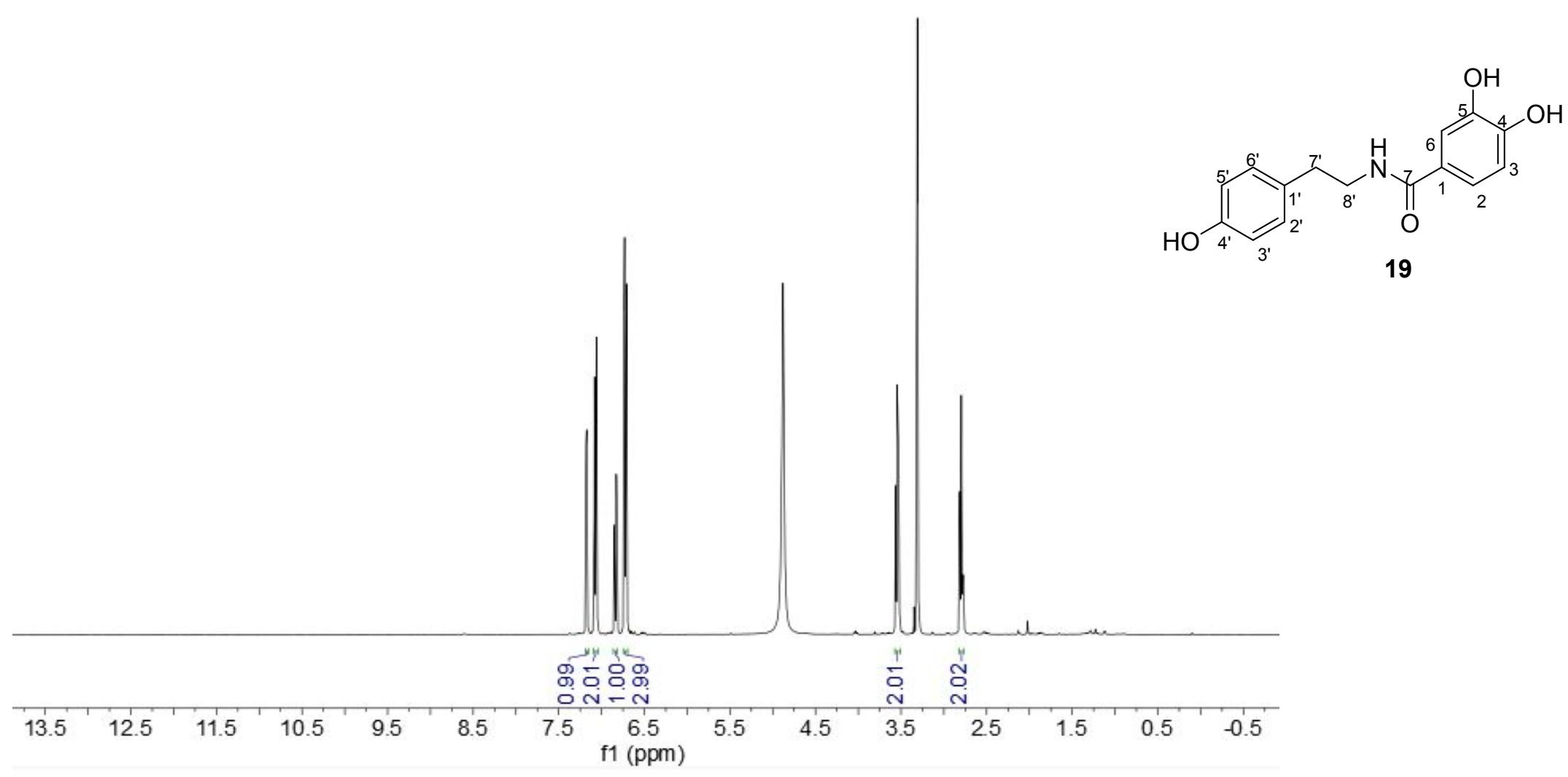


Figure S124. ${ }^{13} \mathrm{C}$ NMR Spectrum of Compound 19 in $\mathrm{MeOH}-d_{4}$

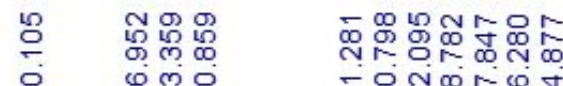

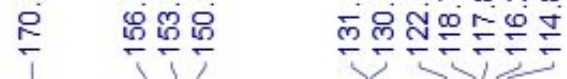

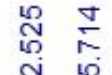

广
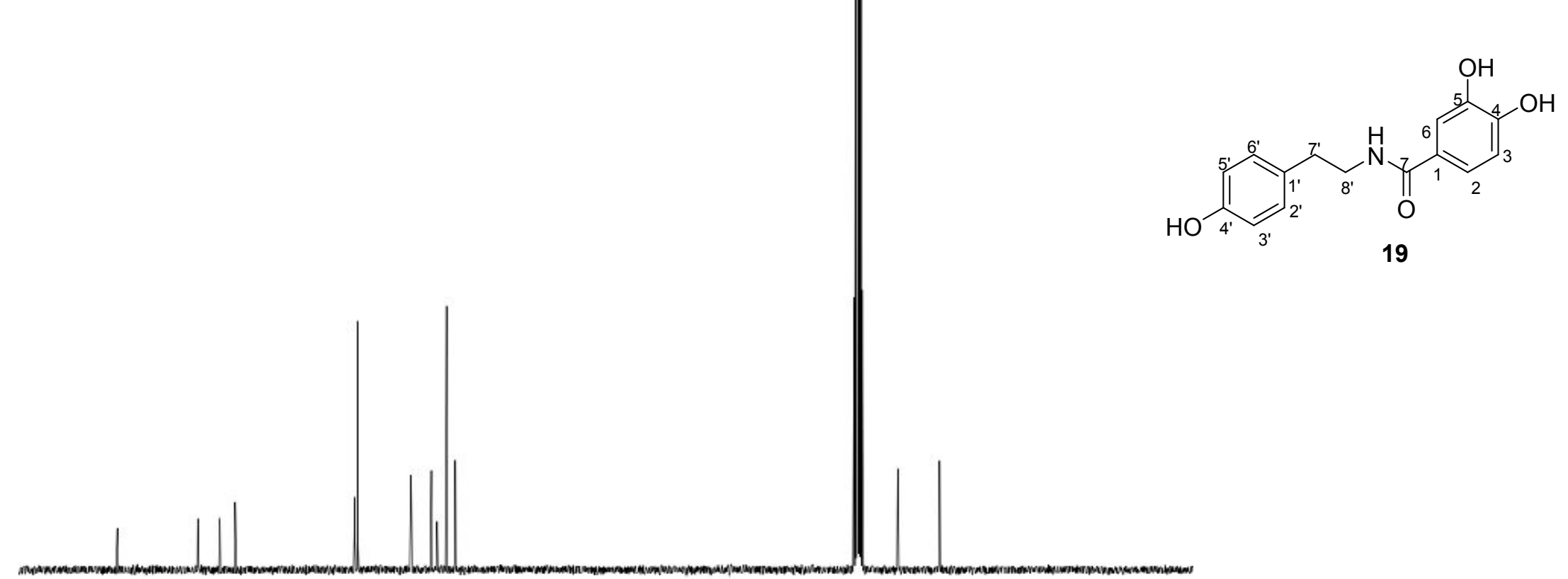
$\begin{array}{llllllllll}180 & 170 & 160 & 150 & 140 & 130 & 120 & 110 & \begin{array}{c}100 \\ \mathrm{f} 1(\mathrm{ppm})\end{array}\end{array}$ 
Figure S125. (+) HRESIMS Spectrum of Compound 19

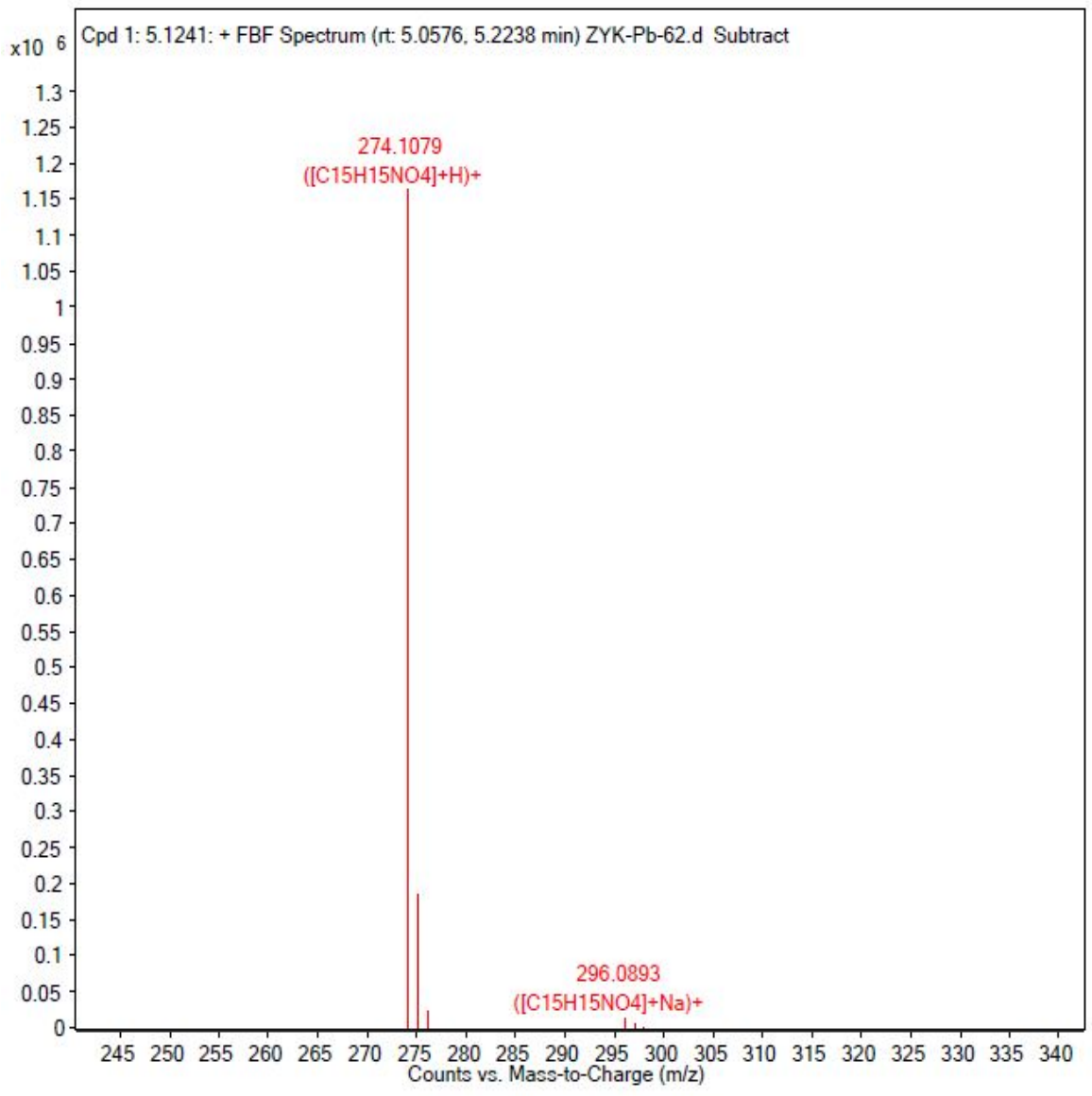


Figure S126. ${ }^{1} \mathrm{H}$ NMR Spectrum of Compound 20 in $\mathrm{MeOH}-d_{4}$

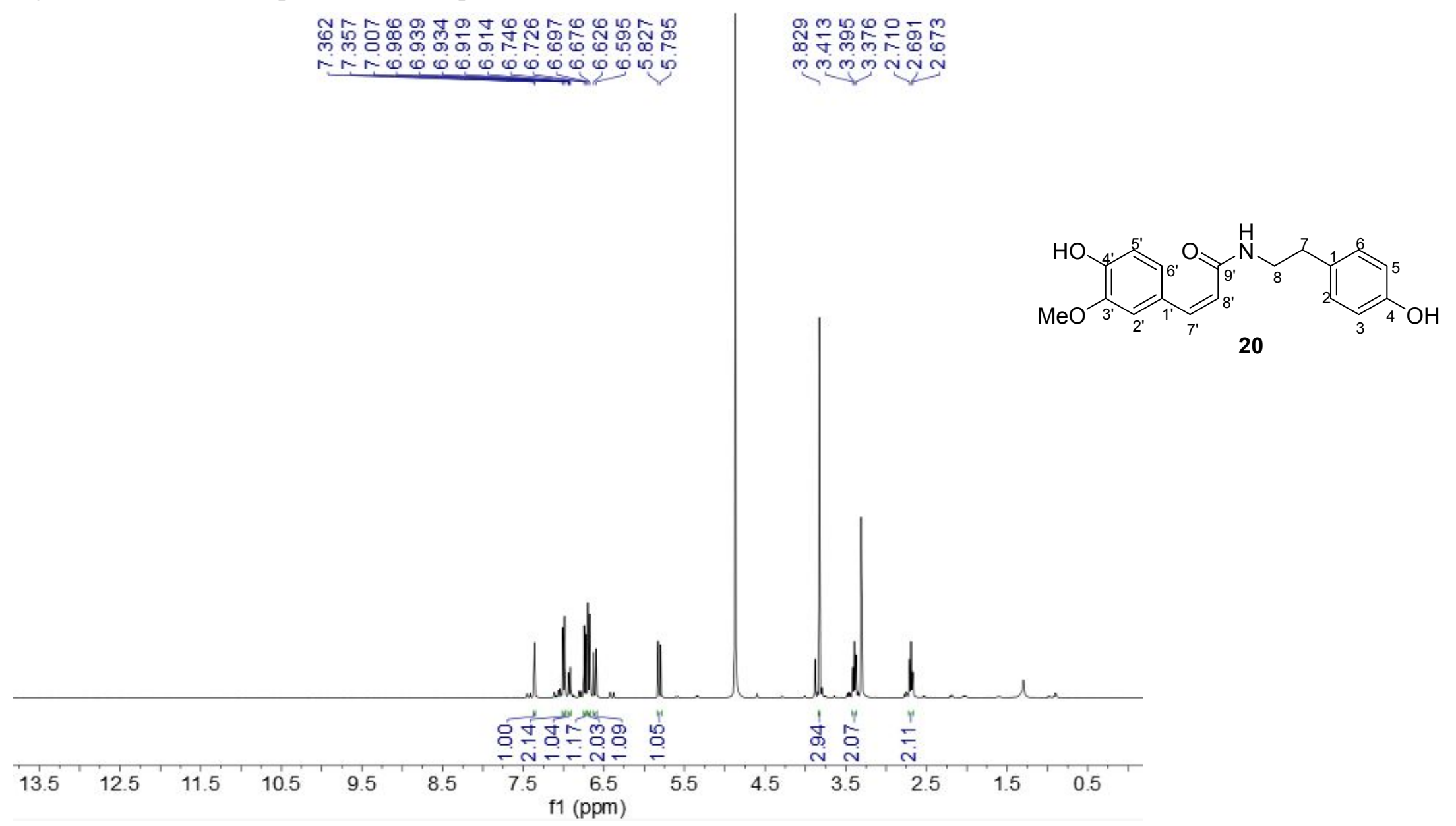


Figure S127. ${ }^{13} \mathrm{C}$ NMR Spectrum of Compound 20 in $\mathrm{MeOH}-d_{4}$
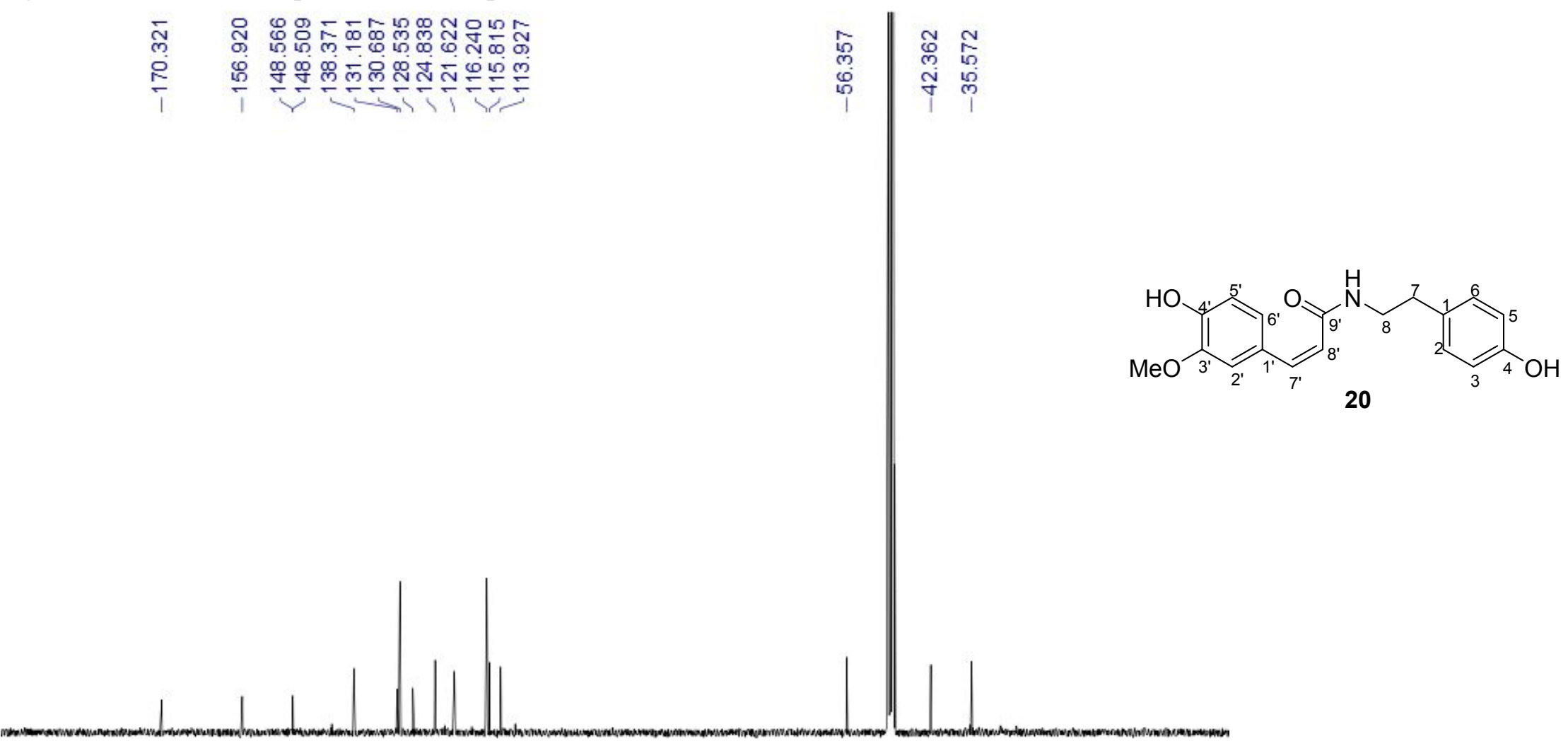

$\begin{array}{lllllllllll}190 & 180 & 170 & 160 & 150 & 140 & 130 & 120 & 110 & 100 & 90\end{array}$ f1 (ppm) 
Figure S128. (+) HRESIMS Spectrum of Compound 20
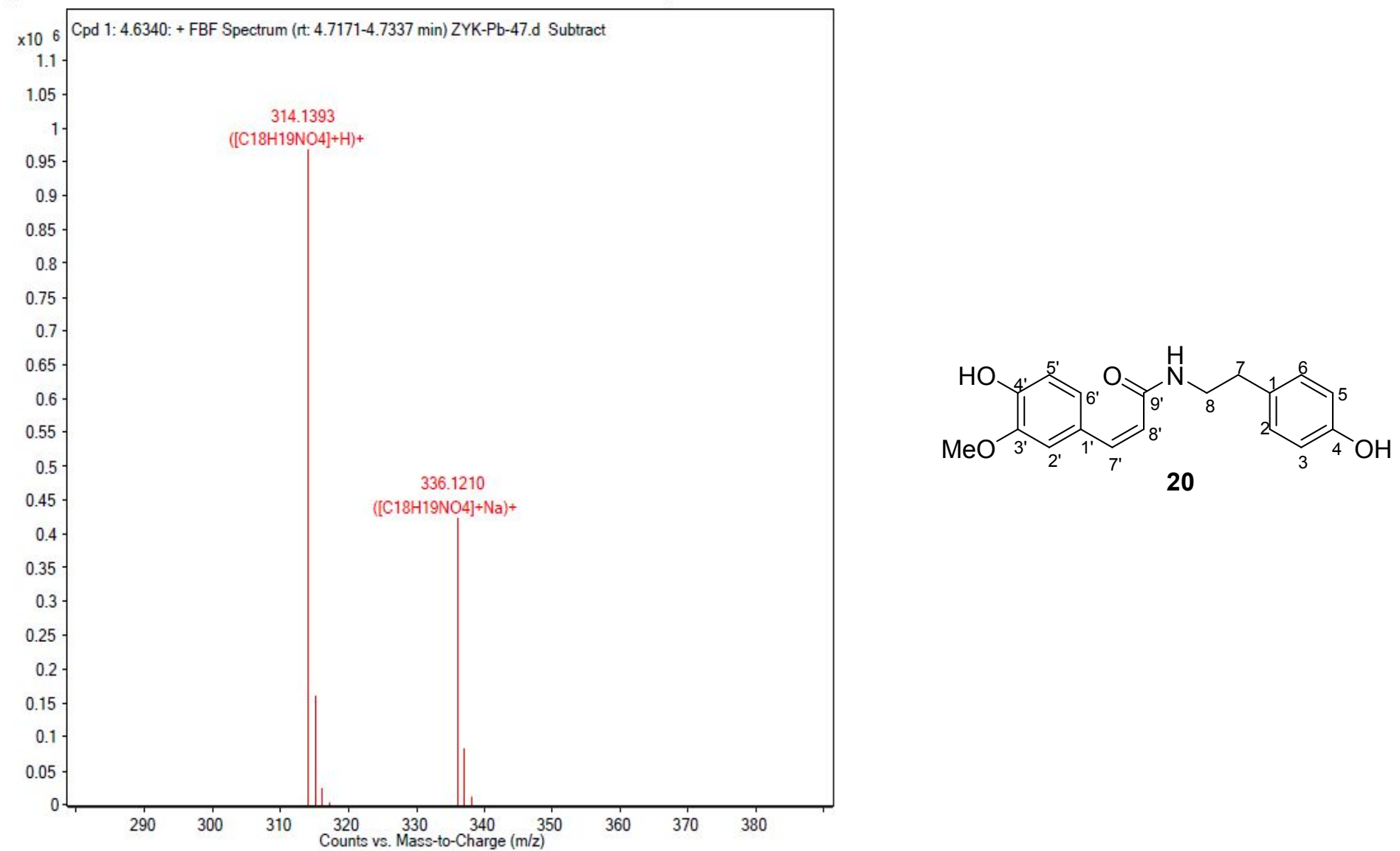
Figure S129. ${ }^{1} \mathrm{H}$ NMR Spectrum of Compound 21 in $\mathrm{MeOH}-d_{4}$

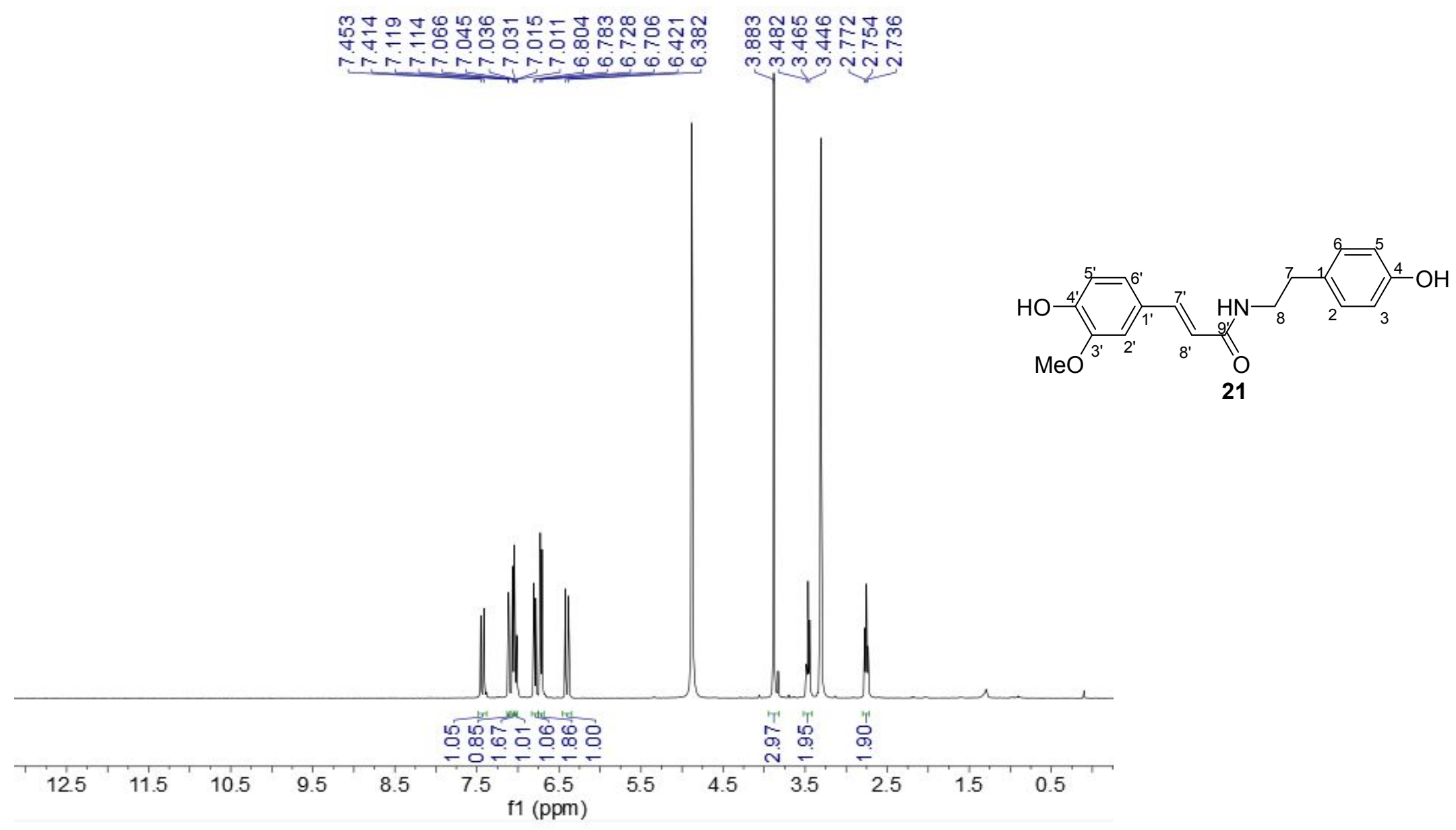


Figure S130. ${ }^{13} \mathrm{C}$ NMR Spectrum of Compound 21 in $\mathrm{MeOH}-d_{4}$

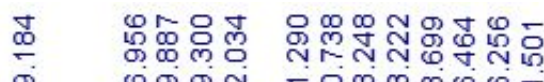

$$
\begin{aligned}
& \text { 。 }
\end{aligned}
$$
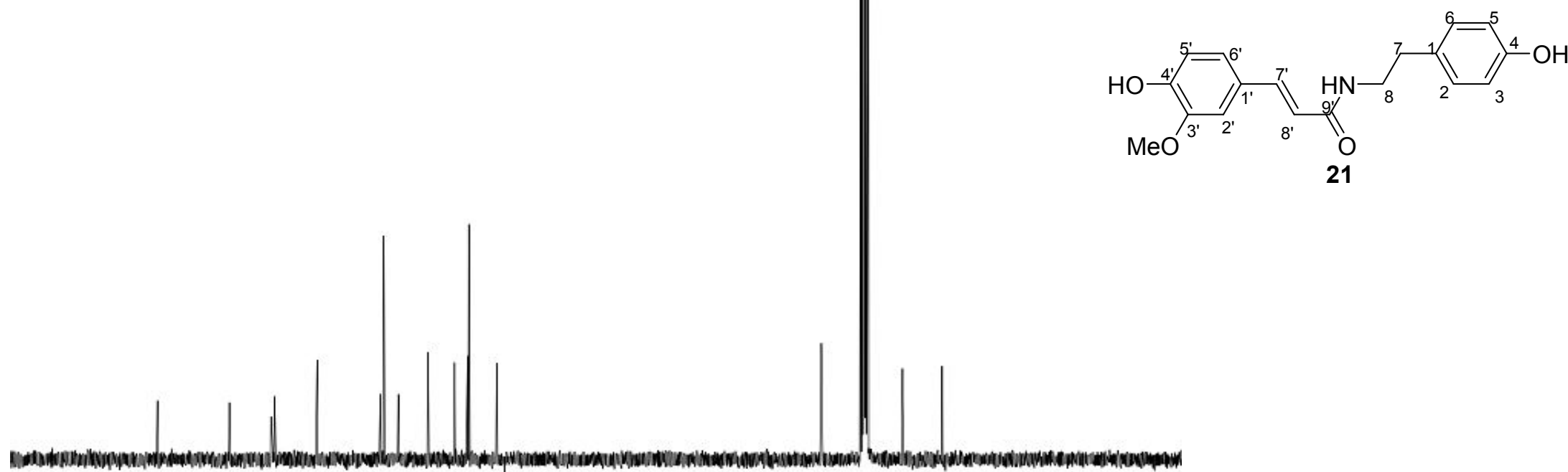

$\begin{array}{lllllllllll}190 & 180 & 170 & 160 & 150 & 140 & 130 & 120 & 110 & \begin{array}{l}100 \\ \mathrm{f} 1(\mathrm{ppm})\end{array}\end{array}$ 
Figure S131. (+) HRESIMS Spectrum of Compound 21
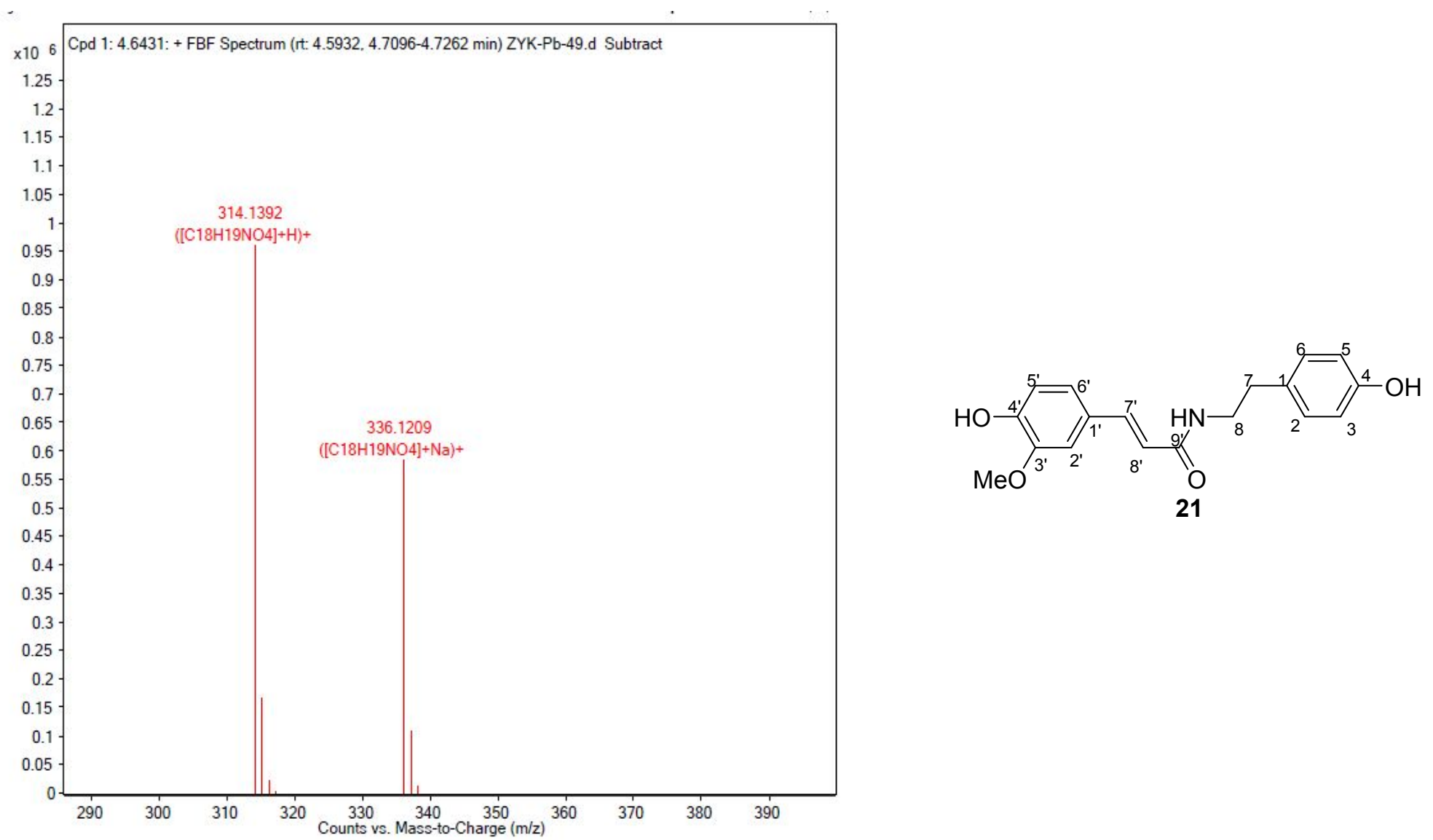
Figure S132. ${ }^{1} \mathrm{H}$ NMR Spectrum of Compound 22 in $\mathrm{MeOH}-d_{4}$

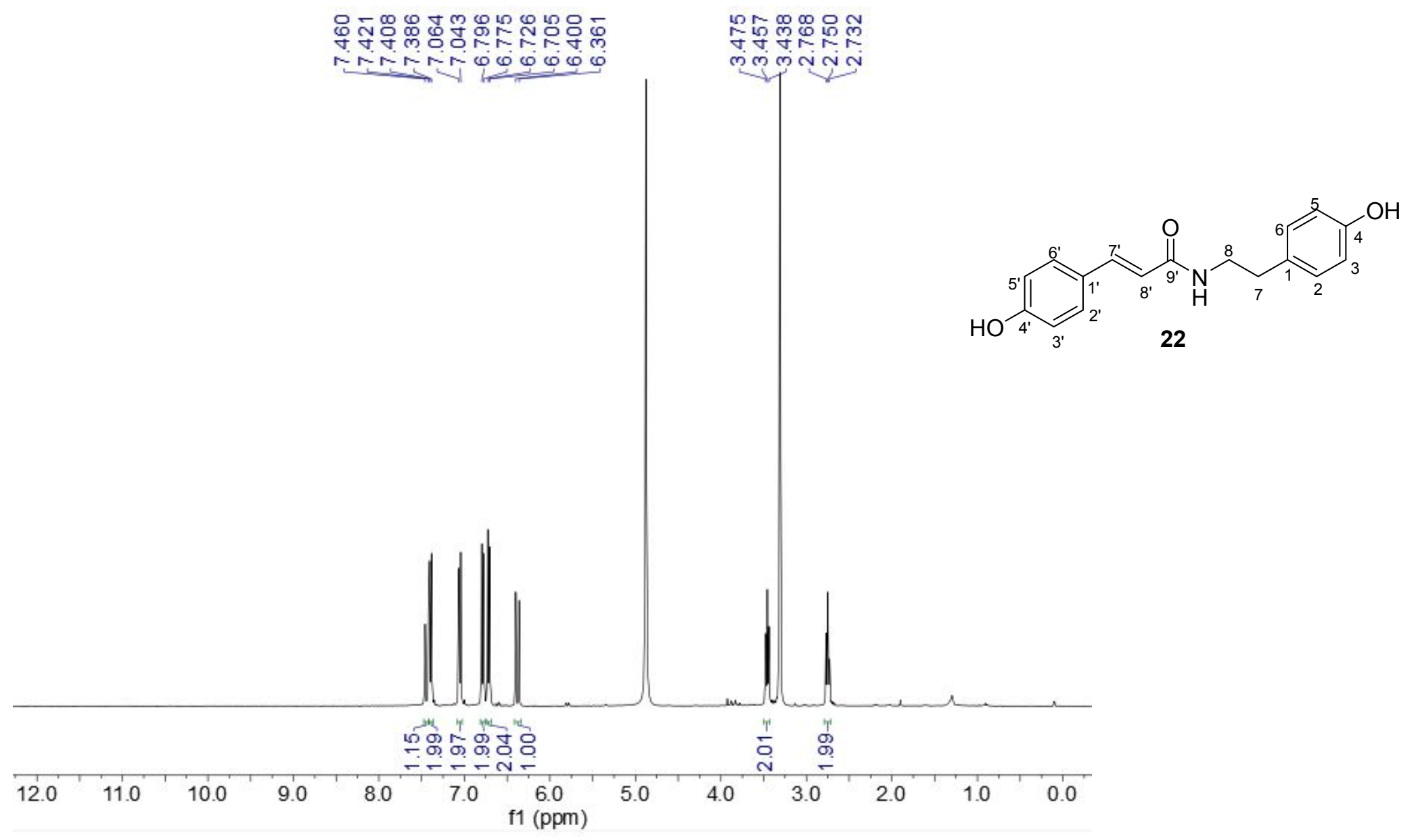


Figure S133. ${ }^{13} \mathrm{C}$ NMR Spectrum of Compound 22 in $\mathrm{MeOH}-d_{4}$

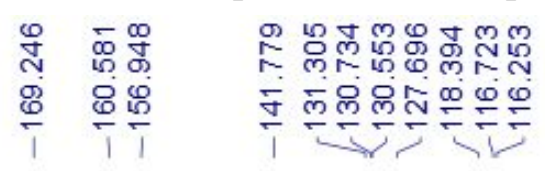

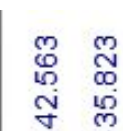

४

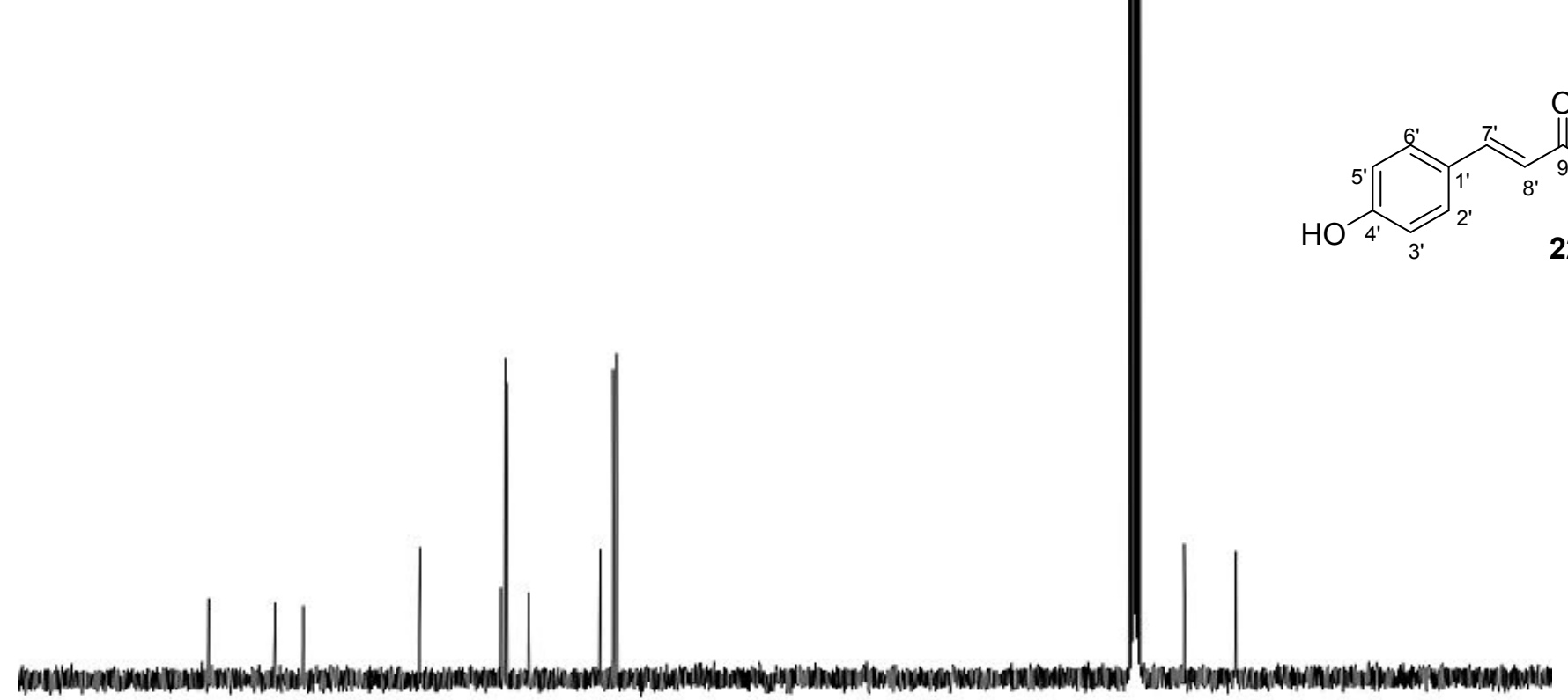

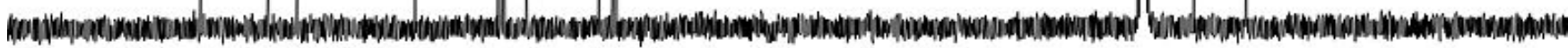

$\begin{array}{lllllllllll}190 & 180 & 170 & 160 & 150 & 140 & 130 & 120 & 110 & 100 & 90\end{array}$

f1 (ppm) 
Figure S134. (+) HRESIMS Spectrum of Compound 22

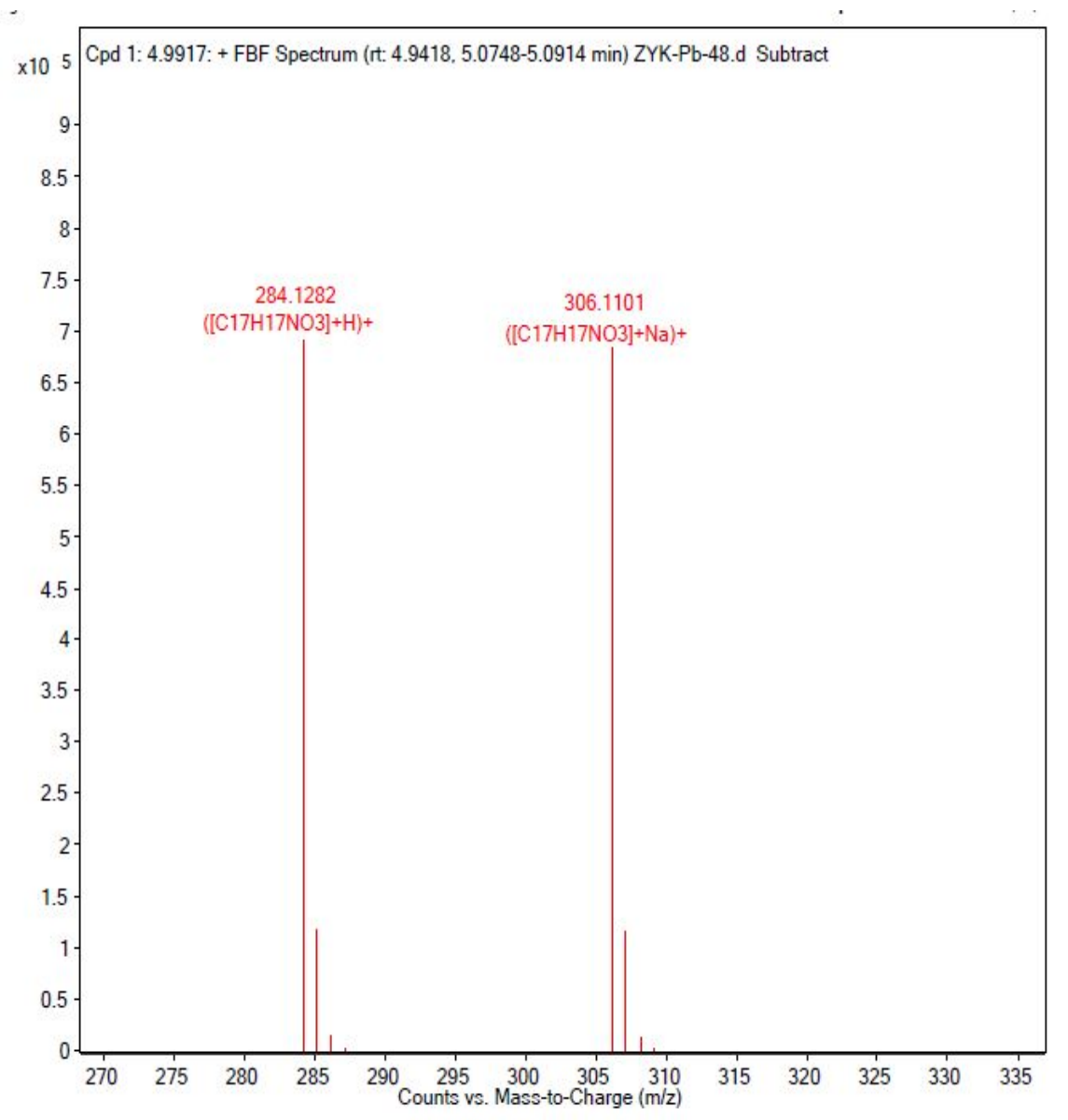

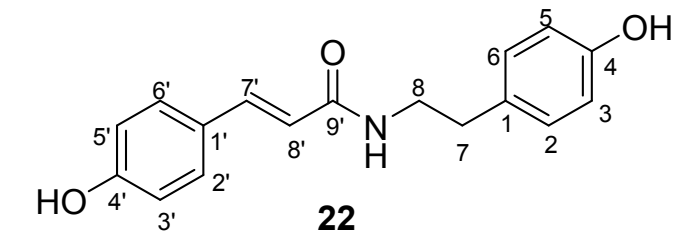


Figure S135. ${ }^{1} \mathrm{H}$ NMR Spectrum of Compound 23 in $\mathrm{MeOH}-d_{4}$

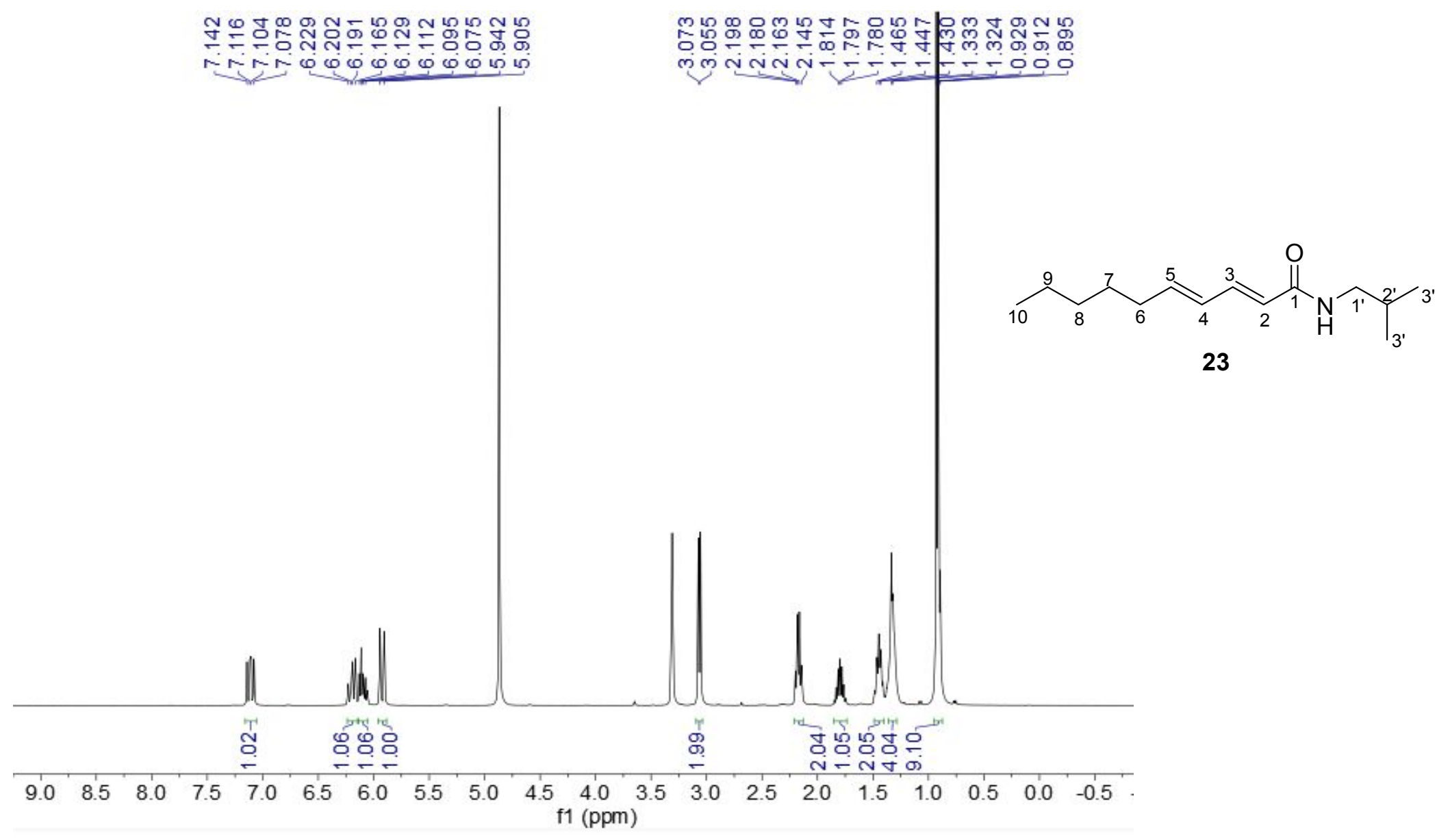


Figure S136. ${ }^{13} \mathrm{C}$ NMR Spectrum of Compound 23 in $\mathrm{MeOH}-d_{4}$

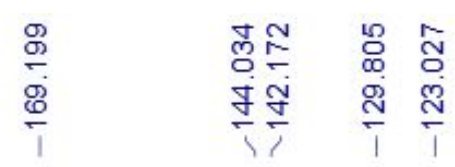

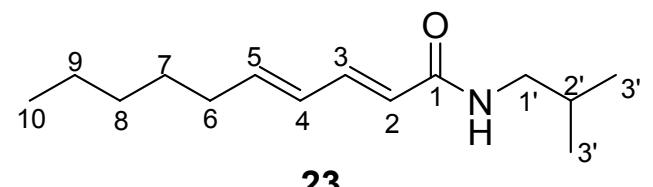
का

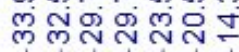
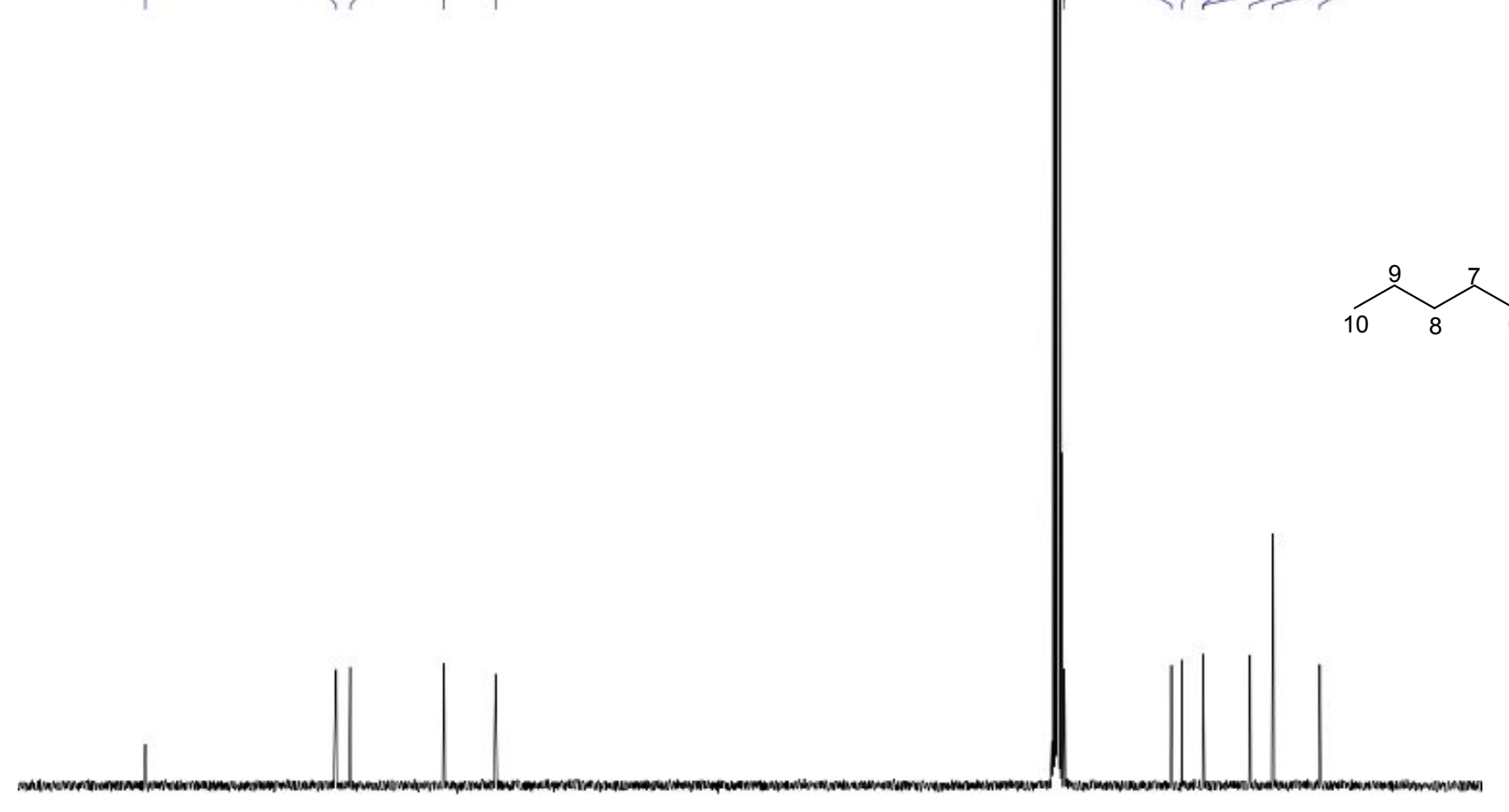

23

$\begin{array}{llllllllll}180 & 170 & 160 & 150 & 140 & 130 & 120 & 110 & 100 & 90\end{array}$ f1 (ppm) 
Figure S137. (+) HRESIMS Spectrum of Compound 23

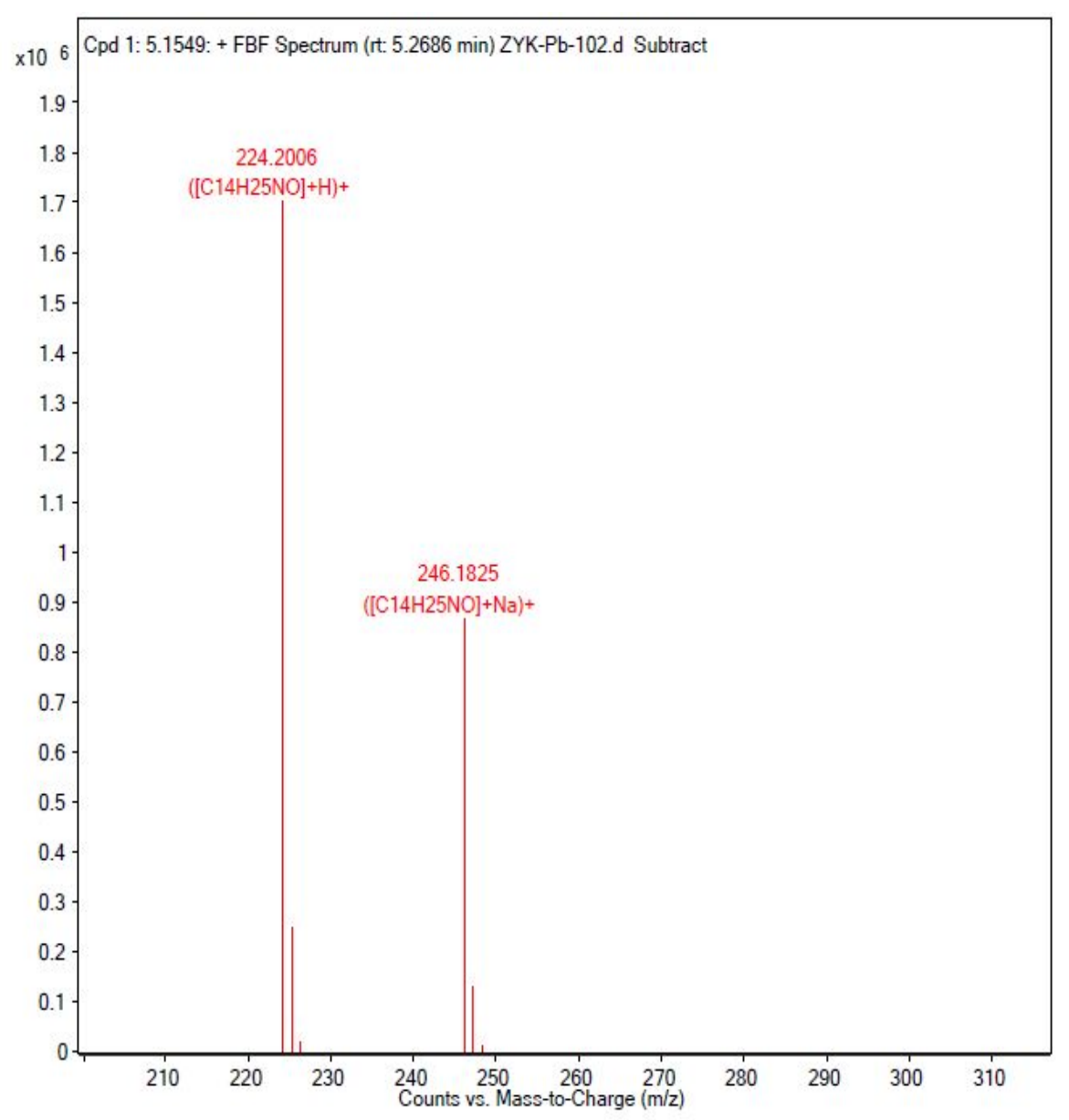


Figure S138. ${ }^{1} \mathrm{H}$ NMR Spectrum of Compound 24 in $\mathrm{CDCl}_{3}$

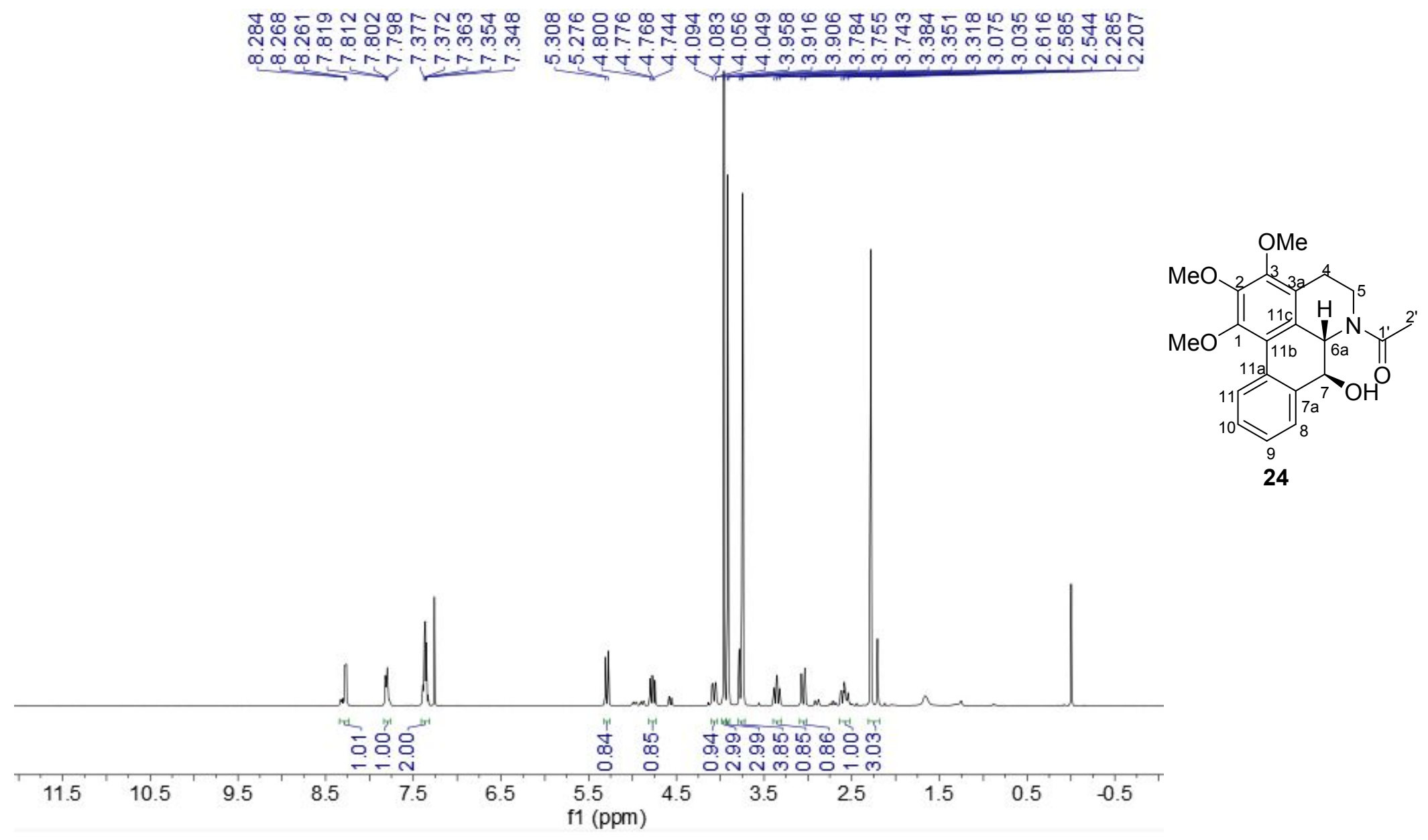


Figure S139. ${ }^{13} \mathrm{C}$ NMR Spectrum of Compound 24 in $\mathrm{CDCl}_{3}$

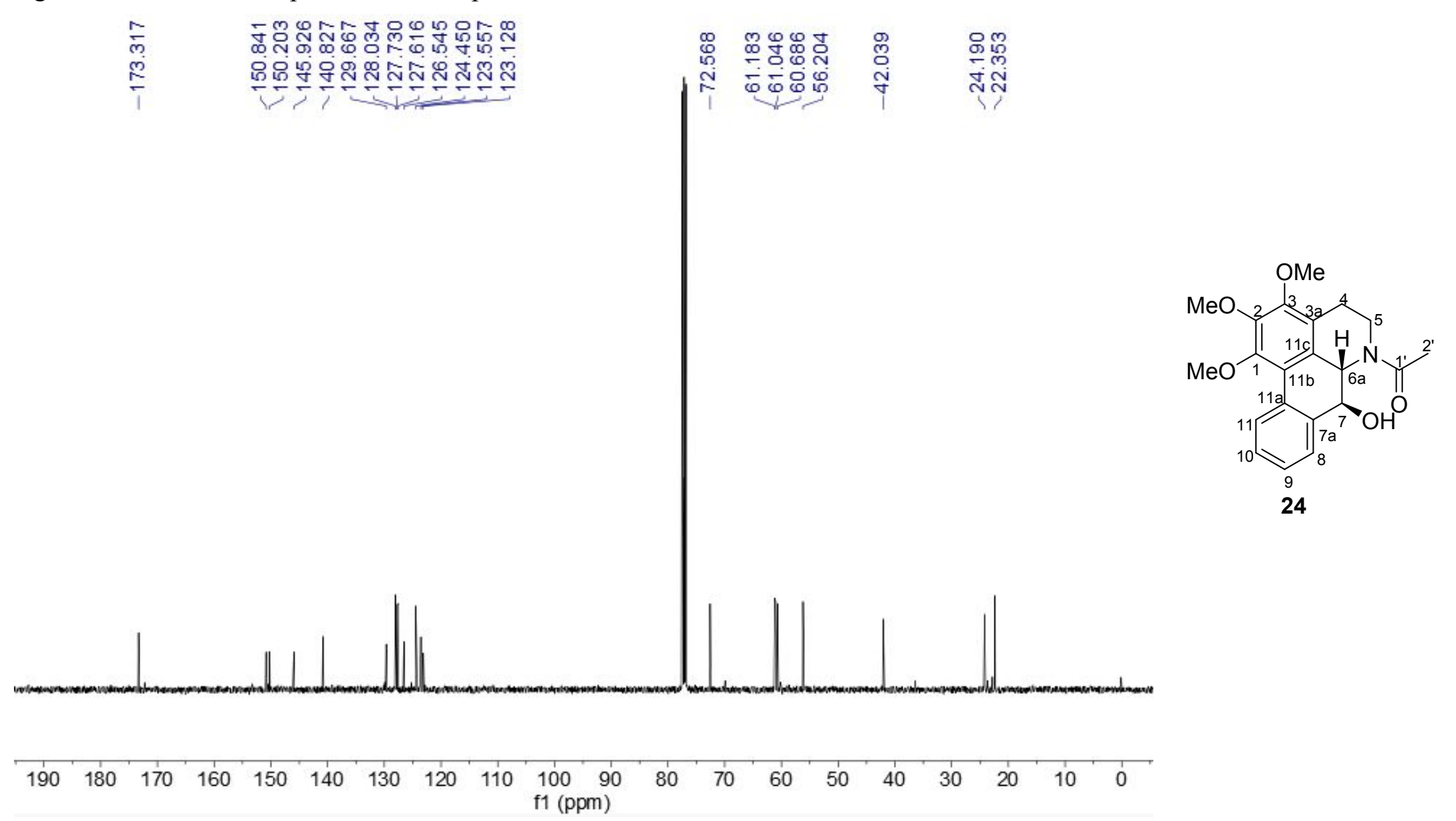


Figure S140. (+) HRESIMS Spectrum of Compound 24

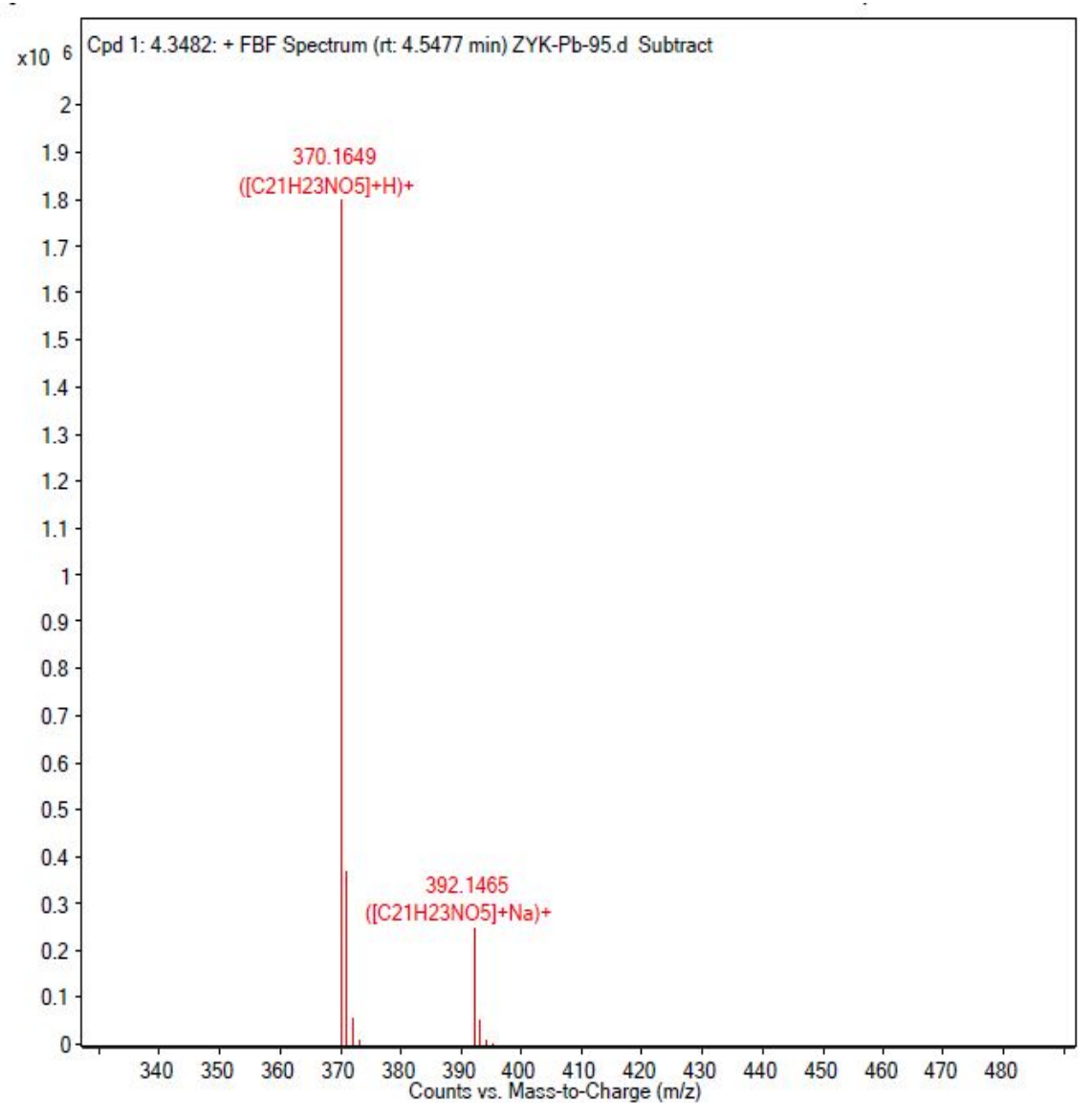

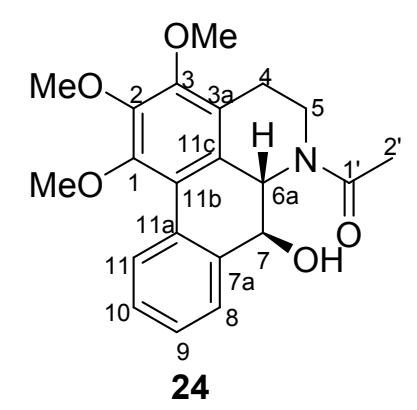


Figure S141. ${ }^{1} \mathrm{H}$ NMR Spectrum of Compound 25 in DMSO- $d_{6}$

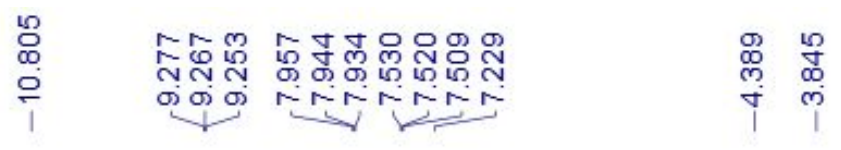

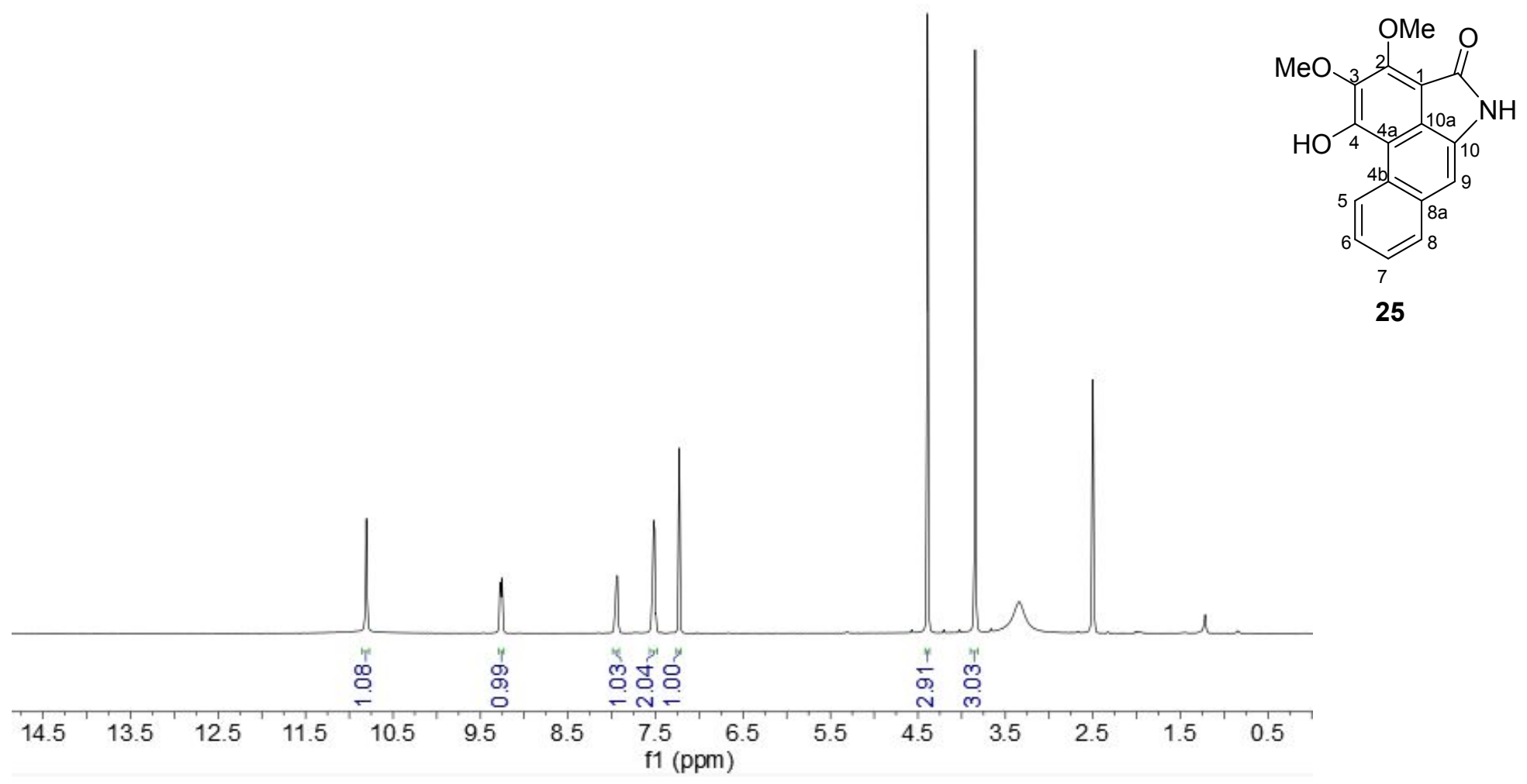


Figure S142. ${ }^{13} \mathrm{C}$ NMR Spectrum of Compound 25 in DMSO- $d_{6}$

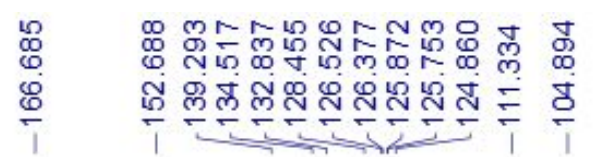

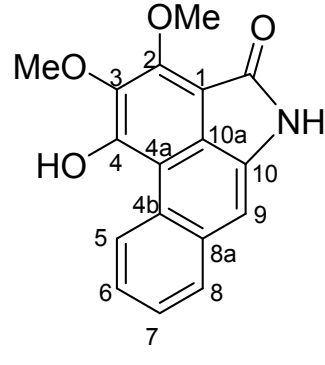

25

$\begin{array}{llllllllllllllllllll}190 & 180 & 170 & 160 & 150 & 140 & 130 & 120 & 110 & \begin{array}{c}100 \\ \mathrm{f} 1(\mathrm{ppm})\end{array} & 90 & 70 & 60 & 50 & 40 & 30 & 20 & 10 & 0\end{array}$


Figure S143. (+) HRESIMS Spectrum of Compound 25

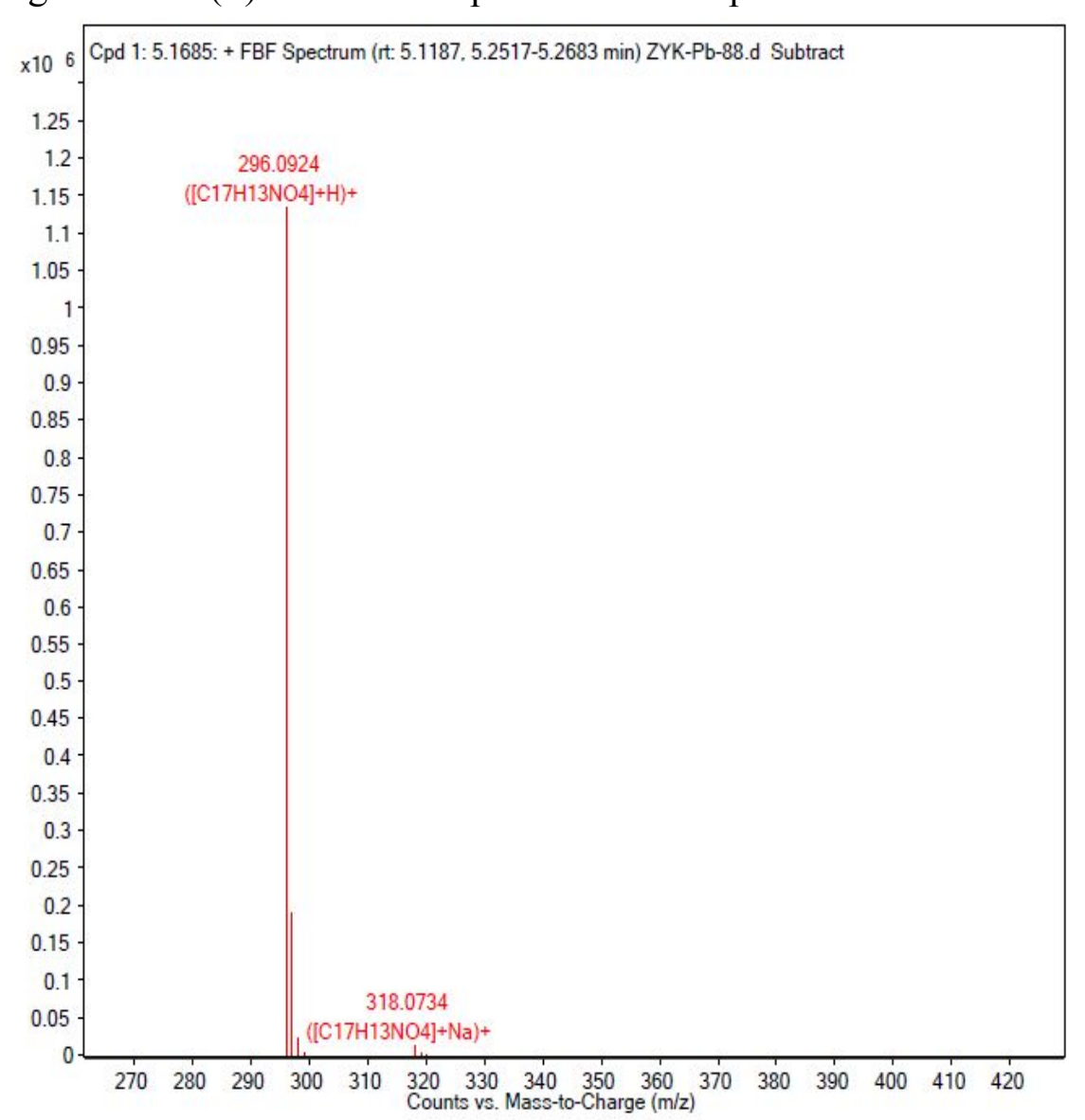

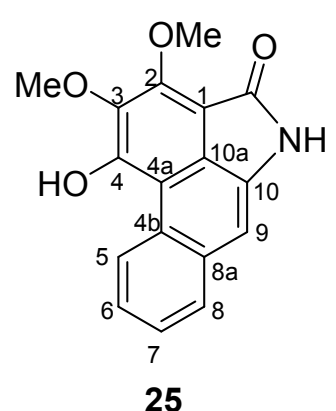

25 
Figure S144. ${ }^{1} \mathrm{H}$ NMR Spectrum of Compound 26 in DMSO- $d_{6}$
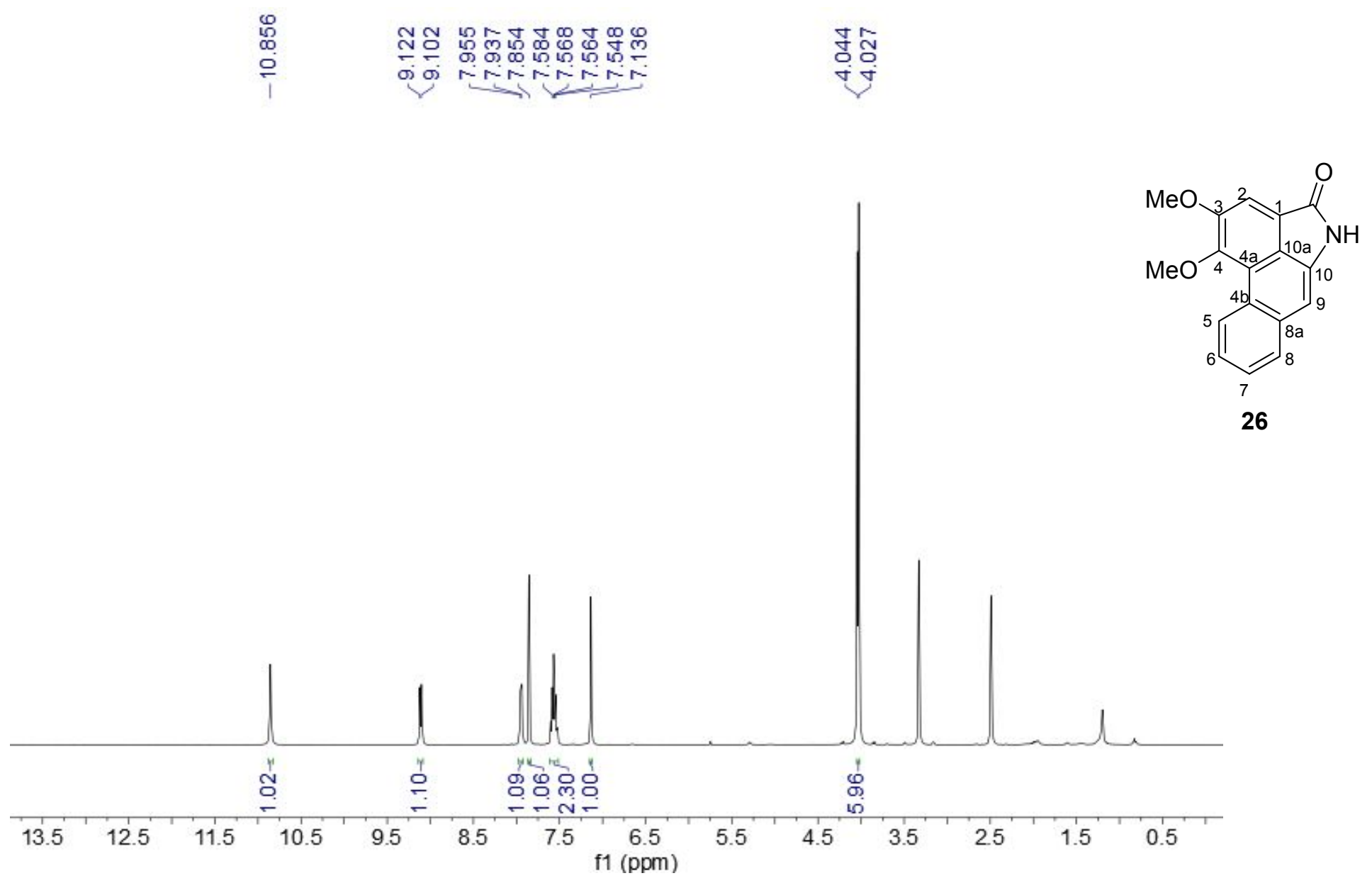
Figure S145. ${ }^{13} \mathrm{C}$ NMR Spectrum of Compound 26 in DMSO- $d_{6}$

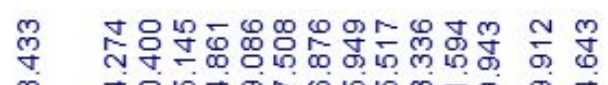

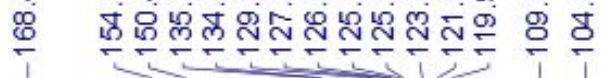

萬察

ค1

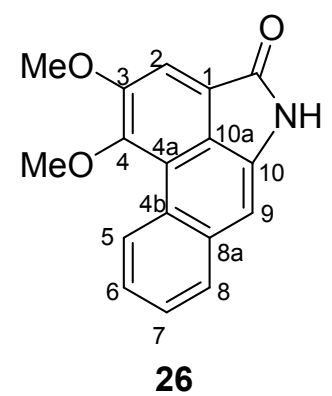

$180^{\prime}$

$170 \quad 160$

$150 \quad 140$

$130 \quad 120$

110

$100 \quad 90$

60

50 
Figure S146. (+) HRESIMS Spectrum of Compound 26

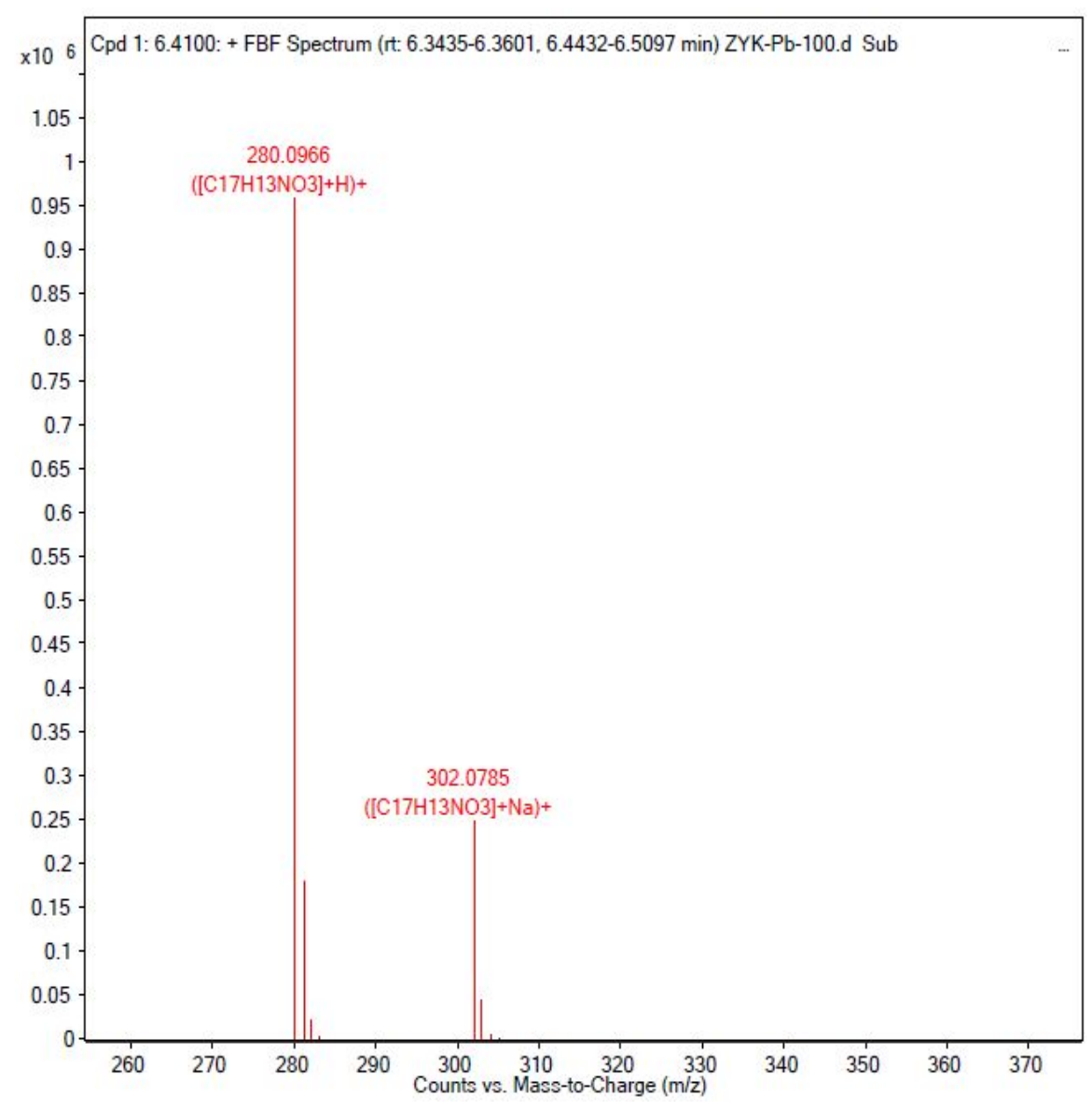


Figure S147. ${ }^{1} \mathrm{H}$ NMR Spectrum of Compound 27 in $\mathrm{MeOH}-d_{4}$

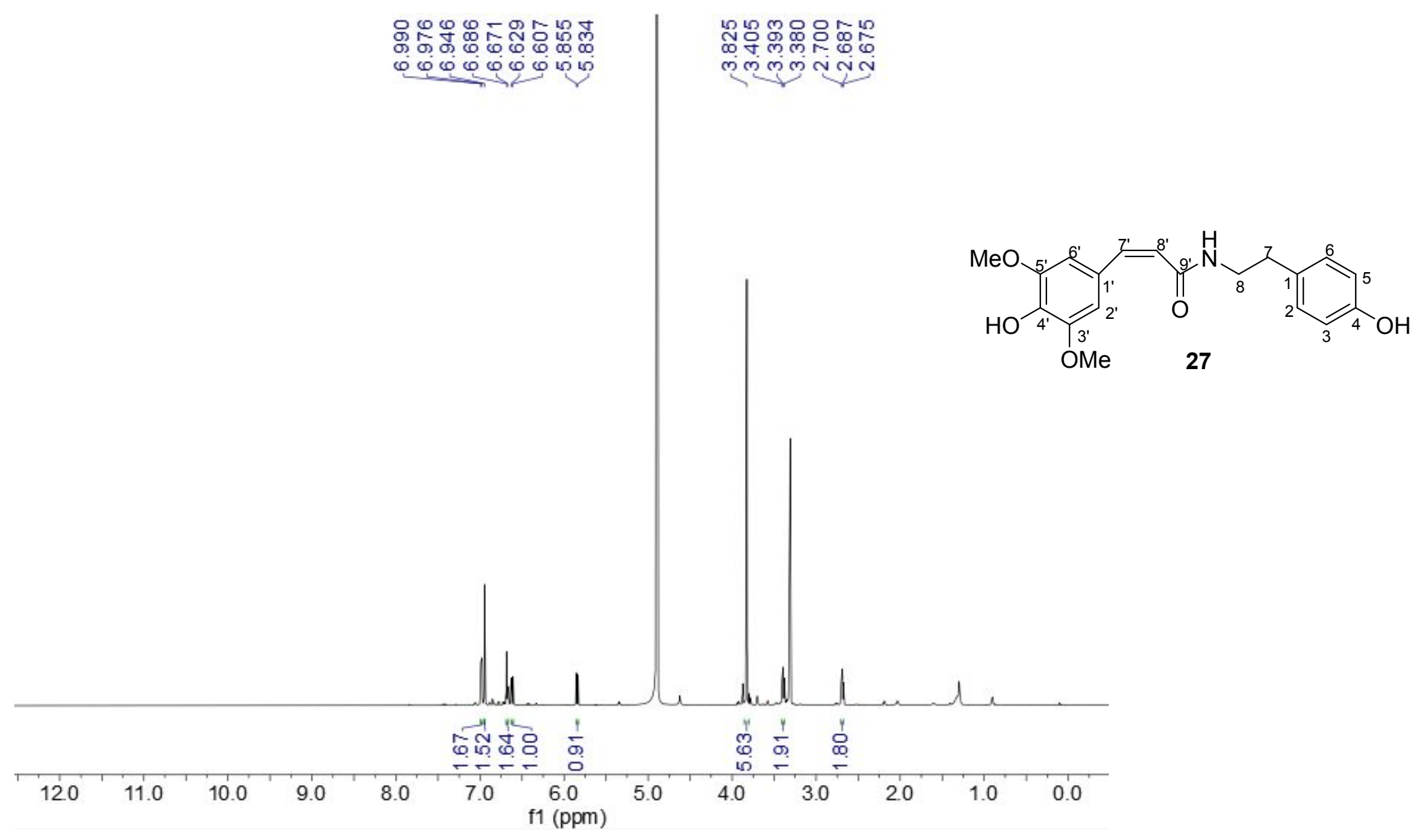


Figure S148. ${ }^{13} \mathrm{C}$ NMR Spectrum of Compound 27 in $\mathrm{MeOH}-d_{4}$

$$
\begin{aligned}
& \text { 每 }
\end{aligned}
$$

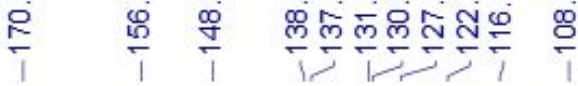
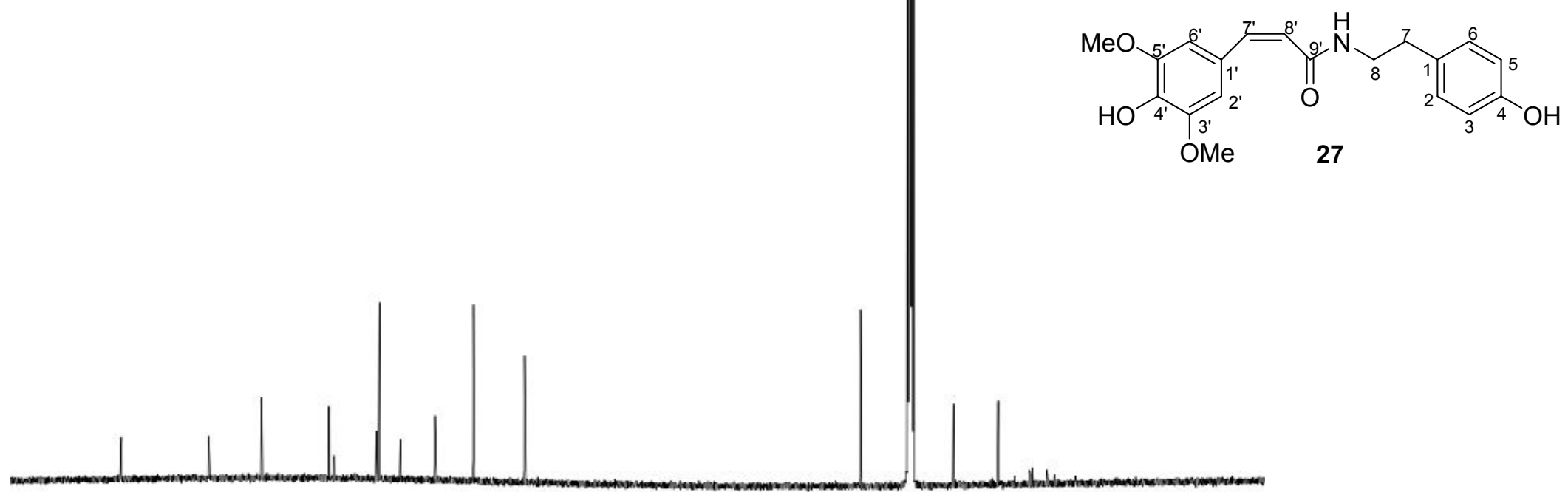

$\begin{array}{lllllllllllllllllll}180 & 170 & 160 & 150 & 140 & 130 & 120 & 110 & 100 & 90 & 80 & 70 & 60 & 50 & 40 & 30 & 20 & 10 & 0\end{array}$ 
Figure S149. (+) HRESIMS Spectrum of Compound 27

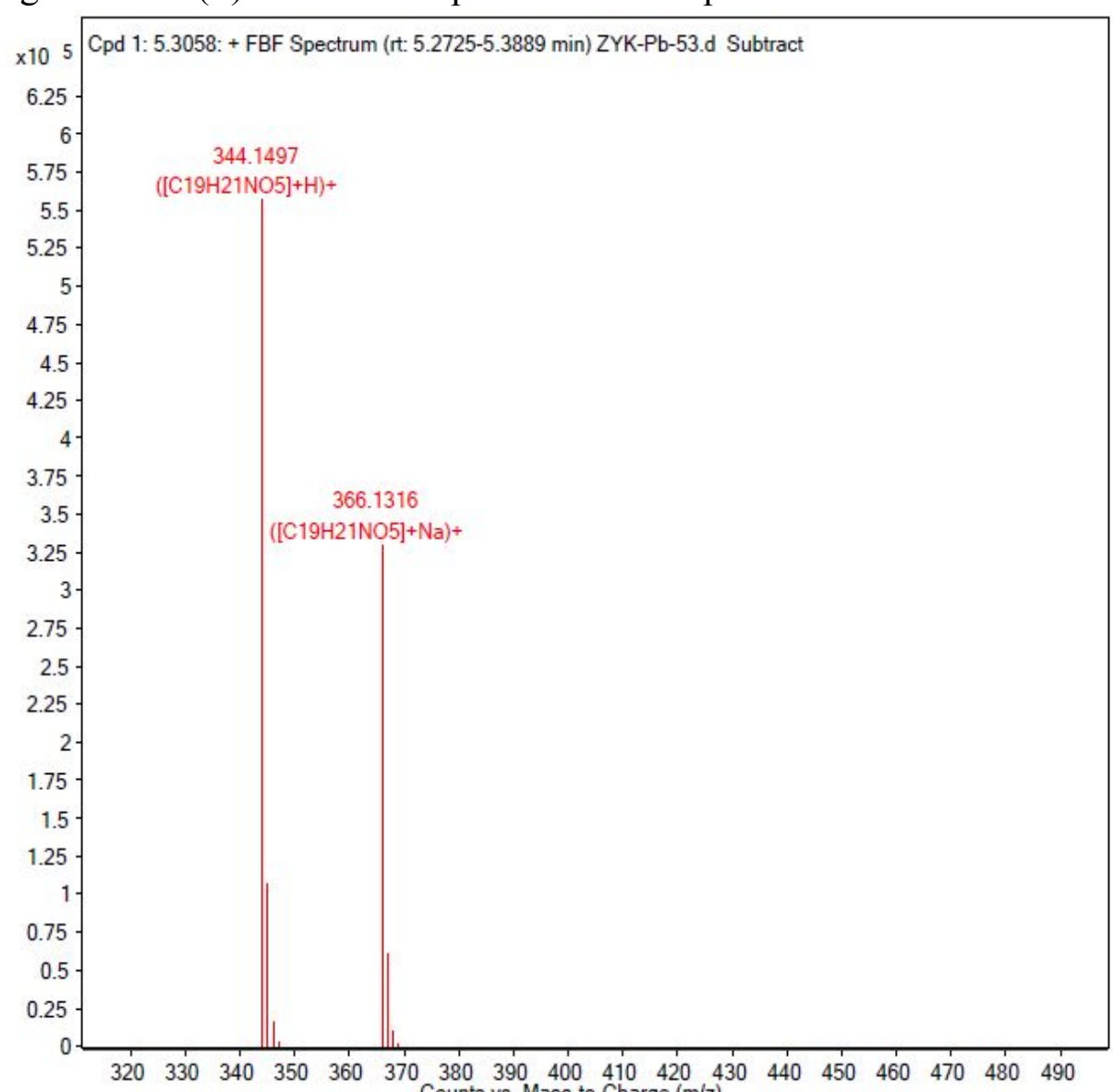

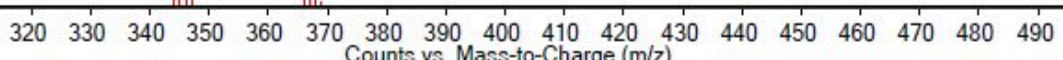

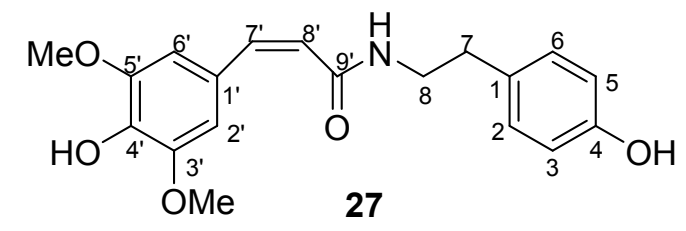


Figure S150. ${ }^{1} \mathrm{H}$ NMR Spectrum of Compound 28 in MeOH- $d_{4}$

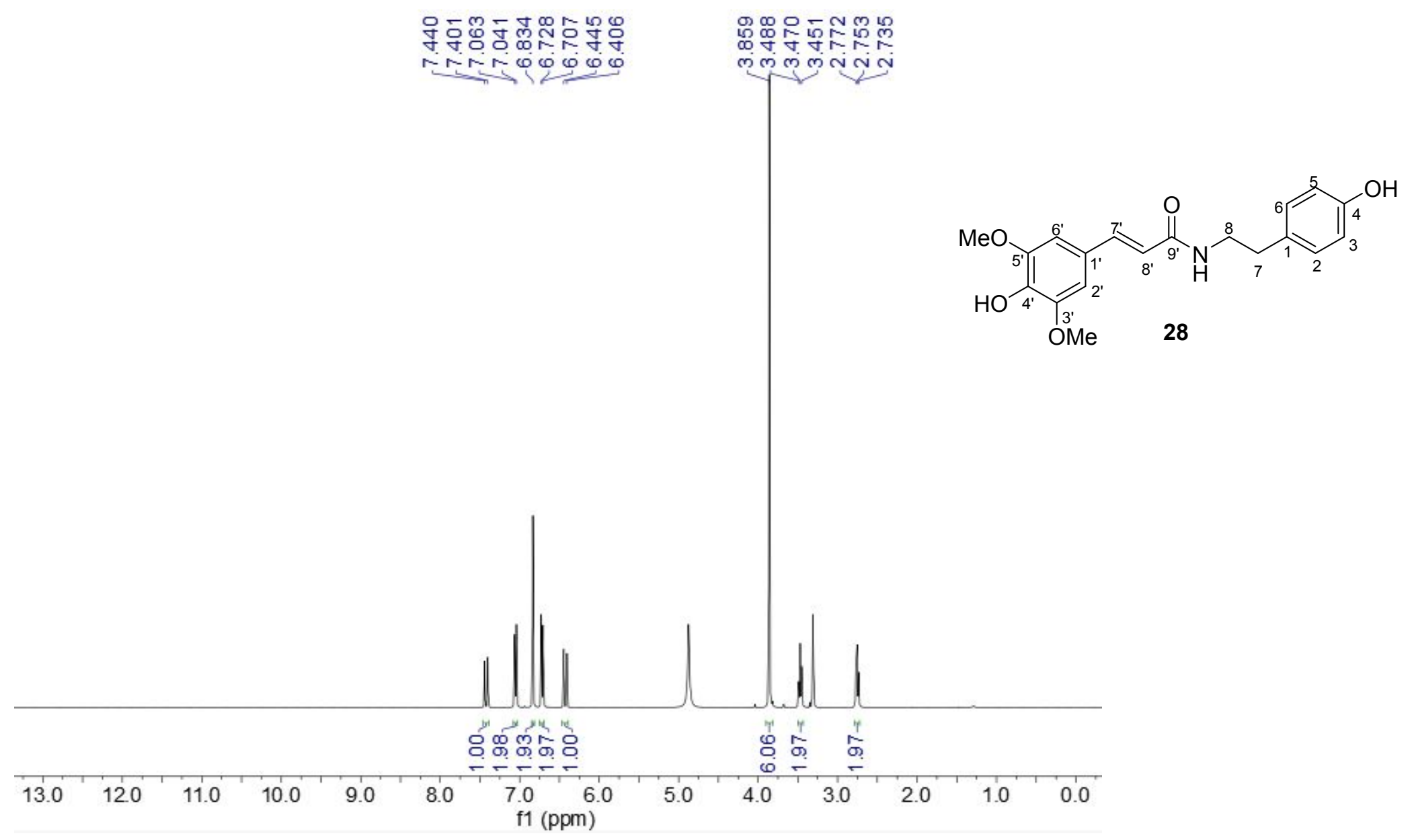


Figure S151. ${ }^{13} \mathrm{C}$ NMR Spectrum of Compound 28 in $\mathrm{MeOH}-d_{4}$

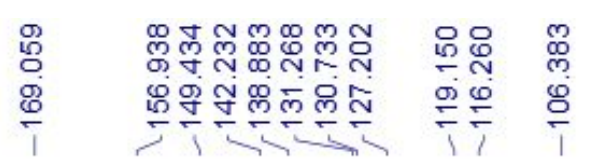

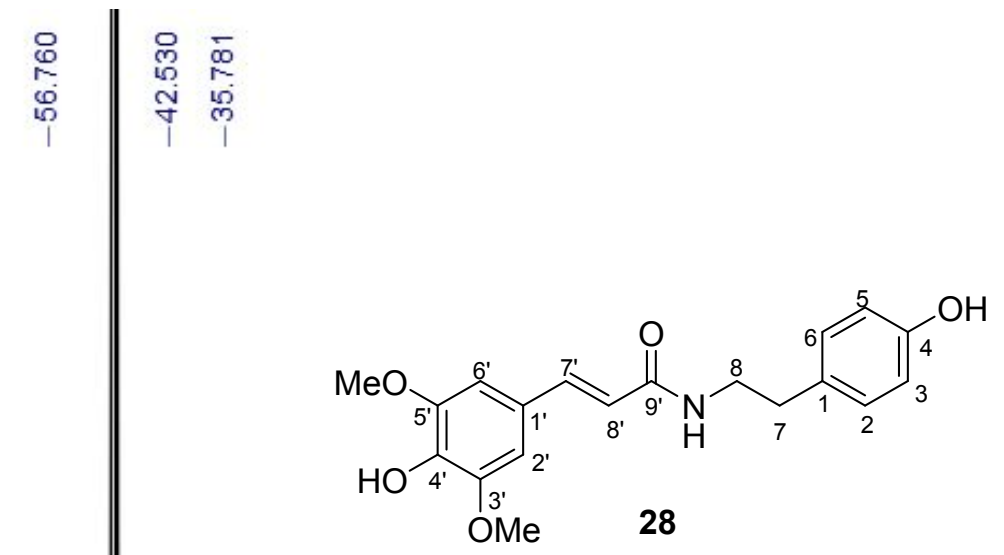

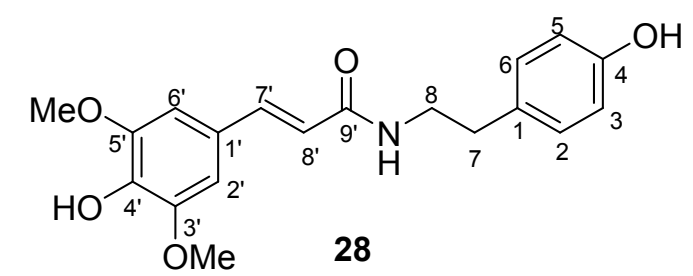

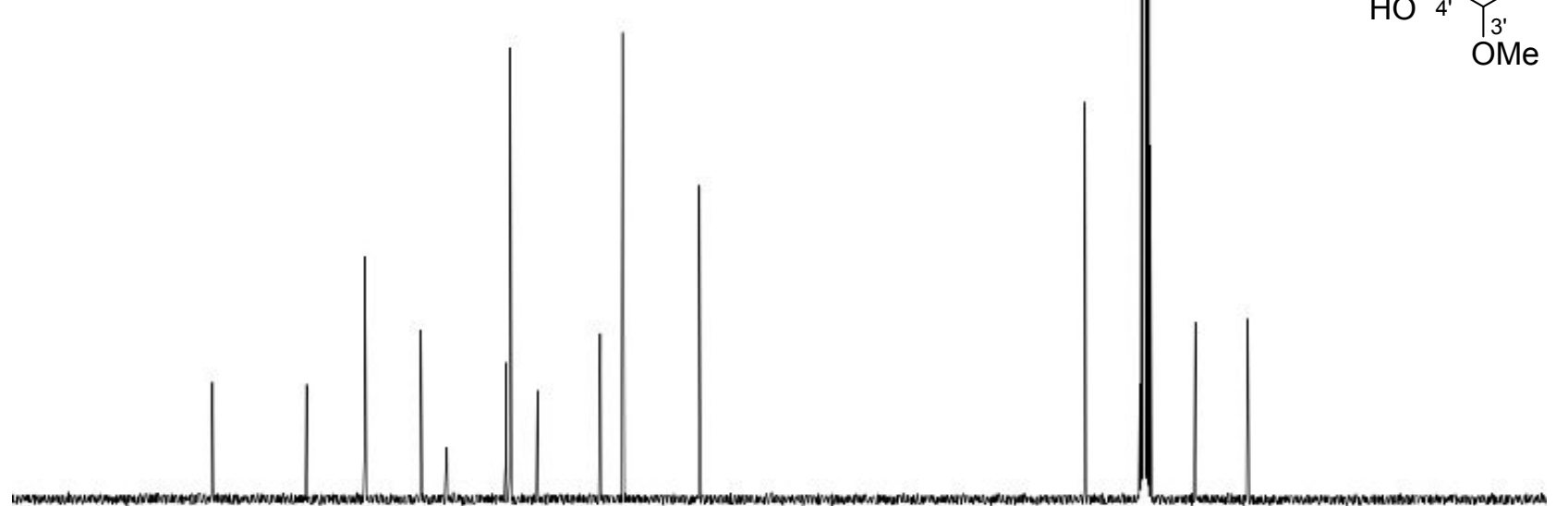

$\begin{array}{lllllllllll}190 & 180 & 170 & 160 & 150 & 140 & 130 & 120 & 110 & 100 & 90\end{array}$ f1 (ppm) 
Figure S152. (+) HRESIMS Spectrum of Compound 28

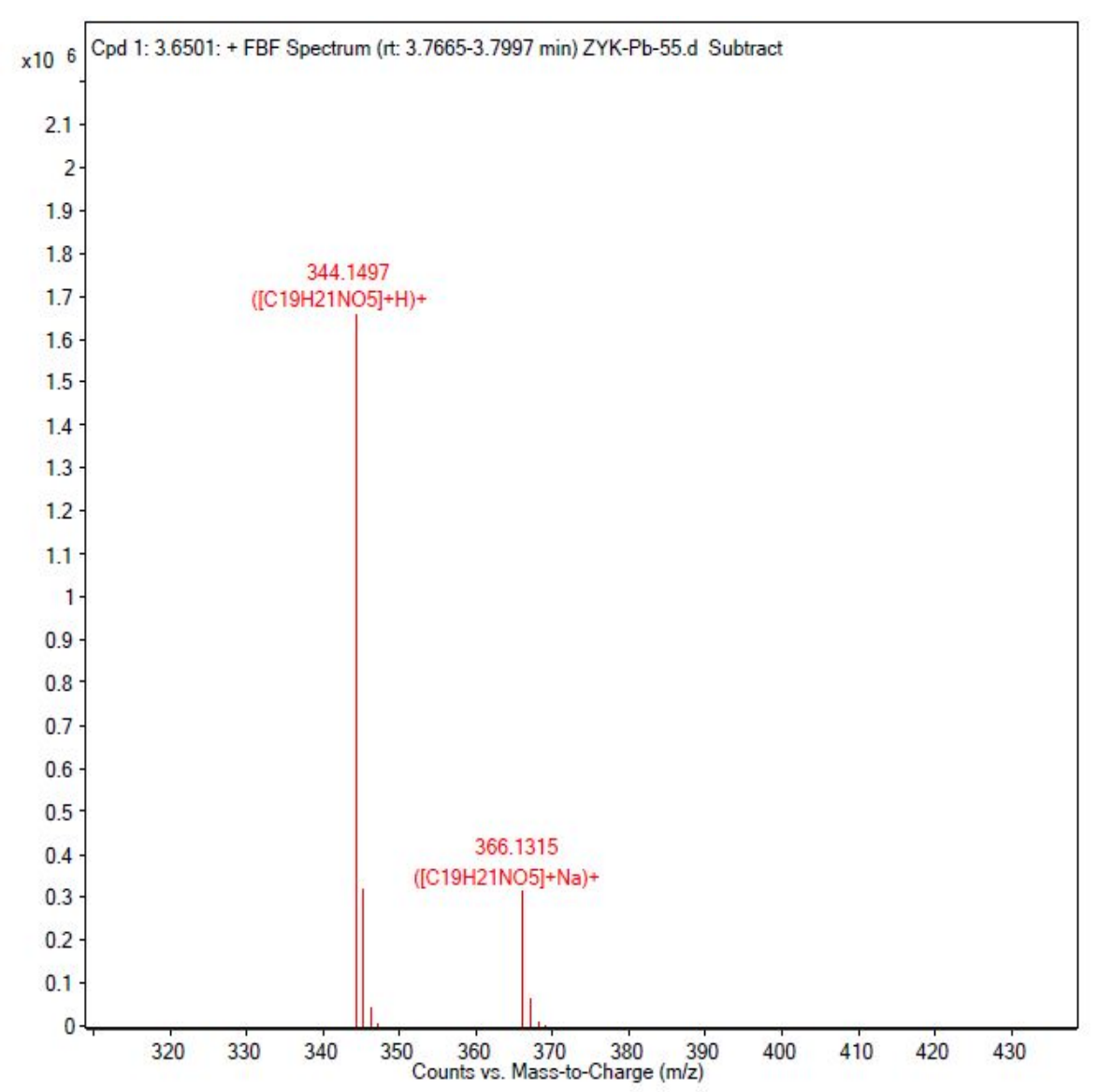

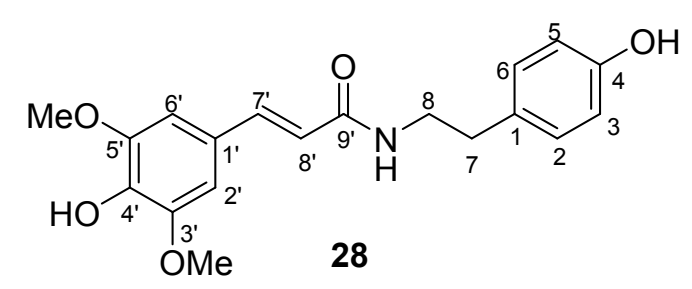


Figure S153. ${ }^{1} \mathrm{H}$ NMR Spectrum of Compound 29 in $\mathrm{MeOH}-d_{4}$

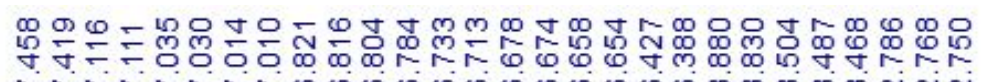

rmprrmen

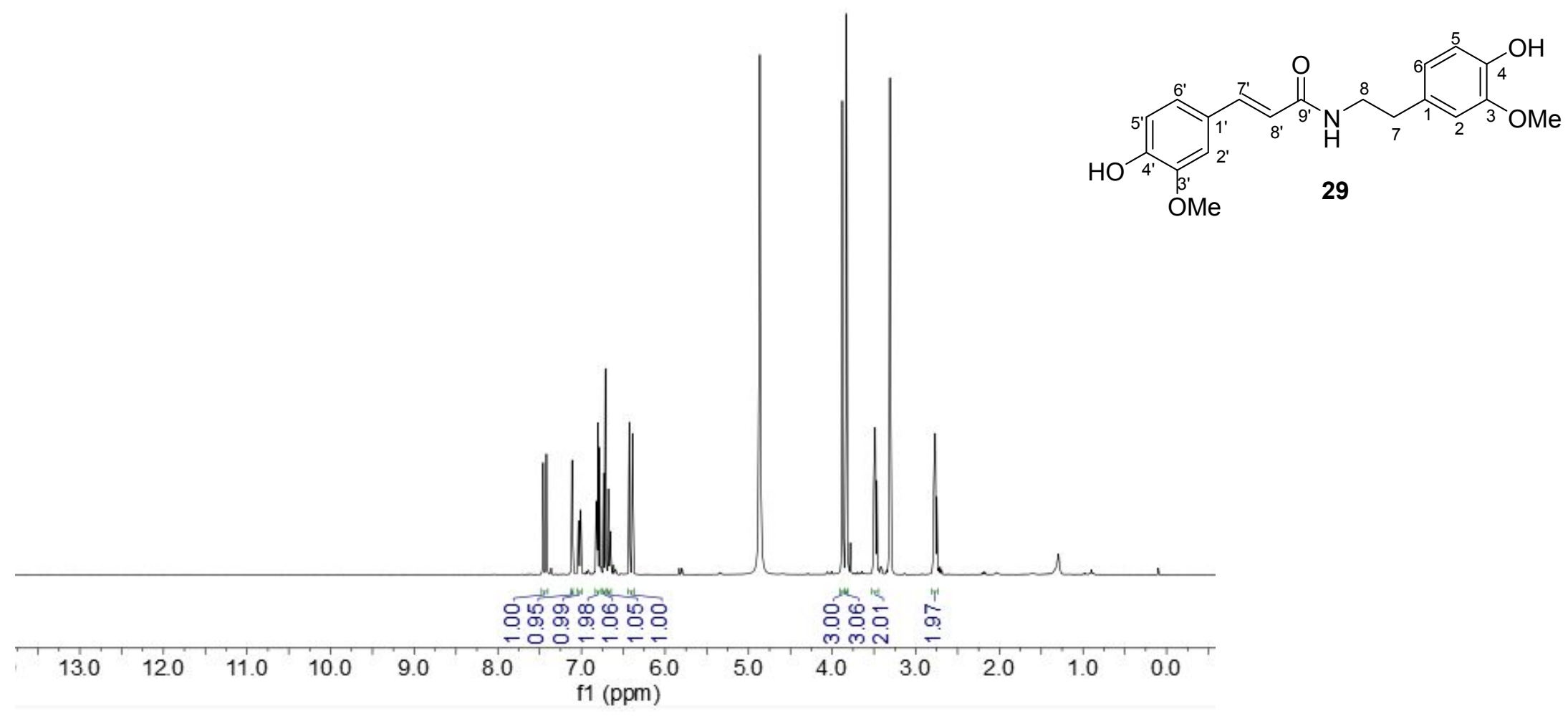


Figure S154. ${ }^{13} \mathrm{C}$ NMR Spectrum of Compound 29 in $\mathrm{MeOH}-d_{4}$

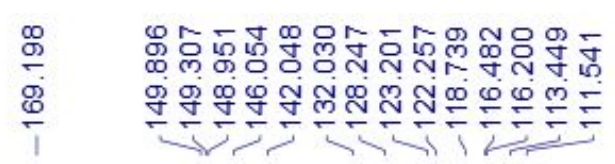

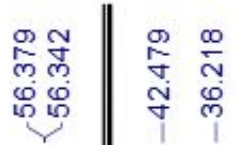

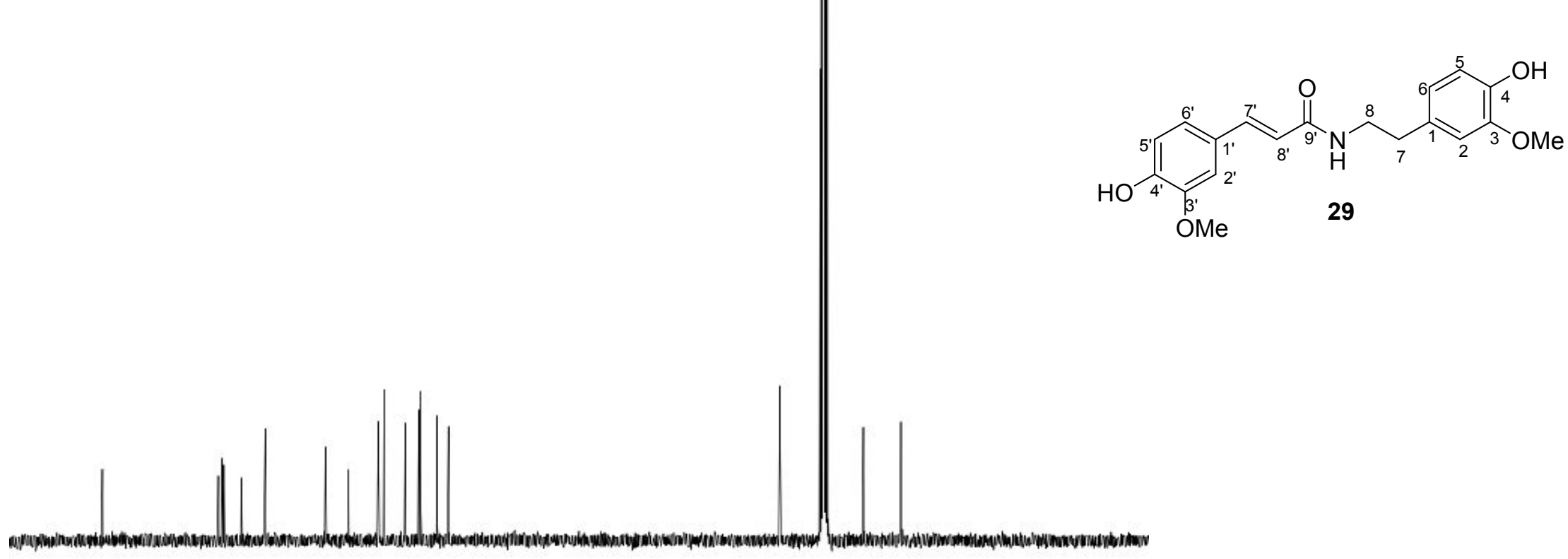

$\begin{array}{lllllllllllllllllll}180 & 170 & 160 & 150 & 140 & 130 & 120 & 110 & 100 & \begin{array}{c}90 \\ \mathrm{f} 1(\mathrm{ppm})\end{array} & 80 & 70 & 60 & 50 & 40 & 30 & 20 & 10 & 0\end{array}$ 
Figure S155. (+) HRESIMS Spectrum of Compound 29

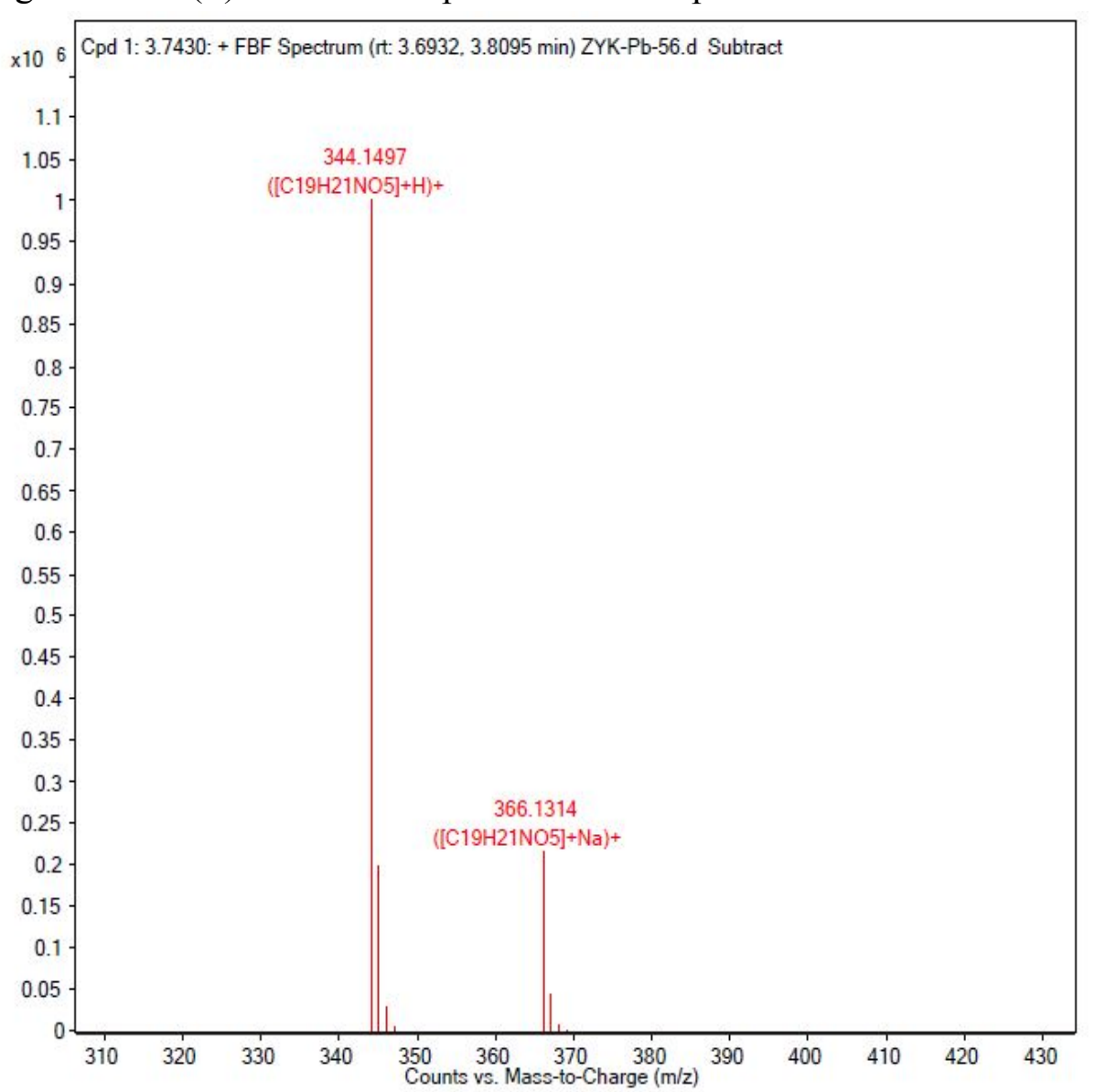

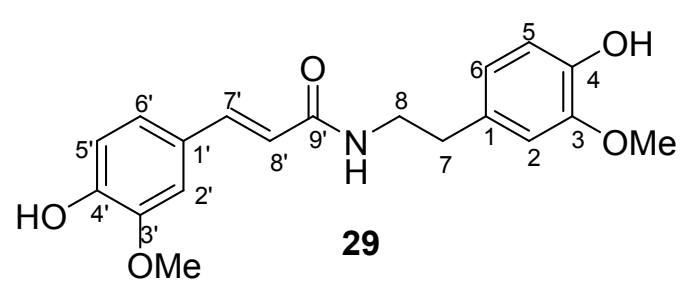


Figure S156. ${ }^{1} \mathrm{H}$ NMR Spectrum of Compound 30 in $\mathrm{MeOH}-d_{4}$

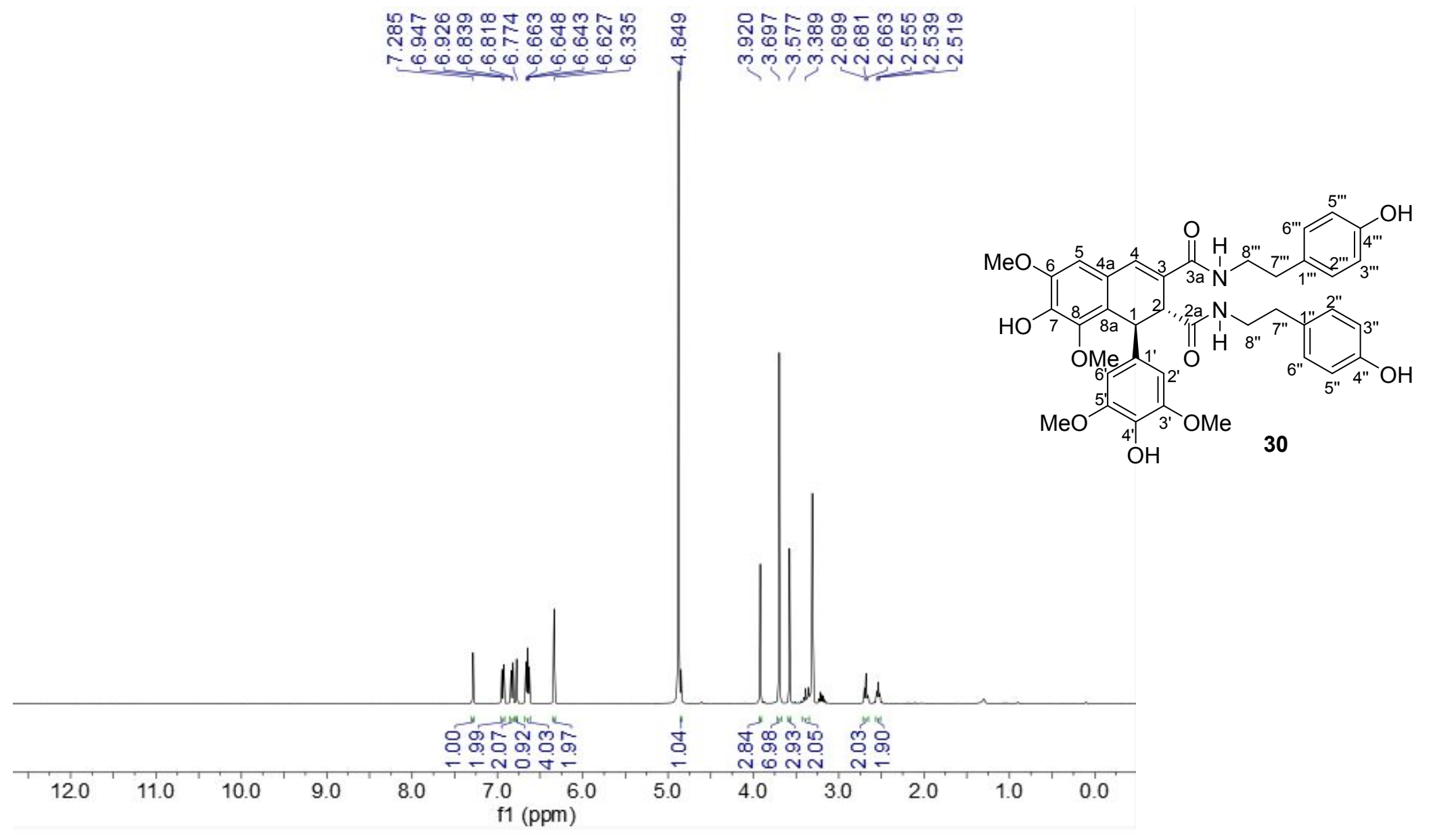


Figure S157. ${ }^{13} \mathrm{C}$ NMR Spectrum of Compound 30 in $\mathrm{MeOH}-d_{4}$

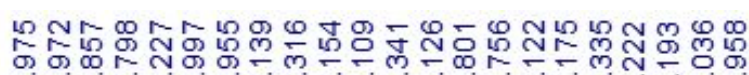

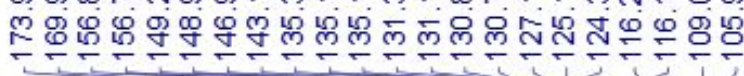

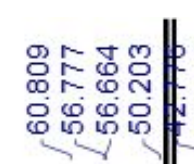<smiles></smiles>

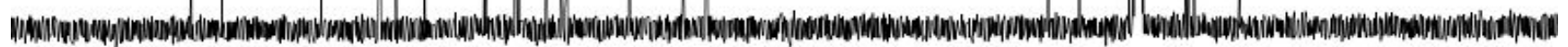


Figure S158. (+) HRESIMS Spectrum of Compound 30

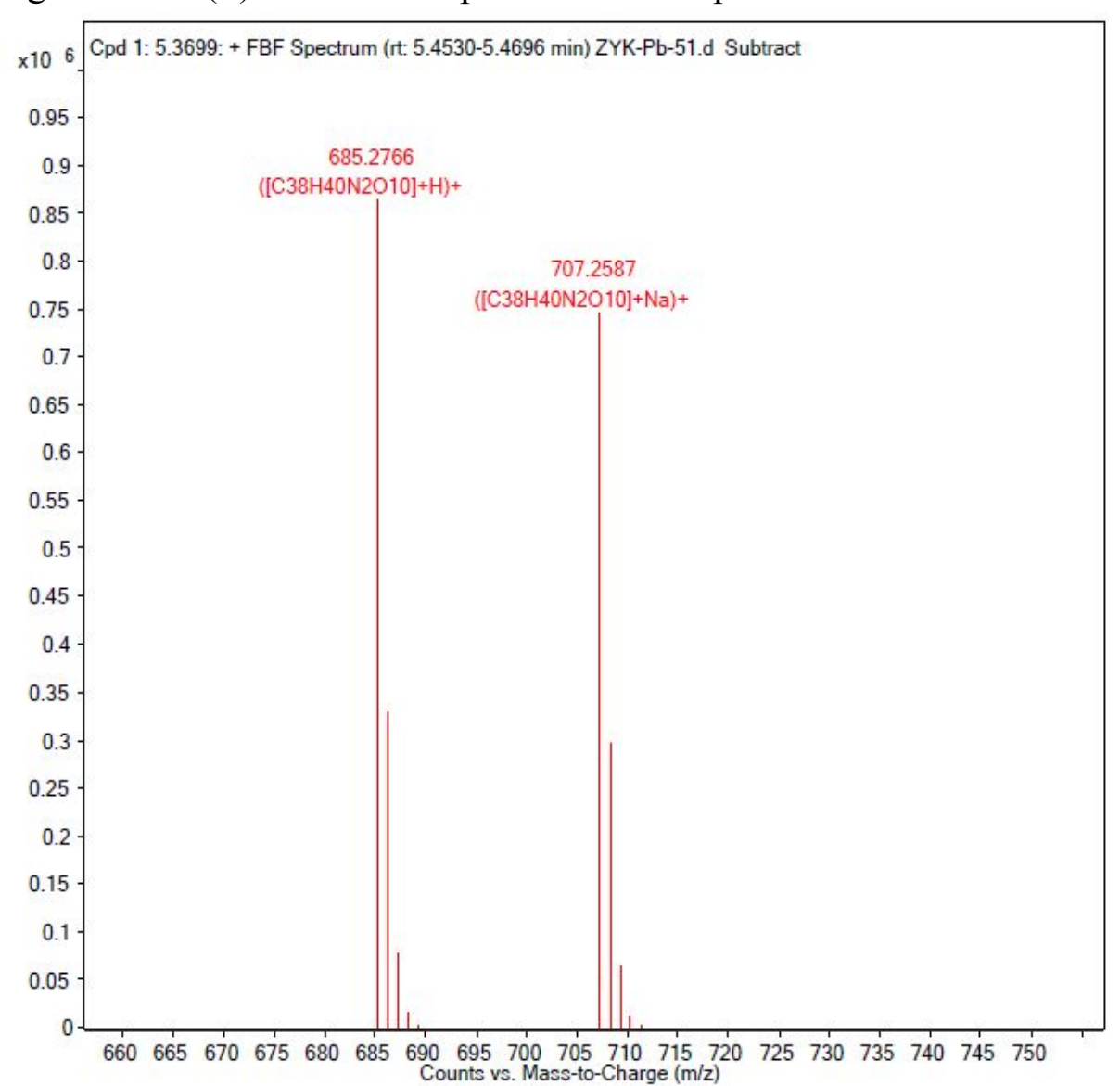

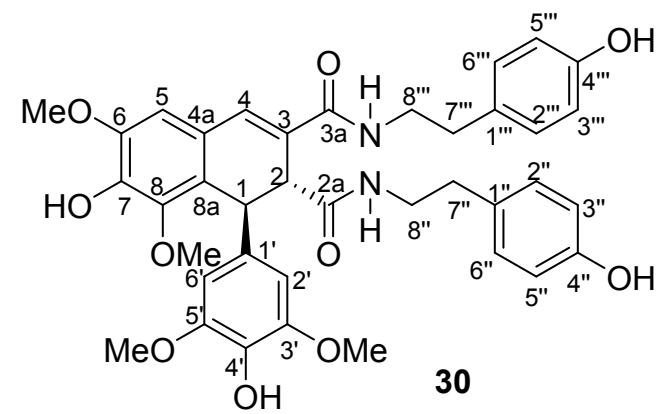


Figure S159. ${ }^{1} \mathrm{H}$ NMR Spectrum of Compound 31 in $\mathrm{CDCl}_{3}$

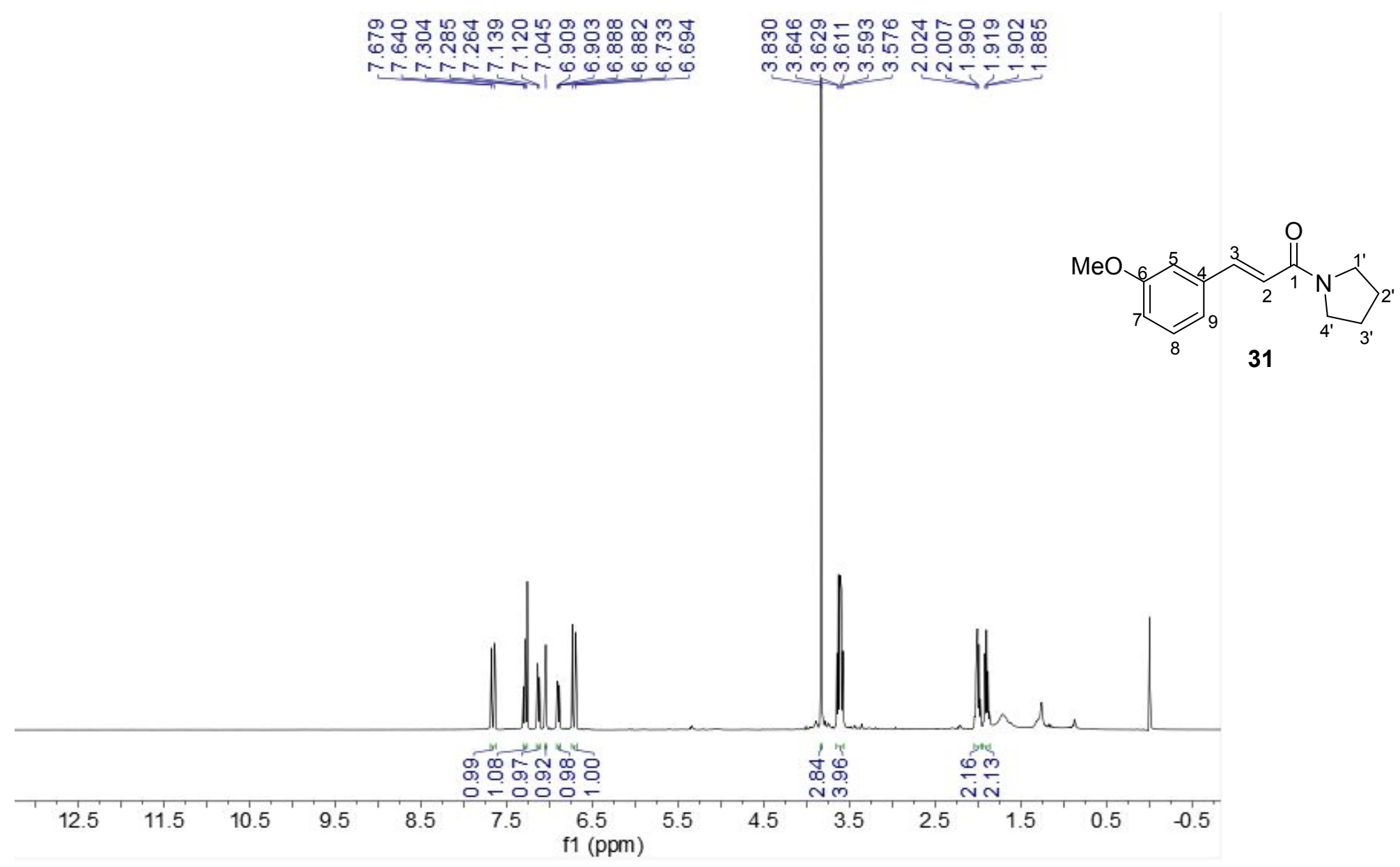


Figure S160. ${ }^{13} \mathrm{C}$ NMR Spectrum of Compound 31 in $\mathrm{CDCl}_{3}$

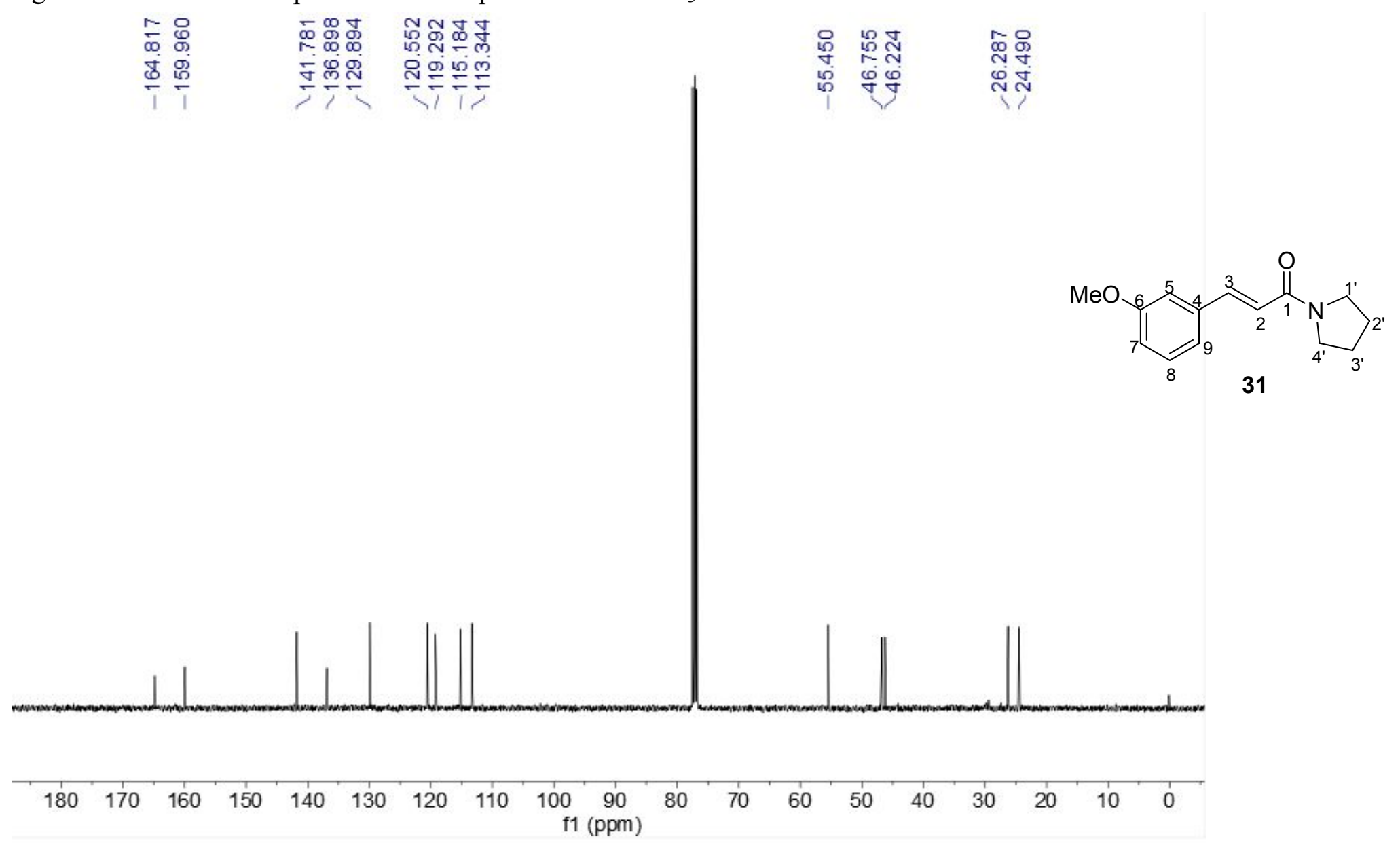


Figure S161. (+) HRESIMS Spectrum of Compound 31

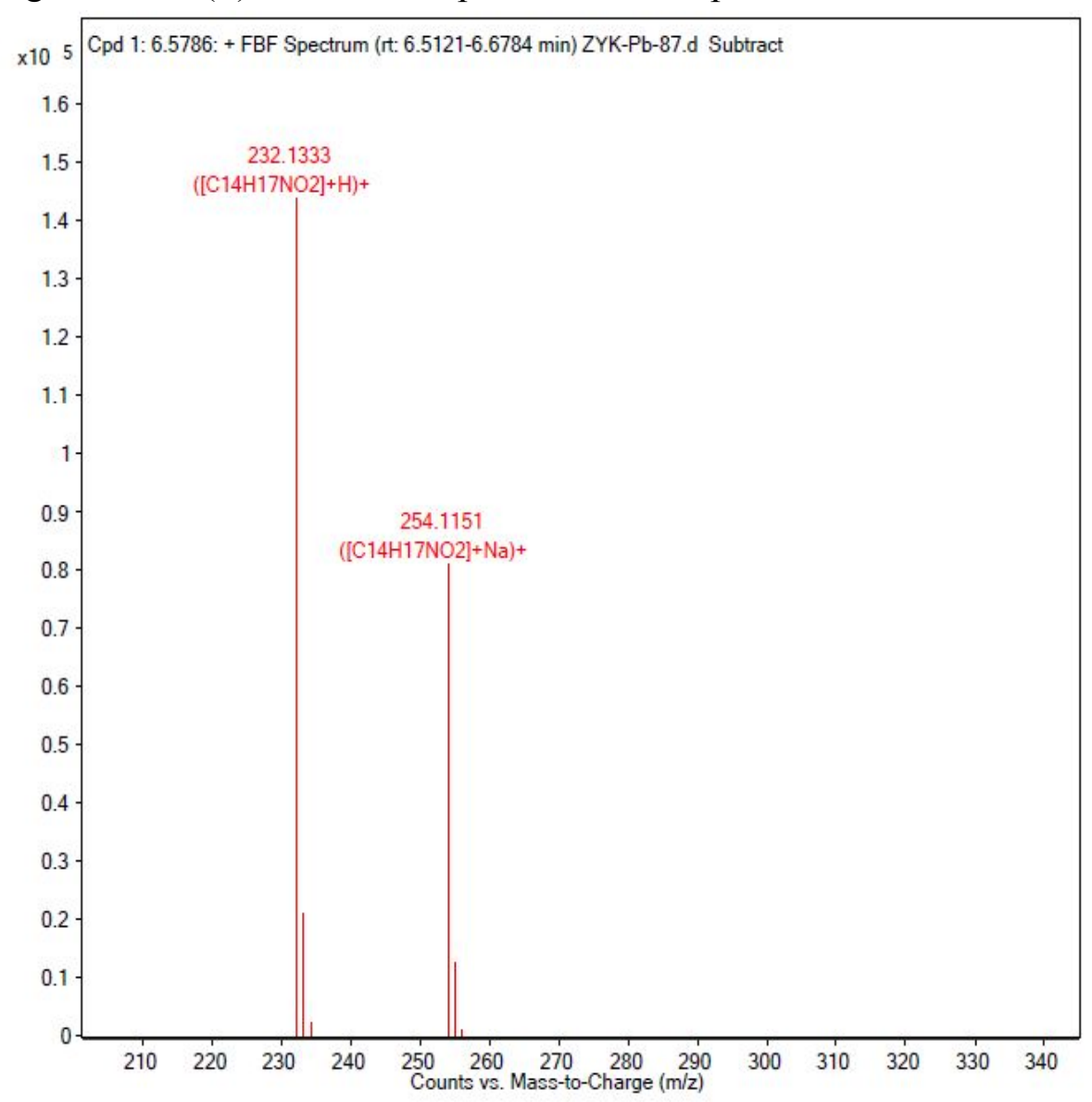

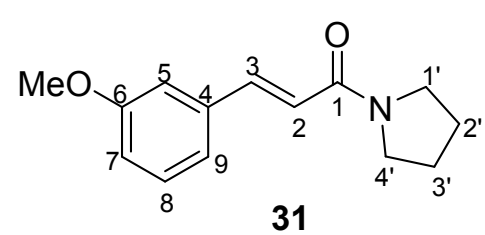

31 
Figure S162. NOESY correlation of Compound 8a

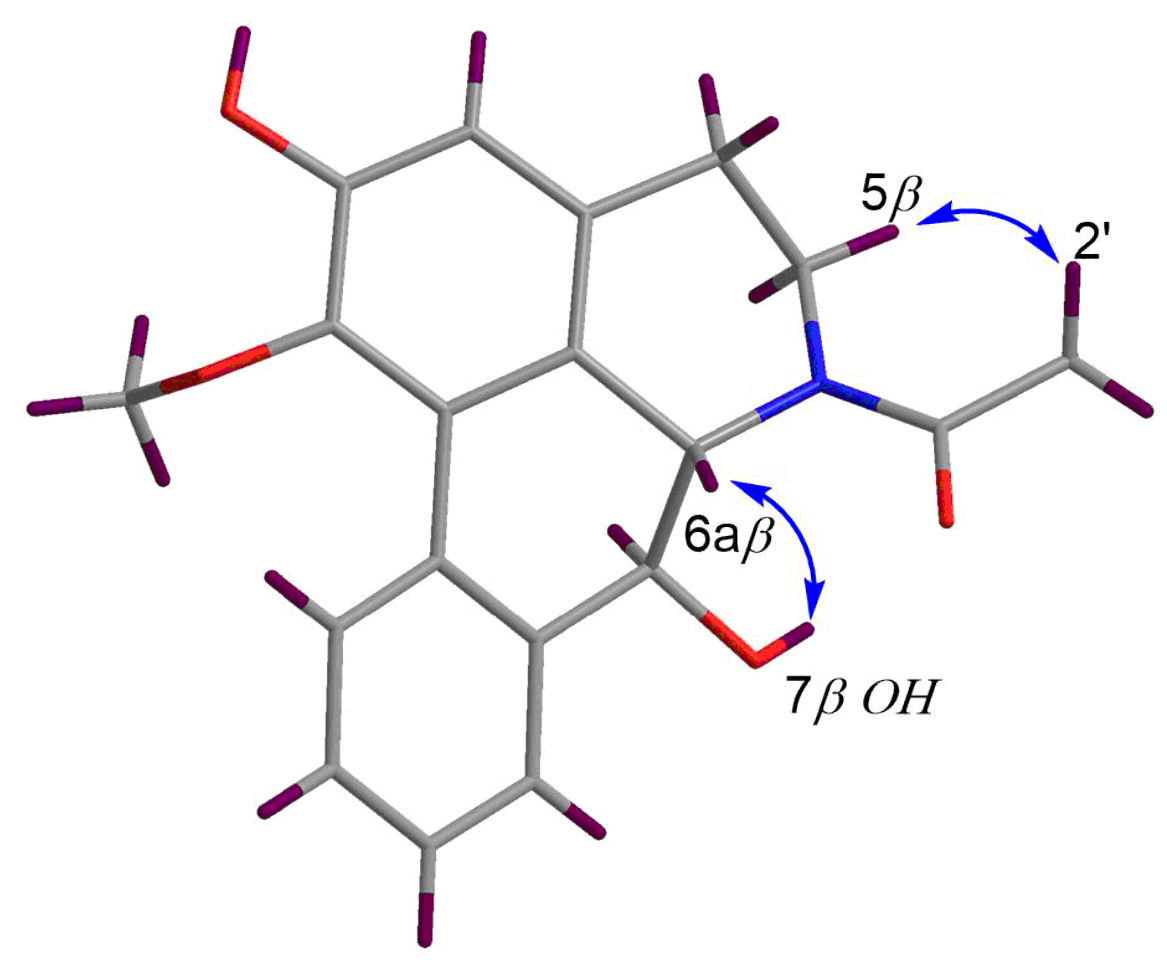


Figure S163. NOESY correlation of Compound 9a and 9b
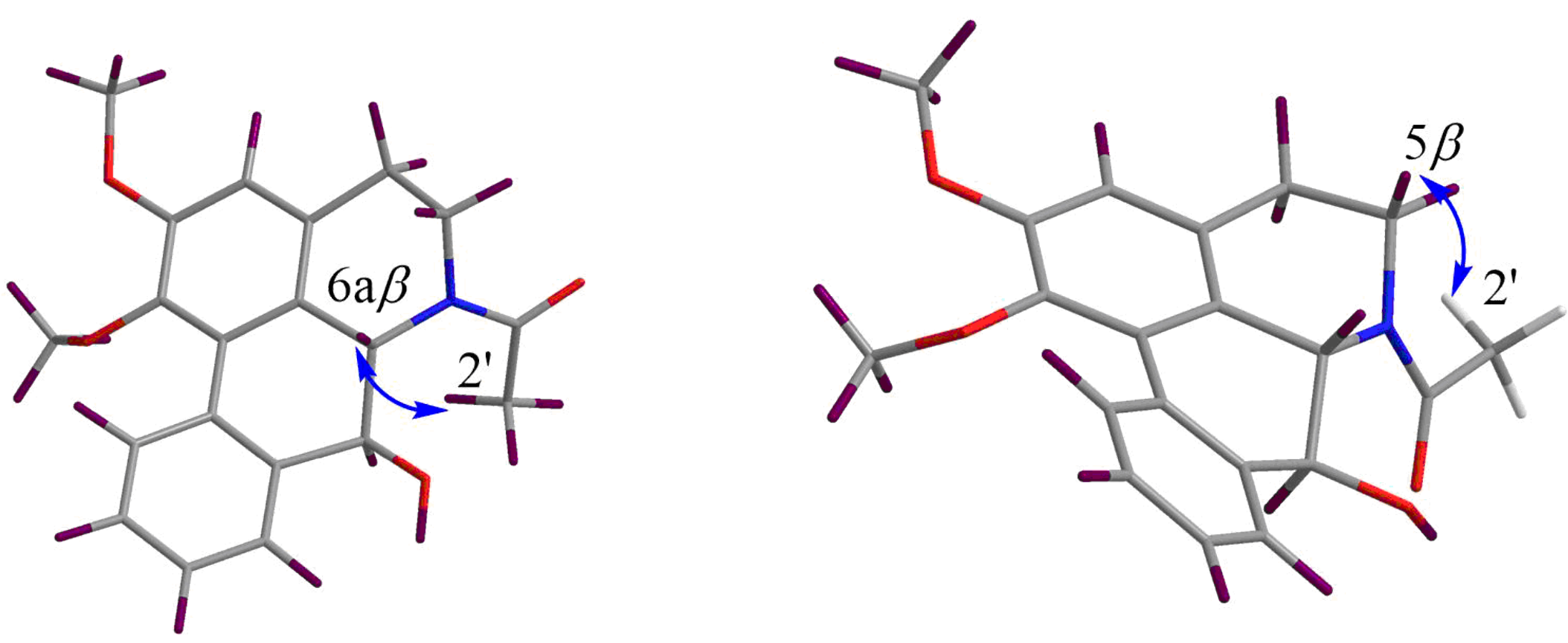
Figure S164. NOESY correlation of Compound 10a and 10b
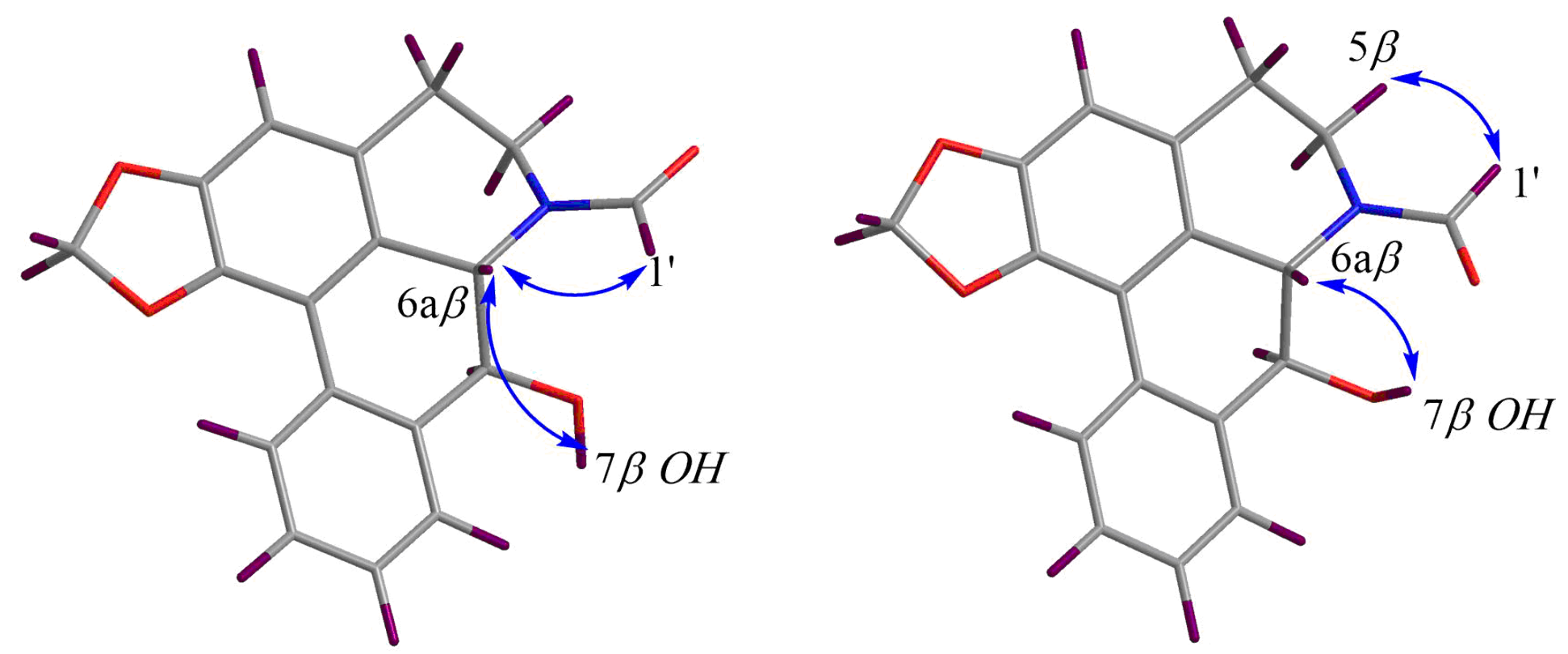
Figure S165. NOESY correlation of Compound 11a

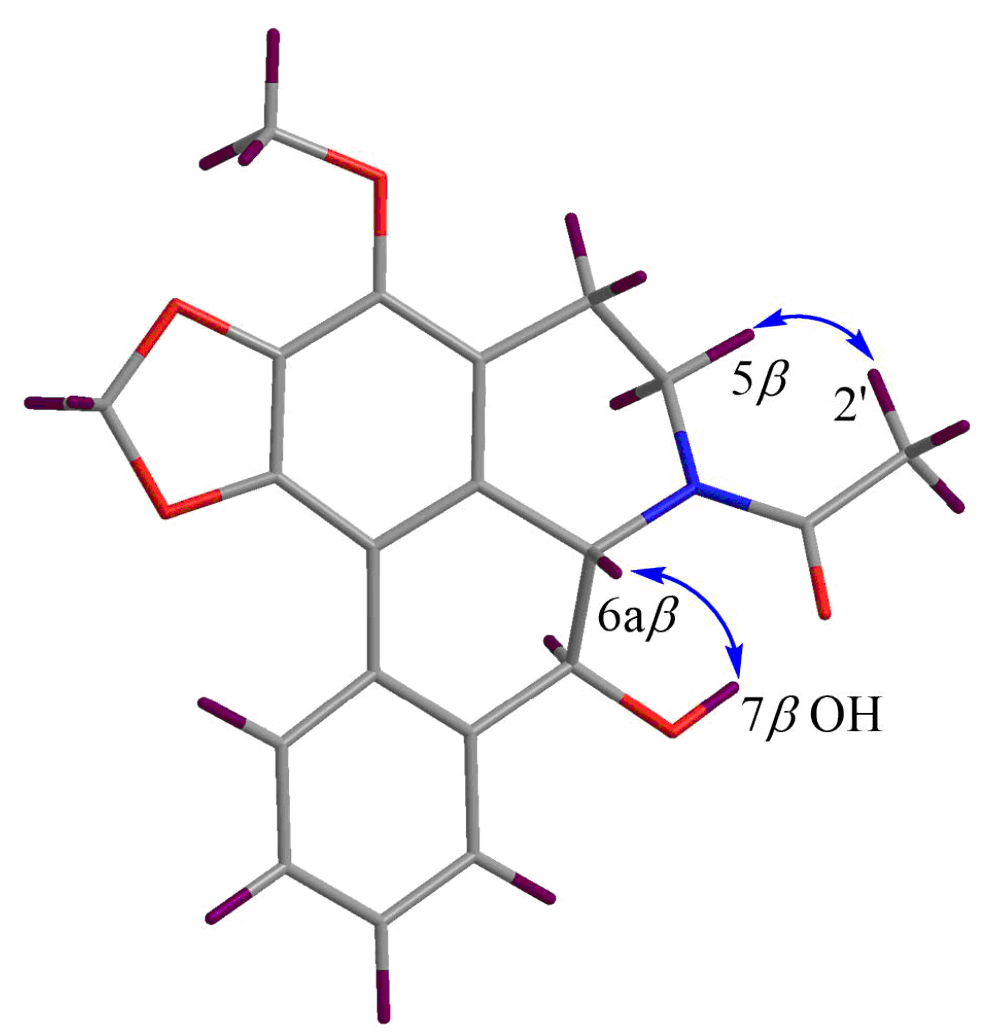


Figure S166. Chiral-phase HPLC Spectrum of Compound 8

Column: Daicel Chiralpak OD-H column (4.6 mm $\Phi \times 250 \mathrm{~mm} \mathrm{~L}$ )

Mobile phase: n-hexane/EtOH (87:13)

Flow rate: $0.7 \mathrm{~mL} / \mathrm{min}$

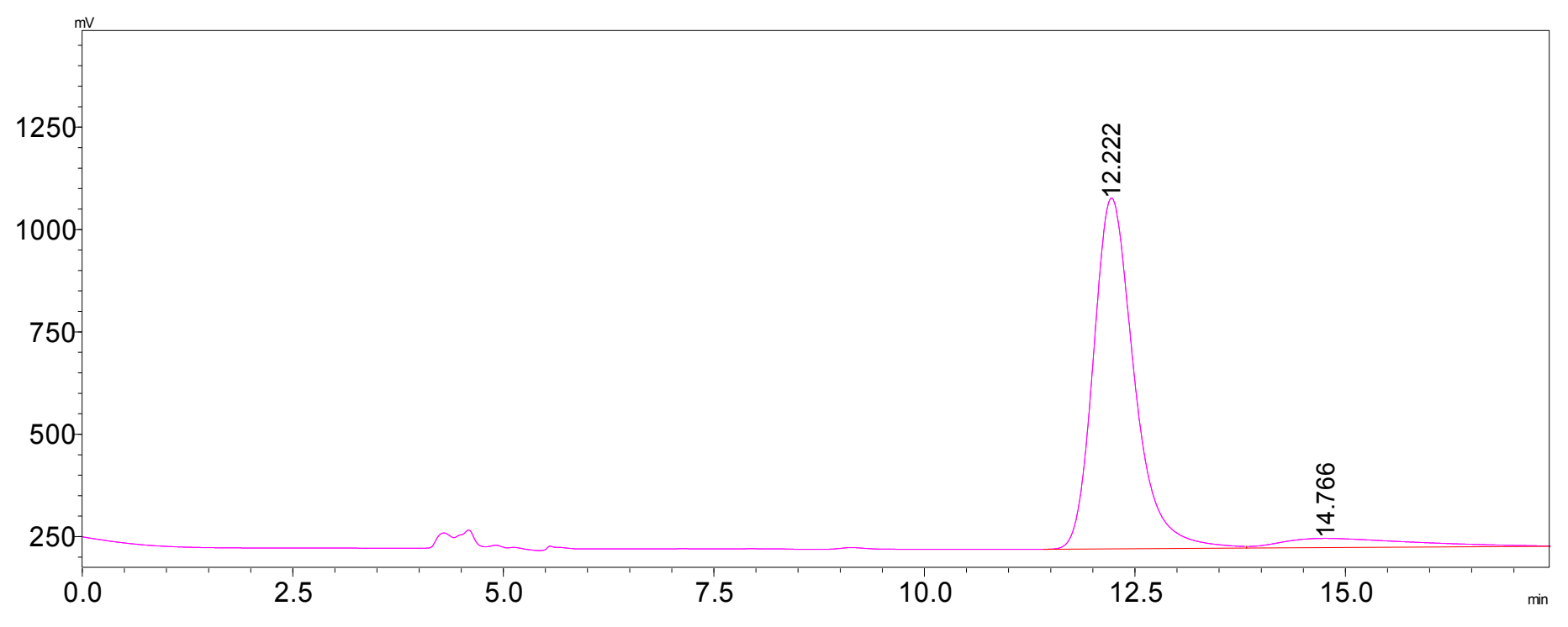

